DEPARTMENT OF BIOTECHNOLOGY

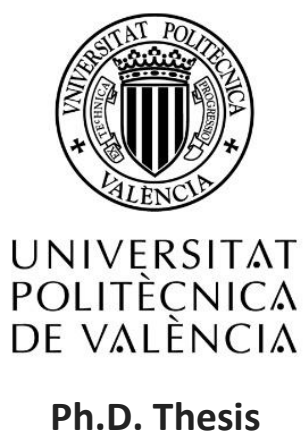

\title{
Epigenetic Regulation of Resistance to TreatMentS IN TRIPLE NEgative AND HER2+ BREAST CANCER: MIRNAS INVOLVED
}

paula Cabello navarro

Supervisors:

Dr. Pilar Eroles Asensio

Dr. Ana Lluch Hernández

Tutor:

Dr. Ramón Serrano Salom

September 2020 



"El verdadero perdedor es aquél que tiene tanto miedo a no ganar que ni siquiera lo intenta."

Pequeña Miss Sunshine 



\section{Agradecimientos}

Acabo una etapa. Y da un poco la sensación de cuando acabas una serie a la que llevas años dedicando tiempo casi a diario. Escenarios que no volverás a ver, incertidumbre sobre qué vendrá después... Al menos, espero seguir viendo a los actores que me han acompañado, a los que quiero agradecer:

A mi directora la Dra. Ana Lluch por aceptarme para pedir la beca predoctoral y ser Uno de los Vuestros. A mi directora la Dra. Pilar Eroles, por enseñarme El Método (científico) y hacer que mi Tesis fuera mucho más agradable que la dirigida por Amenábar.

Gracias a los protagonistas, que me han acompañado a diario en nuestra búsqueda de La Piedra Filosofal: al Laboratorio 2, que son mi Liga de los Hombres (y Mujeres) Extraordinarios, por su ayuda, consejos, ánimos, Tardes de Perro y de ugandés, cafés, chocolate con sorpresa, Morganas, y Mujeres al Borde de un Ataque de Nervios. Gracias también al Rabolatorio, por nombrarme Honoris Causa (incluso tras El Hundimiento del Titanic), por su ayuda, las Fiebres del Miércoles Noche, las escapadas y las risas. Thanks also to the people in Dublin: you made it $A$ Walk to Remember. Gracias a todos los Inclivers que 
en las distintas temporadas 2014-2020 habéis pasado por esos laboratorios: por "el juego del café" y otros innombrables, las charlas en "la esquina del viento" y por enseñarme que la ciencia No es País para Viejos. Muchos ya no estáis, pero algunos y algunas de "nuestra edad" os habéis convertido en verdaderos amigos durante ese camino. Siempre nos quedará "Les Arts".

Quiero agradecer su apoyo a mis amigos, desde los de toda la vida a los más nuevos, por enseñarme Las Ventajas de Ser un Marginado, por aguantar mis turras y estar siempre dispuestos a charlas, pelis, Odiseas en el Espacio, consejos y llamarnos o visitarnos cuando estamos lejos. Gracias por estar "aquí mismo".

Gracias a mis padres por enseñarme a ver El Lado Bueno de las Cosas, que conseguir las metas es Cuestión de Tiempo y por creer siempre en mí. Gracias a La Fiera de mi Niña, la que sabe todo de mí, mi "sestra", Celia. Por tu ayuda y consejos, por estar siempre Abierta hasta el Amanecer, y porque aunque seas la peque aprendo mucho de ti. A Kai, por su amor 24/7. Os quiero.

La temporada final tengo que agradecérsela a Álvaro: por acompañarme en los meses de nuestro Resplandor particular y hacer que yo no enloqueciera escribiendo confinados. Gracias por estar en mis Sonrisas y Lágrimas. Sólo deseo que sigas apoyándome así en nuestro spin-off... Y que te Gusten los Gatos. 




\section{Index}

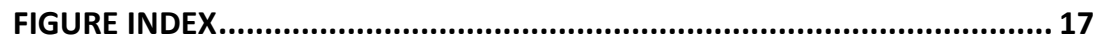

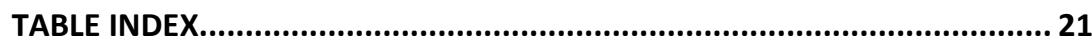

ANNEX INDEX

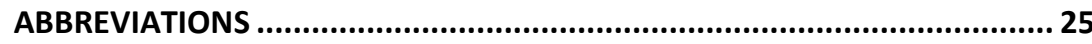

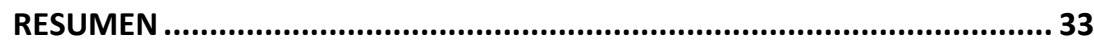

ABSTRACT

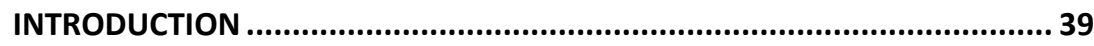

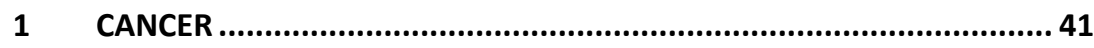

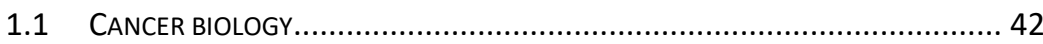

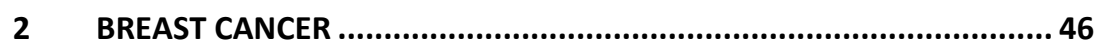

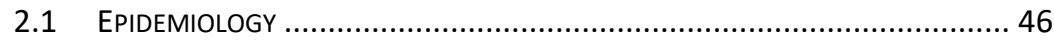

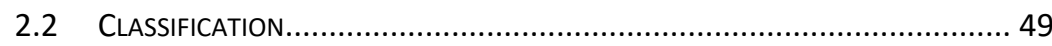

2.2.1 Morphological and histological classification ....................... 49

2.2.1.1 Staging and grade ............................................................52

2.2.1.2 Histological markers............................................................5

2.2.2 Molecular classification .................................................... 55

2.2.3 Molecular profiling platforms for prognosis ........................ 59

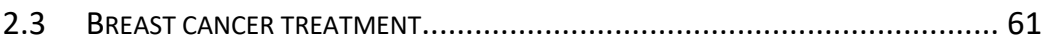

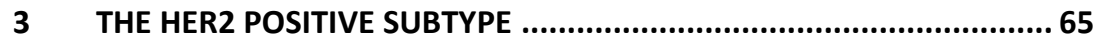




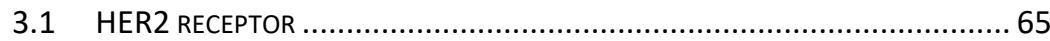

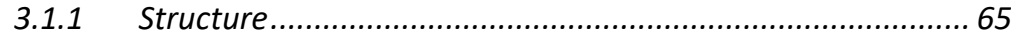

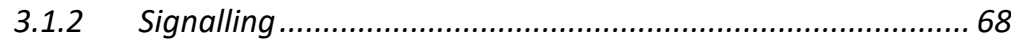

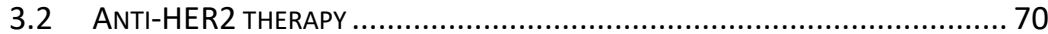

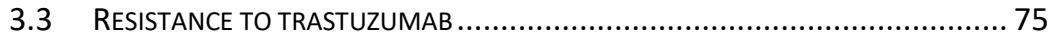

3.3.1 Increased ligand expression ........................................... 76

3.3.2 Receptor alteration …....................................................... 77

3.3.3 Constitutive HER2 pathway activation .............................. 78

4 TRIPLE NEGATIVE BREAST CANCER .......................................... 80

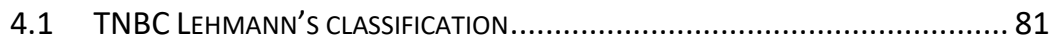

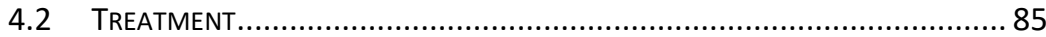

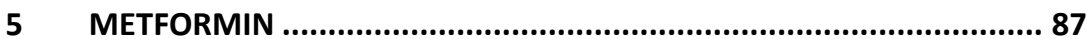

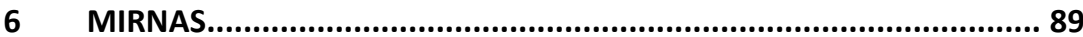

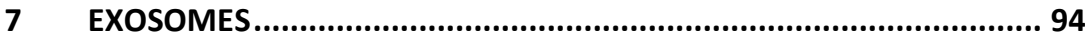

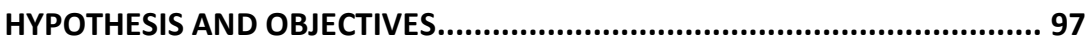

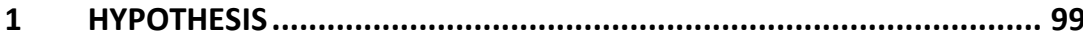

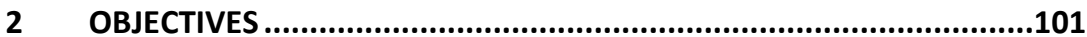

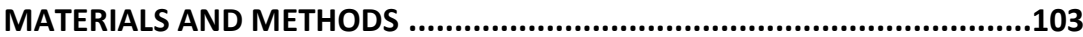

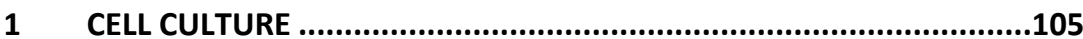

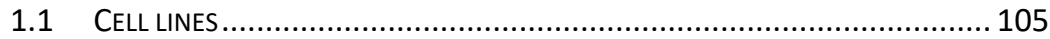

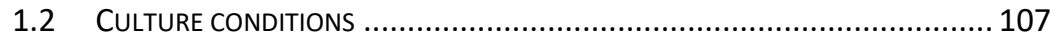

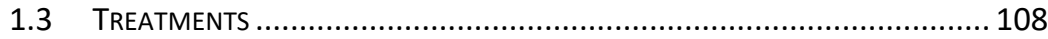

1.4 MICRORNA TRANSFECTION.......................................................... 108 
Index

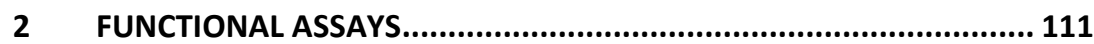

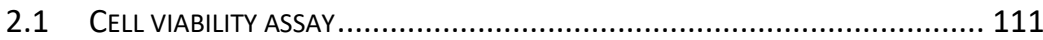

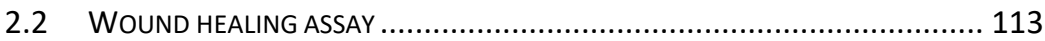

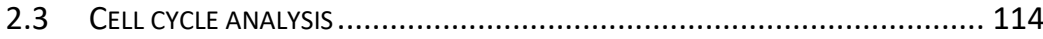

2.4 EXOSOME ISOLATION BY ULTRACENTRIFUGATION ................................... 115

2.4.1 Transmission electron microscopy ................................. 117

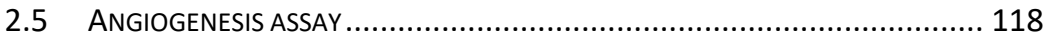

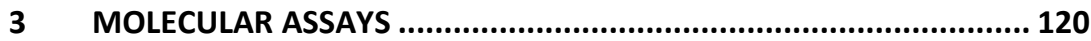

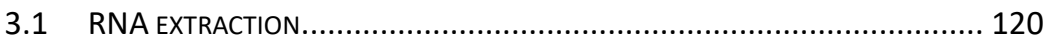

3.1.1 Total RNA extraction ................................................... 120

3.1.2 microRNA extraction ...................................................... 121

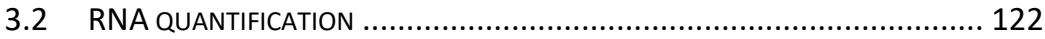

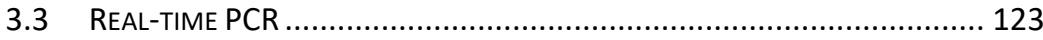

3.3.1 RNA retrotranscription ............................................... 124

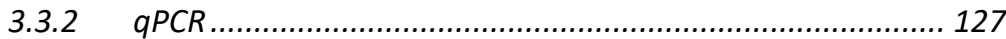

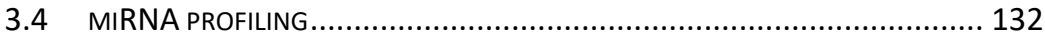

3.4.1 RNA integrity analysis ................................................. 132

3.4.2 microRNA microarray ..................................................... 133

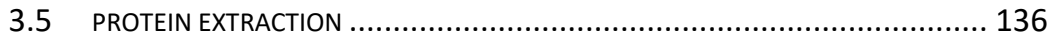

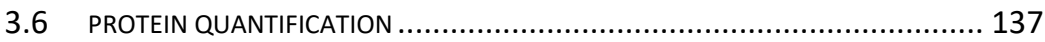

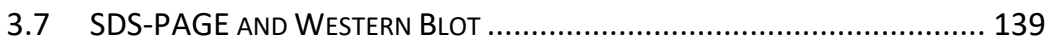

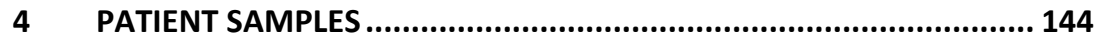

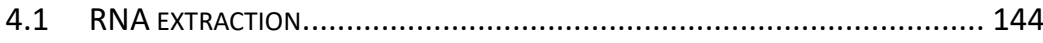

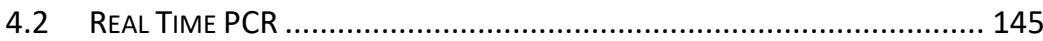

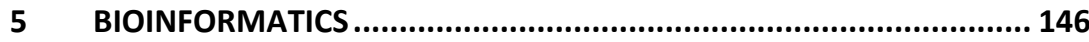


5.1 MICRORNA TARGET PREDICTIONS .................................................... 146

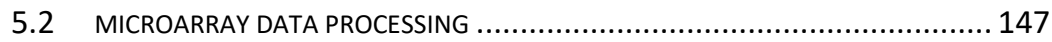

5.2.1 Analysis of expression microarrays ................................. 147

5.2.2 Differential expression analysis..................................... 148

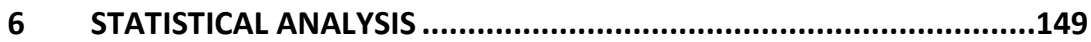

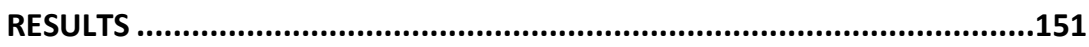

1 EVALUATION OF METFORMIN AS POSSIBLE TREATMENT FOR TRIPLE

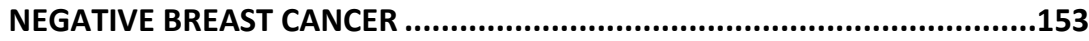

1.1 MiR-26a Expression Modulates Cell Viability ............................... 153

1.2 Effect Of MiR-26A ON CELl Migration......................................... 157

1.3 EVAluation of Potential MiR-26A TARgetS....................................... 159

1.4 Phosphatase and Tensin Homolog (PTEN) Regulation by miR-26A ... 164

1.5 Effect of Metformin on BReast Cancer CellS ............................... 165

1.6 Effect of Metformin through miR-26a on Breast Cancer Cells........ 168

2 EPIGENETIC STUDY OF RESISTANCE TO TRASTUZUMAB ................171

2.1 MIRNA EXPRESSION ANALYSIS BY MICROARRAY AFFYMETRIX GENECHIP MIRNA

$4.0 \quad 171$

2.1.1 Pathway enrichment analysis for breast cancer cell lines ... 178

2.2 VALIDATION OF MIR-23B EXPRESSION BY Q-PCR ................................ 181

2.3 STUDY OF MIR-23B EXPRESSION IN PATIENTS ........................................ 183

2.4 StUdY OF MIR-23B-3P TARGET PTEN............................................... 187

2.5 VALIDATION OF MIR-146A EXPRESSION BY Q-PCR ................................ 190

2.6 STUDY OF MIR-146A EXPRESSION IN PATIENTS ..................................... 191

2.7 STUDY OF MIR-146A-5P IN CELL LINES ................................................ 195

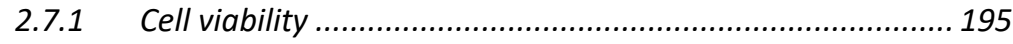


Index

2.7.2 Cell cycle ..................................................................... 199

2.7.3 Gene targets................................................................... 202

2.8 STUDY OF MIR-146A-5P IN EXOSOMES ............................................. 203

2.8.1 Exosome characterization ................................................ 203

2.8.2 miR-146a-5p expression.............................................. 205

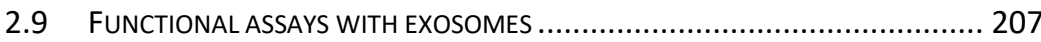

2.9.1 Cell viability .............................................................. 207

2.9.2 EMT regulation........................................................ 210

2.9.3 Wound healing assay .................................................... 212

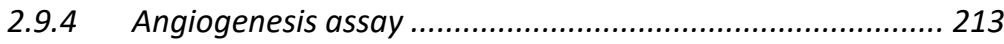

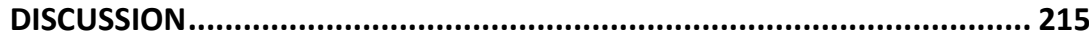

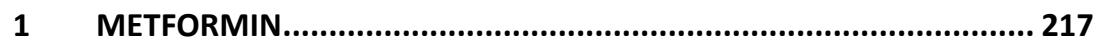

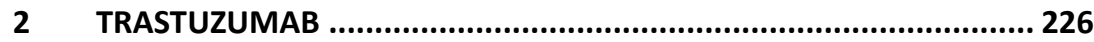

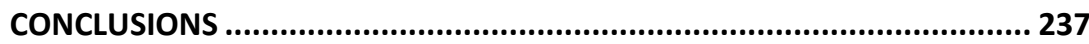

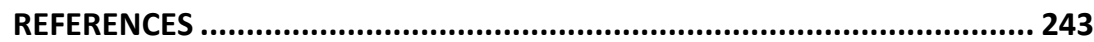

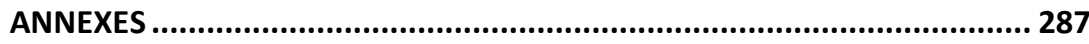





\section{Figure index}

Figure 1. Update of the D. HANAHAN AND R. A. Weinberg CANCER hallmarks AND POTENTIAL THERAPY STRATEGIES TO TARGET THEM ....................................... 44

FIGURE 2. ESTIMATED CASES OF NEW CANCER CASES WORLDWIDE............................ 46

FIGURE 3. SCHEMATIC REPRESENTATION OF THE HUMAN BREAST EPITHELIAL CELL HIERARCHY AND ITS ASSOCIATION WITH THE MAIN BREAST CANCER SUBTYPES...................... 59

FIGURE 4. BREAST CANCER TRADITIONAL SUBTYPES BY IHC AND THEIR MAIN TREATMENT STRATEGIES. 64

Figure 5. SCHEMATIC DIAGRAM OF HER2 AND HER FAMILY SIGNALIING PATHWAYS AND TREATMENTS THAT TARGET HER2 SPECIFICALLY 74

FIGURE 6. LEHMAN'S TRIPLE NEGATIVE BREAST CANCER CLASSIFICATION, GENE ONTOLOGY AND PROPORTION. 83

FIGURE 7. BIOGENESIS OF MICRORNAS AND THEIR EFFECTOR PATHWAYS ..................... 90

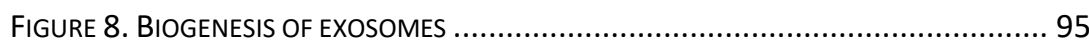

FIGURE 9. SCHEMATIC REPRESENTATION OF CT VALUES IN QPCR RESULTS .................. 131

FIGURE 10. THE EFFECT OF MIR-26A ON CELL VIABILITY. MDA-MB-231, MDA-MB-468, AND MCF-7 AT DAYS 1, 4, AND 7 AFTER TRANSFECTION WITH MIR-26A 154

Figure 11. Determination OF THE MIR-26A MiMETIC (26), THE INHIBITOR (I26), AND THEIR COMBINED EFFECTS ON THE VIABILITY 156

FIGURE 12. WOUND HEALING CELL MIGRATION ASSAY COMPARING CELLS TRANSFECTED WITH 50 NM MIR-26A OR CY3 (CONTROL) 158 
FIGURE 13. GENE EXPRESSION OF DIFFERENT MIR-26A TARGETS FOUR DAYS AFTER TRANSFECTION WITH EITHER 50 NM MIR-26A MIMIC OR ITS INHIBITOR IN MDAMB-231, MDA-MB-468, AND MCF-7 CELL LINES, AS MEASURED BY RT-QPCR

FIGURE 14. PTEN PROTEIN EXPRESSION WAS MEASURED BY WESTERN BLOT 72H AFTER TRANSFECTION WITH MIR-26A OR CY3 IN MDA-MB-231 CELL LINE. 165

FiguRE 15. The EFFECT OF METFORMIN ON MDA-MB-231 CELL LINE VIABILITY AT DIFFERENT TIME-POINTS AND CONCENTRATIONS 166

FIGURE 16. EXPRESSION OF MIR-26A AND TWO OF ITS TARGETS IN MDA-MB-231 MEASURED BY RT-QPCR FOUR DAYS AFTER TREATMENT WITH 10 MM METFORMIN OR VEHICLE 167

FIGURE 17. WOUND HEALING CELL MIGRATION ASSAY COMPARING METFORMIN-TREATED (10 MM) MDA-MB-231 CELLS WITH NON-TREATED CELLS AT 24 AND 30 H.... 168 FiguRE 18. THE EFFECT OF METFORMIN THROUGH MIR-26A ON MDA-MB-231 CELLS 170 FIGURE 19. LOGARITHMIC INTENSITY DISTRIBUTION OF PROBES INCLUDED IN EACH ARRAY. 173

FIGURE 20. VENN'S DIAGRAM SHOWING MIRNAS THAT ARE SIGNIFICANTLY DYSREGULATED BIOLOGICALLY IN THE RESISTANT CELL LINES COMPARED TO THE SENSITIVE. 175

FIGURE 21. EXPRESSION INTENSITY OF MIR-146A-5P SAMPLES OF THE GENECHIP MIRNA

4.0 ARRAY OF AFFYMETRIX MICROARRAY. 176

FIGURE 22. HIERARCHICAL CLUSTERING AND VISUALIZATION OF THE EXPRESSION OF SIGNIFICANTLY DYSREGULATED MIRNAS IN HER2+ CELL LINES

FIGURE 23. PATHWAYS SIGNIFICANTLY DEREGULATED BY MIRNA DIFFERENTIALLY EXPRESSED IN RESISTANT BREAST CANCER CELL LINES COMPARED TO SENSITIVE 180

FIGURE 24. VALIDATION IN THE ARRAY PELLETS BY REAL TIME PCR OF THE EXPRESSION CHANGES FOR MIR-23B-3P OBTAINED IN THE MICROARRAY 182 
FIGURE 25. VALIDATION BY REAL TIME PCR OF THE EXPRESSION CHANGES FOR MIR-23B-5P IN NEW CELLULAR PELLETS 183

FIGURE 26. REPRESENTATION OF OVERALL SURVIVAL CURVES FOR MIR-23B EXPRESSION ANALYSED IN BREAST CANCER SAMPLES FROM METABRIC 184

FIGURE 27. ANALYSIS OF THE EXPRESSION OF THE MIRNA-23B-3P IN BREAST CANCER PATIENTS BY REAL-TIME PCR 186

FIGURE 28. GENE EXPRESSION BY REAL TIME PCR OF THE MIR-146A-5P TARGET AND PATHWAY 188

FIGURE 29. VALIDATION BY REAL TIME PCR OF THE EXPRESSION CHANGES FOR MIR-146A5P IN NEW CELLULAR PELLETS 191

FIGURE 30. REPRESENTATION OF OVERALL SURVIVAL CURVES FOR MIR-146A EXPRESSION ANALYSED IN BREAST CANCER SAMPLES FROM METABRIC 192

FIGURE 31. ANALYSIS OF THE EXPRESSION OF THE MIRNA-146A-5P IN BREAST CANCER PATIENTS BY REAL-TIME PCR 194

FIGURE 32. VIABILITY ANALYSIS IN SKBR-3WT/R CELL LINES TREATED WITH TRASTUZUMAB 196

FIGURE 33. MEASUREMENT OF VIABILITY BY MTT IN CELL LINES TRANSFECTED WITH MIMIC AND INHIBITOR OF MIR-146A-5P 197

Figure 34. CELL CYCLE Distribution OF SKBR-3WT CELLS OVEREXPRESSING MIR-146A-

5P, WITH AN INHIBITOR OR WITH ITS CONTROL 201

FIGURE 35. GENE EXPRESSION BY REAL TIME PCR OF THE MIR-146A-5P TARGET AND PATHWAY 203

FiguRE 36. ChARACTERIZATION OF EXOSOMES OBTAINED BY ULTRACENTRIFUGATION ... 204

FIGURE 37. MIRNA EXPRESSION BY REAL TIME PCR IN EXOSOMES AND CELL LINES ....... 206

FIGURE 38. MEASUREMENT OF VIABILITY BY MTT IN SKBR-3WT CELL LINE WITH COCULTURE OF CONDITIONED MEDIA OR EXOSOMES 208 
FIGURE 39. MEASUREMENT OF VIABILITY BY MTT IN SKBR-3WT CELL LINE WITH COCULTURE OF EXOSOMES AND INHIBITION OF MIR-146A....

FIGURE 40. EMT MARKERS EXPRESSION BY REAL TIME PCR AFTER CO-CULTURE WITH EXOSOMES 211

FIGURE 41. WOUND HEALING CELL MIGRATION ASSAY COMPARING EXOSOME-TREATED SKBR-3WT CELLS WITH NON-TREATED AND SKBR-3R AT $48 \mathrm{H}$ 213

FIGURE 42. IN VITRO MATRIGEL ANGIOGENESIS ASSAY MEASURED AT 8H AFTER SEEDING OF HUVEC AND ADDING OF EXOSOMES FROM SENSITIVE AND RESISTANT CELL LINES 214 FIGURE 43. SCHEMATIC REPRESENTATION OF THE CELL CYCLE PATHWAY AFFECTED BY MIR146A-5P 231 


\section{Table index}

TABLE 1. CliniCAL AND MOleCULAR CELL LINE CHARACTERISTICS............................ 106

TABLE 2. MIX FOR GENE RETROTRANSCRIPTION PER SAMPLE ................................. 125

TABLE 3. MIX FOR MIRNA RETROTRANSCRIPTION PER SAMPLE ............................. 126

TAble 4. Commercial TaqMan Probes for quantitative PCR ........................ 128

TABle 5. Mix quantitative PCR PeR SAMPle Using TAqman teChnology ............ 129

TABLE 6. MIX For RESOLVING GEL AT 10\% ACRYLAMIDE ..................................... 141

TABLE 7. MIX FOR STACKING GEL AT 9\% ACRYLAMIDE...................................... 141

TABLE 8. LIST OF PRIMARY ANTIBODIES AND DILUTIONS USED .................................. 143 



\section{Annex index}

ANNEX I. RESULTS OBTAINED IN THE ARRAY OF MIRNAS EXPRESSION IN THE CELL BT-

474WT/R, SKBR-3WT/R, HCC-1954 AND MDA-MB-231

289

ANNEX II. PUblished PAPER WITH tHe RESULtS ABOUt METFORMIN: "The ANTITUMOR

EFECT OF METFORMIN IS MEDIATED BY MIR-26A IN BREAST CANCER"

301 



\section{Abbreviations}

3'UTR

ABC

ADCC

AJCC

AMPK

APS

ATCC

ATP

ATR

BC

BCA

BRCA1/2

BSA

CCD

CCNB1 3'-untranslated

region

ATP-binding cassette

Antibody-dependent cell death

American Joint Committee on Cancer

AMP-activated protein kinase

Ammonium persulfate

American Type Culture Collection

Adenosin triphosphate

Ataxia telangiectasia and Rad3 related

Breast cancer

Bicinchoninic acid

Breast Cancer gene 1/2

Bovine serum albumin

Charge-coupled device

Cyclin B1 
CCND1

CDH1

CDK

CDKN1A

cDNA

CGH

CK

Ct

CTNNB1

DAPI

DEPC

DMEM

DMSO

DNA

ECD

ECM

EDTA

EGFR
Cyclin D1

E-cadherin

Cyclin-dependent kinase

Cyclin Dependent Kinase Inhibitor 1A

Complementary DNA

Comparative genomic hybridisation

Cytokeratine

Threshold cycle

$\beta$-Catenin

4',6-diamidino-2-phenylindole

Diethyl pyrocarbonate

Dulbecco's Modified Eagle Medium

Dimethylsulfoxide

Deoxyribonucleic acid

Extracellular domain

Extracellular matrix

Ethylenediaminetetraacetic acid

Human epidermal growth factor receptor 
EGFR / ERBB

EGM

EMT

ER

ERBB2

EV

FBS

FDR

FFPE

FISH

FN1

HER2/EGFR2

HUVEC

ICD

ICD-10

IDC

IGF
Epidermal growth factor receptor family

Endothelial cell growth medium

Epithelial-mesenchymal transition

Estrogen receptor

Homologous gene 2 of the avian viral erythrobatic leukemia oncogene

Extracellular vesicle

Fetal bovine serum

False discovery rate

Formalin fixed paraffin-embedded

Fluorescence in situ hybridisation

Fibronectin

Human epidermal growth factor receptor 2

Human Umbilical Vein Endothelial Cells

Intracellular domain

International Statistical Classification of

Diseases and Related Health Problems

Invasive ductal carcinoma

Insulin-like growth factor 
IGF1R

IHC

ILC

LAR

MAPK

MET

miRNAs

mRNA

mTOR

NGF

NK

ORF

OS

PARP

PBS

PCR

PDGF
Insulin-like growth factor 1 receptor

Immunohistochemistry

Invasive lobular carcinoma

Luminal androgen receptor subtype

Mitogen-Activated Protein Kinases

Hepatocyte growth factor receptor

MicroRNAs

Messenger RNA

Rapamycin mammary route

Nerve growth factor

Natural killer

Open reading frame

Overall survival

Poly-(adenosine

diphosphate)-ribose

polymerase

Phosphate buffer saline

Polymerase chain reaction

Platelet derived growth factor 
PDK1/2

PD-L1

PFA

PI3K

PR

PTEN

qPCR

RIN

RIPA

RMA

RNA

RPMI

SD

SDS

SDS-PAGE

snoRNAs
Phosphoinositide-dependent kinase-1/2

Programmed Death-ligand 1

Paraformaldehyde

Phosphatidyl inositol kinase

Progesterone receptor

Phosphatase and tensin homolog

Phosphatidylinositol 3,4,5-trisphosphate 3phosphatase

Real-time quantitative PCR

RNA Integrity Number

Radioimmunoprecipitation assay buffer

Robust Multichip Average

Ribonuncleic acid

Roswell Park Memorial Institute medium

Standard deviation

Sodium dodecyl sulfate

SDS-Polyacrylamide Gel Electrophoresis

small nucleolar RNAs 
STAT1

TCGA

TDM-1

TH1/2

TKI

TMD

TNBC

TNM

UTR

VIM

WHO ignal transducer and activator of transcription 1

The Cancer Genome Atlas

Trastuzumab emtansyne

T helper lymphocites $1 / 2$

Tyrosine kinase inhibitor

Transmembrane hydrophobic domain

Triple negative breast cancer

Tumour size $(T)$, the lymph nodes affectation $(\mathrm{N})$, and the appearance of distant metastasis (M)

Untranslated region

Vimentin

World Health Organisation 


\section{Resum}

El càncer de mama és el càncer més comú en dones arreu del món i la principal causa de mort per càncer en dones junt amb el càncer de pulmó. Aquest càncer té molt bon pronòstic en general, amb una supervivència del $80 \%$. No obstant això, el pronòstic del càncer de mama triple negatiu és molt pitjor, al no conèixerse'n cap diana farmacològica i tractar-se de forma inespecífica. La metformina, fàrmac prescrit per a la diabetis, ha mostrat alguns bons resultats preliminars com a potencial teràpia. D'altra banda, el principal tractament dirigit de les pacients HER2+ és el trastuzumab, que neutralitza el receptor HER2 amplificat; tanmateix, un elevat nombre de pacients desenvolupen resistències al tractament. Els microRNAs són xicotets RNAs no codificants capaços de regular l'expressió gènica epigenèticament, i poden ser secretats de la cèl·lula en vesícules anomenades exosomes.

L'objectiu d'aquest treball és abordar aquestes dues problemàtiques en càncer de mama. Són necessaris estudis dels mecanismes d'acció o resistència d'aquests fàrmacs a través de la regulació epigenètica per microRNAs. Volem determinar la relació del miR-26a i les seues dianes amb l'efecte de la metformina en càncer de mama triple negatiu i estudiar les diferències d'expressió dels microRNAs que generen resistències al trastuzumab en càncer de mama HER2+, així com estudiar la seua manera de transmissió entre cèl·lules.

Es van realitzar assajos cel·lulars tractant amb metformina les línies MDA-MB231, MDA-MB-468 i MCF-7 així com sobreexpressant o inhibint miR-26a i es van mesurar les seues dianes teòriques per qPCR. Per a les línies HER2+ es va realitzar un Affymetrix Genechip miRNA 4.0 microarray comparant línies SKBR-3wt i BT$474 \mathrm{wt} \mathrm{amb}$ les seues respectives línies amb resistència generada a trastuzumab 
i HCC-1954 com resistent innata. Es van estudiar els microRNAs més rellevants de l'array en les línies cel·lulars i en pacients i es va comprovar la seua presència a exosomes, així com l'efecte dels exosomes en la transmissió de la resistència.

La sobreexpressió de miR-26a resultà en una reducció de la viabilitat cel-lular que es recuperà parcialment en inhibir-la. E2F3, MCL-1, EZH2, MTDH i PTEN foren regulats negativament per miR-26a i la proteïna PTEN també es va reduir en sobreexpressar miR-26a. El tractament amb metformina va reduir la viabilitat de les cèl-lules de càncer de mama, va augmentar l'expressió de miR-26a i va conduir a una reducció en l'expressió de $B C L-2, E Z H 2$ i PTEN. La inhibició de miR-26a prevé part de l'efecte en la viabilitat de la metformina i la reducció de l'expressió de PTEN i EZH2. En les línies HER2+, miR-23b-3p i miR-146a-5p foren els principals candidats extrets de l'array. miR-23b-3p va inhibir PTEN significativament en la línia BT-474. miR-146a-5p va augmentar la resistència de les cèl·lules SKBR-3 al trastuzumab i la seua inhibició va reduir la resistència de les SKBR-3r. L'augment de miR-146a-5p en SKBR-3wt va tindre un efecte en cicle cel·lular augmentant la fase $\mathrm{S}$ i la G2/M, inhibint l'expressió de CDKN1A i augmentant la de CCNB1. Els exosomes de les SKBR-3 contenien miR-146a-5p, amb majors nivells en els de les resistents (exoR). Els exoR van augmentar la resistència a trastuzumab, la transició epiteli-mesenquimal i la migració en co-cultivar-los amb SKBR-3wt, i l'angiogènesi de les HUVEC.

Els nostres resultats suggereixen que l'efecte de la metformina està intervingut per una major expressió de miR-26a i reducció de les seues dianes, PTEN i EHZ2. Per tant, l'ús de metformina al tractament de el càncer de mama constitueix una prometedora potencial teràpia. En HER2+, miR-23b sembla provocar resistència a trastuzumab mitjançant PTEN i miR-146a a través del cicle cel-lular. A més, miR146a es transmet en exosomes, que són capaços de reduir la sensibilitat al trastuzumab de les cèl-lules sensibles i augmentar la TEM, migració i angiogènesi. 


\section{Resumen}

El cáncer de mama es el cáncer más común en mujeres en todo el mundo y la principal causa de muerte por cáncer en mujeres junto al cáncer de pulmón. Este cáncer tiene muy buen pronóstico en general, con una supervivencia del $80 \%$. Sin embargo, el pronóstico del cáncer de mama triple negativo es mucho peor, al no conocerse ninguna diana farmacológica y tratarse de forma inespecífica. La metformina, fármaco prescrito para la diabetes, ha mostrado algunos buenos resultados preliminares como potencial terapia. Por otro lado, el principal tratamiento dirigido de las pacientes HER2+ es el trastuzumab, que neutraliza al receptor HER2 amplificado; sin embargo, un elevado número de pacientes desarrollan resistencias al tratamiento. Los microRNAs son pequeños RNAs no codificantes capaces de regular la expresión génica epigenéticamente, y pueden ser secretados de la célula en vesículas llamadas exosomas.

El objetivo de este trabajo es abordar estas dos problemáticas en cáncer de mama. Son necesarios estudios de los mecanismos de acción o resistencia de estos fármacos a través de la regulación epigenética por microRNAs. Queremos determinar la relación del miR-26a y sus dianas con el efecto de la metformina en cáncer de mama triple negativo y estudiar las diferencias de expresión de microRNAs que generan resistencias a trastuzumab en cáncer de mama HER2+, así como estudiar su modo de transmisión entre células.

Se realizaron ensayos celulares tratando con metformina las líneas MDA-MB-231, MDA-MB-468 y MCF-7 así como sobreexpresando o inhibiendo miR-26a y se midieron sus dianas teóricas por qPCR. Para las líneas HER2+ se realizó un Affymetrix Genechip miRNA 4.0 microarray comparando líneas SKBR-3wt y BT474wt con sus respectivas líneas con resistencia generada a trastuzumab y HCC1954 como resistente innata. Se estudiaron los microRNAs más relevantes del array 
en las líneas celulares y en pacientes y se comprobó su presencia en exosomas, así como el efecto de los exosomas en la transmisión de la resistencia.

La sobreexpresión de miR-26a resultó en una reducción en la viabilidad celular que se recuperó parcialmente al inhibirla. E2F3, MCL-1, EZH2, MTDH y PTEN fueron regulados negativamente por miR-26a y la proteína PTEN también se redujo tras la sobreexpresión de miR-26a. El tratamiento con metformina redujo la viabilidad de las células de cáncer de mama, aumentó la expresión de miR-26a y condujo a una reducción en la expresión de $B C L-2, E Z H 2$ y PTEN. La inhibición de miR-26a previene parte del efecto en viabilidad de la metformina y la reducción de la expresión de PTEN y EZH2. En las líneas HER2+, miR-23b-3p y miR-146a-5p fueron los principales candidatos extraídos del array. miR-23b-3p inhibió PTEN significativamente en la línea BT-474. miR-146a-5p aumentó la resistencia de las células SKBR-3 al trastuzumab y su inhibición redujo la resistencia de las SKBR-3r. El aumento de miR146a-5p en SKBR-3wt tuvo un efecto en ciclo celular aumentando la fase S y la G2/M, inhibiendo la expresión de CDKN1A y aumentando la de CCNB1. Los exosomas de las SKBR-3 contenían miR-146a-5p, con mayores niveles en los de las resistentes (exoR). Los exoR aumentaron la resistencia a trastuzumab, la transición epitelio-mesenquimal y la migración al co-cultivarse con SKBR-3wt, y la angiogénesis en las HUVEC.

Nuestros resultados sugieren que el efecto de la metformina está mediado por una mayor expresión de miR-26a y reducción de sus dianas, PTEN y EHZ2. Por tanto, el uso de metformina en el tratamiento del cáncer de mama constituye una prometedora potencial terapia. En HER2+, miR-23b parece provocar resistencia a trastuzumab vía PTEN y miR-146a a través del ciclo celular. Además, miR-146a se transmite en exosomas, que son capaces de reducir la sensibilidad al trastuzumab de las células sensibles y aumentar la TEM, migración y angiogénesis. 


\section{Abstract}

Breast cancer is the most common cancer in women worldwide and the leading cause of cancer death in women along with lung cancer. This cancer has a very good general prognosis, with a survival of $80 \%$. However, the prognosis for triple negative breast cancer is much worse, as it has no pharmacological target and treats it nonspecifically. Metformin, a prescribed diabetes drug, has shown some good preliminary results as potential therapy. On the other hand, the main targeted treatment for HER2 + patients is trastuzumab, which neutralizes the amplified HER2 receptor, but a large number of patients experienced resistance to treatment. MicroRNAs are small non-coding RNAs that are part of epigenetics and are capable of regulating gene expression, and which can be secreted from the cell into vesicles called exosomes.

The objective of this work is to address these two problems in breast cancer, which need to study the mechanism of action or resistance of these drugs, through the epigenetics of microRNAs. We want to determine the relationship of miR-26a and its targets with the effect of metformin in triple negative breast cancer and to study the differences in the expression of microRNAs that process resistance to trastuzumab in HER2 + breast cancer, as well as to study its mode of transmission between cells.

Cellular assays were performed treating the MDA-MB-231, MDA-MB-468 and MCF7 lines with metformin as well as overexpressing or inhibiting miR-26a, and their theoretical targets were measured by qPCR. For the HER2+ cell lines, an Affymetrix Genechip miRNA 4.0 microarray was performed comparing SKBR-3wt and BT474wt lines with their respective cell lines with generated resistance to trastuzumab and HCC-1954 as innate resistance. The most relevant microRNAs of 
the array in cell lines and in patients were studied and their presence in exosomes was verified, as well as the effect of exosomes in the transmission of resistance.

The overexpression of miR-26a resulted in a reduction in cell viability that was partially recovered by inhibiting it. E2F3, MCL-1, EZH2, MTDH, and PTEN were down-regulated by miR-26a, and the PTEN protein was also reduced after overexpression of miR-26a. Metformin treatment reduced the viability of breast cancer cells, increased miR-26a expression, and led to a reduction in $B C L-2, E Z H 2$, and PTEN expression. Inhibition of miR-26a partly prevents the effect of metformin in viability and the reduction of the expression of PTEN and EZH2. In the HER2+ lines, miR-23b-3p and miR-146a-5p were the main candidates extracted from the array. miR-23b-3p was shown to significantly inhibit PTEN in the BT-474 cell line. miR-146a-5p increased resistance of SKBR-3wt cells to trastuzumab and its inhibition reduced resistance of SKBR-3r. The increase of miR-146a-5p in SKBR-3wt had effect on the cell cycle by increasing the S phase and the G2/M, inhibiting the expression of CDKN1A and increasing CCNB1 levels. Exosomes isolated from SKBR3 cell lines contained miR-146a-5p, with higher levels in exosomes from the resistant cell line (exoR). The exoR were shown to increase trastuzumab resistance, EMT, and migration when co-cultivated with SKBR-3wt, and angiogenesis when in culture with HUVEC.

Our results indicate that metformin effectively reduces breast cancer cell viability and suggests that the effects of the drug are mediated by an increase in miR-26a expression and a reduction of its targets, PTEN and EHZ2. Thus, the use of metformin constitutes a promising potential triple negative breast cancer therapy. In HER2+ breast cancer, miR-23b appears to elicit resistance to trastuzumab via PTEN and miR-146a throughout the cell cycle. Furthermore, miR-146a is transmitted in exosomes, which have been shown to reduce the sensitivity to trastuzumab of sensitive cells and increase EMT, migration, and angiogenesis. 


INTRODUCTION 



\section{CANCER}

Cancer is a group of diseases caused by genetic changes that lead to uncontrolled proliferation of abnormal cells capable of invading adjacent tissues. It starts with the transformation of a single cell, and its origin can be due to both external agents and genetically inherited factors.

Cancer has always existed in humans, recorded as a disease and cause of death since ancient Egypt approximately 4,500 years ago. Furthermore, the oldest tumour found in a human fossil, corresponding to a benign tumour in the vertebrae of an Australopithecus sediba, found in the cave site of Swartkrans in the Cradle of Humankind, South Africa, dates to almost two million years old [1]. However, today, cancer is a disease mainly in developed countries [2], due to high life expectancy and lifestyle. After many years of being in second place, it has already become the leading cause of death in high-income countries, where it causes twice as many deaths as cardiovascular disease, according to the findings of a new global study [3].

There are more than 200 types of cancer known, although we usually name them by the organ of their primary site (the part of the body where the cancer started). Lung and breast cancers were the most common cancers worldwide, each contributing $12.3 \%$ of the total 
number of new cases diagnosed in 2018, with 2.09 million cases each [4]. Colorectal cancer was the third most common cancer with 1.8 million new cases in 2018 [5]. In Spain, the most common type of cancer was colorectal cancer, and breast cancer was the most common cancer among women [6]. The aging of the population increases the incidence of cancer and it is expected that by 2030 in Spain there will be a new case of cancer every 1.8 minutes, and one death every 3.8 minutes. Mortality in some types of cancer is still very high, and 5-year overall survival rates, at $53 \%$, do not improve quickly enough, being the main challenge to reach $70 \%$ of cancer survival by 2030 [7]. After the economic crisis (between 2010 and 2016) research and development spending in Spain has decreased by 1.4 billion euros (21\%). Since the beginning of the economic crisis in Spain, the decrease in the mortality rate to be achieved has slowed down significantly, situation that could be exacerbated by the current austerity measures in the health system [8].

\subsection{CANCER Biology}

Tumours, or neoplasms, are groups of abnormal cells that grow into a mass or lump that can be encapsulated or not and form a protuberance that exceeds the limits of the tissue. The term comes

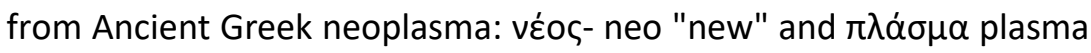
"formation, creation". Tumour is usually a synonym for neoplasm, 
although some neoplasms do not form any tumour, like leukaemia and some carcinoma in situ. Before the neoplasm, cells usually develop dysplasia (delay of differentiation and maturation) or metaplasia (differentiated cells that are replaced by another differentiated cellular type). Neoplasms can be classified in four types according to ICD-10 (internal classification of diseases from the WHO) [9]:

- Malignant neoplasms if they have invaded nearby tissues and sometimes spread to distant tissues through the blood or lymphatic vessel (metastatic).

- In situ neoplasms when it has not ruptured the basement membrane and has not spread even to nearby tissues. It is considered as pre-malignant.

- Benign neoplasms when they lack the ability of invading tissues or spreading and usually grow slowly.

- Neoplasms of uncertain or unknown behaviour if the pathology report cannot assure if they have any malignant potential at diagnosis.

Cancer cells have defects in the regulatory circuits that govern normal cell proliferation and homeostasis. Cancer is a very heterogeneous disease, but tumorigenesis in humans is always a multi-step process of genetic and epigenetic alterations, caused by replication errors, oncoviruses and environmental exposure, that transform the normal cells into malignant through a process of evolution and clonal selection. Each alteration confers some type of 
growth advantage or barrier skipping that can be grouped in six essential alterations in cell physiology considered the cancer hallmarks for dictating malignant growth and for being common for all types of human cancers: self-sufficiency in growth signals, insensitivity to growth-inhibitory signals, evasion of programmed cell death, limitless replicative potential, induction of vascularization, and capacity of invasion and metastasis [10]. Also, new hallmarks are being studied such as genetic instability [11], immune modulation capacity and the importance of the tumour microenvironment [12] (Figure 1).

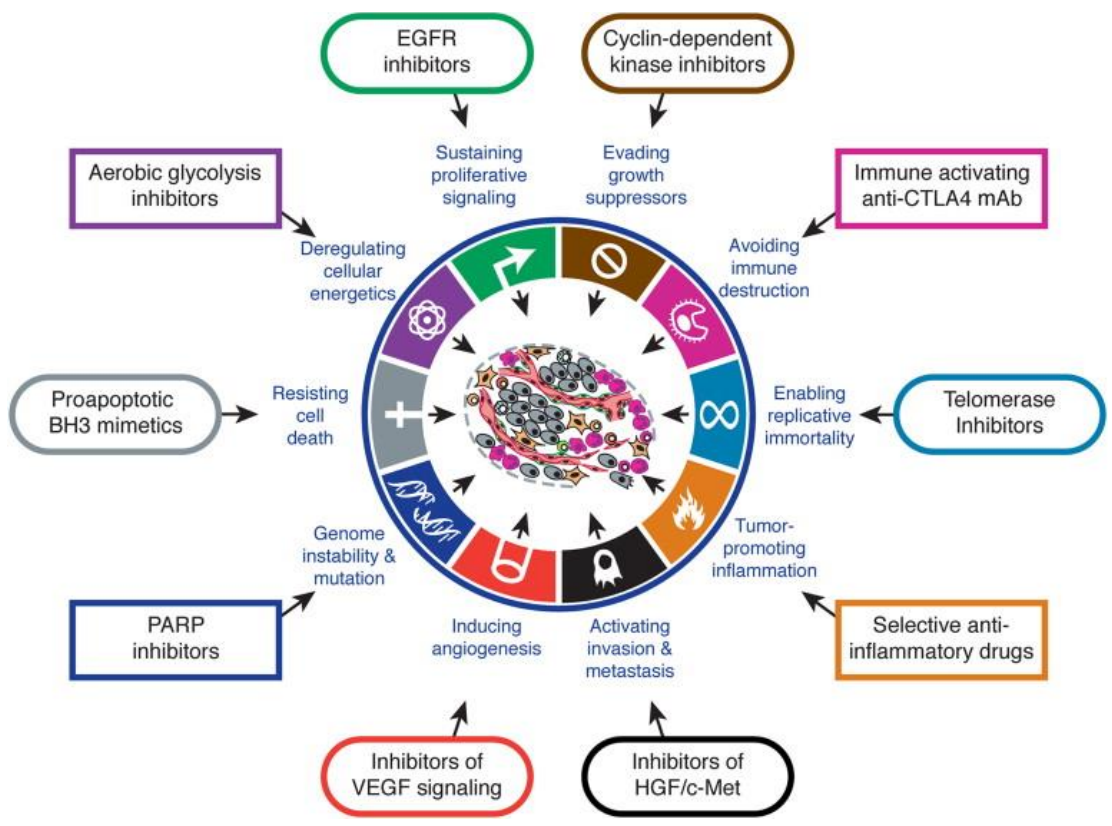

Figure 1. Update of the D. Hanahan and R. A. Weinberg cancer hallmarks and potential therapy strategies to target them. 
Apart from environmental factors and genetic predisposition causing these hallmarks, the capacity of one tissue for developing cancer has been proved to correlate strongly to the number of normal stem cells divisions required for the tissue homeostasis, increasing the risk of progression by time [13], being the cause for many tumours just having "bad luck" in DNA replication and reinforcing the concept that cancer is also a disease of ageing. 


\section{BREAST CANCER}

\subsection{EPIDEMIOLOGY}

Breast cancer is the most common cancer in women worldwide, contributing $25.4 \%$ of the total number of new cases diagnosed in 2018. It is also the most common diagnosed cancer among all people younger than 60 (Figure 2) [5].

It ranks as the fifth cause of death from cancer overall $(522,000$ deaths) and as the leading cause of cancer death among women worldwide [14].

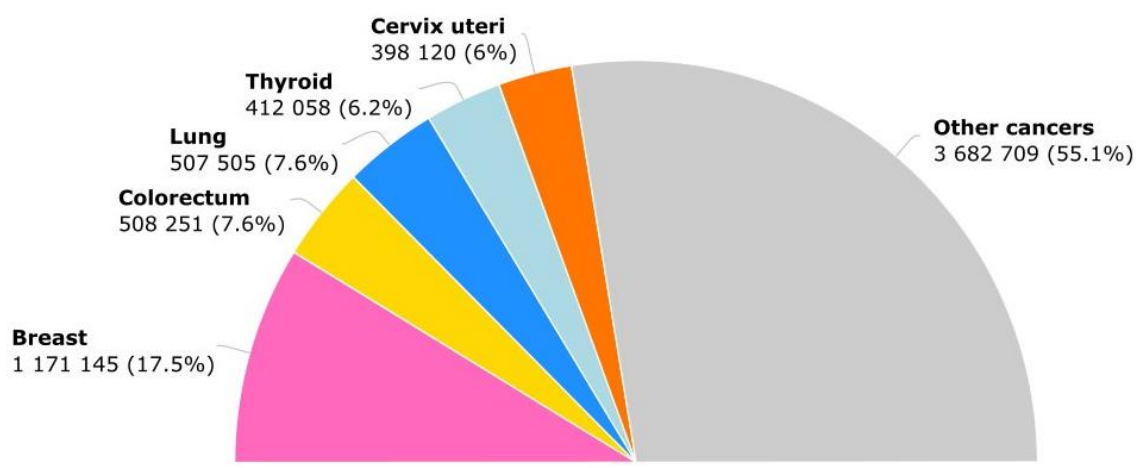

Total : 6679788

Figure 2. Estimated cases of new cancer cases worldwide in both sexes in 2018, ages 0-59 (according to the Global Cancer Observatory. https://gco.iarc.fr/) 
In Spain, breast cancer is also the most frequent neoplasm in women, and the probability of developing breast cancer is estimated to be $8 \%$ [15]. In 2012, 25,215 cases of breast cancer were diagnosed in our country, which represents an incidence of $29 \%$ of all malignancies in women, and caused 6,059 deaths, representing a mortality of $15.5 \%$ [16]. As in other western countries, the incidence of breast cancer has increased considerably, more markedly between the 1970s and 1990s [17]. However, mortality rates decreased as a result of early detection, diagnostic and improved treatment, which led in an increase of 5-year survival, being greater than $75 \%$ [15].

Less than $10 \%$ of breast cancers can be attributed to an inherited genetic mutation. Breast cancer is more commonly associated with environmental, reproductive, and lifestyle factors, some of which are potentially modifiable [18]. Between $5-10 \%$ of patients diagnosed with breast cancer present a hereditary factor, showing mutations in genes with high penetration, such as those responsible for repairing DNA damage, BRCA1 and BRCA2. Other clinical factors such as dense tissue breasts, menstruation before 12 years of age or menopause after 55 years of age [19], can also be relevant risk factors.

In developed countries, most of the risk factors related to breast cancer are associated with our lifestyle, such as sedentarism, diet, body mass, breast density [20], alcohol and drug intake, smoking specially at an early age, hormone replacement therapy during menopause, and modern changes in our reproductive habits such as 
oral contraceptives or late age at first pregnancies and low parity. In addition, the incidence of breast cancer is highly related to the increasing of age [21].

Race is also considered as a risk factor for breast cancer [22], being that African American and Hispanic women from the United States of America have a lower incidence of breast cancer than White women but higher mortality rate. Race could be a biological risk factor due to differences in some mutations [23], reproductive factors [24][25], or differences in plasma hormone levels [26]. However, many studies show that race differences in incidence may be mostly because of social risk factors [27][28]. Social determinants such as poverty, lack of education, neighbourhood disadvantage, residential segregation by race, racial discrimination, lack of social support, and social isolation play an important role in breast cancer stage at diagnosis and survival. This factors are related to late stage at diagnosis of the disease and poorer survival due to inadequate health insurance, barriers to early detection as screening such as a lower mammography use, lack of a primary care physician and unequal access to improvements in cancer treatment [28][29][30]. Even in Spain -where the health system is public and universal- gypsy women, that are the main ethnic group minority, are two times less likely to have had a mammogram than white women, and this inequality could increase mortality caused by breast cancer [31]. 


\subsection{CLASSIFICATION}

Breast cancer is a complex and heterogeneous disease in the clinical, morphological, and molecular aspects of the tumour. Traditional classification is based in histology and stages of the tumour, still used for patient management. It included later the expression of histological markers ER, PR and overexpression of HER2, which was useful to know the response to trastuzumab or endocrine treatment, as well as prognosis of the patient. Lately, genomic technologies have allowed to classify breast cancer in a molecular way according to gene expression panels, comparative genomic hybridisation (CGH) and massive sequencing. This new classification in smaller and more similar subgroups is heading prognosis and treatment towards the aim of personalized therapy.

\subsubsection{Morphological and histological classification}

Regarding clinical diagnosis, the classification of breast cancer and the choice of adjuvant treatment are still based on traditional pathological parameters and on immunohistochemical analysis of three main markers: estrogen receptor (ER), progesterone receptor (PR) and human epidermal growth factor receptor 2 (HER2), which divide breast cancer into Luminal (ER+ and/or PR+), HER2 positive and triple negative [32]. 
Macroscopic examination and integration of clinical information are essential to determine the diagnosis of the breast cancer entity. Macroscopic evaluation should include the description of the lesion, its size and location, the evaluation of the resection margins in the surgical pieces, and the selection of the samples that will be later studied in the microscopic examination. In order to do this diagnostic, samples must be preserved and processed first. The most common method for preservation is fixing the tissue in $10 \%$ formaldehyde, which assures good tissue morphology and DNA and protein preservation, although RNA integrity is poor [33][34]. After the fixation process, the samples are included in solid permanent media such as paraffins or plastic resins. For microscopic evaluation, samples are cut in sections of 3-5 $\mu \mathrm{m}$ and they are stained with haematoxylin-eosin in order to evaluate cellular morphological traits such as size, disposition, chromatin, etc.

In the study of breast pathology, the histological grade must be determined, a correct morphological classification has to be performed and the staging of the disease must be determined based on tumour size, lymph node involvement and the presence or absence of metastasis. The most frequent types of breast cancer according to histopathological classification are:

- Invasive (infiltrating) ductal carcinoma (IDC): these cancer cells come from the cells in the milk duct. It represents more than $80 \%$ of all breast cancer diagnosed cases and $70-80 \%$ of 
all invasive breast carcinomas. It is more common in older ages and has a poor prognosis, with a 10-year survival of around $50 \%$. This prognosis is influenced by the grade, tumour size, lymph node involvement, and vascular invasion [35]. According to the American Cancer Society, approximately 66\% of women who are diagnosed with this subtype are 55 years or older [36].

- Invasive (infiltrating) lobular carcinoma (ILC): It is less common than ductal carcinoma, occurring in $10 \%$ of breast cancer patients. Between 80 and $100 \%$ of cases present loss of E-cadherin expression, which favours the invasiveness of epithelial cells, being tumours with poor prognosis [35]. It originates in the cells that make up the lobes or glandular acini and tend to appear around the age of 60 .

- Pure tubular, cribriform, mucinous carcinomas, metaplastic carcinoma with a fibromatosis-like component, and adenoid cystic carcinoma have an excellent prognosis, with a 10 -year survival greater than $80 \%$, with a very low incidence, not exceeding $7 \%$ of invasive breast cancer cases. Papillary carcinomas are also considered to have a good prognosis, with a 10 -year survival of $60-80 \%$. Medullary carcinomas, which represent $1-7 \%$ of all invasive breast tumours, are considered as intermediate prognosis, and affects mostly women with some BRCA1 mutation. Their cellular morphology is similar to aggressive and very anomalous cancer cells, but they do not 
grow rapidly and the tumour usually does not spread outside the breast to the lymph nodes [35].

- Histological micropapillary, small cell neuroendocrine carcinomas of the breast, clear cell carcinoma, inflammatory carcinoma and glycogen-rich carcinoma show a worse prognosis. Among all the metaplastic carcinomas of the breast, carcinosarcomas specially behave like very aggressive tumours [35].

\subsubsection{Staging and grade}

The grade of a breast cancer is a prognosis factor and represents the aggressive potential of the tumour. For the determination of the histological grade, the recommendations included in the Scarff-BloomRichardson scale [37], later modified in 1999 by Elston and Ellis (Nottingham System) [38], are accepted as consensus due to its important reproducibility among observers. Various studies have demonstrated the concordance of results among pathologists [39][39][40][41]. In this scale, three aspects in tumour differentiation are quantified: 1) the capacity of the tumour to form tubular structures, 2) the degree of pleomorphism or atypia in tumour cells and 3) the number of mitoses present in 10 microscopic fields. The tumour is scored from 1 to 3 in these different aspects and scores are summed: 
- Grade 1 or well differentiated (score 3, 4, or 5). The cells are slower-growing and look more like normal breast tissue.

- Grade 2 or moderately differentiated (score 6,7$)$. The cells are growing at a speed of and look like cells somewhere between grades 1 and 3 .

- Grade 3 or poorly differentiated (score 8, 9). The cancer cells look very different from normal cells and will probably grow and spread faster [42].

The pathologic stage of a breast cancer is a prognostic factor that measures how advanced the patient's tumour is. It is based on the tumour size $(\mathrm{T})$ and how far it has spread (lymph nodes affected $(\mathrm{N})$ or other parts of the body due to distant metastases (M)). The stages are based on the 1977 staging manual of the AJCC (American Joint Committee on Cancer) [43]. The stage is determined by examining tissue removed during surgery and is important in order to determine the right treatment for the patient. According to TNM classification the stage of the disease is obtained. In breast cancer, 4 stages are distinguished: stages I and II are considered as early disease; stages IIIA and IIIB are locally advanced disease stages, stage IIIC means advanced disease and IV corresponds to secondary or metastatic disease. The earliest stage breast cancers are stage 0 (carcinoma in situ), meaning pre-invasive disease. Apart from TNM classification, breast cancer staging includes sometimes also the addition of information about ER, PR, and HER2 receptor status along with 
histological grade, which has made stage grouping for breast cancer more complex than for other cancers [44].

\subsubsection{Histological markers}

One of the earliest and most widely used classifications of breast cancer nowadays is based on the expression of membrane receptors and hormone receptors, all involved in cell division or proliferation.

These subtypes are described according to the status of the Estrogen Receptor (ER), Progesterone Receptor (PR), the epidermal growth factor receptor ERBB2 (HER2), and Ki-67 [45][46][47][48]. Through this mechanism, it was stablished a quick and easy way to classify the breast cancer tumours into different subtypes with few resources and using prognostic and/or predictive markers. These four markers are determined in histology of every breast cancer patients and sometimes more can be added. According to the combination of the semiquantitative expression of the previous markers, studied by immunohistochemistry, four basic subtypes are separated:

- Luminal A: ER+/PR+ and HER2- tumours with Ki-67 $<14 \%$ (luminal cells with low expression of proliferation genes).

- Luminal B: ER+/PR+ and HER2+/- tumours with Ki-67 > 14\% (luminal cells with high expression of proliferation genes and worse prognosis).

- HER2 positive: ER+/-, PR+/- and HER2+ tumours. 
- Triple Negative or basal-like: ER-, PR- and HER2-negative tumours with basal-like cells. Furthermore, these tumours are positive for other aggressive IHC markers such as CK 5/6 (cytokeratines) and/or EGFR (epidermal growth factor receptor) [49].

If the tumour is negative for these 7 markers (ER, PR, HER2, Ki67, CK 5/6 and EGFR) it cannot be classified, making it impossible to establish these tumours in any of the previously mentioned subtypes. Ki-67 threshold cut-off has also been changing for discriminating low proliferating from high proliferating tumours, sometimes $15 \%$ has been used for splitting luminal subtypes $A$ and $B$ and nowadays even $20 \%[50]$.

\subsubsection{Molecular classification}

Although clinicians remain using the histopathological classifications, both the stages and grade with the histological markers, many new molecular classifications have been performed in the last years, using genomic platforms for gene expression and massive sequencing in order to better classify the tumours, trying to avoid unnecessary chemotherapy and to have better disease prognosis. 
In 2000, Perou et al. [51] used cDNA microarrays measuring 8012 human genes to characterize the molecular patterns of gene expression among different breast tumours and described four different subtypes arising from at least two different cell types (luminal and basal epithelial cells): luminal-like, basal-like, HER2enriched and normal-like. These subtypes corresponded to the 4 IHC markers classification because the different mRNA profiles found were driven by signalling from ER or HER2 genes.

- Luminal-like subtype: these tumours according to this microarray classification are all the ER positive and were subdivided in A and $\mathbf{B}$ clusters depending on their profile of proliferating genes some years later by Sørlie et al. [52]. This subtype is similar to the luminal from IHC classification. However, this molecular clusters also classify the ER+/PR+ HER2 + tumours as luminal B, also called luminal B-HER2, and leaves in HER2 subtype tumours only positive for this marker.

- Basal-like subtype: these tumours have multiple expression profiles according to the microarray and so comprises different subgroups that must be studied. They have gene expression typical of basal epithelial cells such as EGFR, cytokeratines such as CK5, CK6, CK14, CK17, CD44, cadherins, caveolin 1 and 2 and nestin. They also usually give negative results for ER, PR and HER2, for that reason they also overlap with tumours defined as triple negative tumours, with a very aggressive and proliferative behaviour, although they are not 
biologically synonyms [53]. This subtype includes most of the tumours of women with mutations in BRCA1 [52].

- HER2-enriched subtype: according to this molecular profile cluster, this subtype does not include those tumours with ER+ or PR+, but only tumours with pure HER2 amplification. These other tumours positive for hormonal receptors are now considered luminal B and, as they have better prognosis than the pure HER2 tumours, this different classification may match better for prognosis.

- Normal-like subtype: these tumours have typical gene expression of basal epithelial cells and adipose tissue and low gene expression of luminal epithelial cell. It is considered to be some normal tissue contamination rather than an intrinsic subtype.

Basal-like, HER2-enriched and normal-like subtypes are all negative for ER receptor, considering all ER-positive breast cancers in the luminal-like subtype.

Following this discovery, additional subgroups have been later described by more authors according to different clustering by gene expression, like molecular apocrine [54], interferon-enriched [55] and claudin-low subtypes [56]: 
- Molecular apocrine subtype: these tumours have apocrine features on histologic examination, are androgen receptor positive (AR+) [54] and usually have amplifications of HER2 region, which can be used as targets for therapy [57][58].

- Interferon-enriched subtype: these tumours have high expression of interferon regulated genes, including STAT1 [59], a transcription factor that mediates interferon regulation of gene expression.

- Claudin-low subtype: these tumours are ER-, PR- and HER2-, as well as basal-like subtype. They were initially part of the basal-like subtype but they have lower expression of genes involved in cell to cell adhesion, such as claudins, e-cadherin and occludins [59]. They are a more aggressive subtype and present lymphocyte markers and biological properties similar to cancer stem cells.

These new subgroups and more that are arising are still not used in the clinics and their impact and potential in treatment or clinical management is still unknown.

The most basic characteristics of the different subtypes related to the degree of cell differentiation and basic characteristics of each subtype are summarized in Figure 3. 


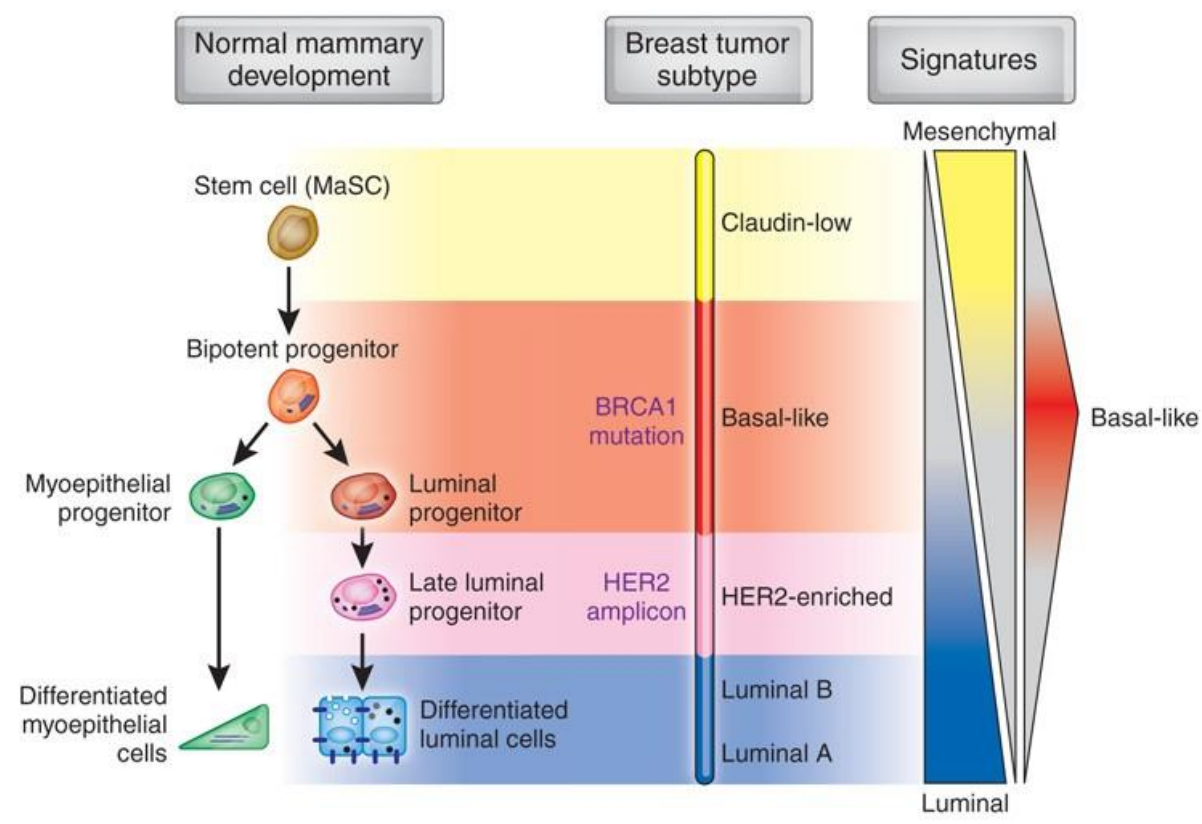

Figure 3. Schematic representation of the human breast epithelial cell hierarchy and its association with the main breast cancer subtypes. Gene expression profiles of these cell populations upon fractionation of the mammary gland and cell sorting, revealed similarities to specific subtypes of breast cancer. (Prat, A., Perou, C. Mammary development meets cancer genomics. Nat Med 15, 842-844 (2009)).

\subsubsection{Molecular profiling platforms for prognosis}

Apart from these studies with microarrays, some gene panels have been specially designed for the clinical practice, selecting less genes and not willing to create new classifications but to classify the patients for better diagnostic and according to prognostic gene markers. Their objective is therefore based on trying to group the 
different types of breast cancer into subtypes sufficiently different from each other, which can predict tumour prognosis, as well as effectiveness against different drugs.

In order to simplify the genetic signature, Parker [60] developed a 50-gene signature that replicated this classification, which he named PAM50. This signature consisted of 50 genes related to different aspects of the tumour, such as adhesion, cell death, proliferation, migration, and which gave a predictive value for the patient's prognosis. It is one of the most used for the clinics as it classifies the patient tumour into one of the five main subtypes and gives a measure of recurrence risk at 5 years. In the United States, the most used test for determination of patients who may benefit from chemotherapy is Oncotype DX, which predicts profit or not of adjuvant treatment with tamoxifen in patients with breast cancer, negative for axillary nodes and with estrogen receptor expression [61][62]. This genetic signature is based on PCR expression of 21 genes, including 16 cancer-associated genes and 5 endogenous genes [62]. MAMMAPRINT studies a panel of 70 genes and indicates the recurrence risk 10 years after diagnosis [63][64][65]. Other similar tests are Veridex 76 gene, MapQuant Dx [66] and Theros [67][68].

In recent years, second generation tumour prognosis arrays have been developed based not only on genes related to proliferation, but also on the tumour immune response [69][70]. 
Although these prognostic panels were thought to replace the prognosis based on clinicopathologic parameters [71][72], these prognostic signatures must be complementary to the traditional factors, such as tumour size and presence of metastasis. Some authors also defend that the traditional IHC classification with 4 protein markers may be as accurate and sufficient for prognosis as these new genetic panels [73].

\subsection{BREAST CANCER TREATMENT}

Along with advances in early detection, the correct selection of treatment has made it possible to reduce mortality from this neoplasm in recent decades. The treatment of breast cancer has evolved considerably in recent years thanks to the incorporation into routine clinical practice of the biological markers described before, ER, PR, and HER2, and the development of targeted therapies against these molecules, avoiding the inspecificity and secondary effects of chemotherapy.

In early and locally advanced disease (stages I, IIA, IIB and IIIA) the ultimate goal of treatment is curative, performing local treatment with surgery and systemic treatment, whereas in metastatic disease (stages IIIC and IV) treatment is palliative, focused in prolonging the life of patients with the highest quality of life [74][75]. However, the 
selection of systemic therapy currently depends on the tumour subtype defined by ER, PR and HER2, and the tumour stage independent.

In recent years, the general trend is to perform conservative surgery, mainly lumpectomy, avoiding radical mastectomy [76] and restricting axillary emptying due to its high morbidity [77]. Surgery may be accompanied by radiation therapy in cases where there is proximity of the tumour with the resection margins, as this treatment reduces the risk of recurrence by $10-20 \%$ [76][78]. After surgery and/or radiotherapy, patients receive systemic treatment, called adjuvant therapy, the main purpose of which is to reduce the risk of disease recurrence. The commonly selected treatment consists of chemotherapy in combination with hormonal therapy or anti-HER2 therapy (Figure 4). However, in T2 and T3 tumour sizes, treatment prior to surgery is applied, called neoadjuvant therapy, and it aims to reduce the tumour size in response to chemotherapy, making it possible to perform surgery. Furthermore, this therapy allows assess the response to treatment by evaluating the complete pathological response, a prognostic factor for disease-free survival [79].

Chemotherapy is the most widely used treatment in cancer and the different types are classified according to their mechanism of action. In breast cancer the most widely used are anthracyclines (doxorubicin and epirubicin), whose main mechanism of action is the inhibition of topoisomerase II and inducing cell death [80], and taxanes 
(docetaxel and paclitaxel) with microtubule binding capacity, preventing cell division and proliferation [66]. However, after the development of gene expression microarrays and the discovery of different molecular patterns in cancer, different studies showed that there are tumour subtypes that do not benefit from treatment with chemotherapy [81].

Hormone therapy is currently the therapy of choice for the treatment of ER and/or PR positive breast tumours (luminal A and B). Its mechanism of action is based on the blocking of cellular activity mediated by ER and PR. There are two main groups of these drugs: selective ER modulators, called SERMs, with tamoxifen being the most used, and aromatase inhibitors, with letrozole being the most used [82][83]. These patients also receive treatment nowadays with new drugs like everolimus (mTOR inhibitor) [84] and palbociclib (CDK4/6 inhibitor that inhibits COX II and eventually reduces epithelial to mesenchymal transition) [85].

Anti-HER2 therapy is currently the treatment of choice for those patients with breast tumours with HER2 amplification, both in early stages and in metastatic disease. It is mainly based in the combination of trastuzumab and chemotherapy, until disease relapse or toxicity. In cases of progression, it is advisable to continue with anti HER2 treatment, either lapatinib or trastuzumab in combination with other chemotherapeutic agents, or in combination with new drugs like pertuzumab or T-DM1, that were developed to overcome resistance 
to trastuzumab. These therapeutic strategies for HER2 positive subtype are deeper developed in the next section.

The different treatment strategies according to the subtype are summarised in Figure 4.

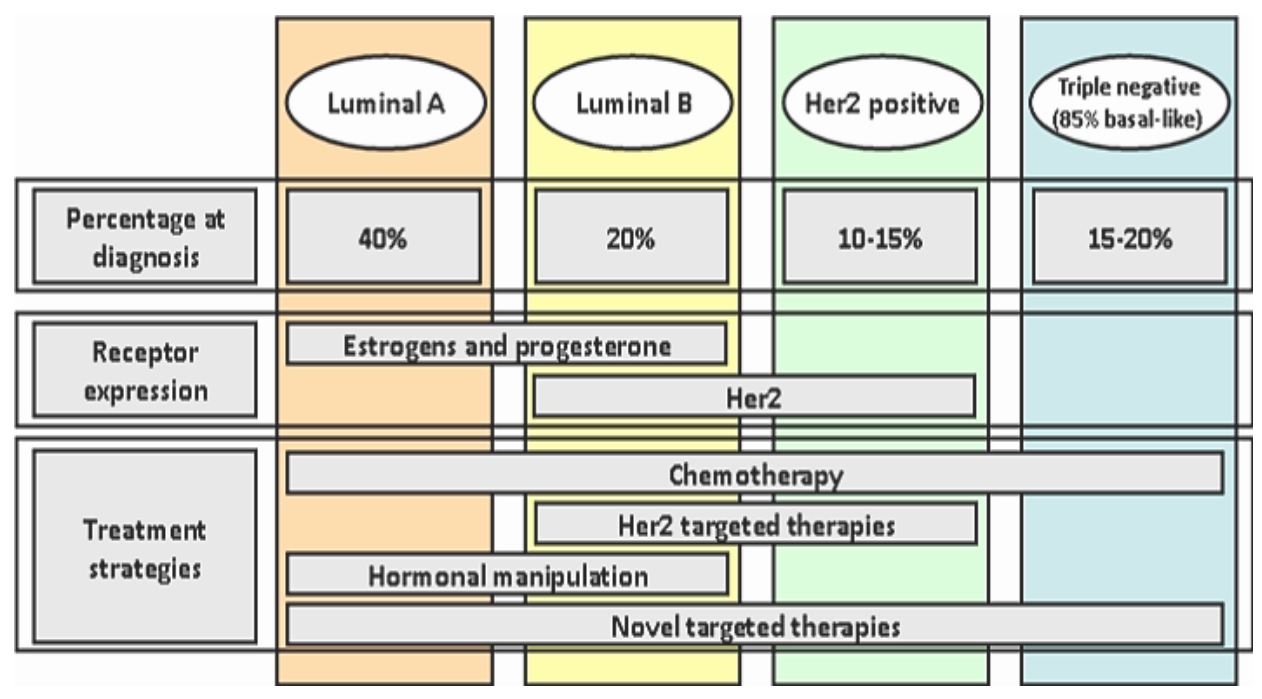

Figure 4. Breast cancer traditional subtypes by IHC and their main treatment strategies. 


\section{THE HER2 POSITIVE SUBTYPE}

HER2 positive breast cancer is a subtype of breast cancer in which patients have HER2 gene amplification or HER2 protein overexpression (diagnosed by FISH or immunohistochemistry respectively), affecting approximately $20 \%$ of breast cancer patients. HER2+ breast cancer has always been of poor prognosis compared with other subtypes such as hormonal, but the use of anti-HER2 targeted therapies in recent years combined with chemotherapy has increased survival rates and decreased the risk of recurrence, turning HER2 into a therapeutic target.

\subsection{HER2 RECEPTOR}

\subsubsection{Structure}

The HER2 oncogene (ErbB-2/neu) is located on chromosome $17 q 12$ and encodes the HER-2 glycoprotein, one of the receptors in the epidermal growth factor receptor family (known as EGFR or ErbB). This protein is overexpressed or mutated in many breast cancer patients and its known as HER2+ breast cancer subtype, being approximately $15-20 \%$ of breast cancer total cases [86][87].

The EGFR family is composed in humans by four plasma membrane receptors with intrinsic tyrosine kinase enzyme activity 
(also called TKR for tyrosine kinase receptors), which are: the receptor for epidermal growth factor (EGFR, ErbB-1 or HER1) and their counterparts: HER2 (ErbB-2), HER3 (ErbB-3) and HER4 (ErbB-4). Structurally, the receptors of this family are quite similar, and they all consist of three domains [86]:

- An extracellular domain (ECD) that intervenes in ligand binding and receptor dimerization.

- A transmembrane hydrophobic domain (TMD).

- An intracellular domain (ICD) with intrinsic enzyme activity tyrosine kinase.

The biological function of these receptors usually occurs in the following way: the binding of a ligand (growth factor) to the extracellular domain of the receptor induces it to form dimers in the plasma membrane, both between receptors of the same type (homodimers) and between two distinct receptors (heterodimers). Ligand binding, in addition to dimerization, involves the activation of its cytoplasmic tyrosine kinase activity so that, once the dimers are formed, they are capable of transactivating by cross-phosphorylation in their tyrosine residues from their cytoplasmic domain. Phosphorylated tyrosines serve as "anchors" to proteins possessing $\mathrm{SH} 2$ and PTB domains. These proteins have also their tyrosines phosphorylated by the tyrosine kinase receptors and trigger the initiation of a signalling cascade. 
The extracellular domain of this receptor family is made up of four subdomains: I/L1, II/CR1, III/L2 and IV/CR2 (Figure 5), which really represent a tandem repeat of a unit consisting of two subdomains ( $L$ and CR). The structures of the extracellular region of HER1 (sHER1) in complex with EGF obtained by crystallography show that the ligand binds to subdomains I and III, and that an elongated projection of subdomain II mediates dimerization between receptors. However, in the crystallographic structures of the non-active forms of sHER1 and SHER3, this prolongation of subdomain II is observed forming a contact with a pocket of subdomain IV of the same receptor. Based on this, a model of activation of these receptors was proposed in which the receptors in the absence of ligand appear in an inactive and autoinhibitory or "closed" form that when binding its ligand undergoes a conformational change due to the reorganization of its domains towards an active or "open" form [86]. This conformational change brings subdomains I and III closer together, breaking the interaction between subdomains II and IV and thus releasing the prolongation of subdomain II so that it can participate in the dimerization of the receptors [88].

The contact between subdomains II and IV that restricts the conformational change in the inactive form of sHER1 and sHER3 is not found in SHER2 and in its domains I and III are faced. This absence of contact between subdomains II and IV could be explained by not having conserved two key residues in the contact region of subdomain IV (Gly563 and His565 of HER3 are replaced by Pro and Phe, 
respectively, in HER2). The interaction between HER2 subdomains I and III is stable since it forms a core with hydrophobic residues shrouded by hydrophilic contacts [88]. This proximity of subdomains I and III in SHER2 is very similar to the rearrangement observed in SHER1 structures in complex with EGF. This constitutively open and active structure of HER2 could explain the absence of a high affinity ligand for HER2 since it does not require its binding to free itself from an autoinhibitory conformation. Having a fixed conformation, HER2 should also be able to interact with any other receptor that is available to dimerize, explaining its predisposition to serve as a co-receptor with the rest of the ErbB receptors in the absence of ligand (although it has been seen that mainly does with HER3 which lacks intrinsic tyrosine kinase activity) [87]. It would also explain why HER2 overexpression in culture cells causes its activation and a malignant phenotype, while HER1 or HER3 overexpression is not transformative until the ligand is added: the closed conformation of these receptors is a protective barrier to avoid self-activation. The HER2 lack of this barrier contributes in part to its transformative potential when overexpressed.

\subsubsection{Signalling}

The tyrosine kinase residues of the phosphorylated receptors serve as an anchor for numerous adapter or "scaffold" proteins that allow the binding of other proteins and initiate intracellular signalling 
pathways. They bind to phosphorylated tyrosines, proteins with $\mathrm{SH} 2$ or PTB domains, which also recognize the amino acids that surround these tyrosines, so that the binding is specific at each receptor. The main signalling pathway activated by the HER2 receptor is that of PI3K, followed by the MAP kinase pathway (MAPK) [86][89]. The estrogen pathway is important in the subgroup of patients who share HER2+ with positive hormone receptors (RH). A cross-communication of HER2 with the IGF-1R receptor pathway has also recently been observed, which is notable in some of the resistance to treatments discussed below.

- PI3K pathway: the PI3 kinase pathway begins with the phosphorylation of phospholipids present in the cell membrane phosphatidylinositol-4,5-bisphosphate (PIP2), converting it to phosphatidylinositol-(3,4,5)-triphosphate (PIP3). PIP3 enables binding of the Akt kinase (also known as protein kinase $\mathrm{B}[\mathrm{PKB}]$ ) via a $\mathrm{PH}$ domain that binds to inositols with high affinity. By binding to PIP3, Akt can be activated by PDK1 (phosphatidyl inositol-dependent kinase 1), which binds to the PH domain of another nearby PIP3 and phosphorylates Akt. In the same way, the mTOR complex is recruited, a protein responsible for the regulation of cell growth, proliferation and death, which also activates Akt, which also participates in cell growth and proliferation functions regulating various transcription factors. This pathway is usually regulated by PTEN phosphatase, which dephosphorylates PIP3 back into 
PIP2. However, an overexpression of HER2 in cancer causes overactivation of the pathway in an unapproachable way for PTEN, leading to uncontrolled growth and proliferation and avoidance of cell death [90][91].

- MAPK pathway: MAP kinases are serine-threonine kinases, and their signalling pathway begins with the binding of the GRB2 adapter protein to the HER2 receptor by its phosphorylated tyrosines. Ras comes to GRB2 to join and GRB2 activates it. Ras then binds and activates Raf, this one to MEK, and this one to ERK, and finally the pathway leads to cell proliferation, division and differentiation [91].

\subsection{ANTI-HER2 THERAPY}

The main mechanism of action of anti-HER2 therapy is to block the activation of both signalling routes, considerably reducing cellular mechanisms happening downstream of these two pathways.

- Trastuzumab (Herceptin ${ }^{\circledR}$ ): It is a monoclonal antibody and the most commercialized specific treatment against HER2 for breast cancer. Herceptin ${ }^{\circledast}$ binding blocks HER2 signalling but its action includes antibody-dependent cell death (ADCC) [86][66], blocking of receptor aggregation and stimulation of HER2 endocytosis to remove it from the cell surface. Herceptin monovalent Fab fragments do not possess the 
antiproliferative properties of the entire antibody. Herceptin also inhibits HER2 from being activated by cleavage of the extracellular domain by the area near the membrane, a process that usually occurs at very low levels but increases when HER2 is overexpressed. Herceptin binds to the Cterminus of subdomain IV of HER2 (Figure 5) [66], where the binding pocket for the domain II loop is in the inactive states of HER1 and HER3. Interaction occurs through 3 regions of HER2: electrostatic interactions occur in the first and third junction loops, and hydrophobic contacts occur in the second junction loop formed by the CDR3 loops of the heavy and light chains of the antibody. The binding of Herceptin to the juxtamembrane region facilitates the action of the endocytic machinery while preventing unwanted activation of the kinase by functioning as a steric barrier against the direct interaction of the transmembrane regions, possibly necessary for optimal signalling. Binding at this site also sterically blocks proteolytic activation of HER2 and may also block its interaction with other proteins.

- Pertuzumab: It is a recombinant humanized monoclonal antibody based on human IgG1 immunoglobulin. It works by blocking the association of HER2 with other members of the EGFR family, thereby inhibiting the formation of heterodimers. Pertuzumab binds to an epitope from subdomain II of the HER2 extracellular domain (Figure 5), 
which is the domains responsible for dimerization. Since the binding site of pertuzumab (ECD subdomain II) is different from the one of trastuzumab (ECD subdomain IV) they have complementary mechanisms of action and can be combined for the treatment of breast cancer with HER2 overexpression. Furthermore, pertuzumab also activates antibody-dependent cytotoxicity with the same potency as trastuzumab [66][92][93].

- Tyrosine kinase inhibitors: Lapatinib, the main one, is a small molecule that is administered orally and inhibits the tyrosine kinase (TK) activity of both HER1 and HER2. Although it blocks HER1 and HER2 with the same potency, it only has a therapeutic effect in HER2-positive breast cancers. Unlike trastuzumab or pertuzumab, lapatinib is a small molecule that can easily cross the blood-brain barrier, and this could be effective in treating metastases in the brain. Studies have shown that lapatinib causes a reduction of tumours of the nervous system in some of the patients. Furthermore, the cardiac risk when treated with lapatinib appears to be lower than with trastuzumab [66][93][94]. Other examples of inhibitors of tyrosine kinases are neratinib and afatinib [94][95].

- Inhibitors of heat stroke protein 90 (Hsp90): Hsp90 is a chaperone that aids in the folding, maturation, conformation, and stabilization of the HER2 protein and substrates 
downstream of its signalling pathway such as Raf and Akt. Geldanamycin and its derivative tanespimycin/17-AAG have anti-tumour properties and may decrease the expression of Hsp90 substrate proteins, including HER2. Hsp90 is highly expressed in most cells, but Hsp90 inhibitors show selective action on cancer cells [66][93][96]. Truncated forms of HER2 continue to require $\mathrm{Hsp90}$, so their inhibitors are effective in these cases as well [87].

- T-DM1: Also known as trastuzumab-DM1 is an anti-HER2 antibody (trastuzumab) conjugated to a cytotoxic agent (emtansine). It is based on the endocytosis mechanism that HER2 receptors undergo when recognized by Trastuzumab. When conjugated, this conjugate will release its cytotoxic agent and cause cell death only to those cells that have been recognized by T-DM1 trastuzumab, therefore being much more selective than conventional chemotherapy [86][93][96].

The signalling pathways of the HER family and the main target therapies among the mentioned against HER2 receptor are schemed in Figure 5. 


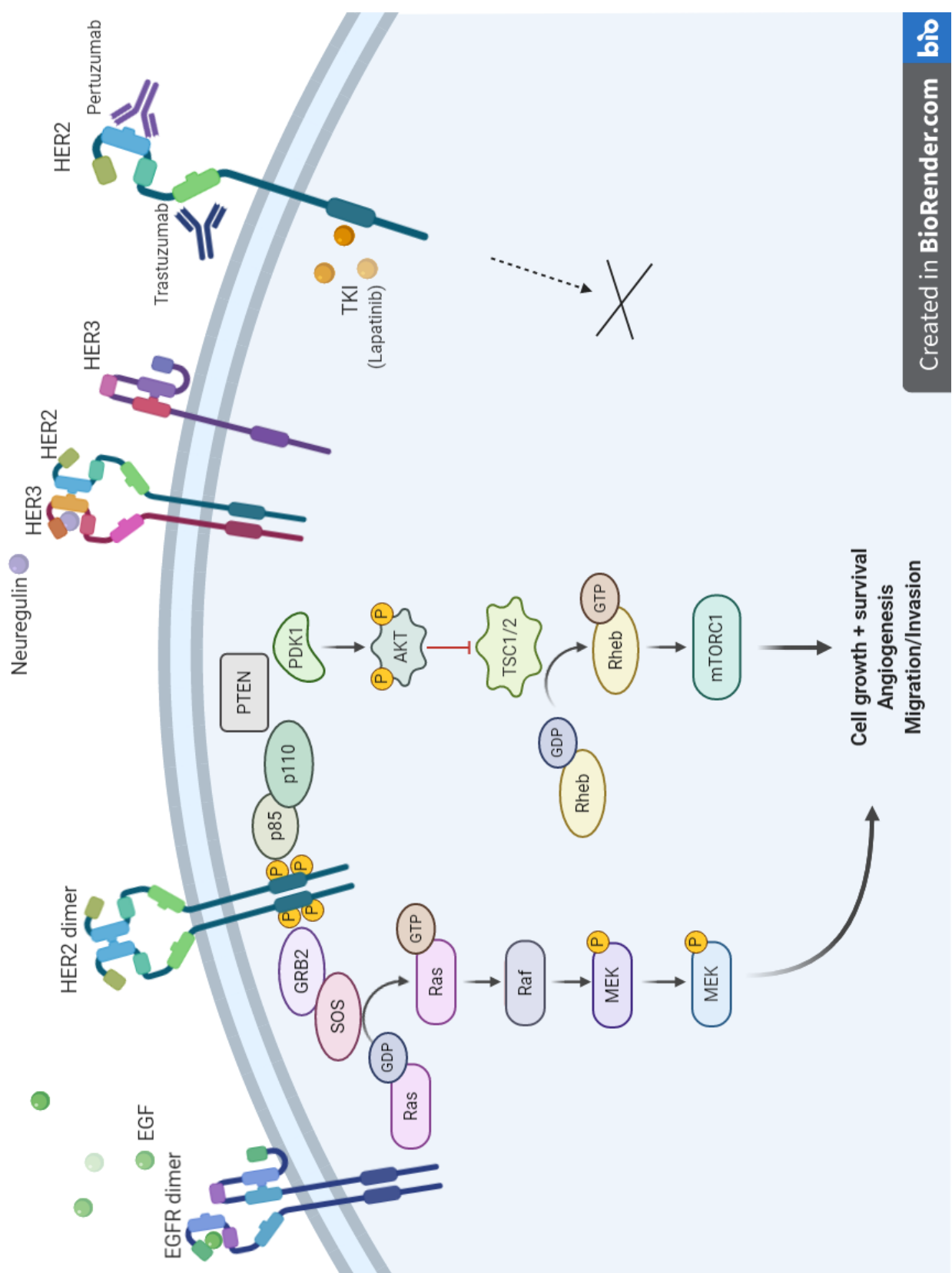

Figure 5. Schematic diagram of HER2 and HER family signalling pathways and treatments that target HER2 specifically. 


\subsection{RESISTANCE TO TRASTUZUMAB}

The incorporation of anti-HER2 therapy in clinical practice has meant an important advance in the treatment of an aggressive tumour subtype, increasing five-year disease-free survival. However, $25 \%$ of patients in early stages do not respond to treatment [97][98]. Furthermore, approximately $70 \%$ of metastatic tumours that initially respond well to treatment progress after 6 to 8 months of continued exposure to anti-HER2 therapy [93]. This is mainly because in certain tumours there are other alterations involved in the process of tumour proliferation or metastasis or because the tumour develops new molecular alterations to avoid treatment. In addition, thanks to the incorporation of the study of molecular profiles, it has been shown that there is an important intratumor heterogeneity, meaning that within the same tumour several populations with different molecular alterations can be detected and they may not present the same behaviour to certain treatments [99].

Two types of resistance to treatment can be distinguished: primary resistance or acquired resistance. The primary resistance model is defined by the presence of molecular alterations when diagnosing the disease that cause the tumour cells to evade the mechanism of action of anti-HER2 therapy, and so the tumour to be unaffected by treatment. According to the intratumor heterogeneity, the responses to the treatment in primary resistance may be different. In the presence of a monoclonal tumour, in which all tumour cells 
present the same molecular alteration that confers resistance to treatment, progression of the disease will be observed during treatment. However, in a heterogeneous tumour, where most of the tumour cells are sensitive to anti-HER2 therapy and a smaller proportion have primary resistance, a partial response to treatment will be observed, eliminating sensitive cells but not the resistant cells, but there will be a relapse of the disease in a short time after the end of treatment. The acquired resistance model is defined by a primary tumour that is sensitive to treatment with anti-HER2 therapy but in which new clones with molecular alterations de novo appear after continued exposure to treatment and then are able to evade the mechanism of action of anti-HER2 therapy, causing a relapse of the disease and a non-response to treatment [97].

Different molecular mechanisms are involved in trastuzumab resistance, both primary and acquired. They have been defined and can be classified into three levels: 1) increased expression of EGF family ligands; 2) alteration in the HER2 receptor or other members of the HER family, or interactions with other receptors; and 3) constitutive activation of HER2-mediated signalling pathways.

\subsubsection{Increased ligand expression}

The increase in specific ligands of the HER2 family or other families of tyrosine kinase receptors has been described as an 
important phenomenon of compensatory signalling, causing resistance to anti-HER2 therapy. Neuregulin (HER3 ligand) overexpression has been described as an important mechanism of resistance. This ligand is the main activator of HER2/HER3 dimerization, however it also causes HER4 activation [100][101]. Furthermore, the increase of IGF, ligand of IGF1R, causes the overactivation of the RAS/MAPKs and PI3K/AKT/mTOR signalling pathways [102].

\subsubsection{Receptor alteration}

The main alteration of the receptor is the presence of truncated forms of HER2 (p95HER2), which lack extracellular domain, therefore trastuzumab cannot recognize or bind to the receptor and block its kinase activity. The generation of p95HER2 occurs from the proteolytic cleavage of total HER2, and it is postulated that trastuzumab resistance could be mediated by selection of tumour cells expressing p95HER2. The presence of this truncated form correlates with a worse prognosis in HER2 patients [103][104]. HER2 and EGFR mutations [105][106] have also been described as resistance factors to antireceptor treatment.

Other resistance mechanisms involve the increase or constitutive activation of other tyrosine kinase receptors that can activate the same cellular signalling pathways as HER2. The overexpression of the 
c-MET receptor triggers the activation of the PI3K/AKT/mTOR pathway, resulting in compensatory intracellular signalling upon blocking of HER2 signalling [107]; and the overexpression of the IGF1R receptor activates the cascade of RAS/MAPKs and PI3K/AKT/mTOR [108].

\subsubsection{Constitutive HER2 pathway activation}

Any constitutive alteration downstream of HER2 receptor in the RAS/MAPKs and PI3K/AKT/mTOR signalling cascades would cause the proliferation and invasion processes to continue active regardless of receptor blocking by trastuzumab.

One of the main molecular alterations described in breast cancer that cause this effect is the loss of expression of the tumour suppressor PTEN, the main repressor of the PI3K/AKT/mTOR cascade. This dual phosphatase dephosphorylates AKT by preventing the activation cascade from continuing. Loss of PTEN has been described as an important mechanism of resistance to trastuzumab since it causes constitutive activation of AKT, preventing cell arrest and inhibiting the apoptosis that would cause trastuzumab [109][110]. This loss of PTEN expression has been described in approximately $15 \%$ of HER2-positive breast tumours, exhibiting poorer disease-free survival and poorer response to treatment with anti-HER2 therapy [111]. 
Mutations in PIK3CA, the catalytic subunit of PI3K, have been also described, which cause the same trastuzumab resistance effect [112]. These mutations are present in breast tumours with an incidence of $25-40 \%$ and cause the activation of the PDK1 and PDK2 proteins that activate AKT.

There have also identified mutations in AKT1, which cause the constitutive activation of the protein and comprise an important mechanism of resistance to trastuzumab treatment. These mutations have been described in several tumour types, estimating that they are present in $6 \%$ of breast tumours [113].

All these alterations prevent trastuzumab from blocking the HER2 pathway. Furthermore, a significant number of patients present primary or acquired resistance to trastuzumab treatment by other mechanisms that remain still unknown, and resistance must be deeper studied. 


\section{Triple Negative Breast CANCER}

Triple negative breast cancer (TNBC) is defined by the absence of expression of estrogen receptors (ER) and progesterone receptors (PR) as well as not having overexpression or amplification of receptor 2 for human epidermal growth factor (HER2) [114].

This breast cancer subtype represents around $15-20 \%$ of all breast cancer patients and is associated with a high recurrence rate, worse prognosis, and poor survival compared to other types of breast cancer [114][115]. This is due, among other issues, to the heterogeneity and aggressive nature of this disease [115]. But another important factor is that there are no well-defined molecular targets to be able to undertake the search for therapy directed against them, since this type of cancer is defined precisely by the targets that it lacks, and it does not present any of its own. Furthermore, TNBC metastases are more aggressive compared to the other types and occur mainly in the viscera, especially in the lungs and brain [116], and to a lesser extent in the bones [117].

A first molecular characterization by Perou in 2011 classified the TNBC as basal-like (50\%), claudin low (30\%), and the luminal subtypes A, B, and HER2 for the remaining 20\% [118]. Furthermore, certain clinical trials raised the suspicion of molecular heterogeneity also among triple negative breast cancer, since only $20-30 \%$ of the patients in these trials achieved a complete pathological response to 
neoadjuvant chemotherapy, which was strongly associated to a prolongation of overall survival and event-free survival [117][119][120]. Furthermore, these patients with TNBC who presented a complete pathological response had the same prognosis as patients with breast cancer who were not of the TNBC type [117]. However, among patients who did not achieve a complete pathologic response, those with TNBC had markedly less favourable outcomes (shorter survival due to a higher local early recurrence rate, especially between the first and third year after diagnosis) than patients who did not have TNBC [121]. This heterogeneous response to neoadjuvant chemotherapy suggested that there might be different subtypes of TNBC associated with high or low complete pathologic response rates, and individualizing therapy by subtype using a molecular profile would allow predicting which patients would benefit from the therapy. Furthermore, the characterization of this molecular profile could reveal new targets of the TNBC against which to develop specific drugs for each subtype and stop treating them as a subtype altogether [122].

\subsection{TNBC LEHMANN'S CLASSIFICATION}

This more complete and separate molecular classification of the TNBC was carried out also in 2011 by Lehmann and Bauer et al. [123], who found that the triple negative subtypes did not correspond to the previous classification (Claudin Low, Luminal A, etc.) and that they 
needed one of its own separate classification. They described 7 subtypes of TNBC according to their gene expression in chips: they found 6 defined subtypes and one unstable group. TNBC subtypes were identified using 21 public gene expression profiles of breast cancer mRNAs by cluster analysis of more than 500 TNBC cases. The 7 TNBC subtypes were characterized based on gene ontologies and differential gene expression and were called basal-like 1 (BL1), basallike 2 (BL2), immunomodulatory (IM), mesenchymal (M), mesenchymal stem-like (MSL), luminal androgenic receptor (LAR) and unstable (UNS).

The main TNBC subgroups derived from Lehmann's classification, their characteristics and their proportions are schemed in Figure 6. 


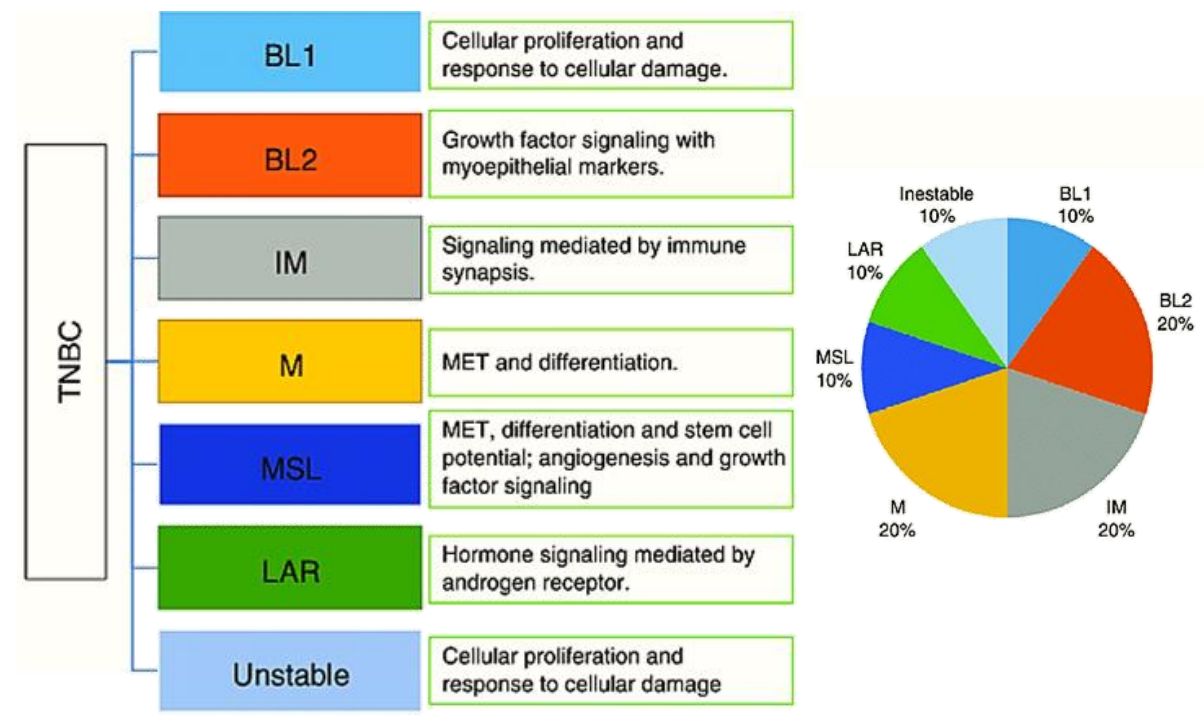

Figure 6. Lehman's triple negative breast cancer classification, gene ontology and proportion. $T N B C$, triple negative breast cancer; $B L 1$, basal like $1 ; B L 2$, basal like 2; IM, immunomodulatory; M, mesenchymal; MSL, mesenchymal stem cell-type; LAR, androgen luminal receptor; MET, mesenchymal epithelial transition [124].

- Basal-like subtype 1 (BL1): it is characterized by presenting an increase in the activity of the components and routes related to the cell cycle and cell division, in addition to possessing high levels of genes related to the response to DNA damage such as ATR and BRCA1, as well as mutations in the latter gene.

- Basal-like subtype 2 (BL2): it is characterized by presenting high activity in the growth factor pathways (EGF, NGF, MET, IGF1R and Wnt/ $\beta$-CATENIN), and also glycolysis and gluconeogenesis signalling pathways. Some markers demonstrate the basal/myoepithelial origin of this subgroup. 
- Mesenchymal Subtypes (Mesenchymal (M) and Mesenchymal Stem-like (MSL)): On the one hand, the Mesenchymal subtype is related to components and routes involved in cell mobility, interaction with extracellular matrix receptors, and differentiation pathway (such as the Wnt, ALK, and the TGF- $\beta$ signalling pathways). The Mesenchymal Stemlike subtype shares biological characteristics with the Mesenchymal subtype, including cell motility, cell differentiation, and growth pathways. However, some genes uniquely represent this subtype, such as genes related to growth factors and pathways, including, inositol phosphate metabolism, EGFR, PDGF, calcium signalling, G protein receptor, and signalling of components like ERK1/2, as well as $A B C$ transporters and adipocytokines.

- Immunomodulator subtype (IM): it presents biological functions related to cells and immune processes. These processes include immune cell signalling (such as the TH1/TH2 pathway, the NK cell pathway, B cell receptors, DC pathways, and $T$ cell receptor signalling), cytokine signalling (cytokine pathways, IL-2 and IL-7 pathways), antigen presentation and processing, and signalling through the core of the immune signalling pathway. The characteristics of this subtype are characteristic of tumour cells and are not the result of any infiltration caused by immune response. 
- Luminal Androgen Receptor Subtype (LAR): this subtype is related to hormonal regulatory pathways, including steroid synthesis, porphyrin metabolism, and estrogen and androgen metabolism. The levels of androgen receptor expression are very high, with an average of 9 times more expression than in the rest of the subtypes. These tumours also express numerous downstream target elements of the androgen receptor and coactivators.

Despite all these efforts, the classification of the TNBC is still unclear as it has not been shown to be useful in improving the choice of treatment [124] so several more have been done recently trying to simplify it [125][126] and for attempting a clinical application [127], since in practice the immunohistochemical classification continues to be used.

\subsection{Treatment}

A serious problem of the TNBC, that makes it of great interest for its study, is the absence of a specific target, with chemotherapy still the default treatment. The TNBC shows higher chemosensitivity compared to ER positive breast cancer, but instead most of the patients with TNBC present residual disease in the breast and in the 
lymph nodes after neoadjuvant treatment. The absence of targeted therapy leads these patients to a greater susceptibility to recurrence and therefore to a lower overall survival compared to other types of breast cancer [128].

Anthracyclines, specifically doxorubicin, and combinations of taxanes like paclitaxel or docitaxel (with cyclophosphamide and doxorubicin) are among the most common treatments used to treat TNBC [117][129][130]. However, resistance to doxorubicin is often present, comprising a potential obstacle to treatment success [98][131].

New strategies for finding specific targets for more personalized therapy of this subtype have arisen lately, derived from the subgrouping of TNBC. Treatment with PARP inhibitors are good therapeutic strategies for patients with BRCA1 mutations [132] or homologous recombination deficiency [133]. The antiandrogen enzalutamide has shown activity in women with advanced TNBC whose tumours express the AR [134] (LAR subtype). Also, high PD-L1 and high lymphocytic infiltrate in tumours (in the immunomodulatory subtype) has been described as a prognostic factor for better pathological complete response to neoadjuvant therapy [135] and PDL1 is also being tested as a target for therapy in this subgroup [136][137]. 


\section{METFORMIN}

Metformin (1,1-dimethylbiguanide hydrochloride) is an oral hypoglycaemic drug with an outstanding safety record that has been prescribed worldwide for the treatment of type II diabetes as the most common therapy. This drug reduces insulin resistance increasing glucose levels by activating the AMPK (AMP-activated protein kinase) pathway through specific inhibition of the mitochondrial respiratory chain complex 1 in a range of tissues including hepatocytes, skeletal muscle, endothelial cells, pancreatic beta cells, and neurons [138]. The AMPK activation causes the cell to switch from an anabolic to a catabolic state in an attempt to restore energy balance [139] and finally inhibits the hepatic gluconeogenesis, lipogenesis and protein synthesis while stimulating fatty acid oxidation and glucose uptake in the liver [140].

Numerous epidemiological data have revealed that oral use of metformin in patients with type II diabetes mellitus has a protective effect on them by reducing the incidence of different tumours and improving the prognosis of cancer patients [141][142]. Recent studies show that metformin can inhibit the proliferation of various types of cancer, such as carcinomas of the colon, lung and pancreas [143][144][145], although the molecular mechanism is unknown. Among the different hypothesis, it is possible that treatment with metformin lowers serum levels of insulin and IGF-1, thus reducing the 
stimulus for growth. Given the potential importance of the Warburg effect in cancer metabolism, a glucose-rich environment could also provide favourable conditions for aerobic glycolysis. Treatment with metformin would therefore reduce hyperglycaemia and any associated growth advantage in susceptible tumours [146]. Other insulin-independent hypothesis support that AMPK could fatally reduce ATP levels in the cell [139] or fatty acid biosynthesis (involved in HER2 activation [147]). AMPK activation also inhibits inflammatory cytokines synthesis, suggesting that metformin could target proinflammatory cytokines within the tumour microenvironment, inhibiting growth in susceptible cancers [148]. 


\section{MIRNAS}

MicroRNAs (miRNAs or miRs) are small non-coding endogenous RNA molecules (approximately 22 nucleotides) found in proteincoding gene introns, non-coding gene introns, or non-coding gene exons, that regulate gene expression at the post-transcriptional level [149][150].

MicroRNAs are transcribed by RNA polymerase II as a long primary transcript (pri-microRNA) that is cleaved in the nucleus by RNase III Drosha and its cofactor DGCR8 in a 60-70 nucleotide precursor with double helix hairpin structure ( pre-microRNA) (Figure 7, a) [151]. This pre-microRNA is transferred to the cytoplasm by Exportin 5 [152], is processed by RNase III Dicer together with TRBP or PACT cofactors into a double-stranded RNA of approximately 22 nucleotides [153] called microRNA/microRNA* and is divided in two strands by the cytoplasmic helicase (Figure 7, b-d). The chain with the least stability at the 5 'end (guide chain) is preferably selected and incorporated into the RISC complex (RNA-Induced Silencing Complex), which comprises the Argonaut proteins, the microRNA chain and other factors. In this complex, the microRNA is directed to its target mRNA (Figure 7, e). 


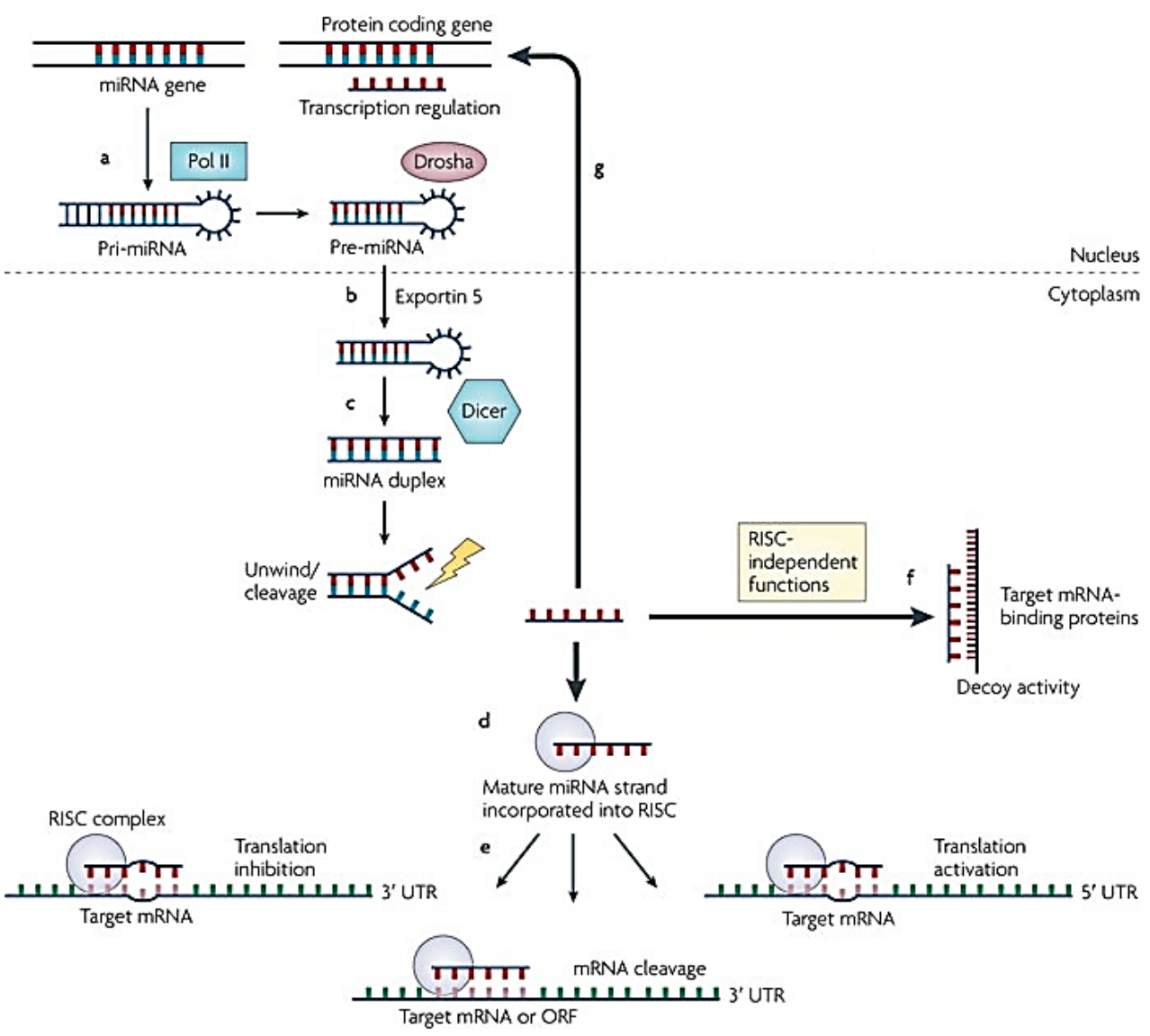

Figure 7. Biogenesis of microRNAs and their effector pathways. a. MicroRNAs are transcribed by RNA polymerase II (Pol II) into long primary transcripts of variable size miRNA (pri-miRNA), which are recognized and cleaved in the nucleus by the RNase III Drosha enzyme, thereby forming a hairpin precursor called pre-miRNA. b. Pre-miRNA is exported from the nucleus to the cytoplasm by exportin 5 and is processed by another RNase enzyme called Dicer. c. Dicer produces a transient 19-24 nucleotide double-stranded miRNA. d. Only one of the strands of the double-stranded miRNA (mature miRNA) is incorporated into a large protein complex called RNA-induced silencing complex (RISC). e. The mature miRNA guides RISC to cut the miRNA or induce 
repression of its translation, depending on the degree of complementarity between the miRNA and its target. Although the most frequent site of interaction is the 3 'untranslated region (3'-UTR) of the target mRNA, miRNAs have been described that bind to open reading guideline (ORF) sequences, as well as to the 5 '- UTR. This latter interaction has been associated with activation rather than repression. $f$. MiRNAs can also bind directly to proteins, particularly RNA-binding proteins, in a sequencedependent manner and prevent these proteins from binding to their target RNAs. These miRNA activities are independent of RISC. g. MiRNAs can also regulate gene transcription by directly binding to or modulating methylation patterns at the promoter level of their target genes. (Figure extracted from Garzón et al. 2010).

Binding occurs by total or partial base pairing, which leads respectively to degradation (frequent in plants) or inhibition of translation (more frequent in mammals, which is also followed by mRNA degradation) [154]. Binding takes place between the 3'-UTR region (untranslated) of the mRNA and nucleotides 2-8 of the 5 '-region of the microRNA (known as the 'seed' region). Binding is always performed at the $3^{\prime}-$ UTR of the target mRNA even though the microRNA may pair with the 5'-UTR [155][156] region, the promoter, or the open reading frame regions, since when the microRNAs bind to the promoter region, they do so at the genomic level, returning to the nucleus [157] and in this case they can induce gene expression instead of repressing it (Figure 7, e) [158][159].

The study of microRNA biogenesis and its key events has allowed its use as a pharmacological target. For example, AC1MMYR2, a small 
molecule that acts as a specific inhibitor of miR-21, was designed from the structural conformation of pre-miR-21. This molecule blocks the processing of miR-21 by RNase Dicer, thereby inhibiting tumour growth and reversing the epithelial-mesenchymal transition in epithelial tumour cells and in an orthotopic model, implanting the microRNAs in the same organ of origin of the tumour in nude mice [160].

On the other hand, microRNAs can be secreted in the circulating regions of the tumour or in fluids through vesicles or exosomes in order to be transported and protected into other target cells [161]. Furthermore, the small size of these microRNAs gives them much more stability than mRNAs, which is why, above their usefulness as therapy, they can be especially good biomarkers for different types of cancer, as they can be extracted from the blood [162][163] and biological fluids (urine [164], saliva [165]) such as frozen, paraffinized tissues, etc., and since many present a differential expression in healthy or tumour tissue [166].

MicroRNAs have already demonstrated their potential as biomarkers for prognosis in response to therapy in different cancers [167][168][169][170][171] and as therapeutic tools in other cancers, not only by inhibiting them with drugs [160], but for example also introducing them into liposomal vehicles for systemic distribution in model mice in lung cancer or hepatocellular carcinoma [172][173]. 
Molecular signatures of differentially expressed microRNAs have been found between the basal and luminal breast cancer subtypes [174][175], and could specifically classify ER, PR, and HER2/neu receptor states [166][176][177]. However, in subsequent studies it has been shown that the TNBC has the highest tendency to form a cluster with a unique microRNA signature with respect to tumour samples positive for one or more of these immunohistochemical markers [178][179].

In a previous study by our group [180], significant changes were also seen in miR-26a (previously studied in other cancers such as kidney or lung) when treating TNBC lines with doxorubicin. These expression changes in miR-26a were related to doxorubicin resistance due to alterations in its ADME (absorption, distribution, metabolism, and drug excretion). This microRNA seems of interest in the mechanism of drugs in triple negative breast cancer treatment and we aimed to perform more studies with miR-26a in drugs different from doxorubicin. 


\section{EXOSOMES}

Exosomes are small extracellular vesicles that mediate intracellular communication in short and long distances, needed for survival and maintenance of homeostasis in pluricellular systems. They measure from 40 to $120 \mathrm{~nm}$ and are secreted by almost all types of cells. These vesicles carry nucleic acids (mostly miRNAs), proteins, lipids, and metabolites contained in their cells of origin (Figure 8).

However, dysregulation of these communication mechanisms can also be involved in cancer development and progression. The recent discovery that extra cellular vesicles are able to convey complex multimolecular biological messages between cells has the potential to revolutionise our understanding of the communication circuitry in cancer [181]. Exosomes from tumoral cells of different cancers have been shown to send distant messages in order to activate angiogenesis [182][183], modify the microenvironment [184] for better tumour growth or for preparing a new niche for metastasis [182]. 

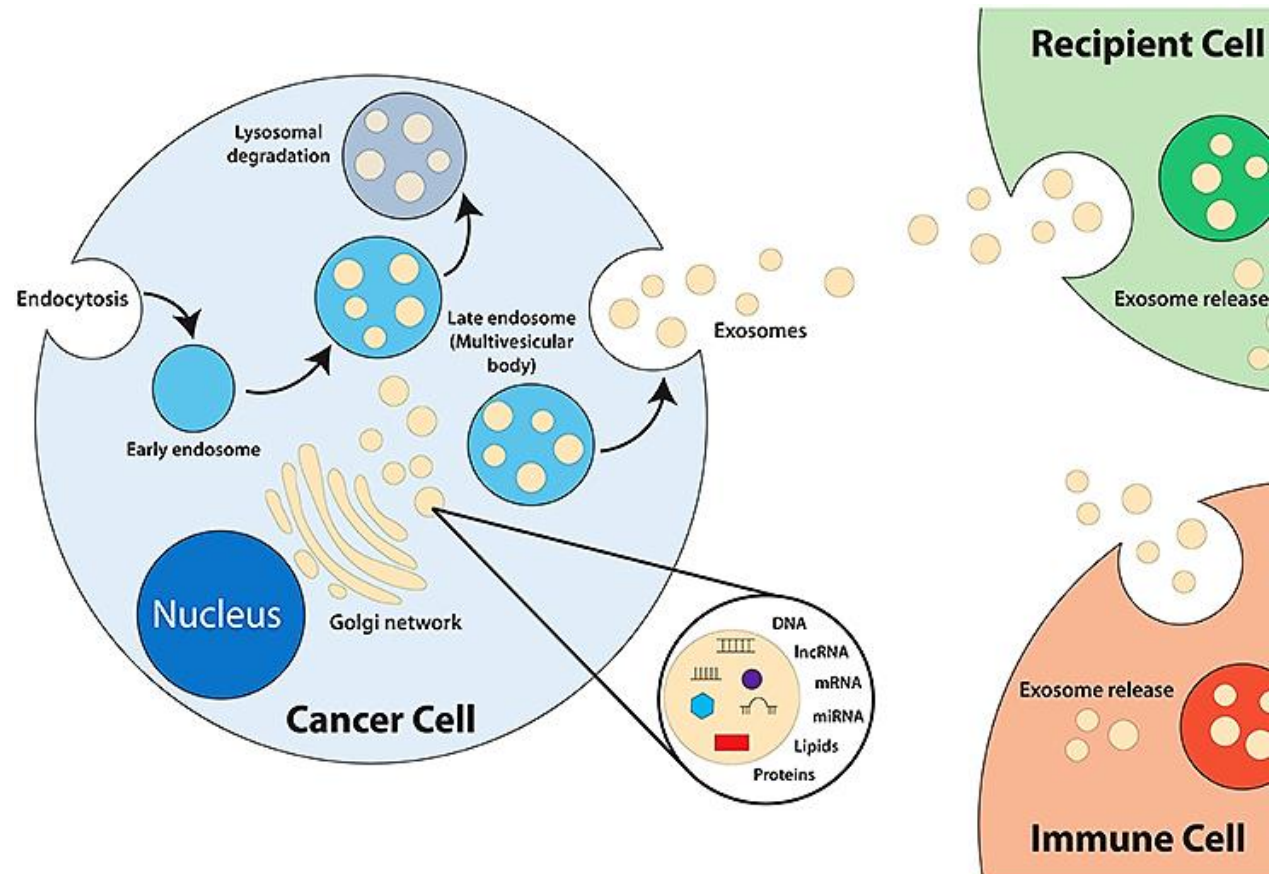

Figure 8. Biogenesis of exosomes. (Figure extracted from Othman et al., 2019).

Exosomes have also been shown to be involved in the transmission of resistance to chemotherapy from cell to cell [185][186], suggesting that this transmission of resistance does not happen only vertically by cell division as we have always assumed, but also horizontally by cell to cell communication, working such as resistance in bacteria through transmission of plasmids.

Exosomes have been also proposed as a useful clinical tool, both as biomarkers for diagnosis [187] of tumours and for monitoring 
treatment response in patients [188], since exosomes have been shown to be able to provide tumour information from the patient by liquid biopsy in a non-invasive way. Their stability in circulation and tumour-targeting capacity is showing also their applicability in the delivery of anti-cancer molecules as a potential novel treatment tool [189][190][191], and specially for immunotherapy [191][192][193][194]. Finally, they could also be an interesting target to block their supportive role in tumour progression and their function blocking a proper response to therapy, such as their implication in resistance [195][196]. 


\section{HYPOTHESIS}

AND OBJECTIVES 



\section{HYPOTHESIS}

Triple negative breast cancer represents around $15 \%$ of all breast cancers. This type of breast cancer is particularly aggressive, and it is very present among young women with a very bad prognosis. However, this breast cancer subtype is the only group among breast cancer that still lacks a specific treatment nowadays since it does not present any direct target. As there are not specific treatment options for triple negative breast cancer, it can be only treated by surgery, chemotherapy, and radiotherapy.

Metformin, a drug already commercialised for diabetes mellitus type II, has been proved to reduce viability in this breast cancer cells in culture. However, the mechanism of action of this drug is still not clearly understood. Some microRNAs have been associated with this process, including miR-26a-5p. A drug that is already commercialised and whose mechanism of action in cancer could be unravelled comprises a very attractive alternative to chemotherapy for with triple negative breast cancer patients. 
Apart from the dramatic case of triple negative breast cancer patients, another very problematic issue among patients with a specific treatment is resistance to trastuzumab among HER2+ breast cancer patients. The genetic mechanisms of resistance to this drug have been deeply studied. However, there is still not much knowledge about the epigenetic mechanisms that could cause resistance, such as microRNA dysregulations.

We think that these small molecules may be implied not only in some mechanisms for resistance generation, but also for the transmission of the resistance, acting as cell to cell signalling molecules through extracellular vesicles. Understanding the paper of microRNAs and extracellular vesicles in resistance to trastuzumab may help patients in the future to overcome resistance by blocking these microRNAs or its targets. 


\section{OBJeCtIVES}

The main objective of the present PhD project is to analyse the epigenetic mechanisms in terms of microRNA expression dysregulations that occur related to these two treatments, metformin and trastuzumab, in breast cancer.

In order to address these issues, we propose the following secondary objectives:

1. To study the effect of the candidate miR-26a-5p in triple negative breast cancer and its gene targets in order to explain its mechanism of action.

2. To evaluate the effect and mechanism of action of metformin in triple negative breast cancer and its relationship with miR26a-5p expression.

3. To compare the miRNA expression differences between two wild type HER2+ breast cancer cell lines (SKBR-3 and BT-474) and their derived resistant cell lines apart from an innate resistant cell line (HCC1954) and a triple negative breast cancer cell line (MDA-MB-231) in order to describe their mechanism of resistance to trastuzumab. 
4. To evaluate the relevance of the selected microRNAs in patient's survival and their potential targets.

5. To analyse the presence of those microRNAs in extracellular vesicles in order to check if they participate not only in resistance generation but also in its cellular transmission. 


\section{MATERIALS}

AND METHODS 



\section{Cell culture}

\subsection{CeLl LINES}

For this study we included two pairs of wildtype/resistant breast cancer cell lines with HER2 amplification: SKBR-3wt/r and BT-474wt/r. We also used HER2 amplified cell line HCC1954, luminal A cell line MCF-7 and triple negative breast cancer cell lines MDA-MB-231 and MDA-MB-468. All wild type cell lines were obtained from the American Type Culture Collection (ATCC, Manassas, VA, USA) and their characteristics are shown in table 1 . SKBR-3r and BT-474r cell lines are resistant to trastuzumab and were obtained from Dr. Federico Rojo's group at the Fundación Jiménez Díaz Hospital (Madrid), where the resistance was developed by exposition to the drug as an acquired resistant cellular model [197]. 
Table 1. Clinical and molecular cell line characteristics.

Cell line

\section{Tumour}

type

Origin Subtype

ER PR HER2*

BT-474

IDC

P. $\mathrm{Br}$

Luminal $\mathrm{B} \quad+\quad+\quad++$

SKBR-3

$A C$

PE

Luminal-

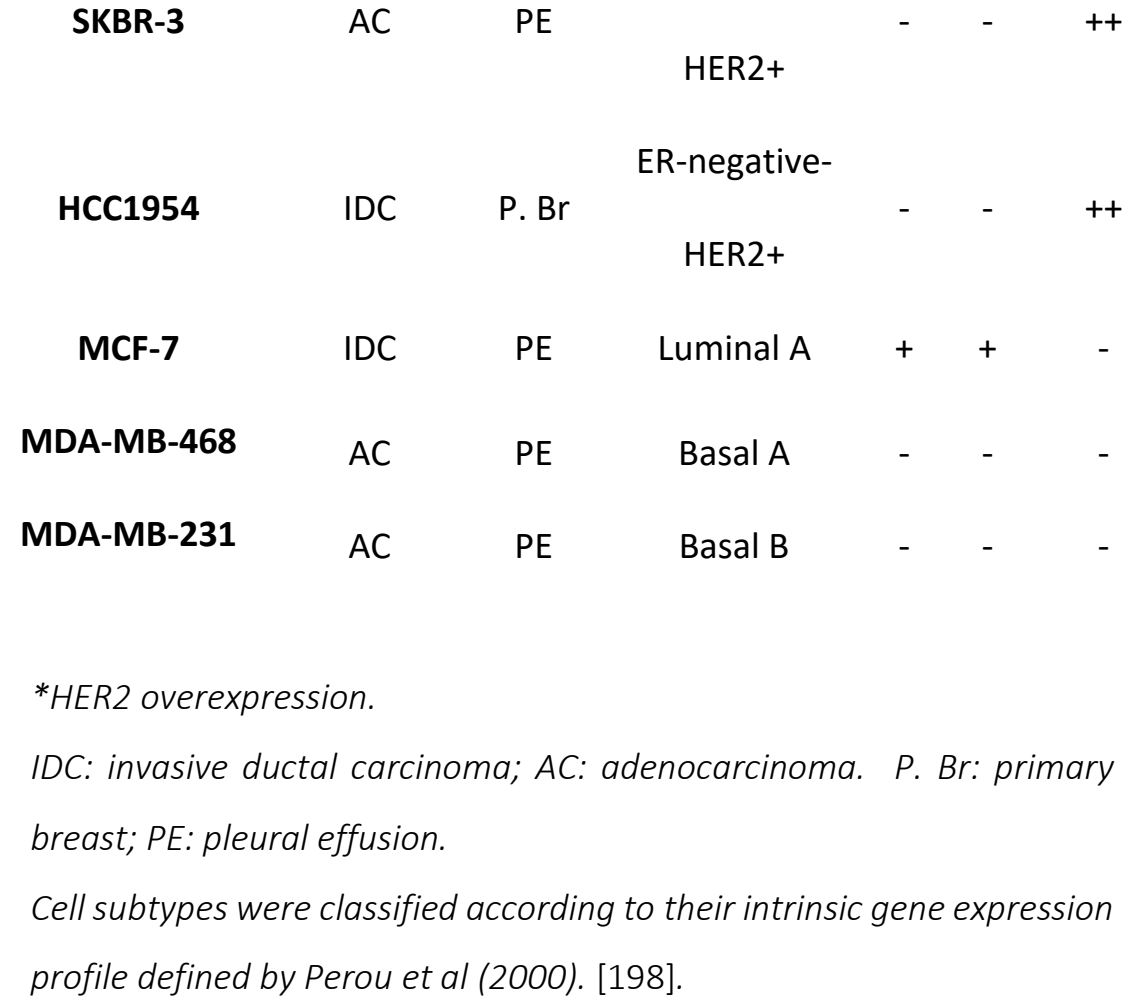




\subsection{CULTURE CONDITIONS}

Cell lines BT-474, SKBR-3, MDA-MB-468 and MDA-MB-231 were cultured in DMEM Ham's F-12 culture media (Biowest, Nuaillé, France) containing 10\% FBS (Gibco by Life Technologies, Gaithersburg, MD), 1\% L-glutamine (Gibco by Life Technologies, Gaithersburg, MD) and 1\% penicillin-streptomycin (Biowest, Nuaillé, France). HCC1954 cell line was cultured in RPMI media (Biowest, Nuaillé, France) containing 10\% FBS, 1\% L-glutamine and 1\% penicillin-streptomycin. MCF-7 cell line was maintained in DMEM media (Biowest, Nuaillé, France) supplemented with $10 \%$ FBS, $1 \%$ L-glutamine and $1 \%$ penicillinstreptomycin.

Cells were grown in flasks with filter and kept at $37^{\circ} \mathrm{C}$ in a $5 \% \mathrm{CO}_{2}$ incubator. Media was replaced with fresh media every 2-3 days after a wash with PBS (Biowest, Nuaillé, France). Cells were trypsinized and split when they reached $70-80 \%$ of confluence using trypsin/EDTA 0,25\% (Gibco by Life Technologies, Gaithersburg, MD). Cell counting for seeding in plates was performed with help of a Neubauer chamber and trypan blue stain in order to recognize viable cells. Cells were frozen in FBS with 10\% DMSO (Sigma-Aldrich, St. Louis, MO, USA). 


\subsection{TREATMENTS}

Metformin (1,1-Dimethylbiguanide hydrochloride) (SigmaAldrich, St Louis, MO, USA) was obtained from the company and was reconstituted in water in a $100 \mathrm{mM}$ solution.

Trastuzumab (Herceptin, Roche, Basel, Switzerland) was obtained from the pharmacy service from Hospital Clínic Universitari de València in powder and was reconstituted in water in a $21 \mathrm{mg} / \mathrm{ml}$ solution.

Trastuzumab was used at a previously stablished concentration of $15 \mu \mathrm{g} / \mathrm{ml}$ for treatment [197] and it was also added in that concentration to complete medium for maintaining SKBR-3r and BT$474 r$ cell lines. Both for treatment of maintenance of resistance, fresh trastuzumab was replaced every 2 days.

\subsection{MICRORNA TRANSFECTION}

Transfection of nucleic acids in human cells is a very useful tool to study the effect of a gene of microRNA in the cell. Commonly, genes are inserted as plasmids but microRNAs are short and single stranded and thus very labile, so we need to buy commercial microRNA mimics to increase the amount of a microRNA in the cell, or an inhibitor in order to decrease it. Transitory transfection can be performed by 
physical methods such as electroporation, laser or microinjection or chemical methods like lipofection. Lipofection method is based on the electric charges to interact with the cell membrane, it is very efficient and not very cytotoxic. We used this method to transfect our microRNA mimics or inhibitors using Lipofectamine 2000 (ThermoFisher, Whaltham, MA, USA).

Lipofectamine is a chemical non-viral lipofection agent made of several types of lipids, such as cationic cholesterol derivatives and diacylglycerol, and polyamine lipid derivatives. Cationic lipids consist of a positive charged chemical group bounded to one or two hydrocarbon chains. This positive group interacts with the negative charged phosphate of the nucleic acid and the transfection complex is formed. Lipofectamine gives this complex a final positive charge, which allows it to interact with the negative charged cell membrane and the complex is finally endocyted by the cell into the cytoplasm.

The microRNA mimics and inhibitors were bought in powder and reconstituted in RNAse free water to a stock concentration of $5 \mu \mathrm{M}$. Cells were seeded $24 \mathrm{~h}$ prior to transfection so that they reached 70 $90 \%$ confluence by the moment of transfection. Lipofectamine is first diluted 1:12 in Optimem medium and the miRNA mimic or inhibitor is diluted as well with Lipofectamine 1:12 separately. Both mixes are put together in a 1:1 ratio and incubated for 15 minutes in order to form the transfection complexes described before. Mix was then added to non-supplemented medium and added to the cells for $6 \mathrm{~h}$. After this 
time, media was replaced with fresh supplemented media. We used $10 \mu \mathrm{l}$ Lipofectamine for every $\mathrm{ml}$ of medium without serum nor antibiotics and microRNA mimics and inhibitors were used at a final concentration of $50 \mathrm{nM}$ after optimising concentrations. Every experiment was done by triplicate.

Products used for transfection protocol:

- hsa-miR-146a-5p mirVana ${ }^{\circledR}$ mimic \#MC10722 (Ambion)

- $\quad$ hsa-miR-146a-5p mirVana ${ }^{\circledR}$ inhibitor \#MH10722 (Ambion)

- $\quad$ miRNA mimic 2.0 NEG\#1, 20N 15511511 (Ambion)

- $\quad$ hsa-miR-23b-3p mirVana ${ }^{\circledR}$ miRNA mimic \#MC10711 (Ambion)

- hsa-miR-23b-3p mirVana ${ }^{\circledR}$ miRNA inhibitors \#MH10711 (Ambion)

- hsa-miR-26a-5p mirVana ${ }^{\circledR}$ miRNA mimic \#MC11119 (Ambion)

- hsa-miR-26a-5p mirVana ${ }^{\circledR}$ miRNA inhibitor \#MH11119 (Ambion)

- Opti-MEM $^{\circledast}$ I (1X) [+]Hepes; [+]2,4g/l Sodium Bicarbonate medium; [+]L-Glutamine \#31985-070 (Gibco)

- $\quad$ Lipofectamine $^{\mathrm{TM}} 2000$ reagent 10696153 (Thermofisher)

- 6 well plates and 96 well plates (Corning flasks) 


\section{FUNCTIONAL ASSAYS}

\subsection{Cell VIABILITY ASSAY}

Cell viability and proliferation is an important assay for evaluating the cellular response to different conditions or treatments. Cell proliferation characteristics include cellular metabolic activity and cell membrane integrity. One method for measuring metabolic activity is to incubate the cells with a tetrazolium salt such as MTT, which is cleaved into a coloured formazan product by metabolically active cells. Cells are then detected with the proliferation reagent, which is converted in live cells from the yellow tetrazole MTT to the purple formazan form by a cellular reductase. Cell viability was measured in the different breast cancer cell lines using a MTT (3-(4,5dimethylthiazol-2-yl)-2,5-diphenyltetrazolium bromide) tetrazolium reduction assay cell growth [199] determination kit (\#GDC1; SigmaAldrich, St. Louis, MO, USA).

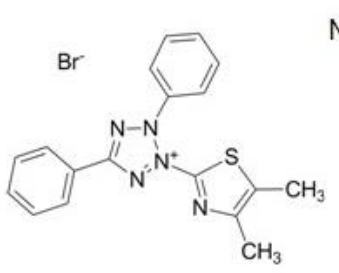

MTT

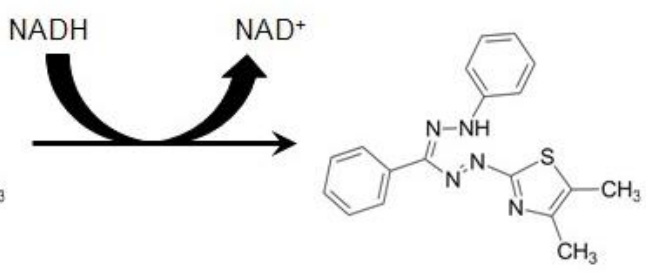

Formazan 
At the indicated intervals, $10 \%$ MTT in uncoloured DMEM media was added to each well in sterile conditions and the plate was incubated for four hours at 37 ․․ Purple formazan crystals are formed from yellow MTT by succinate dehydrogenase in viable cells, since dead cells lose the capacity to reduce MTT into formazan. The medium was then carefully discarded and $50 \mu \mathrm{L}$ MTT solvent was added to each well to dissolve the formazan crystals. The absorbance at 570 and 690 $\mathrm{nm}$ was measured using a microplate spectrophotometer and percentages of surviving cells from each group relative to controls were calculated in triplicate. For the viability assays, cells were seeded at an initial density of $3 \times 10^{3}-5 \times 10^{3}$ cells in a 96-well plate and incubated with medium, transfection reagents, and 50nM mimic control miRNA, or nM miRNA mimic/inhibitor, or exosomes for different time periods at $37^{\circ} \mathrm{C}$. Media for transfection was replaced after $6 \mathrm{~h}$. For metformin (Sigma-Aldrich) treatment, $24 \mathrm{~h}$ after seeding, the cells were treated with metformin $(0,1,5,10,20,40 \mathrm{mM})$ and viability was measured at 24,48 , and $72 \mathrm{~h}$ as described above. For trastuzumab (Roche) treatment, $24 \mathrm{~h}$ after seeding, cells were treated with $15 \mu \mathrm{g} / \mathrm{ml}$ trastuzumab and viability was measured at 7 days, changing media with fresh trastuzumab every 2 days. 


\subsection{WOUND HEALING ASSAY}

Cellular migration occurs during many important physiological processes. For example, regulated cell migration is present in embryonic development, tissue damage or wound healing. However, in many pathological situations this migration is deregulated, including cancer metastasis.

Wound healing assay studies migration of cells based on the observation over time of the change in a monolayer of confluent cells that have had a gap or "wound". The cells at the edge of the gap will move towards the opening until new cell-cell contacts are established, thus closing the wound. The procedure is simple: A physical gap is created within a cellular confluent monolayer, and images of living cells are captured periodically, finally comparing all images to determine the speed of cell migration.

Cell migration at different conditions was examined by wound healing assay [200]. Cells were cultured in six-well plates to $100 \%$ confluence, having determined different seeding cell number for each cell line in order to have a monolayer at $24 \mathrm{~h}$. A plastic pipette tip was then used to generate a wound area across the centre of each well and the wells were washed with PBS. Media was replaced and cells were allowed to migrate for hours until closing the wound. Micrograph images were taken with a microscope at $40 x$ magnification at the indicated time points. Experiments were repeated in triplicate. 


\subsection{Cell CYCLE ANALYSIS}

Flow cytometry is a biophysical technology based on the use of laser light, used in the counting and classification of cells according to their morphological characteristics, presence of biomarkers, and protein engineering. In flow cytometers, cells suspended in a fluid pass through a very thin transparent tube on which a thin beam of laser light strikes. The light transmitted and dispersed by the passage of the cells through the tube is collected by detection devices, allowing inferences regarding the size and complexity of the cells. It also allows simultaneous analysis of other physical and chemical characteristics, evaluating an average of more than two thousand particles per second.

A wide range of fluorophores can be used as labels for fluorescent labelling in flow cytometry. Fluorophores are usually chemically bound to specific antibodies capable of recognizing a certain target molecule on the surface or inside the cell. These fluorescent labels can also be chemically bound to almost any chemical compound that has a certain affinity for the membrane or some other cellular structure. Each fluorophore has a characteristic excitation peak, and also a characteristic emission wavelength. However, the emission spectra of different labels frequently overlap, therefore, the combination of markers that can be used depends on the wavelength of the lamp or 
the laser used to excite fluorochromes and in the types of detectors that are available.

For cell cycle analysis, cellular DNA was measured using DAPI (4',6-diamidinofenyl-indol) a fluorescent marker that binds strongly to regions enriched in adenine and thymine in DNA sequences. For this protocol, aliquots of $2 \times 10^{6}$ cells in suspension were kept on ice prior to fixation. The cells were washed twice with cold PBS, decanted, and the pellet was resuspended before the addition of ethanol. The cells were then fixed by slowly pipetting $1 \mathrm{ml}$ of $80 \%$ ice-cold ethanol into the cell suspension while vortexing; the cells were left in ethanol at $-20^{\circ} \mathrm{C}$ for $2 \mathrm{~h}$ and were then washed twice with cold PBS. Finally, cells were resuspended in $1 \mathrm{ml}$ freshly made DAPI/TX-100 solution and incubated for 30 minutes at room temperature before analysis by flow cytometry (DAPI excitation at $405 \mathrm{~nm}$ and emission at $450 \mathrm{~nm}$ ).

\subsection{EXOSOME ISOLATION BY ULTRACENTRIFUGATION}

For the complete characterization of isolated extracellular vesicles (EVs) (TEM, RNA, western blot) at least 8 T175 flasks are required, which will generate $160 \mathrm{ml}$ of media. Once cells reached 70$80 \%$ confluence, media was removed and flasks were washed with 5$6 \mathrm{ml}$ of sterile PBS per flask and 3 times for each flask (this washes away any residual extra cellular vesicles present due to FBS in the media). 20 
$\mathrm{ml}$ of FBS free media were added to each T175 flasks and were incubated for $24 \mathrm{~h}$ at $37{ }^{\circ} \mathrm{C}$ and $5 \% \mathrm{CO}_{2}$. After $24 \mathrm{~h}$ condition media was collected and centrifuged at 2,000 $\mathrm{g}$ for 30 minutes in order to remove dead cells and apoptotic bodies (dead cells can release EVs into the sample and potentially contaminate the EV isolate). After centrifugation we decanted the supernatant into a new $50 \mathrm{ml}$ tube by pouring gently (the visible pellet containing dead cells and apoptotic bodies will remain at the bottom of the tube). If labelling cells with NIR-AZA dye, then dye was resuspended in $20 \mathrm{ml}$ of complete media to a final concentration of $5 \mu \mathrm{M}$ (enough for 1 T175 flask). Cells were washed twice with 5-6ml of sterile PBS per flask. Media/dye was added to cells and incubated for $2 \mathrm{~h}$ at $37 \stackrel{\circ}{\mathrm{C}}$ and $5 \% \mathrm{CO}_{2}$. Then media was removed, cells were washed with PBS and FBS free media was added as described above for $24 \mathrm{~h}$.

If processing frozen media for exosome isolation, the samples were defrosted overnight in the fridge. Twenty to thirty minutes prior to running the samples, the ultracentrifuge on and turn so that the machine could get to $4^{\circ} \mathrm{C}$. Equal volumes of media were dispensed into the $36 \mathrm{ml}$ ultracentrifuge tubes (ref: 355642 Beckman) reaching a maximum of $22 \mathrm{ml}$. Tubes were balanced in a microbalance to the microgram for the ultracentrifuge. The Beckman $70 \mathrm{Ti}$ Rotor was carefully placed into the Beckman Optima IE-80K Ultracentrifuge and 8 tubes with media were placed inside. Tubes must be at least $3 / 4$ full to prevent them from collapsing under the high forces in the 
ultracentrifuge, so the remaining volume was filled with filtered PBS until approximately $22 \mathrm{ml}$ and equal weight. The first spin for bigger extracellular vesicles (microvesicles) is $10,000 \mathrm{~g}$ for 30 minutes at $4 . \mathrm{C}$ with slow deceleration. The supernatant was poured gently into another ultracentrifuge tube and the microvesicle pellet was discarded. The new tubes were weight again and balanced adding PBS as necessary. This supernatant containing exosomes was centrifuged at $100,000 \mathrm{~g}$ for 90 minutes. The supernatant was poured off and the tubes were dried from media remaining. The exosome pellet was resuspended in $1 \mathrm{ml}$ of $0.2 \mu \mathrm{m}$ filtered PBS by pipetting up and down gently. $20 \mathrm{ml}$ of filtered PBS were added to each tube to prevent collapsing and the tubes were weight again and balanced with PBS. Tubes were centrifuged again at $100,000 \mathrm{~g}$ for 90 minutes and supernatant was discarded. The pellet containing exosomes was gently resuspended in $100 \mu \mathrm{l}$ of PBS in total, resuspending together every pellet from same condition. $10 \mu \mathrm{l}$ of the sample were immediately fixed in 4\% PFA for transmission electron microscopy preparation and the rest of the sample was stored at $-80 \stackrel{\circ}{ } \mathrm{C}$ for long term.

\subsubsection{Transmission electron microscopy}

Exosome samples were fixed in $4 \%$ paraformaldehyde for 5 minutes and took to the SCSIE Microscopy Service (Universitat de 
València, Burjassot). The sample was pipetted onto a 400-mesh copper grid and double stained with uranyl acetate for 20 minutes and lead citrate for 10 minutes. The grids were then observed under the JEOL JEM1010 transmission electron microscope at $80 \mathrm{kV}$. Images were acquired and saved in CCD camera system under the electron microscope at $80 \mathrm{kV}$ following automatic settings for the exposure time.

\subsection{ANGIOGENESIS ASSAY}

Angiogenesis, the formation of new blood vessels from preexisting ones, a process that is essential for embryogenesis and organ growth, plays a role in several pathological conditions, including tumour growth. New vessels supply oxygen and nutrients to tissues, remove waste products and promote immune surveillance. This process is triggered by hypoxia or insufficient oxygen tension, and it is tightly regulated by pro- and anti-angiogenic signals. While physiological angiogenesis is a highly organised sequence of cellular events, pathological angiogenesis is less well controlled, leading to immature blood vessels and poor remodelling.

Angiogenesis can be studied in vitro culturing endothelial cells onto a basement-membrane-like substrate on which the cells form tubules. These tubules mostly contain a lumen and the cells develop 
tight cell-cell and cell-matrix contacts. This powerful semiquantitative assay has many advantages: it is quick and easy to perform, can be scaled up for high-throughput analysis and can be used for screening test molecules that may promote or inhibit angiogenesis, as they can be added exogenously to the endothelial cell medium.

Human umbilical vein endothelial cells (HUVEC-2) were got from Corning and were cultured in EGM-2 medium from Lonza. Matrigel was bought from Corning.

For this assay $120 \mu \mathrm{l}$ of matrigel was plated per well in a 48 well plate and left it at 37 ㅇ for 30 minutes. Tips and plate were pre-cooled leaving them in the freezer overnight the day before the assay so that the gel did not set in the process. Each well was filled with $1 \mathrm{ml}$ endothelial media and 30,000 HUVEC cells were seeded on top in a spiral motion for even distribution. Images were taken after 8 and $24 \mathrm{~h}$ at 10X taking 5 images per well and each condition was assayed by triplicate. ImageJ was used for the analysis. Nodes were counted and length was measured drawing the outline of the networks visible using the straight-line tab and summing the result of each image. Average was calculated among all images per well. 


\section{MOLECULAR ASSAYS}

\subsection{RNA EXTRACTION}

\subsubsection{Total RNA extraction}

RNA purification for studying gene expression was performed using the TRIzol method. TRIzol (Invitrogen) is a ready to be used reagent for the purification of RNA both from cells or tissue samples. It consists of a mono-phase solution of phenol and guanidine isocyanate salt which maintains the integrity of RNA during the sample lysis and homogenisation. It alters cells stability and dissolves cellular components so that the cells are lysed, and RNA can be obtained.

RNA extraction was performed from 6 well plates containing 300,000 cells per well and all the protocol was made on ice to prevent RNA degradation. Plates were put on ice and wasted media was discarded. Cells were washed with $1 \mathrm{ml}$ of cold PBS and scrapped with disposable cell lifters. Cells were pelleted by centrifuging 5 minutes at $400 \mathrm{~g}$ and PBS was discarded. Each pellet was homogenised with 500 $\mu l$ of Trizol by pipetting gently. $100 \mu$ of chloroform were added to each tube and tubes were mixed by inverting them several times. After a 3-minute incubation on ice, the tubes were centrifuged for 15 minutes at $16,000 \mathrm{~g}$ and at $4 \stackrel{\circ}{ } \mathrm{C}$ in a pre-cooled centrifuge. This step allows the sample to separate in two phases: an aqueous phase and an organic phase with chloroform. RNA remains only in the aqueous 
phase; thus, this phase was transferred to a new Eppendorf tube and the old tubes were discarded with the rest of the sample. For RNA precipitation, $250 \mu \mathrm{l}$ of isopropanol were added to each tube and samples were incubated overnight at $-20^{\circ} \mathrm{C}$.

After precipitation, RNA was pelleted by centrifuging the sample 15 minutes at $16,000 \mathrm{~g}$ at $4 \stackrel{\circ}{ } \mathrm{C}$. Supernatant was discarded and pellet was washed on ice with $500 \mu \mathrm{l}$ of cold $75 \%$ ethanol. Tubes were vortexed for 3 seconds for proper washing and then centrifuged 15 minutes at $16,000 \mathrm{~g}$ at $4 \stackrel{\circ}{\circ}$. Ethanol was discarded by decantation and RNA was resuspended in 30-50 $\mu$ l of DEPC treated RNAse free water. RNA quantification was performed with NanoDrop ND-2000 spectrophotometer (Thermo Fisher Scientific, Waltham, MA). RNA was stored at -80 으.

\subsection{2 microRNA extraction}

For microRNA analysis, RNA was extracted with mirVana miRNA Isolation Kit that uses a rapid procedure to isolate small RNAs from tissue and cells using an efficient glass fibre filter (GFF)-based method.

Cells were scrapped from 6 well plates on ice with cold PBS and pelleted centrifuging 5 minutes at $400 \mathrm{~g}$. Depending on the cell amount, $300-600 \mu \mathrm{l}$ of lysis solution from the kit was added and samples were vortexed to homogenise the lysate. We added $1 / 10$ of 
the previous volume of homogenate additive and incubated the sample 10 minutes on ice. Tubes were then vortexed 30-60 seconds for mixing and centrifuged 5 minutes at $16,000 \mathrm{~g}$ at room temperature in order to separate the aqueous phase from the organic phase. After centrifuging, the interphase must be compact. The aqueous phase was transferred to a new tube and we added 1.25 of the volume of ethanol $100 \%$. Samples were mixed and passed through a cartridge with a fiberglass filter from the kit and then centrifuged for 15 seconds at $16,000 \mathrm{~g}$. The filter was washed with $700 \mu \mathrm{l}$ of wash solution 1 followed by 15 seconds centrifugation at $16,000 \mathrm{~g}$ and then twice with $500 \mu \mathrm{l}$ of wash solution 2/3 followed by centrifuging for 15 seconds at $16,000 \mathrm{~g}$. RNA was eluted from the filter with $100 \mu$ of nuclease free water which had been pre warmed at $95 \stackrel{\circ}{ } \mathrm{C}$ and centrifuging 30 seconds at maximum speed. Eluted RNA was then stored in a new tube at $-80 \stackrel{\circ}{ } \mathrm{C}$.

\subsection{RNA QUANTIFICATION}

RNA concentration is often determined by measuring absorbance at $260 \mathrm{~nm}$ in a spectrophotometer following the Lambert-Beer Law:

$c=(A * \varepsilon) / I$

where:

$\mathrm{c}=$ acid nucleic concentration in $\mathrm{ng} / \mu \mathrm{l}$ 
$\mathrm{A}=$ absorbance in $\mathrm{AU}$

$\varepsilon=$ the wavelength depending on the extinction coefficient in $\mathrm{ng}-\mathrm{cm} / \mu \mathrm{l}$

$\mathrm{I}=$ distance in $\mathrm{cm}$

The extinction coefficient generally accepted for RNA is $40 \mathrm{ng}-\mathrm{cm} / \mu \mathrm{l}$.

The purity of RNA was analysed by the absorbance ratio at 260 and $280 \mathrm{~nm}$ (OD260/280) being 2 the ratio generally accepted for RNA samples. If the ratio is lower it may indicate the presence of protein, phenol or other contaminants that absorb strongly at or near $280 \mathrm{~nm}$. The 260/230 values for pure nucleic acid are often higher than the respective $260 / 280$ values. Expected $260 / 230$ values are commonly in the range of 2.0-2.2. If the ratio is appreciably lower than expected, it may indicate the presence of contaminants which absorb at $230 \mathrm{~nm}$. EDTA, carbohydrates and phenol all have absorbance near $230 \mathrm{~nm}$. The TRIzol reagent is a phenolic solution which absorbs in the UV both at $230 \mathrm{~nm}$ and $270 \mathrm{~nm}$.

\subsection{REAL-TIME PCR}

Real-time PCR (RT-PCR or qPCR) is a powerful tool for measuring relative gene or microRNA expression through calculation of 
differences in the amount of specific RNAs. This difference is measured according to the cycle of PCR in which the fluorescence by the amplification of a gene cDNA is in its exponential phase.

\subsubsection{RNA retrotranscription}

After the RNA extraction it is necessary to convert RNA into cDNA by retrotranscription before amplifying. For every assay we retrotranscribed 1,000 ng of RNA using commercial kits from Life Technologies.

\section{Genes}

For qPCR of genes, we used High-Capacity CDNA Reverse Transcription Kit (\#4368814, ThermoFisher Scientific). which contains random primers, thus retrotranscribing into CDNA the total RNA of the sample as detailed in table 2 . 
Table 2. Mix for gene retrotranscription per sample:

$\begin{array}{cc}\text { Reagent } & \text { Volume } \\ \text { Random primers } & 4 \mu \mathrm{l} \\ \text { dNTPs } & 1.6 \mu \mathrm{l} \\ \begin{array}{c}\text { MultiScribe Reverse } \\ \text { Transcriptase }\end{array} & 2 \mu \mathrm{l} \\ \text { 10x RT Buffer } & 4 \mu \mathrm{l} \\ \text { RNA } & \text { Volume for } 1,000 \mathrm{ng} \\ \text { RNAse free water } & \text { Up to } 20 \mu \mathrm{l} \\ \text { Total volume } & 20 \mu \mathrm{l}\end{array}$

The mixes were put into a thermocycler at $25 \stackrel{\circ}{ } \mathrm{C}$ for 10 minutes, followed by 37 ㅇ $\mathrm{C}$ for 120 minutes. Finally, temperature decreased to

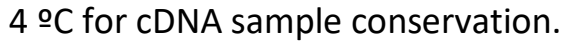

microRNAs

microRNas were retrotranscripted with its specific kit (REF) for which specific primers were necessary. Primers were mixed and 
diluted 1:100 into a primer pool in TE Buffer $1 \mathrm{x}$. Then for every sample we prepared the mix in table 3.

Table 3. Mix for miRNA retrotranscription per sample:

$\begin{array}{cc}\text { Reagent } & \text { Volume } \\ \text { Primer pool } & 6 \mu \mathrm{l} \\ \text { dNTPs } & 0.3 \mu \mathrm{l} \\ \begin{array}{c}\text { MultiScribe Reverse } \\ \text { Transcriptase } \\ \text { 10x RT Buffer } \\ \text { RNAse inhibitor }\end{array} & 3 \mu \mathrm{l} \\ \text { RNA } & 0.2 \mu \mathrm{l} \\ \text { RNAse free water } & \text { Volume for } 1,000 \mathrm{ng} \\ \text { Total volume } & \text { Up to } 20 \mu \mathrm{l} \\ \end{array}$

The mixes were put into a thermocycler at 16 o $\mathrm{C}$ for 30 minutes, then at $42{ }^{\circ} \mathrm{C}$ for 30 more minutes followed by $85 \stackrel{\circ}{\circ}$ for 5 minutes. Finally, temperature decreased to 4 으 for cDNA sample conservation. 


\subsection{2 $\quad \mathrm{qPCR}$}

Quantification of cDNA of both microRNA or gene expression was carried out by using specific commercial Taqman probes from Applied Biosystems (\#4331182, ThermoFisher Scientific) and the commercial solution TaqMan Master Mix, which contains all the reagents needed for the reaction. TaqMan Gene Expression Master Mix (\#4369016, ThermoFisher Scientific) was used for quantification of mRNAs and TaqMan Universal MasterMIx II- NO UNG (Applied Biosystems) was used for qPCR measuring miRNA expression.

Commercial TaqMan probes from Applied contain for every gene or microRNA a mix with two primers (forward and reverse) and a specific oligonucleotide called probe that binds to the centre of the PCR product amplified by the primers. This oligonucleotide is marked covalently in its $5^{\prime}$ by a fluorophore and in its $3^{\prime}$ by a quencher. When the fluorophore is excited by a light in the thermocycler, the quencher inhibits its fluorescence and no signal is emitted. Every time the PCR product is amplified by the polymerase, its $5^{\prime}-3^{\prime}$ exonuclease activity degrades the probe, releasing the fluorophore and the quencher separately, and so fluorescence is emitted. This happens in every amplification cycle and detected fluorescence is proportional to amount of cDNA present in the PCR product.

The TaqMan probes used in this thesis are detailed in table 4. 
Table 4. Commercial TaqMan Probes for quantitative PCR.

$\begin{array}{cc}\text { Gene } & \text { Reference } \\ \text { miR-26a-5p } & 000405 \\ \text { miR-23b-3p } & 000400 \\ \text { miR-146a-5p } & 000468 \\ \text { CASP3 } & \text { Hs00234387_m1 } \\ \text { CCNE2 } & \text { Hs01051898_m1 } \\ \text { APAF1 } & \text { Hs00559441_m1 } \\ \text { ABL2 } & \text { Hs00943652_m1 } \\ \text { BCL2 } & \text { Hs04986394_s1 } \\ \text { XIAP } & \text { Hs00745222_s1 } \\ \text { PTEN } & \text { Hs02621230_s1 } \\ \text { TP53 } & \text { Hs02621230_s1 } \\ \text { E2F3 } & \text { Hs00605457_m1 } \\ \text { CDC25A } & \text { Hs00947994_m1 } \\ \text { BCL2L1 } & \text { Hs00236329_m1 } \\ \text { EZH2 } & \text { Hs01016789_m1 } \\ \text { MCL1 } & \text { Hs06626047_g1 } \\ \text { MTDH } & \end{array}$




\begin{tabular}{|c|c|}
\hline CDKN1A & Hs00355782_m1 \\
\hline CCNB1 & Hs01030099_m1 \\
\hline VIM & Hs00958111_m1 \\
\hline FN1 & Hs01549976_m1 \\
\hline CTNNB1 & Hs00355045_m \\
\hline
\end{tabular}

Every $\mathrm{qPCR}$ reaction both for microRNAs and genes was prepared with the previous probes and the mix detailed in table 5 .

Table 5. Mix quantitative PCR per sample using Taqman technology:

\section{Reagent}

2X TaqMan Master Mix

20X TaqMan probe

CDNA (100-250 ng)

RNAse free water

Total volume

\section{Volume}

$5 \mu l$

$0.3 \mu \mathrm{l}$

$2 \mu \mathrm{l}$

$2.5 \mu \mathrm{l}$

$10 \mu \mathrm{l}$

The TaqMan Master Mix used was TaqMan Gene Expression Master Mix (\#4369016, ThermoFisher Scientific) for quantification of 
mRNAs and TaqMan Universal MasterMIx II- NO UNG (Applied Biosystems) was used for measuring miRNA expression.

The mixes were prepared in 384 well plates in triplicate for every sample and QuantStudio Thermocycler (Applied Byosistems) was programmed specifically for this technology. The two first steps were heating at $50 \stackrel{\circ}{ }$ for 2 minutes, and then at $90 \stackrel{\circ}{ }$ for 2 minutes for cDNA denaturing. This was followed by 40 cycles of two steps that allowed CDNA amplification, consisting of 15 seconds at $95 \stackrel{\circ}{\circ}$ for denaturing every time and 1 minute at $60 \stackrel{\circ}{\circ}$ for annealing and elongation.

\section{Fold change calculation}

The fluorescence of each gene or microRNA was determined by their $\mathrm{Ct}$ (cycle threshold): the number of cycles required for the fluorescent signal to cross the threshold (Figure 9). The threshold is set automatically by the software when the signal exceeds background level but can be adjusted and must correspond to the amplification stage where fluorescence in each well is still in the exponential phase before reaching the plateau for saturation of the detector. Ct levels are inversely proportional to the amount of target nucleic acid in the sample. Weak positive $\mathrm{Ct}$ of 38-40 usually represent environmental contamination. 


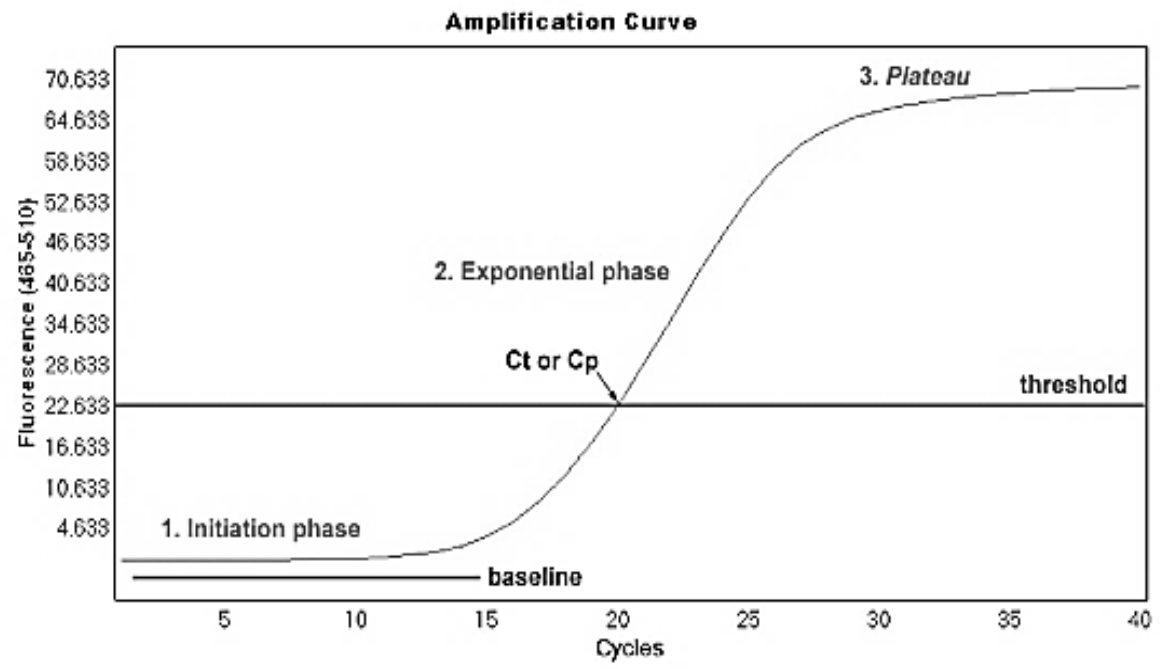

Figure 9. Schematic representation of Ct values in qPCR results.

Ct of every gene or microRNA of interest were normalised to its endogenous control $(\triangle \mathrm{Ct})$. Endogenous control for genes was GAPDH, considered a housekeeping gene that should be constant for every sample. Nucleolar RNA RNU43 and miR-16a were used as endogenous controls of microRNAs and only miR-16a when it came to microRNAs present in exosomes. After this normalisation, we followed the $\Delta(\Delta \mathrm{Ct})$ method [201] in order to know relative expression of genes or miRNAs, meaning the increment between the $\Delta \mathrm{Ct}$ of the studied group compared to the $\Delta \mathrm{Ct}$ of a control group, usually untreated cells or cells with vehicle of the transfection. The calculation of the $\Delta \Delta \mathrm{Ct}$ allowed us to obtain the fold change expression between two samples using the 
formula $2^{-\Delta \Delta C t}$. The obtaining number estimates the relative expression of a specific gene or microRNA between the treated sample and the control.

All this Ct values were obtained using The QuanStudio ${ }^{\text {TM }}$ Design and Analysis Software v1.4 (Applied Biosystems ${ }^{\mathrm{TM}}{ }^{\mathrm{m}}$ by Life Technologies ${ }^{\mathrm{TM}}$, Carlsbad, California, USA) and data were represented as average \pm standard deviation. Statistical analysis were carried out using a twotailed Student T Test and $\mathrm{p}$-values under 0.05 were considered statistically significant.

\subsection{MIRNA PROFILING}

\subsubsection{RNA integrity analysis}

For the microarray, quality and concentration of total extracted RNA was determined with the RNA 6000 LabChip $^{\circledR}$ and the 2100 Bioanalyzer (Agilent Technologies).

The integrity of total RNA was determined using Agilent 2100 Bioanalyzer equipment and Agilent RNA 6000 Nano Assay LabChip ${ }^{\circledR}$ (Agilent Technologies Inc., Santa Clara, CA, USA). This technology is based on capillary electrophoresis and allows the analysis of total RNA concentration between 25 and $500 \mathrm{ng} / \mu \mathrm{l}$, using $1 \mu \mathrm{l}$ of sample. The result of the analysis can be visualized as a conventional 
electrophoresis, in which RNA fragments separated by size are observed, in addition to providing profiles or electropherograms for each sample. This technology applies a complex algorithm that automatically determines a value of RIN (RNA Integrity Number), with values between 1 and 10. The RIN considers the entire electrophoretic profile, including the presence and absence of degradation products, resulting in a reliable measure of RNA integrity. RIN value is very reproducible and allows us to make a numerical assessment of the integrity of the RNA and make comparisons between samples. We only used samples having a RIN number of 8 or higher for the microarray.

\subsection{2 microRNA microarray}

Measurement of the changes in the expression profile of the microRNA (miRNA) is extremely important to decipher the biological context of differentially expressed genes. Affymetrix GeneChip ${ }^{\mathrm{TM}}$ miRNA Arrays are powerful tools for the study of the role of short noncoding RNA (miRNA, small nucleolar RNA [snoRNA] and small RNA of the Cajal body [scaRNA]) in complex diseases such as cancer.

The term microarray is commonly used to describe a variety of platforms including protein microarrays and tissue microarrays (or TMAs). A microarray is typically defined as a collection of microscopic dots arranged in a matrix or in a grid format and adhered to a solid 
surface or membrane. These dots usually refer to probes that are designed such that each probe hybridizes to a specific nucleic acid sequence corresponding to a particular RNA sequence in order to study gene or microRNA expression. The sequence that binds to the probe, which is often referred to as a target, is labelled with a detectable molecule or a fluorochrome. Level of hybridization between the probe and the target can be measured by fluorescence intensity through an image analysis.

Affymetrix microarrays are obtained by the synthesis of oligonucleotides of 25 mer using the photolithography technique on a quartz surface. RNA microarrays are often referred to as dual channel microarrays or two-colour microarrays because two samples, each marked with a different fluorochrome, are hybridized into a single matrix. As a result of the combination of two samples in a single device relative expression levels can be determined. Affymetrix high-density array provides the most sensitive, accurate, and complete measurement of small non-coding RNA transcripts involved in gene regulation. This platform is permanently updated, it is highly reproducible and accurate.

We performed an assay using Affymetrix GeneChip ${ }^{\text {TM }}$ miRNA 4.0 Array (Affymetrix, Santa Clara, CA). This matrix contains all mature miRNA sequences in miRBase Release 20 including 30,424 mature miRNAs (all organisms), 5,214 human, mouse, and rat miRNA, 1,996 
human snoRNA and scaRNA and 3,770 probe sets unique to human, mouse, and rat pre-miRNA hairpin sequences.

This experiment was performed following the manufacturer's intructions. Briefly, $300 \mathrm{ng}$ of total RNA of each sample was labelled with biotin with a commercial Kit FlashTag ${ }^{\mathrm{TM}}$ Biotin HSR RNA Labeling Kit (Affymetrix Ltd., Santa Clara, CA). For this, RNA Spike Control Oligos were added to the samples with Poly (A) Tailing Master Mix (containing 10X Reaction Buffer, 25mM Magnesium Chloride and $1 \mu \mathrm{l}$ of ATP Mix diluted 1: 500 in $1 \mathrm{mM}$ Tris buffer) and was mixed gently. The reaction was incubated at $37^{\circ} \mathrm{C}$ for 15 minutes to allow attachment of the poly(A) tails. Samples were centrifuged, FlashTag Biotin HSR Ligation Mix 5X and $2 \mu$ of T4 DNA ligase was added and samples were incubated for 30 minutes at room temperature for the ligation reaction until reaction was stopped with HSR Stop Solution.

The hybridization mixture was prepared with the reagents from the kit according to manufacturer's instructions and added to the biotin labelled RNA sample for 5 minutes at $99^{\circ} \mathrm{C}$ and 5 minutes at $45^{\circ} \mathrm{C}$. These reactions were injected in the microarray and incubated in the hybridization oven for $18 \mathrm{~h}$ at $48{ }^{\circ} \mathrm{C}$ under agitation. After hybridising, microarrays were washed, and probes were stained for detection.

Microarrays were scanned using the GeneChip Scanner GCS3000 with self-loading (Affymetrix Ltd., Santa Clara, CA) that registered the 
images with provided software from Affymetrix ${ }^{\circledR}$ GeneChip ${ }^{\circledR}$ Command Console $^{\circledR}$ (Affymetrix Ltd., Santa Clara, CA), which computed these images, saved them in a file with extension type *.DAT, and transformed them into numerical and analysable intensity values in *.CEL files. Preparation and detection of Affymetrix Genechip ${ }^{\circledR}$ miRNA 4.0 microarrays were performed at multigenic analysis service in UCIM (Universitat de València).

\subsection{PROTEIN EXTRACTION}

For protein extraction 300,000 cells per well were cultured in a 6 well plate, cells were treated or transfected and $72 \mathrm{~h}$ later were harvested at $80-90 \%$ confluence. For this aim, the plate was placed on ice in order to better conserve proteins and media was removed. Cells were washed with cold PBS and detached with cell scrappers in the PBS. Cells in suspension were collected and centrifuged 5 minutes at $400 \mathrm{~g}$ at $4 \stackrel{\circ}{\circ}$ for pelleting and supernatant was discarded.

RIPA Lysis and Extraction Buffer (\#89900, ThermoFisher Scientific), (100 to $200 \mu$ l depending on the pellet size) with a dissolved antiprotease and antiphosphatase reagent (\#A32959, ThermoFisher Scientific) was added to the tubes and pellet was homogenised with the solution. Cells were sonicated into this solution in 5 pulses of 10 seconds at $40 \%$ per tube for better efficiency of cell lysis and protein 
release. Cells were incubated on ice for 50 seconds between sonicating cycles and sonication was carried out on ice as well in order to avoid protein degradation or denaturing.

Lysed cells were then centrifuged for 15 minutes at 16,000 g and 4 으 in order to pellet and discard the cellular debris. Supernatant containing the proteins was collected and transferred to a new tube. A small amount was collected for immediate protein quantification and the rest of the protein was stored at $-80 \stackrel{\circ}{ } \mathrm{C}$ for long term protein conservation.

\subsection{PROTEIN QUANTIFICATION}

Protein quantification was performed using the commercial kit Pierce BCA Protein Assay Kit (\#23227, ThermoFisher Scientific) following the manufacturer's instructions. Bicinchoninic Acid Assay (BCA Assay) is based in the biuret reaction, that involves the protein capability to reduce $\mathrm{Cu}^{+2}$ to $\mathrm{Cu}^{+1}$ in an alkaline solution and result in a purple colour formation by the bicinchoninic acid. The reduction of copper is mainly caused by four amino acid residues including cysteine, tyrosine and tryptophan that are present in protein molecules. However, unlike the Coomassie dye-binding methods, the universal peptide backbone also contributes to colour formation, helping to minimize variability caused by protein compositional differences in 
amino acids. Compared to the Bradford assay, the BCA assay is more objective since the universal peptide backbone also contributes to colour formation. One disadvantage of the BCA assay compared to the Bradford assay is that it is susceptible to interference by some chemicals present in protein samples, including reducing agents (DTT, beta-mercaptoethanol...), copper chelators (like EDTA) and buffers with high concentration, which can be avoided by generating diluted samples.

For calculating the concentration from absorbance, we need to first measure absorbance of known protein concentrations to stablish a pattern curve. We used BSA stock provided at $2 \mathrm{mg} / \mathrm{ml}$ and made 5 serial dilutions in water with a concentration between 0 and $50 \mu \mathrm{g}$ in a total volume of $25 \mu \mathrm{l}$ made per duplicate. $2.5 \mu \mathrm{l}$ from each sample were diluted 1:10 in $22.5 \mu \mathrm{l}$ of water and were also measured by duplicate, getting the average value.

Reagent B from the kit was diluted 1:50 in reagent $A$ and $200 \mu \mathrm{l}$ of the mix were added to each pattern or sample replicate in a 96 well plate. The plate was incubated for 30 minutes in dark at room temperature and absorbance was measured at $562 \mathrm{~nm}$. The absorbance readings which fall into the linear section of the standard curve drawn with the BSA sample dilutions were used to calculate the final concentration of the undiluted protein sample. This absorbance values were placed in the equation of the line obtained $(y=m x+n)$ substituting the $x$ (the dependent variable). After getting the result for 
the y (concentration), we had to multiply depending on the dilution of the sample to get the protein final concentration.

\subsection{SDS-PAGE AND WESTERN BLOT}

Electrophoresis is a technique which allows separating charged molecules according to their mobility when they are submitted to an electric field. SDS-PAGE stands for SDS poly acrylamide gel electrophoresis, a type of electrophoresis which allows proteins to separate according to their molecular weight.

Protein samples were mixed with loading buffer containing $40 \%$ Glycerol, 240 mM Tris/HCl pH 6,8, 8\% SDS, 0.04\% bromophenol blue and $5 \%$ beta-mercaptoethanol. Beta-mercaptoethanol reduces disulphide bonds between protein subunits, allowing them to separate independently, glycerol makes the sample heavier to stay in the well before electric field is applied, and bromophenol blue is used as a tracking dye.

SDS (sodium dodecyl sulphate) is an anionic detergent that denatures proteins, making them lose their secondary and tertiary structure. The SDS has a high negative charge that overwhelms any charge the protein may have, imparting all proteins with a relatively equal negative charge (two negative charges (from every SDS 
molecule) to every two amino acids). It also has a hydrophobic tail that interacts strongly with protein (polypeptide) chains. SDS-coated proteins have been shown to be linear molecules, 18 Angstroms wide and with length proportional to their molecular weight, so the molecular radius (and hence their mobility in the gel) is determined by the molecular weight of the protein. Since the SDS-coated proteins have the same charge to mass ratio, there will be no differential migration based on charge. This is the way how SDS-PAGE is capable of separating proteins only by their molecular weight, independently of their charge.

Protein samples in loading buffer were boiled for 5 minutes at 95 ㅇ $\mathrm{C}$ in a thermoblock for denaturing them and after this, samples could be stored long term at room temperature.

The acrylamide gels were made using a Bio-Rad system with crystals and were designed with two phases: stacking and resolving. The stacking gel corresponds to the top centimetres of the gel that present a lower acrylamide concentration and the resolving is the rest of the gel with an acrylamide concentration of 8-12\% depending on the proteins to detect (30\% Acrylamide/Bis Solution, 19:1 \#1610154, Bio-Rad). SDS is also present in the gel to make sure that once the proteins are linearized and their charges masked, they stay that way throughout the run. Table 6 describes the amounts for resolving or lower gel and table 7 contains the solutions for the stacking or top gel. 
Table 6. Mix for resolving gel at $10 \%$ acrylamide:

$\begin{array}{cc}\text { Reagent } & \text { Volume } \\ \mathrm{H}_{2} \mathrm{O} & 2 \mathrm{ml} \\ 30 \% \text { Acrylamide mix } & 1.7 \mathrm{ml} \\ 1.5 \mathrm{M} \text { Tris }(\mathrm{pH} 8.8) & 1.3 \mathrm{ml} \\ 10 \% \text { SDS } & 0.05 \mathrm{ml} \\ 10 \% \text { APS } & 0.05 \mathrm{ml} \\ \text { TEMED } & 0.002 \mathrm{ml} \\ \text { Total volume } & 5 \mathrm{ml}(1 \mathrm{gel})\end{array}$

Table 7. Mix for stacking gel at 9\% acrylamide:

Reagent

$\mathrm{H}_{2} \mathrm{O}$

$30 \%$ Acrylamide mix

1.0 M Tris (pH 6.8)

$10 \%$ SDS

$10 \%$ APS

TEMED

Total volume
Volume

$1.4 \mathrm{ml}$

$0.33 \mathrm{ml}$

$0.25 \mathrm{ml}$

$0.02 \mathrm{ml}$

$0.02 \mathrm{ml}$

$0.002 \mathrm{ml}$

$2 \mathrm{ml}$ (1 gel) 
First well of each gel was loaded with $3 \mu$ of Precision Plus Protein TM Dual Color Standards (\#161-0374, Bio-Rad), and then protein was loaded in equal amounts (usually $30 \mu \mathrm{g}$ per well). The gel was run in running buffer (1:10 dilution of 10x Tris/Glycine/SDS pH 8,3 \#1610732, Bio-Rad) at $80 \mathrm{~V}$ for 15 minutes so that protein could concentrate through the stacking gel and then at $120 \mathrm{~V}$ for 90 minutes allowing proteins to migrate and separate through the acrylamide pores.

Proteins were then transferred from the gel to a nitrocellulose membrane by wet electrotransference at a constant voltage of $120 \mathrm{~V}$ for 90 minutes in cold Tris/Glicina pH 8,3 1X plus 20\% methanol. After transference, membranes were incubated with $5 \%$ powder milk in $1 \mathrm{X}$ TBS 0.1\% Tween-20 (\#P9416-100ML, Sigma Aldrich) for 1 hour in agitation, in order to block them and prevent unspecific antibody binding. Membranes were cut and incubated with the correspondent primary antibodies diluted depending on the antibody as described in Table 8 in 5\% powder milk in 1X TBS-Tween (TBS-T) overnight at $4 \stackrel{\circ}{\circ}$ in agitation.

The next day, membranes were washed 3 times for 10 minutes in TBS-T in order to remove antibody excess and then incubated in the correspondent secondary antibody anti-Rabbit (1677074S Cell Signalling) or anti-Mouse (1677076S Cell Signalling) diluted 1:2,500 in $1 \%$ milk in TBST-T depending on the species of the primary antibody used. Both secondary antibodies were conjugated with horseradish 
peroxidase (HRP). Membranes were washed 10 min 3 times with TBST for removing the antibody excess.

Visualization of results of the western blot was perform through chemoluminiscence using the Pierce ${ }^{\mathrm{TM}} \mathrm{ECL}$ Western Blotting Substrate (\#32106 from Thermo Scientific). The two solutions from the kit were mixed 1:1 and the membranes were incubated with the mix for 2-3 minutes in dark conditions at room temperature. Results were obtained by the LAS3000 equipment which detected the signal and transformed it into an image. Images were analysed by ImageJ.

Table 8. List of primary antibodies and dilutions used.

\section{Antibody}

PTEN (138G6) Rabbit mAb \#9559 (Cell Signalling)

Calnexin ab22595 Rabbit polyclonal to Calnexin (Abcam)

Tsg-101 ab125011 Rabbit monoclonal [EPR7130(B)] (Abcam)

CD9 ab92726 Rabbit monoclonal [EPR2949] (Abcam)

$\beta$-Actin (8H10D10) Mouse mAb \#3700 (Cell

Signalling)

GAPDH ab8245 Mouse monoclonal [6C5] (Abcam)
Dilution

$1: 1000$

1:500

$1: 1000$

$1: 1000$ 


\section{PATIENT SAMPLES}

In order to validate the results obtained in the cell lines and microarray regarding the expression of the miRNAs, breast cancer patients of HER2 + molecular subtype were selected, as well as healthy breast samples from of breast reductions, through the Pathological Anatomy Service of the Hospital Clínico de Valencia. All patients signed an informed consent for the use of the extracted biological material.

\subsection{RNA EXTRACTION}

There are several extraction kits for FFPE samples (embedded in paraffin). We used the RecoverAll Total Nucleic Acid Kit from Ambion. 4 paraffin sections of 5 to $10 \mu \mathrm{m}$ were placed in a $1.5 \mathrm{ml}$ eppendorf tube, obtained from longitudinal sections of tissue that had been previously selected because they had good representativeness of the tumour. The sections were dewaxed with two $100 \%$ Xilol baths at 50 oC for removal of fixation reagents. Once the tissue was dewaxed, it was washed with $100 \%$ ethanol to eliminate the possible remains of Xilol. Protease and a digestion buffer are subsequently added to each sample and allowed to incubate for one hour at 50 드 followed by 15

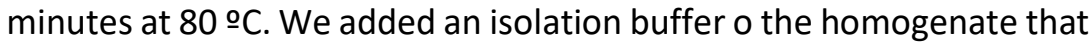
is filtered through a membrane to which, due to the buffer conditions, 
all the nucleic acids in the sample specifically bind, while other components (such as salts and proteins) They do not and pass through the filter without being retained. After this, the membrane is washed with two different wash buffers. At this point, the DNA bound to the filter is removed by a thirty-minute digestion with DNAse enzyme. After this digestion, the DNA fragments are removed by sequential washing steps with the two washing buffers. Finally, the purified RNA is released from the column by nuclease-free water and the sample is stored at $-80^{\circ} \mathrm{C}$. The concentration and purity of RNA is subsequently measured by Nanodrop.

\subsection{ReAL TIME PCR}

As samples came from paraffins, we performed a preamplification step after the retrotranscription to CDNA, in order to enrich the cDNA sample, since RNA quantity in samples embedded in paraffin is small and not always detectable by real time PCR. We used 2X TaqMan PreAmp Master Mix (Applied Biosystems), 20X of the different probes of the genes of interest (Applied Biosystems), $250 \mathrm{ng}$ of cDNA and water to a final volume of $25 \mu$. Each mix with the sample was placed in a well of a 96 plate and the amplification reaction was carried out by the following program: $10 \mathrm{~min}$ at 95 ㄷ; 14 cycles of 15 seconds at $95 \stackrel{\circ}{\circ}$ and 4 minutes at $60 \stackrel{\circ}{ }$. Once the samples were 
amplified, they were frozen at $-20^{\circ} \mathrm{C}$ for maintenance and subsequent use in real-time PCR (see section 3.3).

\section{BIOINFORMATICS}

\subsection{MICRORNA TARGET PREDICTIONS}

The miRBase database (http://www.mirbase.org/), a search resource that contains the sequences and annotations of the miRNAs, was used to rename all miRNAs with similar criteria. Each entry in the miRBase sequence database represents the fork of an immature transcript of a miRNA (called mir) and contains information about the location and sequence of mature miRNA genes (called miR). The miRNA-mRNA interactions were computationally predicted and combined by calculating the Union of Diana Genes (Gene Union) using the Diana-microT-CDS web service. The web service v2.1 DIANAmiRPath was used to identify KEGG pathways (Kyoto Encyclopedia of Genes and Genomes) that were significant targets of the selected miRNAs.

To analyse the specific targets of miRNAs, the miRWalk2.0 software was used, which provides a large collection of miRNAs target gene interactions, both theoretical and experimentally verified by various techniques. This tool combines not only binding sites of miRNA within the complete sequence of a gene, but also compares binding 
sites resulting from 12 prediction programs of miRNA target genes (DIANA-microTv4.0, Diana-microT-CDS, MiRanda, mirBridge , miRDB4.0, miRmap, miRNAMap, PicTar2, PITA, RNA22v2, RNAhybrid2.1 and Targetscan6.2).

\subsection{Microarray Data Processing}

\subsubsection{Analysis of expression microarrays}

The oligo package (PMID: 20688976) was used to read the .CEL files. The .CEL files store the intensity values of the probes that interrogate the different miRNAs in the expression microarrays for each sample. Once read, the samples were processed using the RMA method implemented in the oligo package. In short, RMA is divided into two steps. Background correction and normalization. The background correction process aims to eliminate the background noise present in the intensity matrix. To achieve this, the algorithm assumes that the intensity measurement of each probe can be divided into the sum of two components $\mathrm{S}$ (signal) and $\mathrm{N}$ (noise). Where $\mathrm{S}$ is assumed to follow an exponential distribution while $\mathrm{N}$ would be normally distributed. Fitting a model with three parameters to the data allows eliminating the noise portion of the intensity values.

The normalization process is necessary to make the intensity distributions of the different samples comparable once the 
background noise has been eliminated. This is achieved using the quantile normalization method. The process generates a new intensity matrix in which the columns are samples and the rows are probes. In the quantile normalized matrix, the maximum values of each column are the same, the second largest values are the same, and so on. The final effect is the homogenization of the intensity distributions between samples.

The mirBase hsa.gff3 annotation file (http://mirbase.org/help/genome.shtml) contains information regarding the genomic location of the set of human miRNAs in addition to their names and alternative identifiers. This file was used to transform the identifiers of the probes into a format provided by Affymetrix into the common use name of each miRNA.

\subsubsection{Differential expression analysis}

The differential expression analysis was carried out using the SAM method implemented in the $\mathrm{R}$ samr package. Acronyms derived from Significance Analysis of Microarrays. Sam computes the di statistic for each gene $\mathrm{i}$, which measures the level of association between the expression of gene $i$ and the variable response (in this case the two defined sample groups). SAM uses permutations tests to determine if the expression levels of any of the genes are significantly associated 
with the response variable. The cut-off value of significance is determined using the delta adjustment parameter, selected by the user based on the false positive rate (FDR). The interpretation of the results graph for the SAM analysis is as follows. Those red colored dots in the upper right margin are overexpressed miRNAs with a false discovery rate value $<0.05$. On the other hand, the points colored in green located in the lower left margin represent downregulated miRNAs. Black dots represent miRNA without significant expression differences in our sample groups. The line represents a quantilequalitative graph (q-q plot) that shows the expected values of di in case of no association. Points are actual values plotted against expected ones. Points that deviate from the line by more than delta are considered differentially expressed genes.

\section{STATISTICAL ANALYSIS}

Analysis of the results was carried out by different statistical programs such as R and GraphPad Prism 8, performing the most suitable tests. ANOVA was applied for studying the microRNAs in patient samples. T Student Test was used for cell samples and other assays. Every experiment was performed at least in triplicate for each condition, from which we obtained the average and standard deviation. P-values under 0.05 were considered statistically significant. 

RESULTS 



\section{EVAluation of METFORMin as POSSIBLE TREATMENT FOR TRIPLE NEGATIVE BREAST CANCER}

The first objectives of this thesis were about studying the candidate miR-26a-5p in breast cancer and in order to corroborate the hypothesis of metformin being a potential therapy for triple negative breast cancer, and to describe the relationship between the drug and the microRNA. For this objective, the following batch of experiments were performed:

\subsection{MiR-26a Expression Modulates Cell Viability}

The effect of exogenous miR-26a on cell viability was studied by transfecting three cell lines (MDA-MB-231 and MDA-MB-468: triple negative, and MCF-7: luminal) with a miR-26a mimetic. Compared to miRNA control (Cy3), miR-26a overexpression decreased cell viability in all three cell lines at all of the time-points assayed (1, 4, and 7 days), and the difference was statistically significant at 4 days $(36 \%$ ( $p=$ $0.0004), 31.11 \%(p=0.0009)$, and $73.89 \%\left(p=4.7 \times 10^{-10}\right)$ decrease in viability for MDA-MB-231, MDA-MB-468, and MCF-7 cells, respectively) and 7 days $\left(75.47 \%\left(p=9.66 \times 10^{-5}\right)\right.$, and $92.32 \%(p=3.78$ $\times 10^{-6}$ ) decrease in viability for MDA-MB-468 and MCF-7 respectively) (Figure 10). 


\section{Results}

A

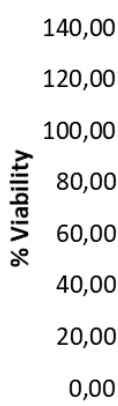

MDA-MB-231

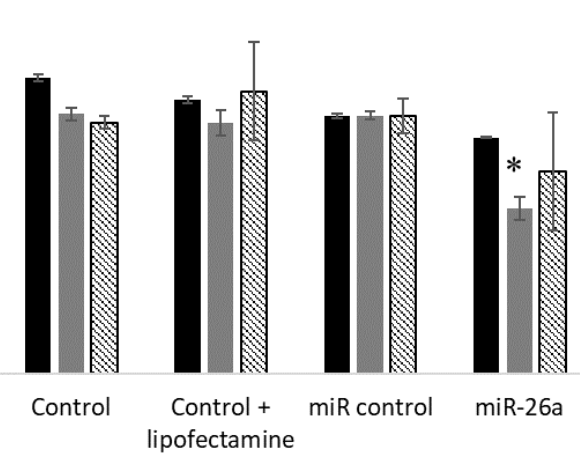

- Day 1 - Day 4 Day 7
B

MDA-MB-468

250,00

200,00

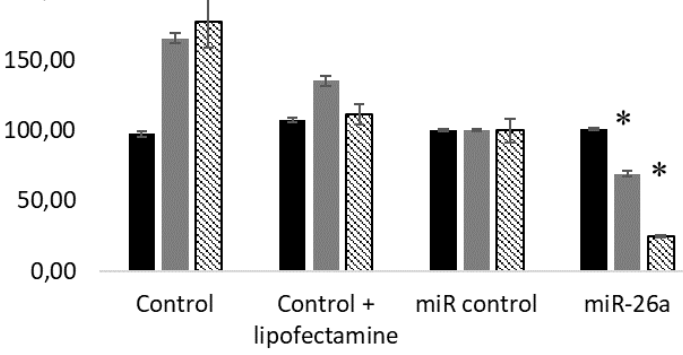

- Day 1 Day 4 Day 7

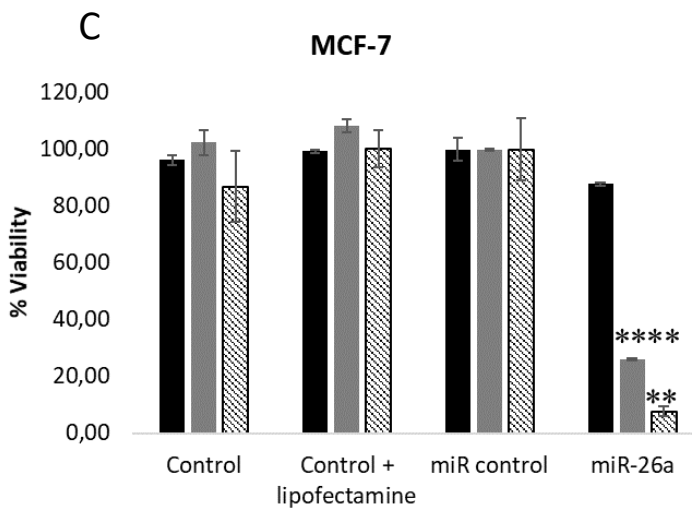

-Day 1 Day 4 \&ay 7

Figure 10. The effect of miR-26a on cell viability. MDA-MB-231 (A), MDA-MB-468 (B), and MCF-7 (C) at days 1, 4, and 7 after transfection with miR-26a. control with CY3 miRNA, miR-26a mimetic; $50 \mathrm{nM}$ of pre-miRNA were transfected in all cases. Error bars represent the standard deviation of three experiments. Statistically significant differences comparing cells transfected with miR-26a to cells transfected with $\mathrm{CY} 3$ miRNA control are shown at the respective time points. (Student $t$ test: ${ }^{*} p<0.05,{ }^{* *} p$ $<0.01, * * * \mathrm{p}<0.005, * * * * \mathrm{p}<0.001)$. 
As expected, miR-26a inhibition increased viability, in some cases significantly (for example at $24 \mathrm{~h}$ in MDA-MB-468). This effect was partially reverted when the mimetic and miR-26a inhibitor were combined (Figure 11). These data support a role for miR-26a in breast cancer cell viability/apoptosis pathways acting as a tumour suppressor. 
A 250

MDA-MB-231
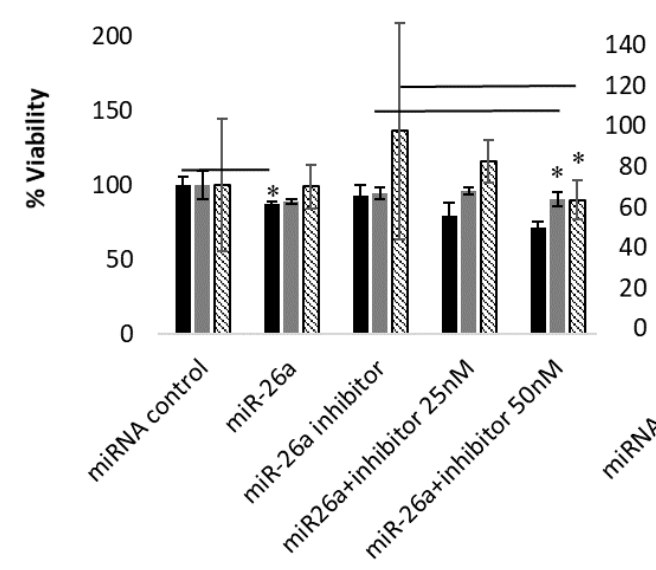

C 250
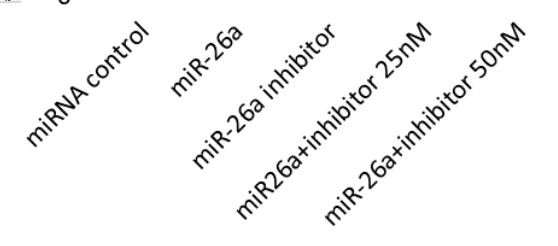

MCF-7

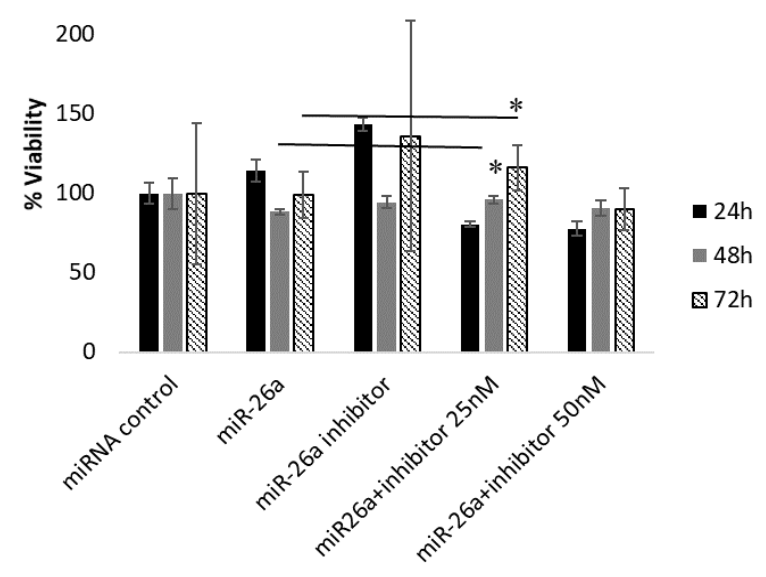

Figure 11. Determination of the miR-26a mimetic, the inhibitor, and their combined effects on the viability of the (A) MDA-MB-231; (B) MDA-MB-468; and (C) MCF-7 cell lines at 24, 48, and $72 \mathrm{~h}$ after transfection. miRNa control, cells treated with $50 \mathrm{nM}$ miR-26a mimetic; cells treated with $50 \mathrm{nM}$ miR26a inhibitor; combination of $25+25 \mathrm{nM}$ or $50+50 \mathrm{nM}$. Values for statistical significance were compared to miRNA control for every timepoint and cell line. Error bars show the standard deviation of three experiments. (Student t test: ${ }^{*} p<0.05,{ }^{* *} p<0.01,{ }^{* * *} p<0.005, * * * * p<0.001$ ). 


\subsection{Effect of miR-26a on Cell Migration}

To evaluate the physiological impact of miR-26a regulation we also studied the migration capacity of MDA-MB-231, MDA-MB-468, and MCF-7 cell lines when miR-26a was overexpressed in a woundhealing assay. From $25 \mathrm{~h}$, cell migration was higher in MDA-MB-231 and MDA-MB-468 cells transfected with the miR-26a mimetic compared to control cells, and the effect was more dramatic at $45 \mathrm{~h}$, especially in MDA-MB-231 cells (Figure 12). 


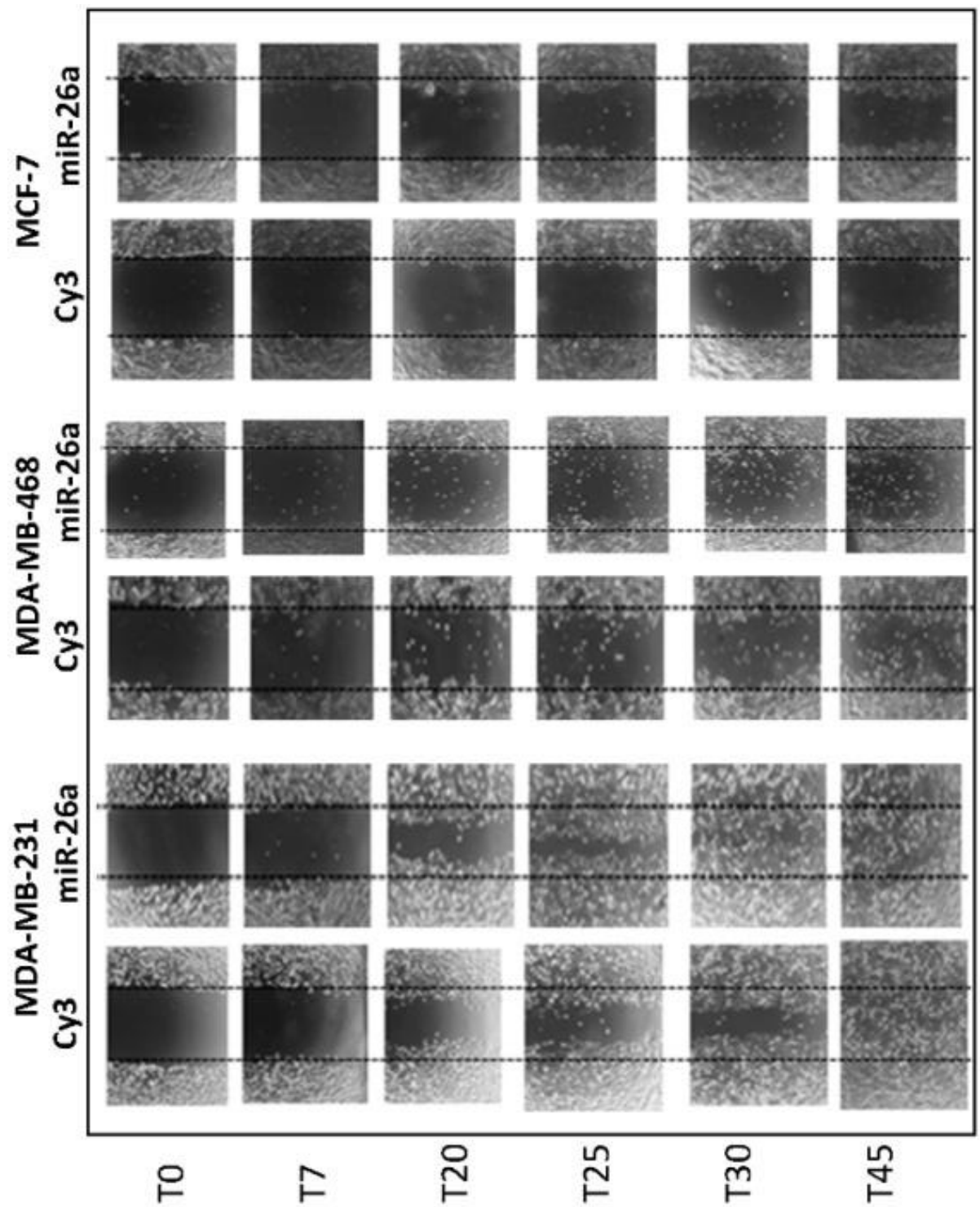

Figure 12. Wound healing cell migration assay comparing cells transfected with $\mathbf{5 0}$ nM miR-26a or CY3 (control). Cells transfected with miR-26a closed the wound before the CY3-transfected cells (25 vs. 30 h). (Magnification 100x).. 


\subsection{EVAluation of Potential miR-26a TARgets}

We searched for and selected theoretical miR-26a target-genes in the miRTarBase and used DAVID Bioinformatics Resources and miRBase. From 950 potential targets detected in the miRTarBase, we selected 11 based of their relevance to cancer and cell viability and apoptosis processes: CASP3, CCNE2, ABL2, APAF1, XIAP, BCL-2, PTEN, p53, E2F3, CDC25A, and BCL2L1 ligand (Table 9). We differentiate between theoretical and proven targets and note if the targets have been validated in cancer. 
Table 9. Theoretical and demonstrated miR-26a selected gene targets obtained with miRTarBase and selected by DAVID Bioinformatics Resources and miRBase. Demonstrated targets are experimentally proven targets by techniques such as RT-qPCR or Western Blot, although none of them are proven in breast cancer.

\begin{tabular}{cc}
\hline miR-26a & Target Genes \\
CASP3 & Theoretical \\
CCNE2 & Demonstrated \\
ABL2 & Theoretical \\
APAF1 & Theoretical \\
XIAP & Theoretical \\
BCL2 & Theoretical \\
PTEN & Demonstrated \\
TP53 & Theoretical \\
E2F3 & Theoretical \\
CDC25A & Theoretical \\
$B C L 2 L 1$ & Theoretical
\end{tabular}


We evaluated the expression of these 11 genes in the three breast cancer cell lines, after transfecting them with a miR-26a mimetic or inhibitor, by RT-qPCR. CASP3 expression significantly increased $(p=$ 0.012 ) in the MDA-MB-468 cell line, and CCNE2 expression significantly increased in both the MDA-MB-231 $(p=0.002)$ and MDA-MB-468 $(p=$ 0.0008 ) cell lines after transfection with the miR-26a inhibitor (Figure 4); in MDA-MB-231 cells $A B L-2$ was diminished after miR-26a transfection $(p=0.06)$ and increased after its inhibition $(p=0.027$; Figure 4); APAF1 expression was higher in MDA-MB-231 ( $p=0.00015)$ and MDA-MB-468 ( $p=0.04)$ cells with miR-26a inhibition, and decreased in MCF-7 cells upon mimetic transfection (not significant); $X I A P$ expression increased with miR-26a inhibition in the MDA-MB-231 significantly $(p=0.00025) ; B C L-2$ increased in the MDA-MB-231 $(p=$ $0.018)$ and MDA-MB-468 $(p=0.023)$ cell lines in the presence of the miR-26a inhibitor; PTEN expression diminished upon miR-26a transfection in the MDA-MB-231 ( $p=0.006)$ and MCF-7 $(p=0.002)$ cell lines, and significantly increased when miR-26a was inhibited in MDAMB-468 cells $\left(p=2.45 \times 10^{-5}\right)$; miR-26a inhibition increased TP53 expression in the MDA-MB-468 cell line $(p=0.0009)$; E2F3 expression diminished in all three cell lines after miR-26a transfection and significantly increased in MCF-7 cells when miR-26a was inhibited ( $p=$ 0.0005); both CDC25A and BCL2L1 expression significantly increased after inhibiting miR-26a in the MDA-MB-468 cell line $(p=0.024$ and $p$ $=0.001$, respectively) (Figure 13) . 
CASP3

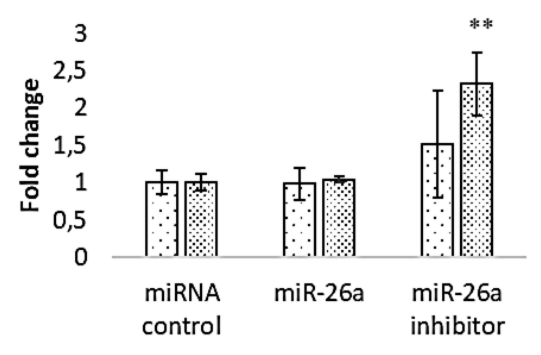

APAF1

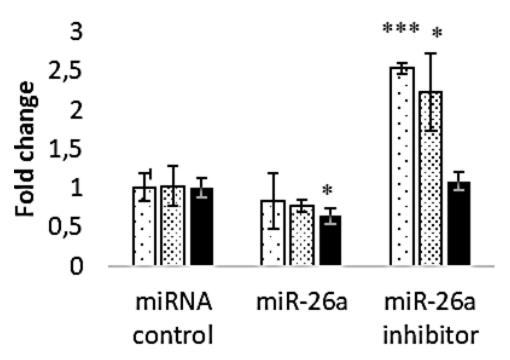

BCL2

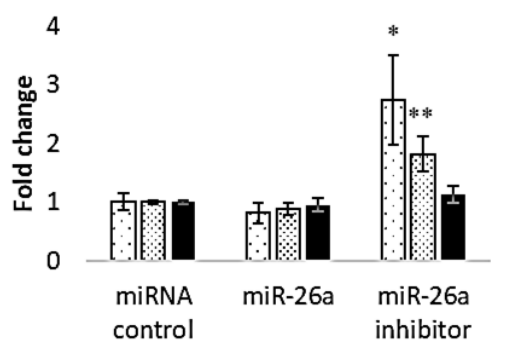

CCNE2

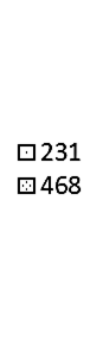

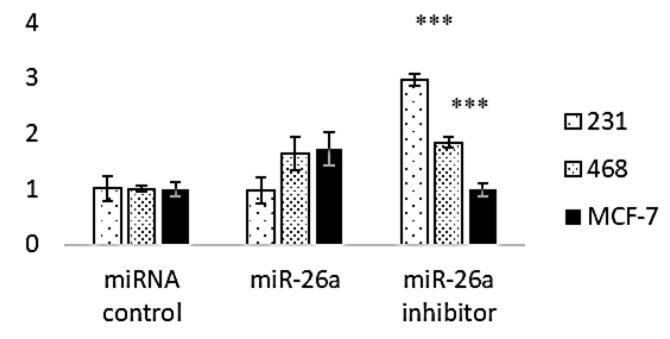

ABL2

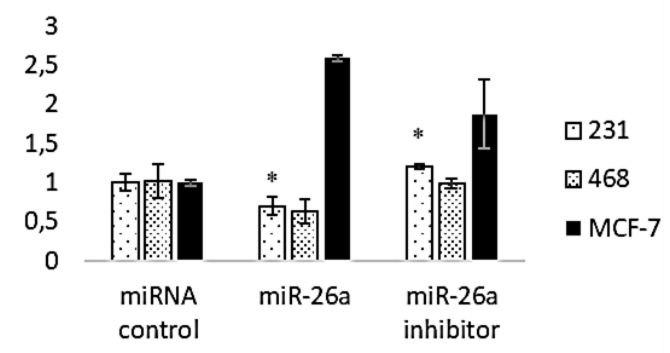

XIAP

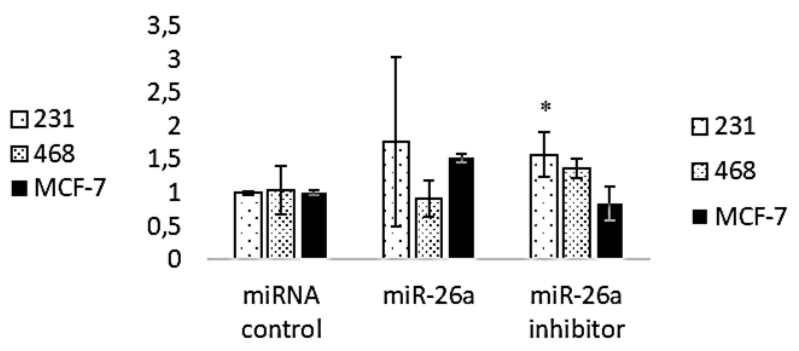


PTEN

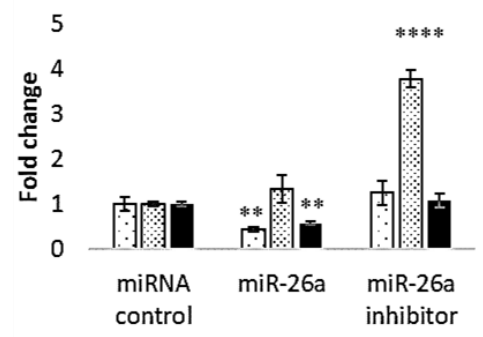

E2F3

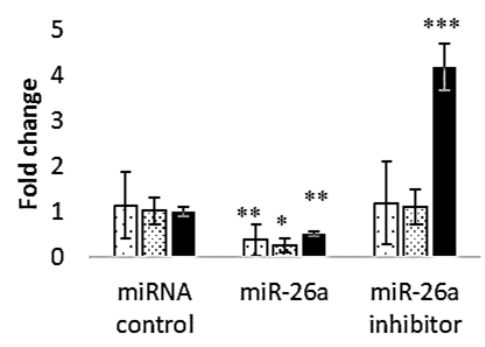

BCL2L1

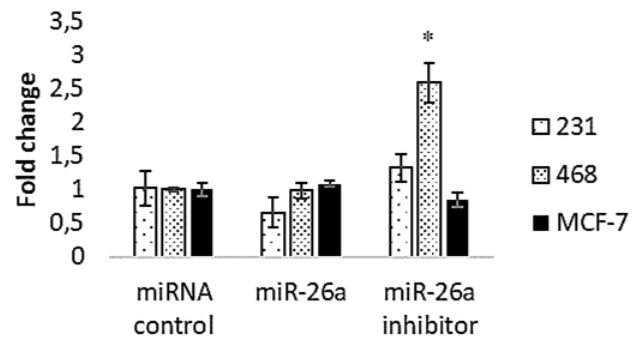

TP53

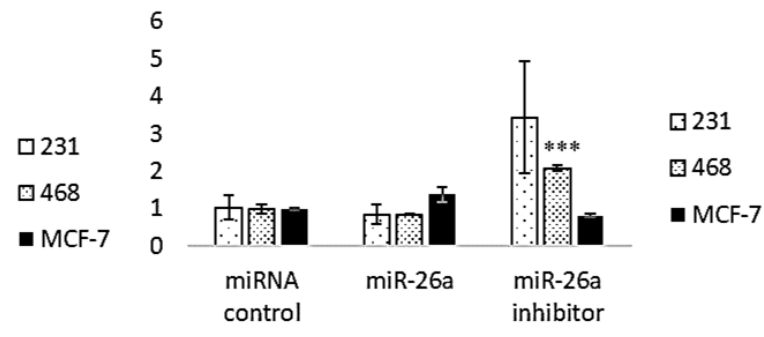

\section{CDC25A}

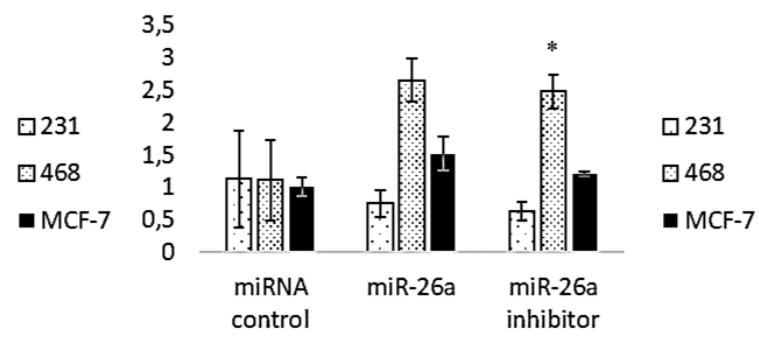

Figure 13. Gene expression of different miR-26a targets four days after transfection with either $50 \mathrm{nM}$ miR-26a mimic or its inhibitor in MDA-MB-231, MDA-MB-468, and MCF-7 cell lines, as measured by RT-qPCR. CY3: CY3 control miRNA. Values were compared to miRNA control for every cell line. Error bars represent triplicate experiments. (Student $\mathrm{t}$ test: ${ }^{*} \mathrm{p}<0.05 ;{ }^{* *} \mathrm{p}<0.01 ;{ }^{* * *} \mathrm{p}<0.005 ; * * * * \mathrm{p}<0.001$ ). 
After evaluation of the results, we considered that PTEN and E2F3 downregulation after miR-26a transfection was the most relevant finding because it suggests that these genes are direct targets of miR26a. This was especially interesting for PTEN as it has proven relevance in cancer processes. It is also very interesting the regulation of BCL-2 by miR-26a, although the mimic didn't have much effect, maybe because its low levels. Thus, we focused on studying the implications of miR-26a in the modulation of PTEN in the context of breast cancer.

\subsection{Phosphatase and Tensin Homolog (PTEN) Regulation by miR- $26 \mathrm{~A}$}

In order to validate PTEN as a miR-26a target in breast cancer, we transfected miR-26a mimetic into the MDA-MB-231 cell line and analysed PTEN protein expression. Western blot analysis showed that levels of this protein significantly decreased (by $35.2 \%$ vs. control, $p=$ 0.008 ) after miR-26a overexpression (Figure 14), in concordance with downregulation of this gene after miR-26a transfection (Figure 13). 


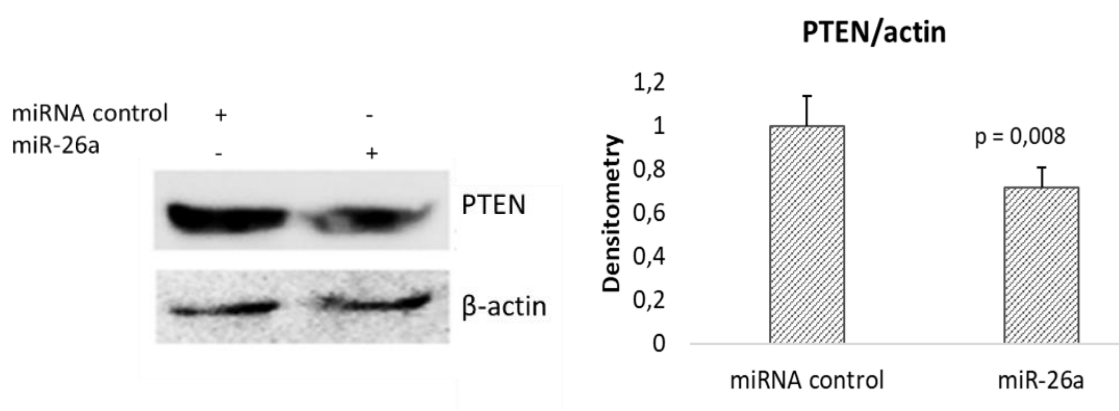

Figure 14. PTEN protein expression was measured by Western blot $72 \mathrm{~h}$ after transfection with miR-26a or CY3 in MDA-MB-231 cell line. $\beta$-Actin was used as a control.

\subsection{Effect of Metformin on Breast Cancer Cells}

In order to study if metformin induces miR-26a overexpression in breast cancer, as previously described in renal [21] and pancreatic [22] cancer, we tested mRNA and protein expression in metformin-treated MDA-MB-231 cells. First, we assessed the effect of metformin on cell viability using a MTT viability test at five different concentrations $(1,5$, 10,20 , and $40 \mathrm{mM}$ ) at 24,48 , and $72 \mathrm{~h}$ of metformin treatment. At concentrations of $10 \mathrm{mM}$ or higher, metformin decreased cell viability at 48 and $72 \mathrm{~h}$ ( $58 \%$ and $66 \%$ decrease a, respectively at $10 \mathrm{mM}$ ) (Figure 15). 


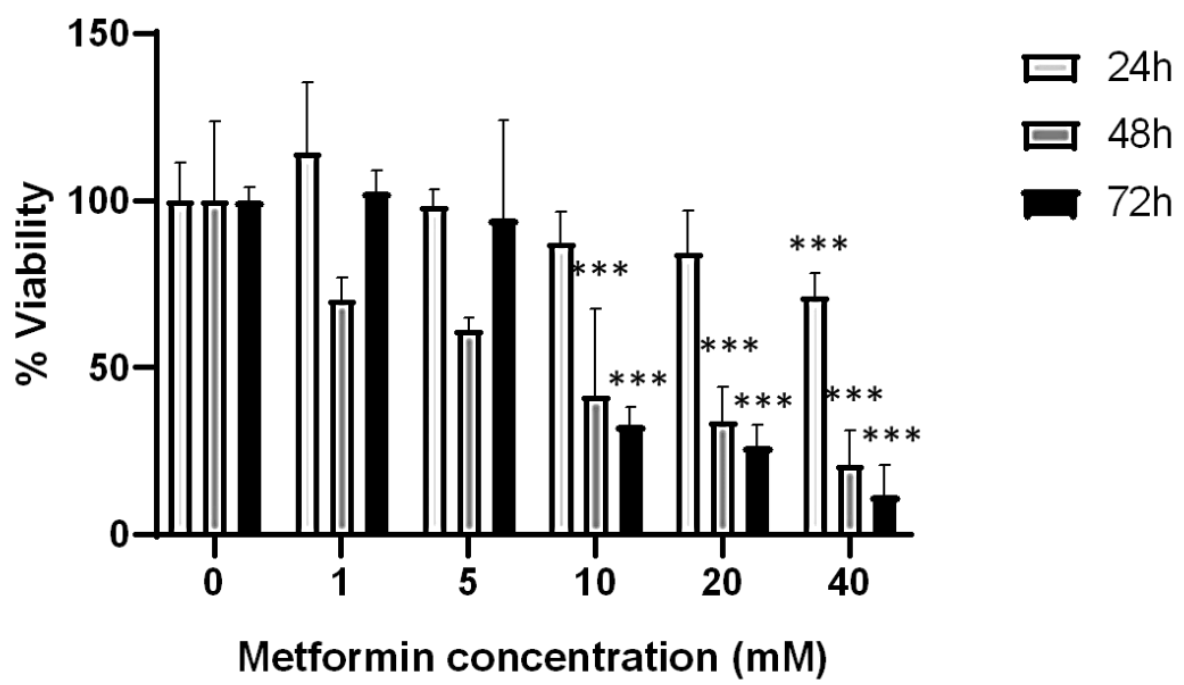

Figure 15. The effect of metformin on MDA-MB-231 cell line viability at different time-points and concentrations. Error bars represent the standard deviation of triplicate experiments. Statistically significant differences are shown for the comparison between treated cells and the control $(0 \mathrm{mM}$, not treated) at respective time-points (Student $\mathrm{t}$ test: ${ }^{* * *} \mathrm{p}<0.001$ ).

We further analysed the effect of metformin on the expression of miR-26a and its proposed targets, PTEN and BCL-2. MiR-26a was significantly increased after treating the cells with metformin $(p=$ 0.012), however, both its potential targets showed a significant decrease in expression with the same treatment $(p=0.038$ and $p<$ 0.001 for PTEN and BCL-2, respectively) compared to non-treated cells 
(Figure 16A). PTEN protein levels were also lower after treatment with the drug (Figure 16B). These data correlate with our results from RTqPCR.

A

miR-26a

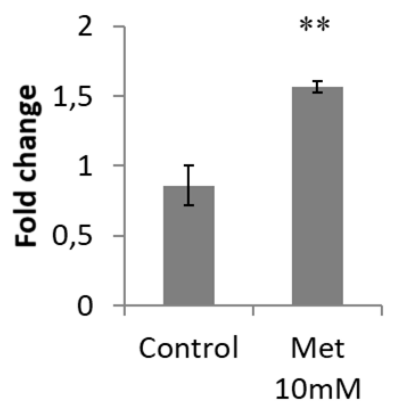

B

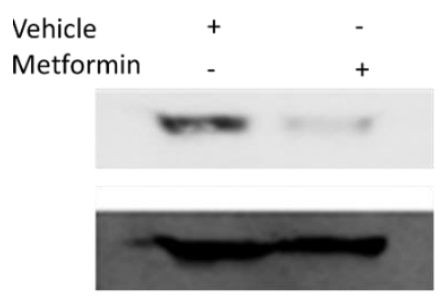

$B$
PTEN

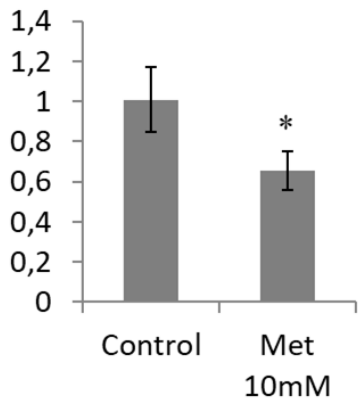

BCL-2

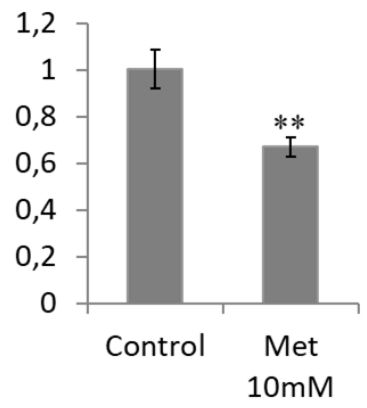

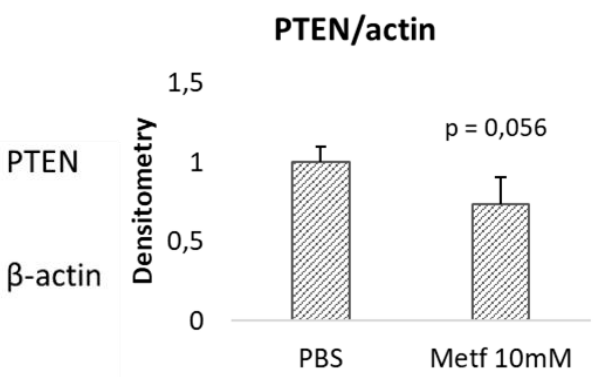

Figure 16. (A) Expression of miR-26a and two of its targets in MDA-MB-231 measured by RT-qPCR four days after treatment with $10 \mathrm{mM}$ metformin or vehicle (PBS). Error bars represent triplicate experiments; (Student $t$ test: $* p<0.05, * * p<0.01)$. (B) PTEN protein expression measured by Western blot. MDA-MB-231 was treated with 10 $\mathrm{mM}$ metformin or PBS, and $\beta$-actin was used as a control. 
Finally, cell migration during metformin treatment was also checked using a wound healing assay to see if treatment with this drug reproduced the effects seen with miR-26a. Treating MDA-MB-231 cells with metformin increased migration, as shown by faster gap-closing at 24 and $30 \mathrm{~h}$ compared to non-treated cells (Figure 17).

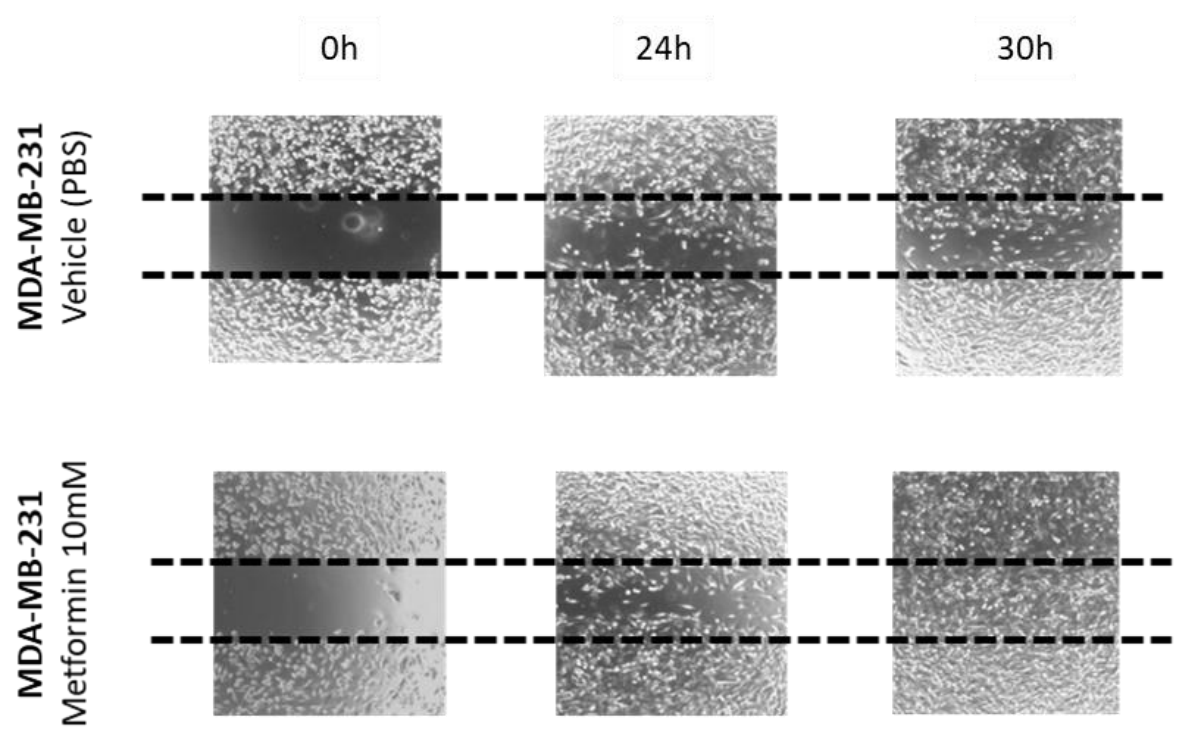

Figure 17. Wound healing cell migration assay comparing metformin-treated (10 mM) MDA-MB-231 cells with non-treated cells at 24 and $30 \mathrm{~h}$. (Magnification 100x).

\subsection{Effect of Metformin through miR-26a on Breast Cancer Cells}

To clarify if the effect of metformin is mediated by upregulation of miR-26a we performed viability and expression analysis combining 
the miR-26a inhibitor and metformin. The cell viability reduction induced by metformin was partially rescued by miR-26a inhibitor (Figure 18A). We think that PTEN inhibition by metformin via miR-26a could explain the increasing in cell migration under the treatment, but the metformin antitumor activity must be due to other miR-26a gene targets. We further analysed the effect of metformin on other miR-26a proposed targets: MCL-1, EZH2, and MTDH, which are proved targets of miR-26a in breast cancer and could be responsible of its antiproliferative effect. MCL-1 (myeloid cell leukemia 1 ) is a pro-survival member of the Bcl-2 (B-cell CLL/lymphoma 2) family [209], MTDH facilitates malignant transformation of normal immortal cloned rat embryo fibroblast cells [213], and EZH2 promotes anchorageindependent growth and invasion of immortalized human mammary epithelial cells [213].

MCL-1, EZH2, and MTDH showed significantly decreased expression (Figure 9B) after transfection with miR-26a mimetic $(p=$ $0.02, p=0.0004$, and $p=0.0004$, respectively) as was seen also for PTEN (Figure 4 and Figure 18B). Metformin significantly reduced EZH2 expression $(p=0.02)$ and the combination of miR-26a inhibitor with the drug significantly reversed the expression levels of EZH 2 and PTEN ( $p=0.019$ and $p=0.05$ respectively) (Figure 18C). 


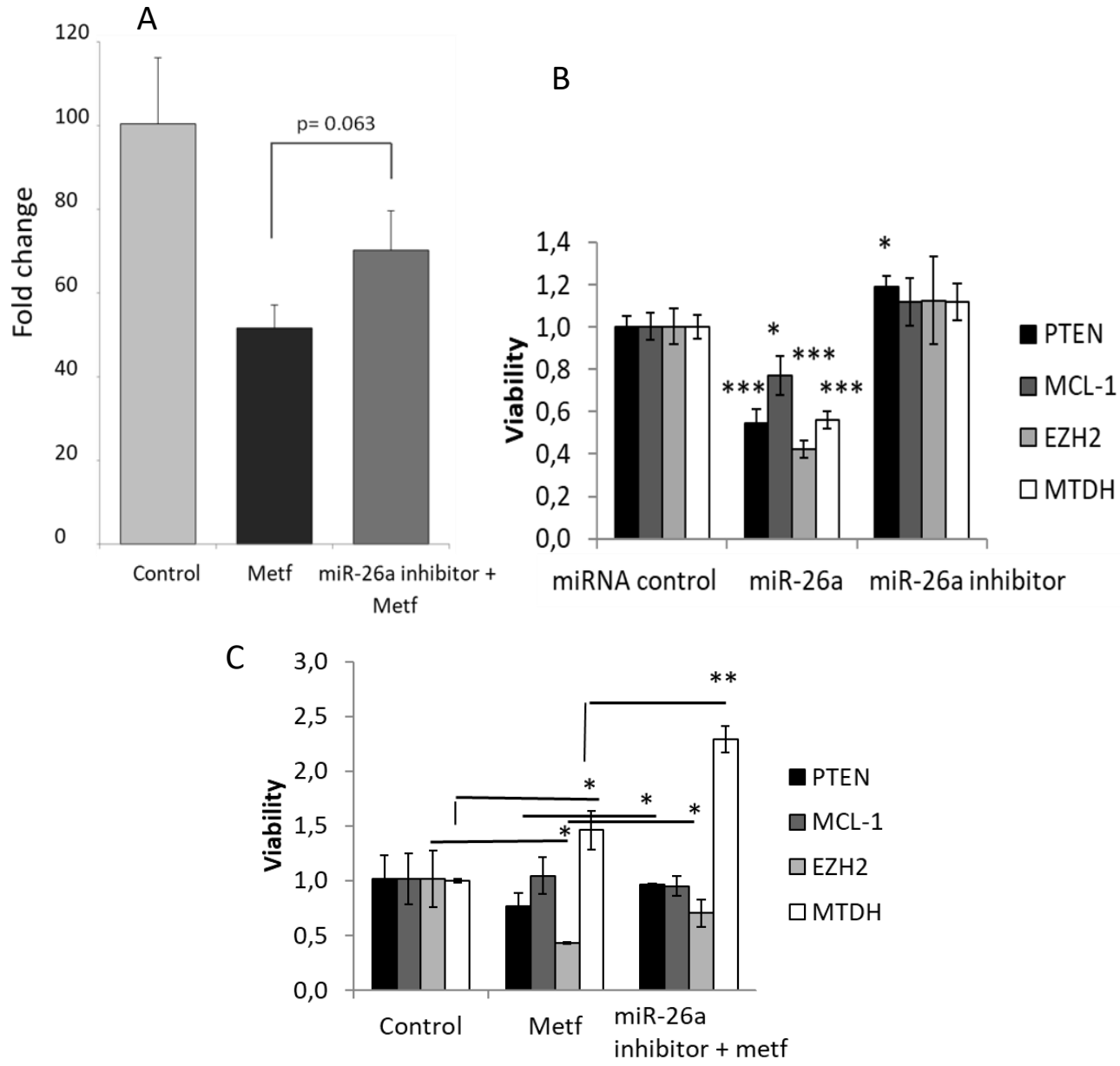

Figure 18. The effect of metformin through miR-26a on MDA-MB-231 cells. (A) Cell viability at $48 \mathrm{~h}$ after $10 \mathrm{mM}$ metformin treatment with or without the miR-26a inhibitor ( $50 \mathrm{nM}$ ); (B) Gene expression of miR-26a targets after transfection with either $50 \mathrm{nM}$ miR-26a mimetic or its inhibitor, as measured by RT-qPCR. CY3: CY3 control miRNA; (C) Expression of miR-26a targets measured by RT-qPCR after treatment with $10 \mathrm{mM}$ metformin (in presence or not of miR-26a inhibitor) or vehicle (PBS). Error bars represent triplicate experiments. (Student t test: ${ }^{*} p<0.05$; ${ }^{* *} p<0.01 ; * * p<0.005$ ). 


\section{EPIGENETIC STUDY OF RESISTANCE TO TRASTUZUMAB}

For the objectives of our PhD project involving resistance to trastuzumab in HER2+ breast cancer, and to evaluate our hypothesis that microRNAs may be involved in its generation and transmission via extracellular vesicles, we performed the following experiments:

\subsection{MIRNA EXPRESSION ANALYSIS BY MICROARRAY AFFYMETRIX GENECHIP MIRNA 4.0}

BT-474wt/r, SKBR-3wt/r and HCC1954 HER2+ breast cancer cell lines pellets were harvested by triplicate for microRNA extraction using the mirVana miRNA Isolation Kit. MDA-MB-231 pellets were harvested by quadruplicate for microRNA extraction as a non-HER2+ breast cancer cell line control for the miRNA microarray. The quality and integrity of the RNA of each sample to be included in the miRNA chip expression study was evaluated using RNA Integrity Number (RIN) from Agilent, a software tool designed to estimate the integrity of total RNA samples. This tool determines the integrity of the sample by the electrophoretic trace of the RNA sample. This includes detecting the presence of degradation products. In this way, the interpretation of an electropherogram can be accessed and different samples can be compared, thus ensuring the reproducibility of the experiments. The assigned RIN is independent of the concentration of the sample, the 
instrument and the analyst, thus becoming a standard for RNA integrity. In our study, the RIN for each sample (including triplicates) was in all cases above 8 on a scale of 1 to 10 .

After array normalisation by Robust Multiarray Average (RMA) we represented the Kernel density estimator in order to evaluate the possible variability among the different arrays composing our cell samples. This step is done for evaluating the possibility that some sample/array may present an unacceptable level of noise and should be removed from the study. The Kernel density estimator showed high symmetry for our cell samples (Figure 19A). 

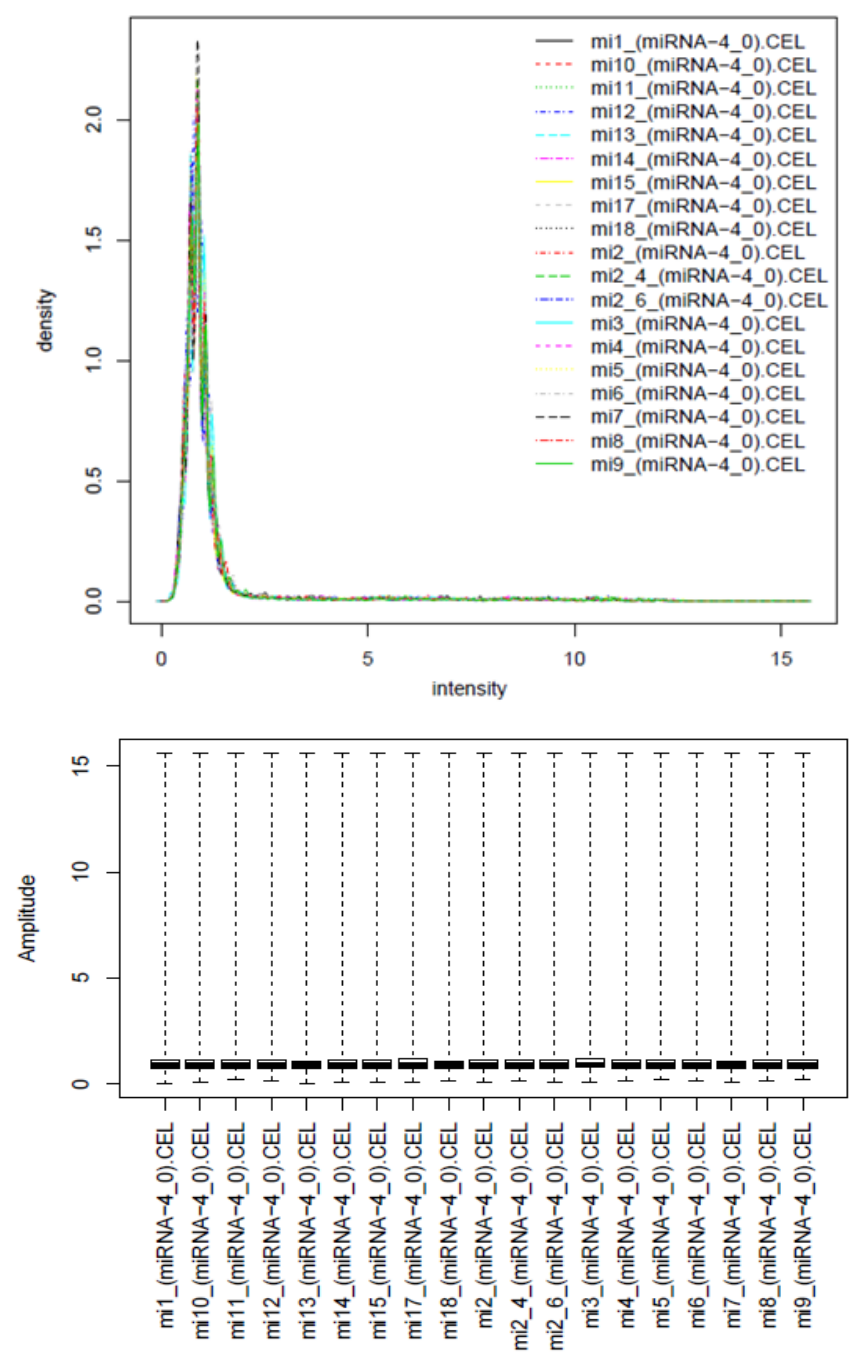

Figure 19. Logarithmic intensity distribution of probes included in each array. (A) Kernel estimator of the intensities for the different microarrays for breast cancer cell lines. (B) Box plot representations of the probe level expression for breast cancer cell lines analysed. (mi1, 2 and 3 correspond to BT-474wt; mi4, 5 and 6 correspond to BT$474 \mathrm{r}$; mi7, 8 and 9 correspond to SKBR-3wt; mi10, 11 and 12 correspond to SKBR-3r; mi13, 14 and 15 correspond to HCC1954; mi17, 18, 2_4 and 2_6 correspond to MDAMB-231). 
In the same way, we appreciated a very good symmetry in the expression variability within array and among all the samples/arrays in the box diagrams representation (Figure 19B). In both plots, the mean Log Intensity values were around 1. Ensuring the symmetry among arrays guarantees that the results from the samples can be comparable to each other.

We analysed the differential expression of 6,631 human miRNAs and pre-miRNAs contained in the Affymetrix GeneChip ${ }^{\text {TM }}$ miRNA 4.0 Array. For BT-474r cell line versus BT-474wt the ANOVA statistical analysis showed that 261 miRNAs were statistically differentially expressed ( $p$-value $<0.05$ ) and after adjusting for biologically significant fold change (considering linear fold change of BT-474r versus BT-474wt $>2$ and $<-2) 16$ miRNAs remained significant. The ANOVA statistical analysis showed that 265 miRNAs were statistically differentially expressed between SKBR-3r cell line and SKBR-3wt ( $p$ value $<0.05$ ) and after adjusting for biologically significant fold change (linear fold change of SKBR-3r versus SKBR-3wt $>2$ and $<-2$ ) 4 miRNAs remained significant. Between HCC1954 and BT-474wt 263 miRNAs were statistically differentially expressed ( $p$-value $<0.05$ ) and only 16 were biologically significant (linear fold change of HCC1954 versus BT$474 w t>2$ and $<-2$ ). For HCC1954 versus SKBR-3wt 310 miRNAs were statistically differentially expressed ( $p$-value $<0.05$ ) and 17 were biologically significant (linear fold change of HCC1954 versus SKBR-3wt $>2$ and $<-2$ ). This results and different comparisons are represented 
in the Venn's diagram (Figure 20). Values obtained and the complete miRNA list are included in Annex I.

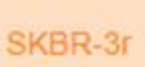

16
2

16

1

4

BT- $-474 r$

Figure 20. Venn's diagram showing miRNAs that are significantly dysregulated biologically in the resistant cell lines compared to the sensitive. The diagram represents the number of miRNAs differentially expressed in each cell line compared to the sensitive cell lines separately and the common dysregulated miRNAs in the combination of two and three of the resistant cell lines after applying the fold change adjustments .

The only common overexpressed miRNA after adjustments in both acquired resistant cell lines (BT-474r and SKBR-3r) which are the ones of most interest for our study and in all three resistant cell lines 
was miR-146a-5p (MIMAT0000449_st). The differential expression of miR-146a-5p comparing sensitive and resistant cell lines where the deregulation is statistically and biologically significant is represented in boxplots with the values obtained from the array (Figure 21).
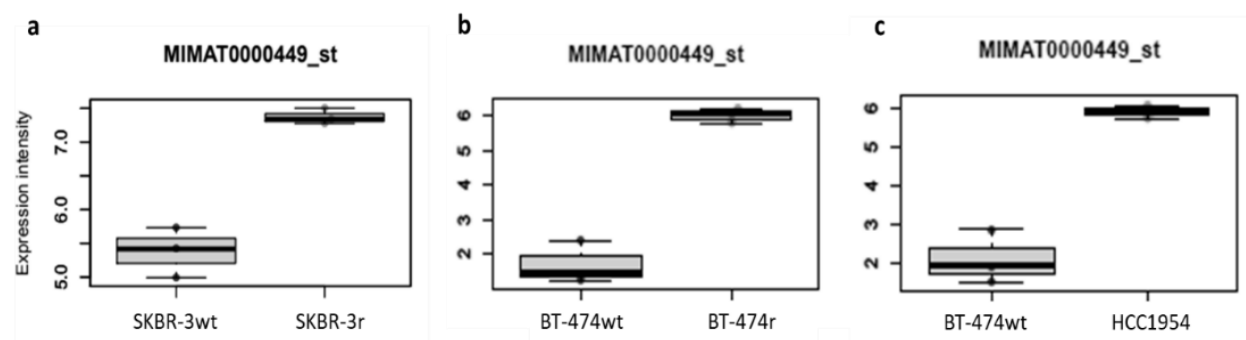

Figure 21. Expression intensity of miR-146a-5p in different samples of the GeneChip miRNA 4.0 Array of Affymetrix microarray by triplicate. a) SKBR-3wt and SKBR-3r; b) BT-474wt and BT-474r; c) BT-474wt and HCC1954.

The ANOVA statistical analysis made a total of 372 different miRNAs that were statistically deregulated among all the cell lines performing the variance analysis ( $p$-value 0.05 ) if we go back to the total differential miRNAs before applying the fold change adjustments. Average linkage hierarchical clustering with data from these 372 miRNAs was performed to obtain clusters of data set. 


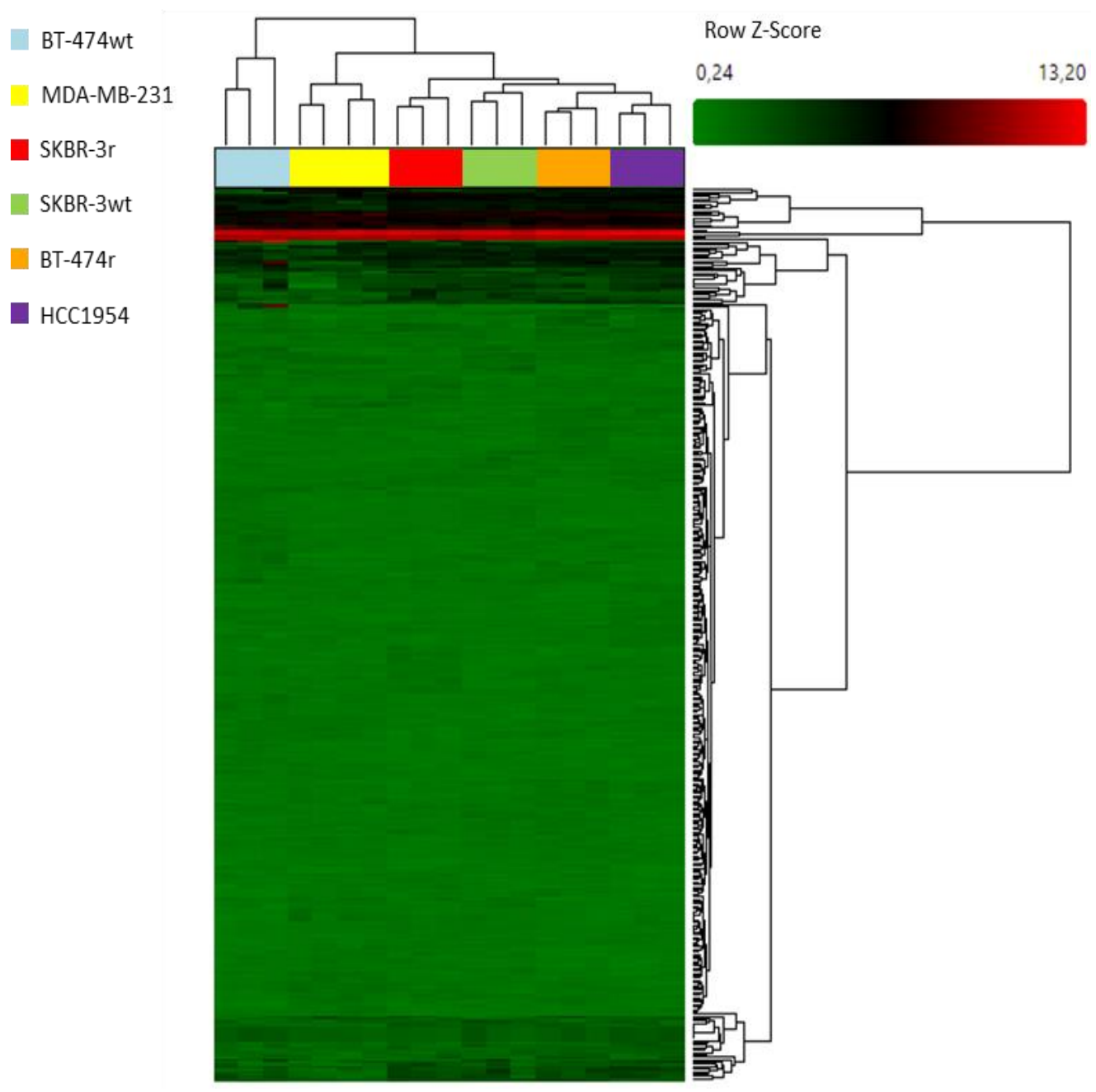

Figure 22. Hierarchical clustering and visualization of the expression of significantly dysregulated miRNAs in HER2+ cell lines (p-value 0.05 ). Heatmap representing the expression of 372 miRNAs that were significantly deregulated in HER2+ breast cancer cell lines ( $p$-value 0.05). The expression is shown in different intensities, green for values lower than the median, red for values that are higher and black for unchanged values with respect to the median. 
Heatmap representation shows how BT-474r overexpressed miRNAs are closer to HCC1954 cell line followed by SKBR-3wt and SKBR-3r, showing that resistant cell lines have similar miRNA expression. Biological triplicates for each breast cancer cell line presented a similar miRNA profile and clustered together in the Heatmap representation (Figure 22). These results show a good reproducibility among biological triplicates.

\subsubsection{Pathway enrichment analysis for breast cancer cell lines}

Pathway enrichment study showed 16 (Figure 23A) and 4 (Figure 23B) pathways that were significantly dysregulated (FDR adjusted $p$ value $<0.05$ ) by the significant miRNAs overexpressed in the cell lines with acquired resistance of our study (BT-474r and SKBR-3r). We found pathways related with extracellular matrix (ECM) receptor interaction (hsa04512), viral carcinogenesis (hsa05203), microRNAs in cancer (hsa05206), pathways in cancer (hsa05200), glioma (hsa05214), chronic myeloid leukaemia (hsa05220), central carbon metabolism in cancer (hsa05230) or proteoglycans in cancer (hsa05205). Additionally, we identified pathways related with ErbB (hsa04012), TGF-beta signalling (hsa04350) and signalling pathways regulating pluripotency of stem cells (hsa04550). Interestingly, fatty acid biosynthesis (hsa00061), lysine degradation (hsa00310) and fatty acid metabolism (hsa01212) were also deregulated by significant miRNA 
found. Adherent junctions (hsa04520) were also deregulated by significant miRNA found. List of deregulated pathways identified are represented in Figure 23. More information about node miRNA's enrichment and FDR p-values associated with each pathway are shown in Annex I. 


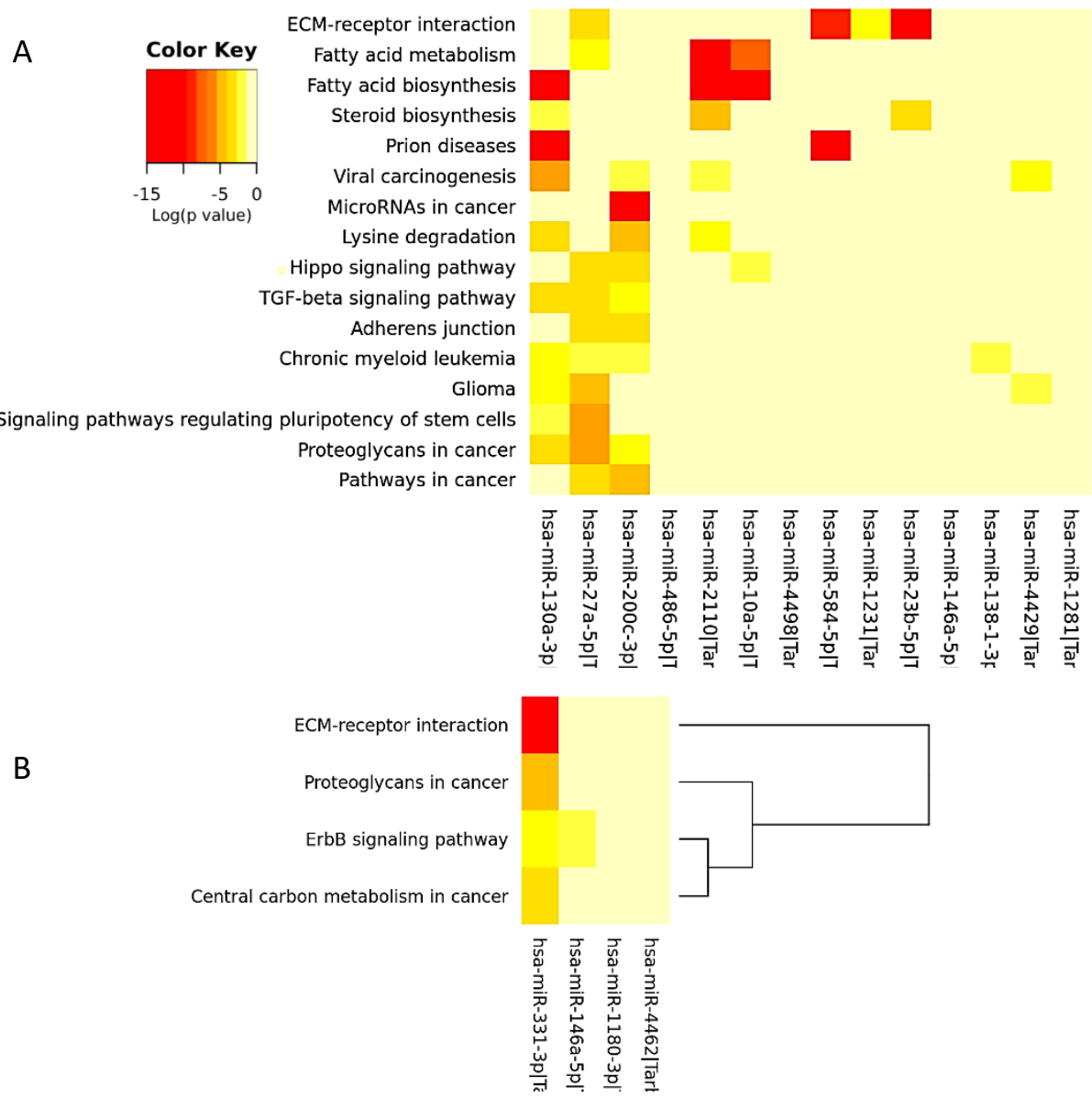

Figure 23. Pathways significantly deregulated by miRNA differentially expressed in resistant breast cancer cell lines compared to sensitive. Enrichment study was performed by DIANA mirPath following Fisher's Exact Test (hypergeometric distribution) as enrichment analysis method and pathways obtained presented an ANOVA $p$-value $<0.05$ with a microT threshold of 0.8 and FDR correction. (A) Pathways altered by the 14 significant miRNAs (apart from U3 and U8, not shown) dysregulated in BT-474r compared to BT-474wt; (B) Pathways in which the 4 miRNA dysregulated in SKBR-3r compared to SKBR-3wt were involved. Dot colour indicates a logarithmic transformation of Benjamini + Hochberg adjusted p-values (red for most significant pathways and yellow for lower p-values). 


\subsection{VALIDATION OF MIR-23B EXPRESSION BY Q-PCR}

One of the most interesting microRNAs dysregulated in the array between BT-474wt and BT-474r was miR-23b-3p, since PTEN is a direct demonstrated target and this could be one of the main causes of their resistance to trastuzumab.

The nature of the data and the methods used for obtaining miR$23 b-3 p$ from the array can produce false positive results due to the technique used or to the stochastic processes. We must then evaluate the robustness of the data obtained by the array and confirm that the selected miRNAs are dysregulated. For this verification, the expression of the most interesting miRNAs was carried out using a more direct technique, such as the analysis of the expression by q-PCR. From the results of the microarray we obtained miR-23b that was overexpressed in BT-474r cell lines compared to BT-474wt and has PTEN as a target, thus being very attractive for study as PTEN mutations or expression changes are a known way of resistance to trastuzumab (Figure 24).

In order to confirm this results, new pellets of both cell lines were collected, and a new RNA extraction was performed to evaluate miR23b-3p expression by real-time PCR. Then we calculated the mean $\mathrm{Ct}$ between replicates, the standard deviation and obtained the $\Delta \Delta \mathrm{Ct}$, as previously described in material and methods section. 
We could see that resistant cell line BT-474r express higher amount of miR-23b-3p (Figure 25) than their cell line of origin and this difference was statistically significant ( $p$-value $<0.05)$.

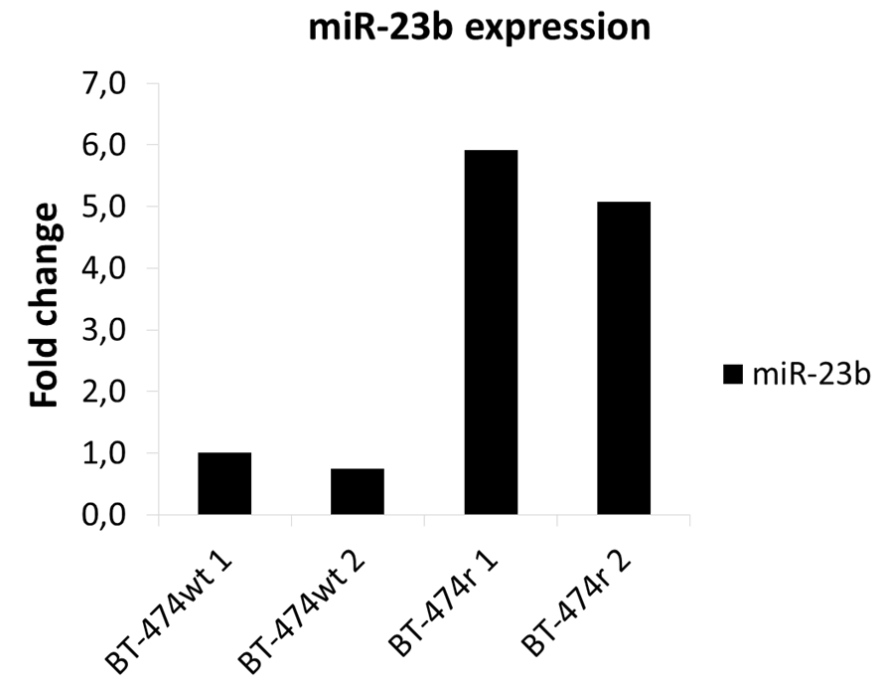

Figure 24. Validation in the array pellets by real time PCR of the expression changes for miR-23b-3p obtained in the microarray. For validation, the $\Delta \Delta C t$ method was used. As endogenous miRNA, RNU43 was used; the expression of the miRNAs in a control situation was considered as standard. Differences in expression between sensitive and resistant cell lines were statistically analysed using a T-student test for comparison of means. Each expression measurement was performed in triplicate. 


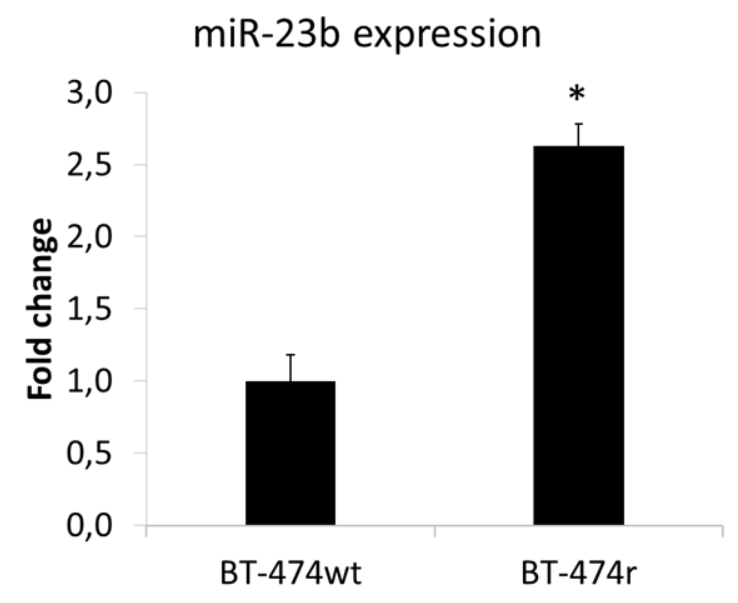

Figure 25. Validation by real time PCR of the expression changes for miR-23b-5p in new cellular pellets. For validation, the $\Delta \Delta \mathrm{Ct}$ method was used. As endogenous miRNA, RNU43 was used; the expression of the miRNAs in a control situation was considered as standard. Differences in expression between sensitive and resistant cell lines were statistically analysed using a T-student test for comparison of means. Each expression measurement was performed in triplicate.

\subsection{STUDY OF MIR-23B EXPRESSION IN PATIENTS}

To test the hypothesis of the potential association of miR-23b-3p overexpression in resistant cell lines with overall survival (OS), we analysed the follow-up data of METABRIC samples with miRNA expression data. Specifically, METABRIC miRNA expression data includes 1,262 breast cancer patients from which 608 are patients with positive HER2 status by IHC. To analyze the prognostic value of miR- 
$23 b-3 p$, the patient samples were split into two groups according to various quantile expressions of the proposed biomarker. The two patient cohorts were compared by a Kaplan-Meier survival plot, and the hazard ratio with $95 \%$ confidence intervals and logrank p-value were calculated.
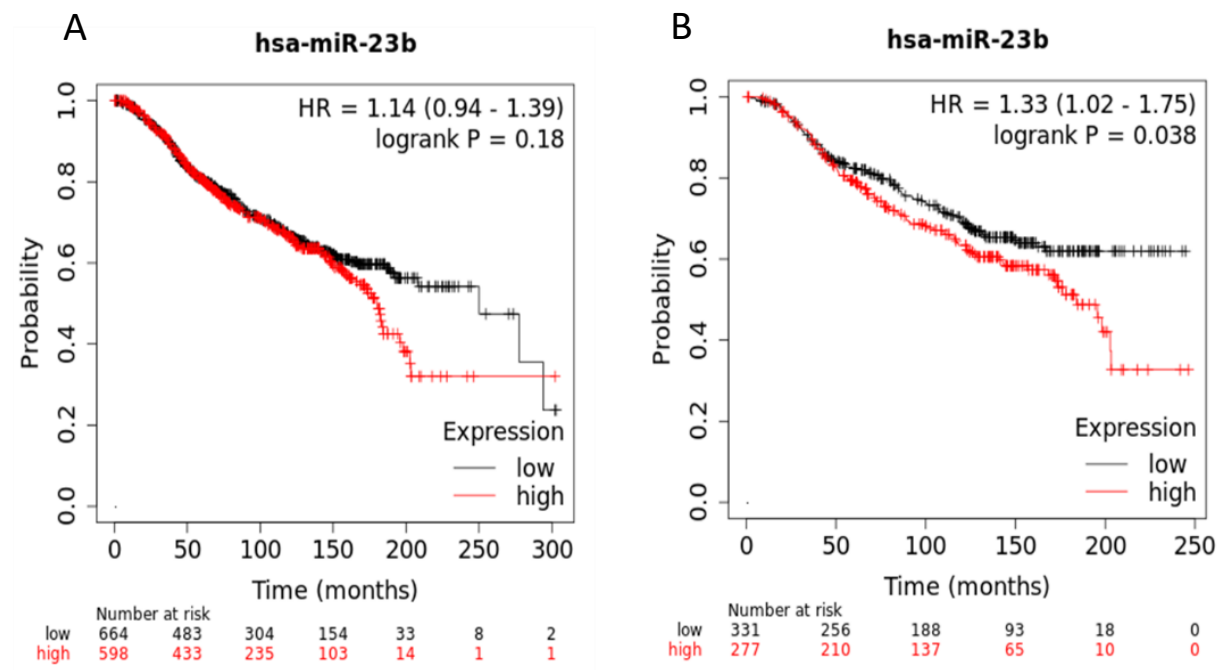

Figure 26. Representation of overall survival curves for miR-23b expression analysed in breast cancer samples from METABRIC. Overall survival in total breast cancer patients (1262 patients). (A); Overall survival in HER2+ patients (608 patients). (B). X axis represents the follow-up time by months and $Y$ axis indicates the percentage of overall survival. Black curves represent patients with miR-23b low expression and red colour line represents patients with miR-23b overexpression. P-values were obtained by univariate cox analysis. 
OS study did not show significant correlation between miR-23b expression status and survival for total METABRIC breast cancer patients (Figure 26a). However, data was different when restricting the study to HER2 positive IHC status patients (Figure26b), where survival was lower for high expression of miR-23b. HER2+ patients with miR-23b overexpression presented worse prognosis with statistical significance $(p$-value $=0.038)$.

In order to corroborate the results from breast cancer cell lines and tumour samples from patients, we analysed miR-23b expression in FFPE samples from patients to check whether the tendency observed in patients from METABRIC was reproducible among the Hospital Clínico's HER2+ breast cancer patients. We had a total of 10 healthy breast samples, 14 patients which responded to trastuzumab treatment and 22 metastatic patients. 


\section{miR-23b-3p expression}

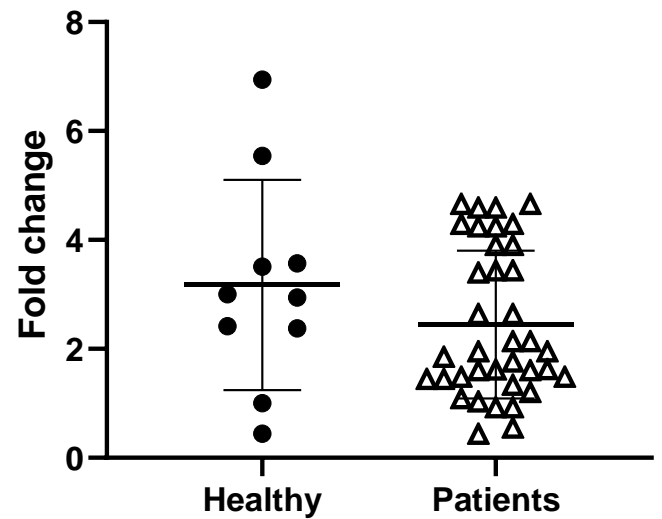

miR-23b-3p expression

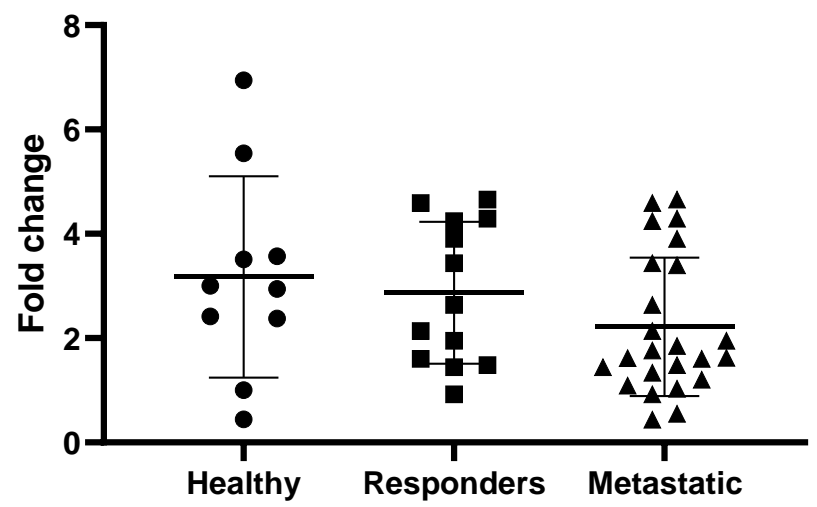

Figure 27. Analysis of the expression of the miRNA-23b-3p in breast cancer patients by real-time PCR. As endogenous miRNA, miR-16a was used; expression levels were compared with respect to the inverse value of $\Delta \mathrm{Ct}$. At the statistical level, normality was verified using the Shapiro-Wilk test. 
The expression levels of this miRNAs were disperse in healthy breast samples compared to tumorous ones, being the median higther but not significant. The miR-23b-3p expression in responders showed a median lighty higher that in metastatics although it does not reach statistical significance (Figure 27). The results didn't show similarity to the data base analysis, however, it is important to highlight that the $n$ evaluated was low (10 healthy samples, 14 responders and 24 metastatic patients).

\subsection{STUDY OF MIR-23B-3P TARGET PTEN}

We measured the expression of PTEN as a miR-23b-3p target. The aim was to study the mechanism of action of this miRNA and its involvement in trastuzumab resistance. 300.000 BT-474wt cells were seeded per well in a 6-well-plate. Cells were transfected with different condition by triplicate: $50 \mathrm{nM}$ of miRNA control, $50 \mathrm{nM}$ of miRNA-23b$3 p$ mimic or $50 \mathrm{nM}$ of miR-23b-3p inhibitor. After $48 \mathrm{~h}$ of incubating the transfection, cells were harvested, and gene expression was measured by real-time PCR. 
A PTEN expression

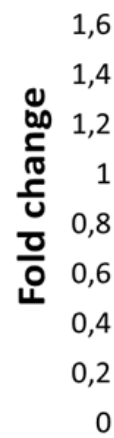

B

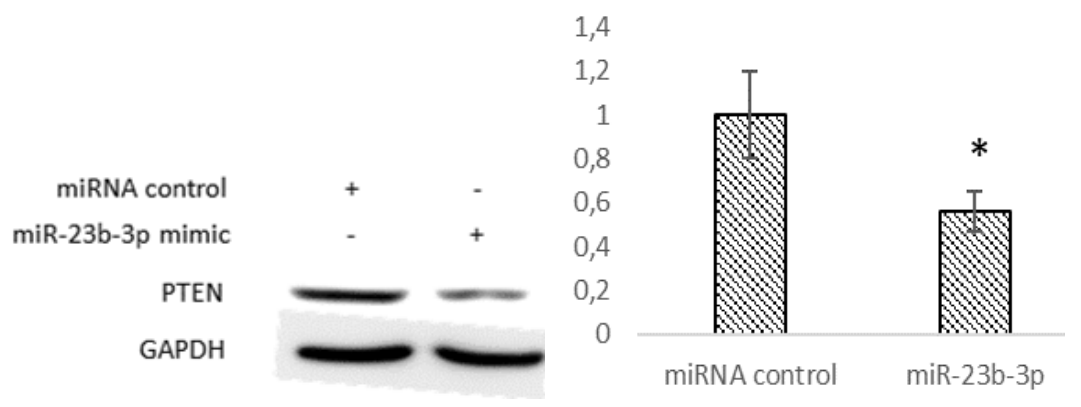

Figure 28. (A) Gene expression by real time PCR of the miR-146a-5p target and pathway. For measuring expression, the $\Delta \Delta \mathrm{Ct}$ method was used. As endogenous mRNA, GAPDH was used; the expression of the mRNAs in a control situation was considered as standard. Differences in expression between sensitive and resistant cell lines were statistically analyzed using a T-student test for comparison of means ( ${ }^{*} p<$ $0.05, * * * p<0.001$ ). Each expression measurement was performed in triplicate. (B) PTEN protein expression measured by Western blot. BT-474wt cells were transfected either with a microRNA control or with miR-23b-3p mimic, and GAPDH was used as a control. 
Significant changes were observed in the expression of the direct target PTEN comparing the control condition and the one transfected with miR-23b-3p mimic (Figure 28A). We could observe that miR-23b$3 p$ overexpression decreased significantly PTEN expression, suggesting a direct regulation of PTEN by miR-23b ( $p$-value $<0.001$ ). The changes in PTEN expression after inhibition of miR-23b-3p inhibitor were also significant ( $p$-value $<0.05$ ), showing a small increase compared to the control situation. Results were reproducible when checked by western blot, showing a significant downregulation of PTEN protein with transfection of miR-23b mimic (Figure 28B). 


\subsection{VALIDATION OF MIR-146A EXPRESSION BY Q-PCR}

From the results of the microarray we obtained that the only statistically and biologically significant miRNA that was overexpressed in both cell lines of study with acquired resistance to trastuzumab (BT$474 r$ and SKBR-3r) was miR-146a-5p, being also overexpressed in the innate resistant cell line HCC1954. As for miR-23b-3p, we had to check this result by qPCR.

Results of measuring manually by $\mathrm{qPCR}$ the expression in the pellets from the array showed significant differences for miR-146a-5p between resistant cell lines and the sensitive, specially the acquired resistant cell lines compared to its wild type cell line of origin. For this reason, we repeated by triplicate the measures in new pellets of BT$474 w t / r$ and SKBR-3wt/ $r$ to validate if the resistant cell lines had different expression compared to their wild type.

We measured the amplification by $\mathrm{qPCR}$, and then we analysed the mean $\mathrm{Ct}$ values for replicates, the standard deviation and obtained the $\Delta \Delta \mathrm{Ct}$ in order to determine the fold change values for studying the relative expression.

We could see that both resistant cell lines BT-474r and SKBR-3r express higher amount of miR-146a-5p (Figure 29) than their cell lines of origin and this difference was very statistically significant ( $p$-value $<$ $0.001)$. 


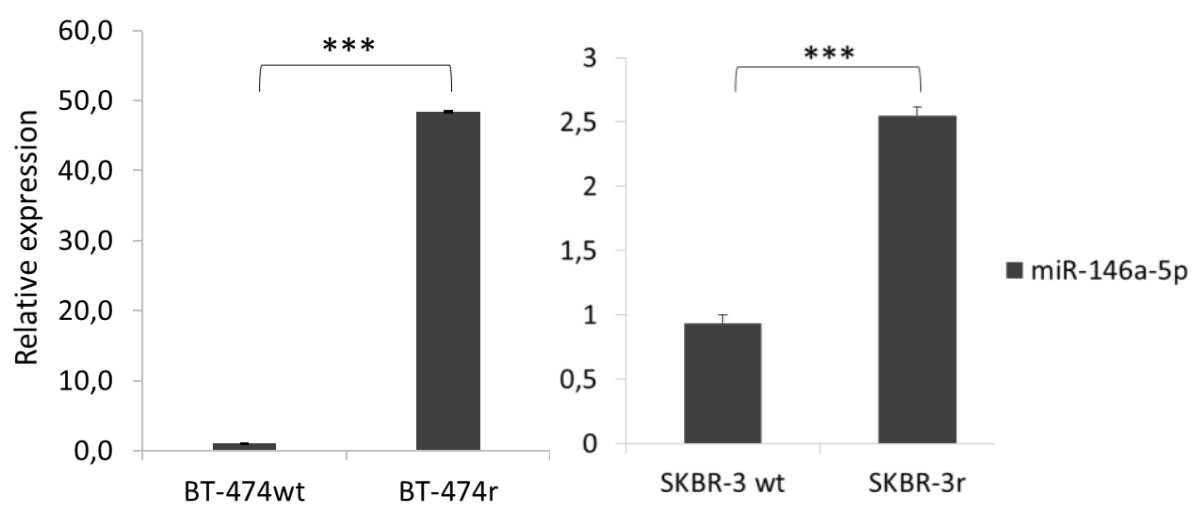

Figure 29. Validation by real time PCR of the expression changes for miR-146a-5p in new cellular pellets. For validation, the $\Delta \Delta C$ t method was used. As endogenous miRNA, RNU43 was used; the expression of the miRNAs in a control situation was considered as standard. Differences in expression between sensitive and resistant cell lines were statistically analyzed using a T-student test for comparison of means. Each expression measurement was performed in triplicate (Student $t$ test: ${ }^{* * *} p<0.001$ ).

\subsection{STUDY OF MIR-146A EXPRESSION IN PATIENTS}

To test the hypothesis of the potential association of miR-146a$5 p$ overexpression in resistant cell lines with OS, we also analysed the follow-up data of METABRIC samples with miRNA expression data.

OS study did not show significant correlation between miR-146a expression status and survival for total METABRIC breast cancer patients (Figure 30a). However, data was different when restricting the study to HER2 positive IHC status patients (Figure $30 \mathrm{~b}$ ), where 
survival was lower for high expression of miR-146a. Although, no significant results were achieved $(p$-value $=0.056)$, HER2+ patients with higher levels of miR-146a tended to worse prognosis.
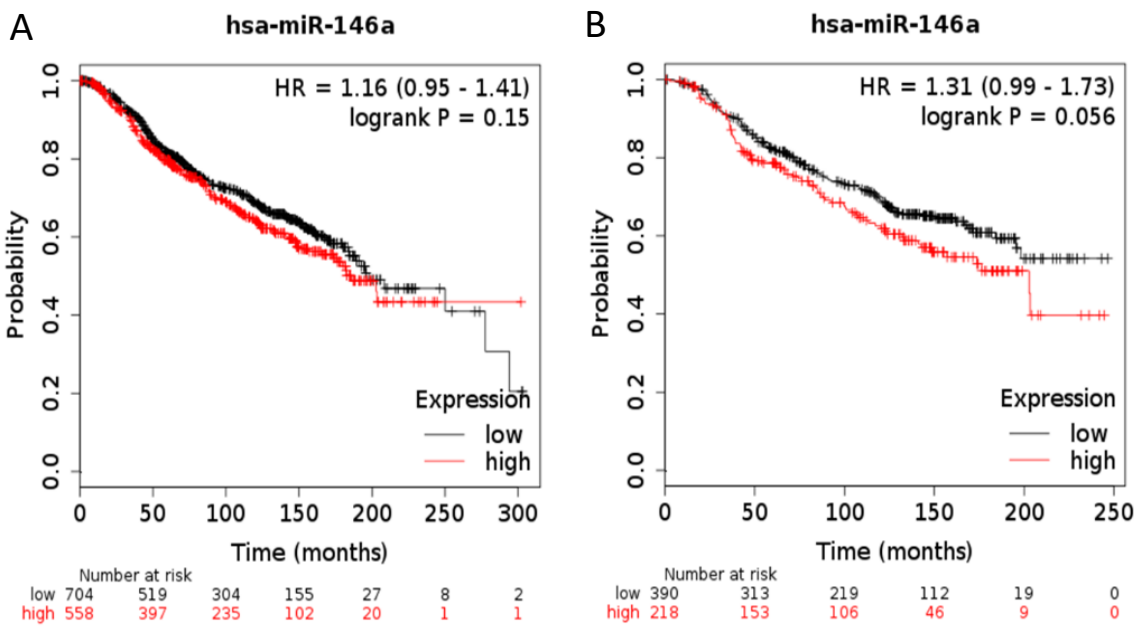

Figure 30. Representation of overall survival curves for miR-146a expression analysed in breast cancer samples from METABRIC. Overall survival in total breast cancer patients (1262 patients). (A); Overall survival in HER2+ patients (608 patients) (B). $X$ axis represents the follow-up time by months and $Y$ axis indicates the percentage of overall survival. Black curves represent patients with miR-146a low expression and red colour line represents patients with miR-146a overexpression. P-values were obtained by univariate cox analysis.

We analysed miR-146a expression in FFPE samples from patients to check whether the tendency observed in patients from METABRIC 
was reproducible among the Hospital Clínico's HER2+ breast cancer patients.

The expression levels of this miRNAs were lower in healthy breast samples compared to tumorous ones without reach significance. When analyzed metastatic patients no increased expression of miR$146 a-5 p$ versus responders could be seen, which could not indicate a relationship with a possible resistance to trastuzumab. However, the results obtained were from a very smal cohort (10 healthy donors, 14 responders and 24 metastatic patients) (Figure 31). 


\section{miR-146a-5p expression}

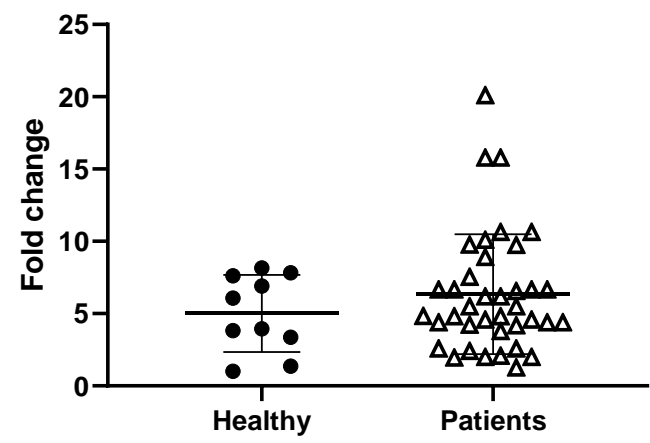

miR-146a-5p expression

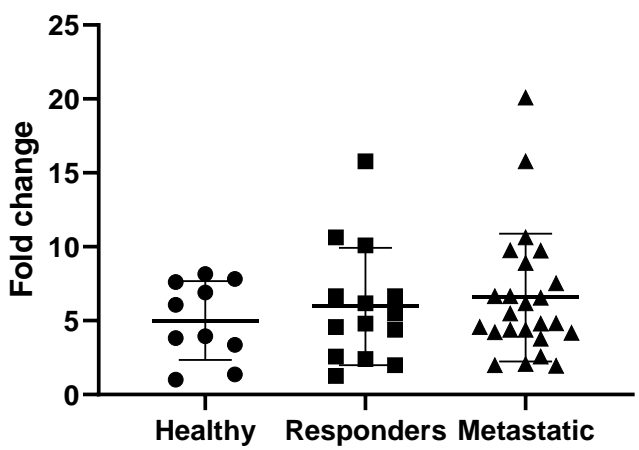

Figure 31. Analysis of the expression of the miRNA-146a-5p in breast cancer patients by real-time PCR. As endogenous miRNA, miR-16a was used; expression levels were compared with respect to the inverse value of $\Delta \mathrm{Ct}$. At the statistical level, normality was verified using the Shapiro-Wilk test. 


\subsection{STUdY OF MIR-146A-5P IN CELL LINES}

\subsubsection{Cell viability}

The viability of the SKBR-3wt and SKBR-3r cell lines was studied under normal conditions and in the presence of treatment (trastuzumab). In 96-well plates, initial seedings of 5,000 cells were made in triplicate for each cell line. Under normal conditions, cell growth was analysed 7 days after time 0 (to), since it is the established time to see the effect of trastuzumab on the viability of this cell line. Under the treatment conditions, the cells were treated at a fixed concentration of $15 \mu \mathrm{g} / \mathrm{ml}$ of trastuzumab and their growth was analysed, in the same way as the controls, after 7 days of exposure to the drug (from t0, the day on cells previously seeded are treated). For the viability analysis, the MTT method was used. The results obtained were statistically analysed by means of a comparison T-test. In the case of the wild type cell line, viability was statistically significantly reduced after 7 days of trastuzumab treatment ( $p$-value $=0,000142$ ). However, for the resistant cell line, viability after 7 days of treatment with trastuzumab was not significantly reduced ( $p$-value $=0,261660$ ), thus agreeing with the expected results for this cell line with acquired resistance (Figure 32). To determine whether or not a cell line can be considered resistant to trastuzumab, it has been established that, regardless of statistical significance, sensitive lines must reduce their viability at least a $20 \%$ after 7 days of treatment with trastuzumab at a concentration of $15 \mu \mathrm{g} / \mathrm{ml}$ in order to consider biological significance 
according to O'Brien's algorithm [202], whereas if the decrease in viability is less, they would be considered resistant cell lines or cell lines that are not responding properly to treatment with trastuzumab.

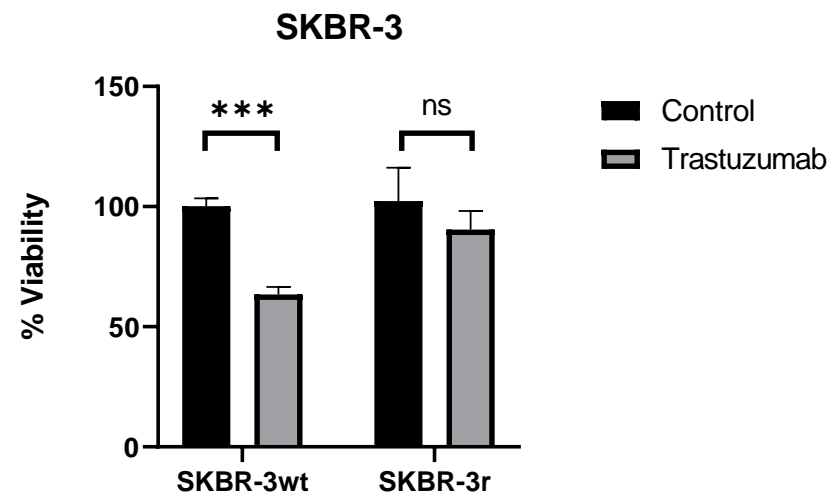

Figure 32. Viability analysis in SKBR-3wt/r cell lines treated with trastuzumab. Viability was measured by MTT at 7 days exposure to $15 \mu \mathrm{g} / \mathrm{ml}$ of trastuzumab. Each experiment was performed in triplicate and was statistically analysed with a T-Student test for comparison of means. Comparisons were made with respect to time zero (t0) of the control line. $(* * * p<0.001)$.

After observing the data obtained from the array and the relation of miR-146a with a worse prognosis in HER2 + breast cancer patients, we proceeded to analyse the possible involvement of this miRNA in resistance to trastuzumab treatment. For this, the SKBR-3wt/r cell lines were transfected with a mimic or an inhibitor of our miRNA of interest. Subsequently, the cell lines were treated with trastuzumab at a concentration of $15 \mu \mathrm{g} / \mathrm{ml}$ for 7 days and viability was measured by MTT. 


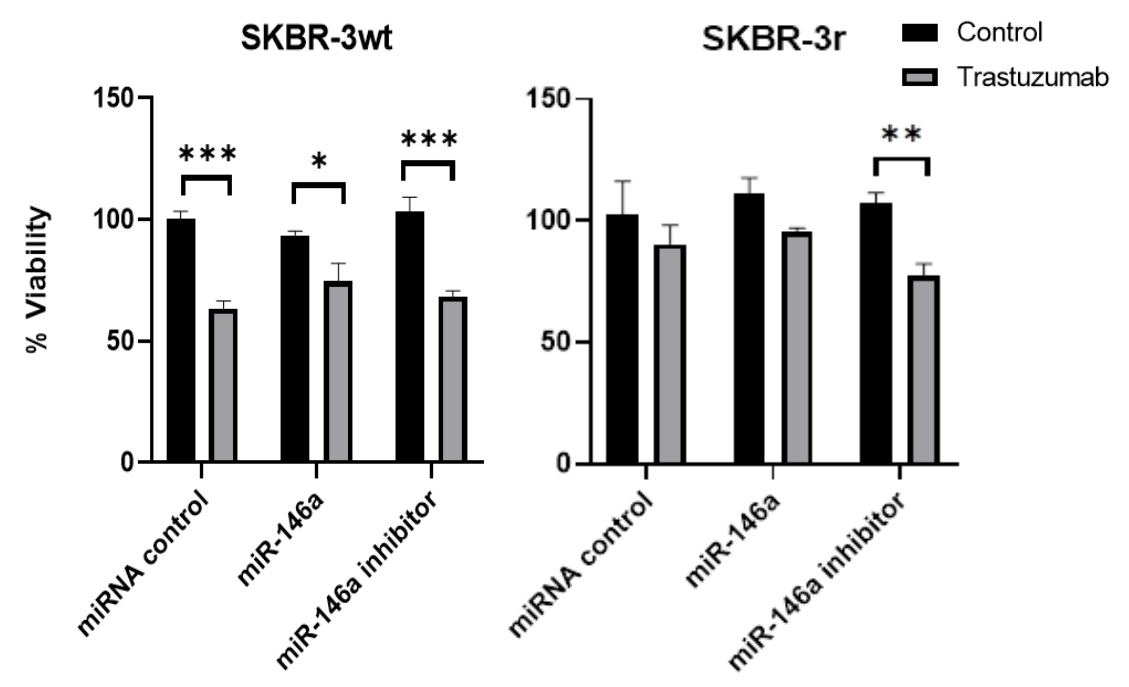

Figure 33. Measurement of viability by MTT in cell lines transfected with mimic and inhibitor of miR-146a-5p. Each cell line was transfected with 50nM mimic / inhibitor and treated with $15 \mu \mathrm{g} / \mathrm{ml}$ of trastuzumab for 7 days. Each experiment was performed in triplicate and was statistically analyzed with a T-Student test for comparison of means. Comparisons were made regarding the transfection control of each cell line (the condition transfected with the miRNA control for miRNA mimics and inhibitors). $(* \mathrm{p}<0.05 ; * * \mathrm{p}<0.01 ; * * \mathrm{p}<0.005)$.

When we transfected with a miRNA control (scramble) we were able to confirm the different effect of trastuzumab treatment over viability of SKBR-3wt (decreasing to $60 \%$ and being biologically sensitive to treatment) or SKBR-3r cell lines (decreasing only to $90 \%$ compared with untreated) (Figure 33). 
When transfecting the cells with miR-146a-5p mimic, we didn't observe any statistically significant change in viability under normal conditions (without treatment) compared to the transfection control without mimics (although viability slightly decreased compared to control cells without any transfection reagent, since they are toxic to the cells and therefore we used lipofectamine and a scramble miRNA in our control condition). When we added trastuzumab together with the miR-146a-5p mimic, the reduction in viability when treating the SKBR-3 wild type cell line became less evident with respect to the levels obtained only with treatment: decrease in viability was statistically significant but with less strength ( $p$-value $=0,014176$ ) and furthermore, the sensitivity to trastuzumab in the wild type cell line was much less biologically significant when transfected with miRNA146a mimic, although it didn't pass the $80 \%$ for being considered resistant.

When transfecting the cell lines with miR-146a-5p inhibitor, we did not observe any statistically significant change in viability under normal conditions (without treatment) compared to the transfection control with a scramble miRNA. However, when we also treated the cells with trastuzumab together with miR-146a inhibitor transfection, statistically significant differences in viability of SKBR-3r cell line were observed ( $p$-value $=0.001587$ ) with respect to normal trastuzumab treatment (without inhibitor). Furthermore, this viability decrease 
values were biologically significant (decreased to $73 \%$ ) compared to treatment in control transfection of SKBR-3r (decreased to 88\%).

In summary, a relevant impact on cell viability in SKBR-3r cell line was observed after the introduction of miR-146a-5p inhibitor in combination with trastuzumab respect to the same conditions of treatment with transfection of the miRNA control (Figure 33).

\subsubsection{Cell cycle}

After analyzing the effect of an increase or decrease of miRNA$146 a$ on cell viability, their possible interaction with gene targets was studied in order to clarify the possible mechanisms of action underlying the decreases and increases in resistance to trastuzumab. For this, we analysed genes described either as potential targets or as already tested targets of those miRNAs, obtained by the miRWalk2.0 bioinformatic software, which combines not only miRNA binding sites within the complete sequence of a gene, but it also analyzes this information along with the binding sites resulting from 12 miRNA gene prediction programs (DIANA-microTv4.0, Diana-microT-CDS, MiRanda, mirBridge, miRDB4.0, miRmap, miRNAMap, PicTar2, PITA, RNA22v2, RNAhybrid2.1 and Targetscan6.2).

One of the main interesting pathways among the targets described for miR-146a-5p was cell cycle. To determine if miR-146a-5p 
had an overall effect in cell cycle, we made seedings of 300.000 SKBR3 wt cells in a 6-well-plate. Cells were transfected with different conditions: $50 \mathrm{nM}$ of miRNA control, $50 \mathrm{nM}$ of miRNA-146a-5p mimic or $50 \mathrm{nM}$ of miR-146a-5p inhibitor. After $72 \mathrm{~h}$ of incubating the transfection, cells were pelleted, and cell cycle was measured by flow cytometry. Significant changes were observed in the distribution of cell cycle phases in wild type cell lines transfected with miR-146a-5p mimic. We could observe that miR-146a-5p overexpression decreased the proportion of phase $\mathrm{GO} / \mathrm{G} 1$, and increased phase $S$ and $\mathrm{G} 2 / \mathrm{M}$ statistically significantly when compared with miRNA control (Figure 34). The cells transfected with miR-146a-5p inhibitor showed similar cell cycle progression than the control condition ( $p$-value $>0.05$ ). 

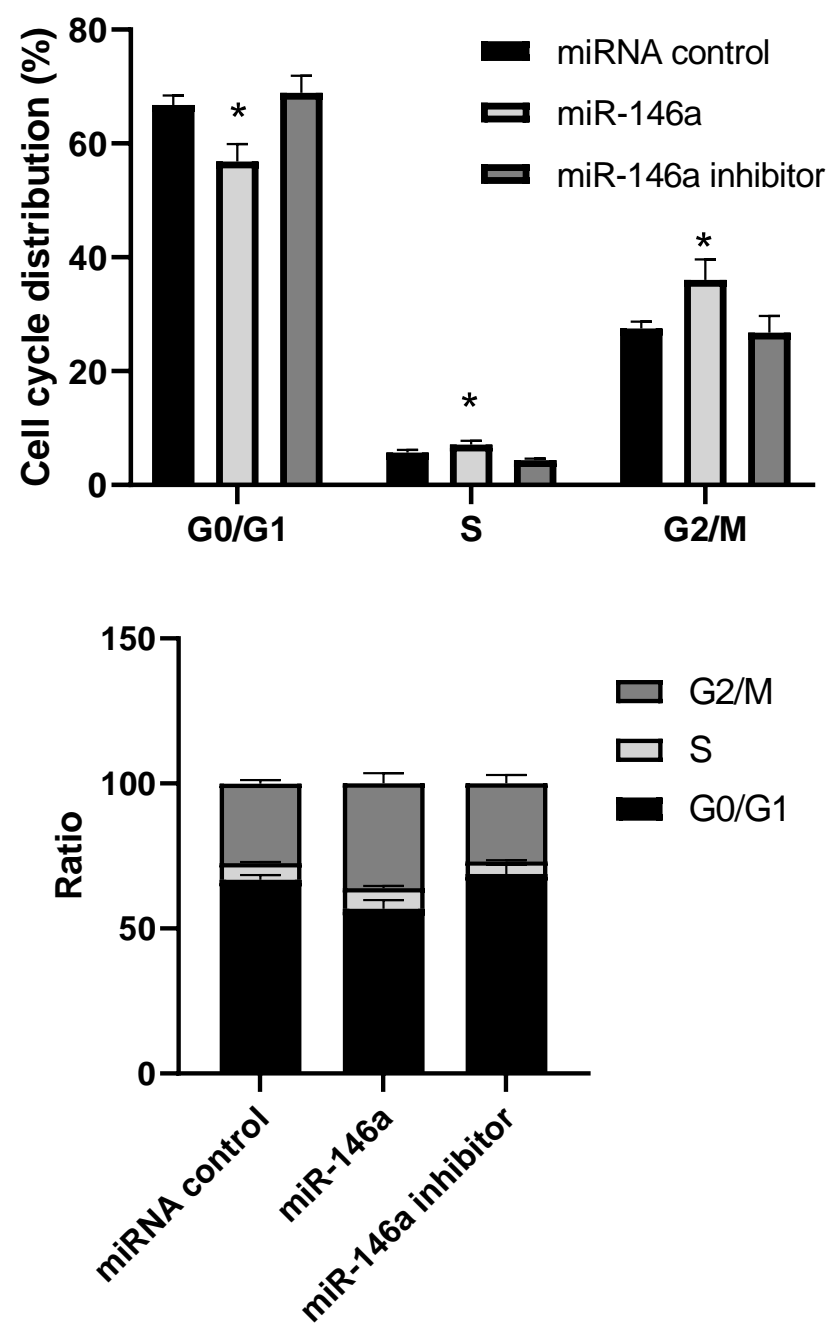

Figure 34. Cell cycle distribution of SKBR-3wt cells overexpressing miR-146a-5p, with an inhibitor or with its control. Cell cycle analysis was performed on SKBR-3wt cells using PI to stain DNA prior to flow cytometry. All experiments were repeated in triplicate. $(* p<0.05)$. 


\subsubsection{Gene targets}

After observing that miR-146a-5p had an effect in cell cycle, we measured the expression of CDKN1A gene as a miR-146a-5p target in cell cycle and CCNB1 as a downstream protein in the pathway. We made seedings of 300.000 SKBR-3wt cells in a 6-well-plate. Cells were transfected with different conditions: $50 \mathrm{nM}$ of miRNA control, $50 \mathrm{nM}$ of miRNA-146a-5p mimic or $50 \mathrm{nM}$ of miR-146a-5p inhibitor. After $48 \mathrm{~h}$ of incubating the transfection, cells were harvested, and gene expression was measured by real-time PCR. Significant changes were observed in the expression of the direct target CDKN1A comparing the control condition and the one transfected with miR-146a-5p mimic (Figure 35). We could observe that miR-146a-5p overexpression decreased significantly CDKN1A expression, showing a direct regulation ( $p$-value $<0.001$ ). The changes in CCNB1 expression after transfection of miR-146a-5p mimic were also statistically significant ( $p$ value $<0.001$ ), showing an increase compared to the control situation and thus suggesting an indirect regulation through CDKN1A. 


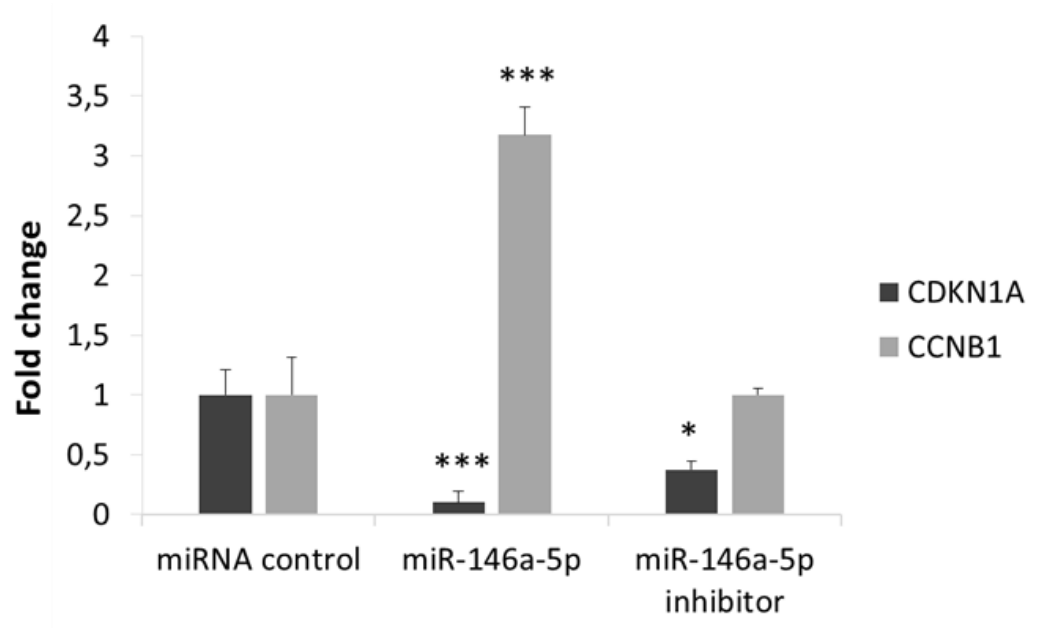

Figure 35. Gene expression by real time PCR of the miR-146a-5p target and pathway. For measuring expression, the $\Delta \Delta \mathrm{Ct}$ method was used. As endogenous mRNA, GAPDH was used; the expression of the mRNAs in a control situation was considered as standard. Differences in expression between sensitive and resistant cell lines were statistically analyzed using a T-student test for comparison of means. Each expression measurement was performed in triplicate.

\subsection{STUDY OF MIR-146A-5P IN EXOSOMES}

\subsubsection{Exosome characterization}

In order to study the possible transmission of resistance by miR$146 a-5 p$ through cells horizontally, we proceeded to examine its expression in exosomes. Exosomes from SKBR-3wt and SKBR-3r cell lines were extracted following the ultracentrifugation method. The 
presence of exosomes in the sample was confirmed by their visualization through electronic microscopy (Figure 36A) and checking some of their protein markers by western blot (Figure 36B).

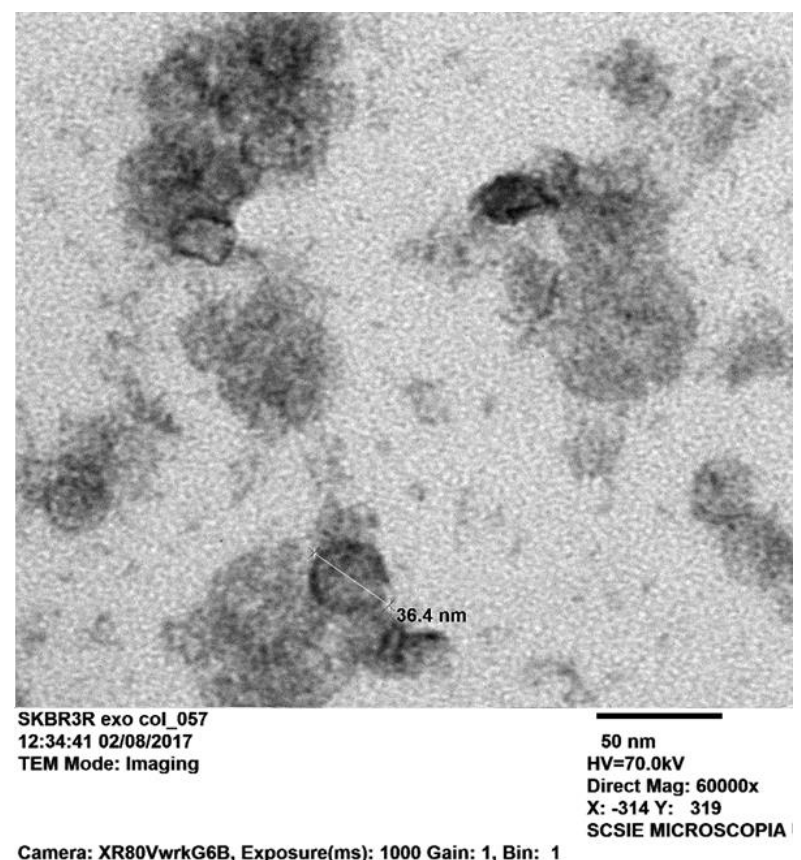
Gamma: 1.00, Level 1, Normal Contrast

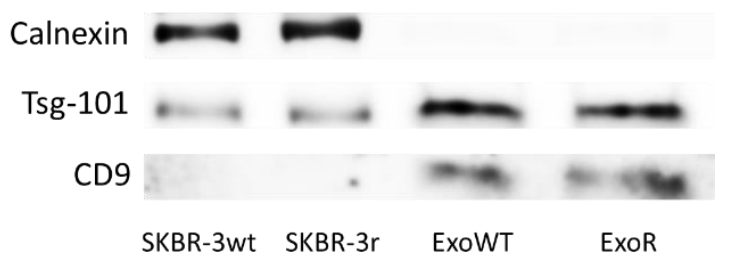

Figure 36. Characterization of exosomes obtained by ultracentrifugation. (A) Exosomes were observed and measured by transmission electronic microscopy after staining (microscope JEOL1010, 60000x). (B) Western blot was performed for measuring the presence of TSG-101 and CD9 typical from exosomes and the absence of calnexin as a cellular control. 


\subsection{2 miR-146a-5p expression}

miRNAs are one of the main content of exosomes. In order to evaluate the presence of miR-146a-5p in exosomes we extracted RNA from $2 \mu \mathrm{l}$ of the exosome samples by triplicate and real-time PCR for some microRNAs was performed. We measured the presence of the studied miR-146a-5p, miR-23b-3p and miR-26a-5p in exosomes from SKBR-3wt/r cell line and we observed that miR-23b-3p and miR-26a$5 p$ were not present in exosomes or not in detectable amounts (Figure 37A). However, miR-146a-5p was present in both exosome samples, being much more increased in exosomes from the resistant cell line ( $p$ value $<0.001)$. When we compared the relative expression by a new real-time PCR in SKBR-3wt/r cell lines and new exosome samples, we obtained the same results from exosomes and its relative expression compared to housekeeping miRNA miR-16a used as a control was also much higher than in cell lines (Figure 37B), showing that exosomes have an enrichment in miR-146a-5p when separating from the cell and the presence of miR-146a-5p in exosomes is very relevant compared to the cell line, especially in exosomes from resistant cell line. 

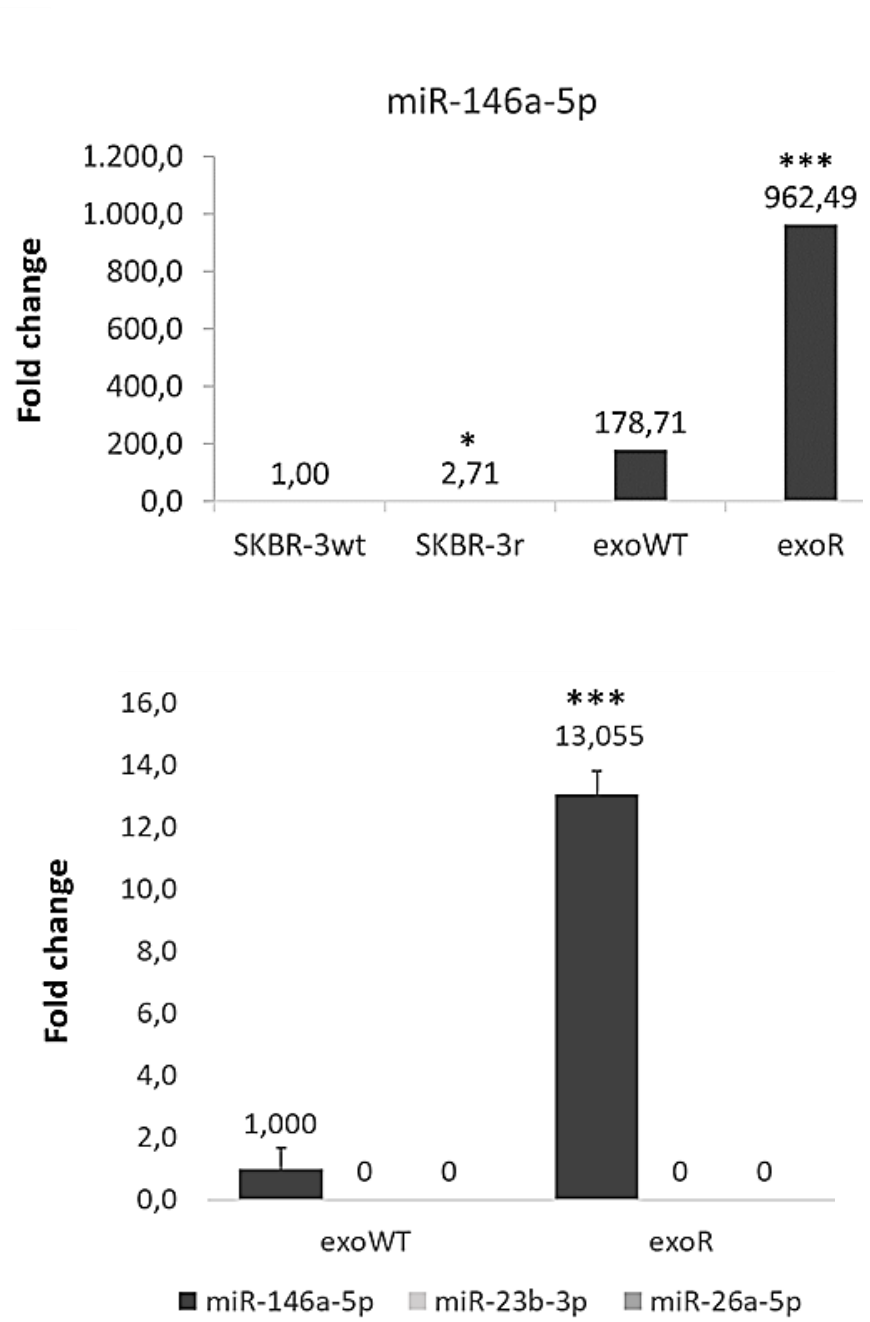

Figure 37. miRNA expression by real time PCR in exosomes and cell lines. For measuring expression, the $\Delta \Delta \mathrm{Ct}$ method was used. As endogenous miRNA, miR-16a was used; the expression of the mRNAs in a control situation was considered as standard. Differences in expression between sensitive and resistant cell lines were statistically analyzed using a T-student test for comparison of means. Each expression measurement was performed in triplicate. 


\subsection{FUNCTIONAL ASSAYS WITH EXOSOMES}

After seeing the high presence of miR-146a-5p in exosomes from resistant cell line SKBR-3r, we proceeded to perform some functional assays with them to check if the co-culture of exosomes with other cell lines could induce some change in the cells or transmit the resistance to trastuzumab.

For these assays, exosomes were isolated from SKBR-3wt and SKBR-3r cells by ultracentrifugation method and had to be filtered with $0.22 \mu \mathrm{m}$ filters in order to guarantee the sterility of the culture.

\subsubsection{Cell viability}

The viability of the SKBR-3wt cell line was studied under normal conditions (Control) and in the presence of treatment (Trastuzumab) when coculturing when exosomes from SKBR-3r cell line or conditioned media collected from SKBR-3r culture. In 96-well plates 5,000 SKBR-3wt cells per well were seeded and treated with trastuzumab alone at $15 \mu \mathrm{g} / \mathrm{ml}$, condition media alone, trastuzumab with condition media, exosomes alone or exosomes with trastuzumab. Treatment was maintained for 7 days as stablished for evaluating sensitivity to trastuzumab and then viability was measured by MTT. In the case of the coculture with condition media, the viability when treating with trastuzumab $(p=0.14)$ increased with respect to the 
control treatment $(p=0.003)$, showing less sensitivity to trastuzumab in the sensitive cell line and reversing partially the resistance (Figure 38). In the case of coculture with exosomes from SKBR-3r cell line, treatment with trastuzumab showed less effect in SKBR-3wt than without exosomes and the increase in viability was statistically significant $(p=0.013)$.

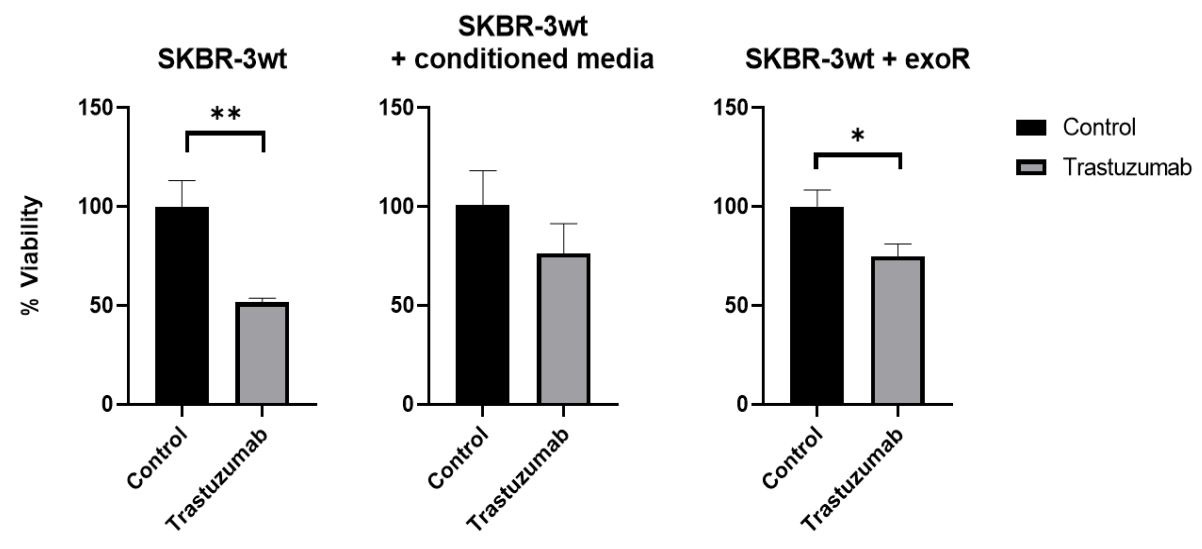

Figure 38. Measurement of viability by MTT in SKBR-3wt cell line with co-culture of conditioned media or exosomes. SKBR-3wt cell line was treated with a $50 \%$ of condition media or exosomes from SKBR-3r cell line with or without $15 \mu \mathrm{g} / \mathrm{ml}$ trastuzumab treatment for 7 days. Each experiment was performed in triplicate and was statistically analyzed with a T-Student test for comparison of means. Comparisons were made regarding the control of each condition. $\left({ }^{*} p<0.05 ;{ }^{* *} p<0.01 ; * * *<0.001\right)$. 
In order to check whether the effect from exosomes from SKBR$3 r$ cell line in the sensitivity to trastuzumab of SKBR-3wt cell line was mediated by miR-146a-5p, we did the same experiment but adding a condition where miR-146a-5p was inhibited in SKBR-3wt by transfection after the co-culture with SKBR-3r exosomes. MTT viability results show that while SKBR-3r exosomes could reduce sensitivity to trastuzumab in SKBR-3wt cell line (77\% of viability), trastuzumab sensitivity was partially reverted when inhibiting miR-146a-5p in the same condition (62\% of viability). In the case of combining exosomes with miR-146a-5p inhibitor, treatment with trastuzumab showed a significant decrease in viability (62\% of viability) ( $p$-value $=0.00548$ ) almost reaching the significance showed in the original SKBR-3wt treatment with trastuzumab ( $56 \%$ of viability) ( $p$-value $=0.00043$ ), while treatment with only co-culture of exosomes showed a less significant difference (77\% of viability) ( $p$-value $=0.0445)$ (Figure 39$)$. These results show that co-culture with exosomes needs miR-146a-5p in order to increase resistance in sensitive cell lines more significantly. Of note, it would be interesting to know if miR-146 contained in exosomes alone would be enough to induce these changes. 


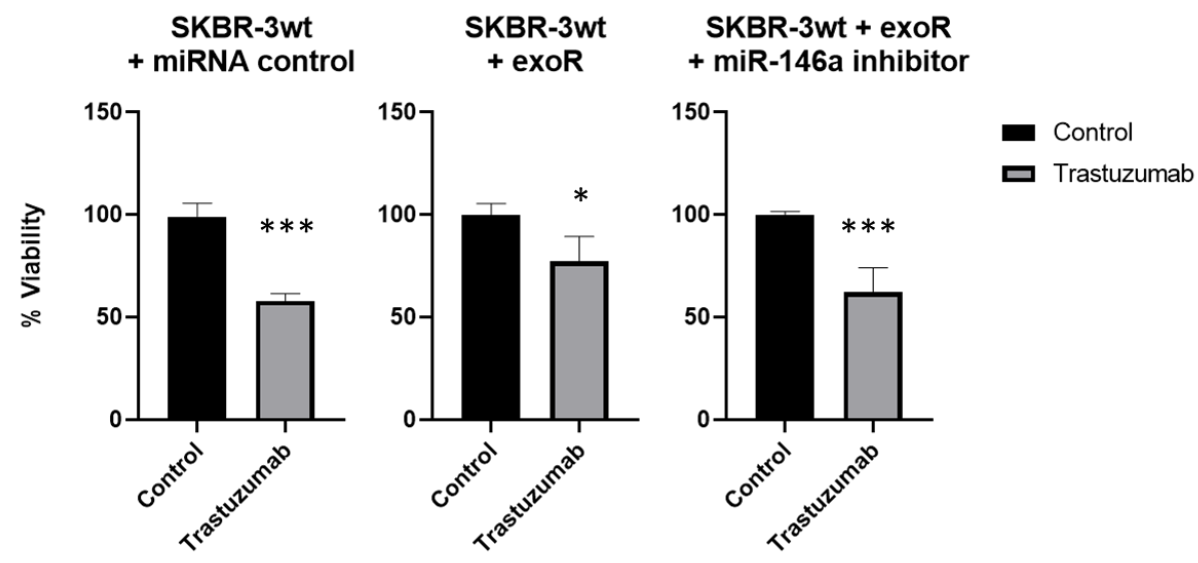

Figure 39. Measurement of viability by MTT in SKBR-3wt cell line with co-culture of exosomes and inhibition of miR-146a. SKBR-3wt cell line was treated with a $50 \%$ of condition media or exosomes from SKBR-3r cell line, or the combination of exosomes from SKBR-3r and miR-146a-5p inhibitor transfected at $50 \mathrm{nM}$, with or without 15 $\mu \mathrm{g} / \mathrm{ml}$ trastuzumab treatment for 7 days. Each experiment was performed in triplicate and was statistically analyzed with a T-Student test for comparison of means. Comparisons were made regarding the control of each condition. $\left({ }^{*} p<0.05 ;{ }^{* *} p<0.01\right.$; $* * * p<0.001)$.

\subsubsection{EMT regulation}

Epithelial to mesenchymal transition of the SKBR-3wt cell line was studied after co-culture with SKBR-3r exosomes. In 12-well plates 30,000 SKBR-3wt cells per well were seeded and co-cultured with exosomes of the resistant cell line or PBS as a vehicle, in triplicate. Treatment was maintained for 72 hours and cells were harvested for 
RNA extraction. EMT markers expression was measured by $\mathrm{qPCR}$ and we could see a significant increase in vimentin (mesenchymal marker) when co-culturing with exosomes (Figure 40) and a decrease of $\beta$ catenin (epithelial marker) with the co-culture, although the change was not significant ( $p$-value $>0.05$ ). Fibronectin expression did not change in presence of SKBR-3r exosomes and $\mathrm{N}$-cadherin could not be detected. This results altogether show that exosomes from SKBR-3r could induce slightly EMT in SKBR-3wt in $72 \mathrm{~h}$ of co-culture.

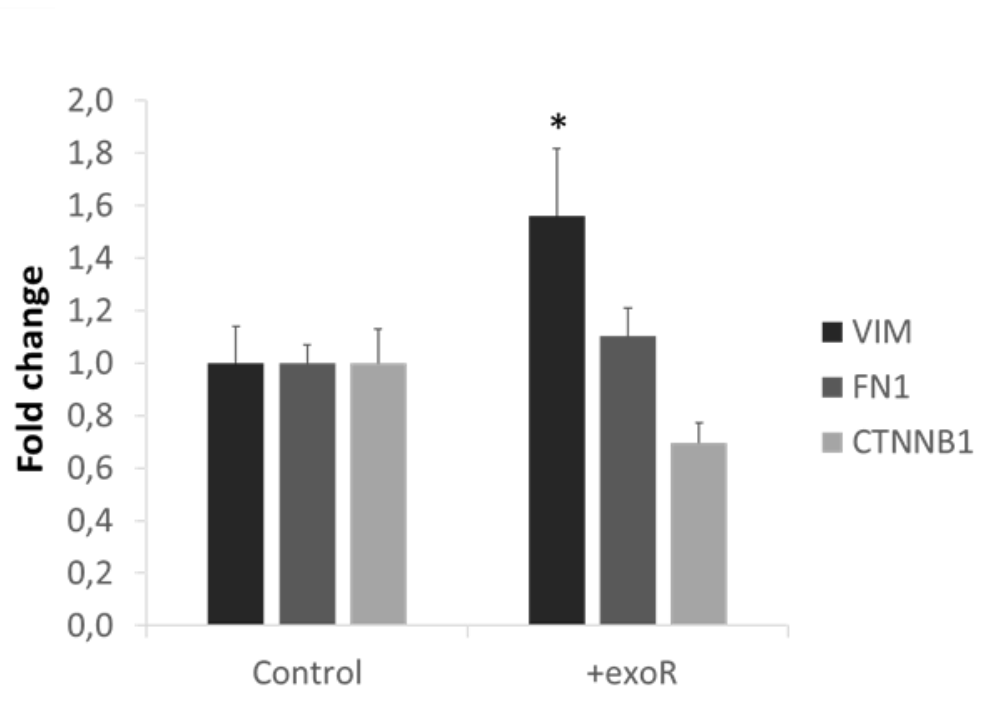

Figure 40. EMT markers expression by real time PCR after co-culture with exosomes. For measuring expression, the $\Delta \Delta \mathrm{Ct}$ method was used. As endogenous mRNA, GAPDH was used; the expression of the mRNAs in a control situation was considered as standard. Differences in expression between control and treated cells were statistically analysed using a T-student test for comparison of means. Each expression measurement was performed in triplicate. 


\subsubsection{Wound healing assay}

After observing some changes in epithelial to mesenchymal transition genes, we studied if exosomes could also induce changes in cell migration. For this, we performed a wound healing assay seeding SKBR-3wt or SKBR-3r cells into. Then, exosomes were added to media of some SKBR-3wt just after realising the wound. We took pictures $48 \mathrm{~h}$ after the creation of the wound and we analysed them by Image $J$ to measure the areas without cells. Co-culturing SKBR-3wt cells with exosomes from resistant cells SKBR-3r increased migration, as shown by faster gap-closing at $48 \mathrm{~h}$ compared to non-treated cells (Figure 41 ) reaching levels of migration of SKBR-3r.

A

SKBR-3r

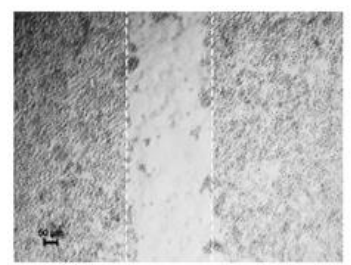

$48 \mathrm{~h}$

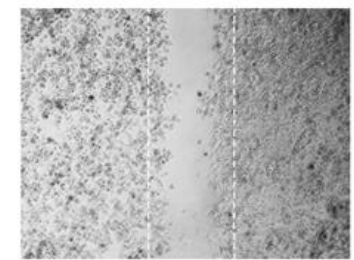

SKBR-3wt
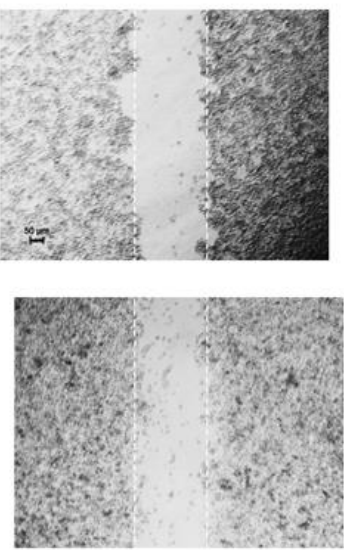

SKBR-3wt + exoR
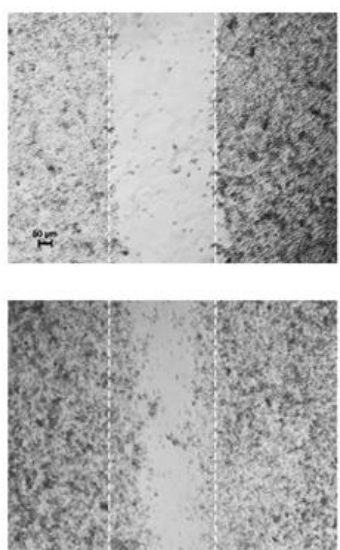
B

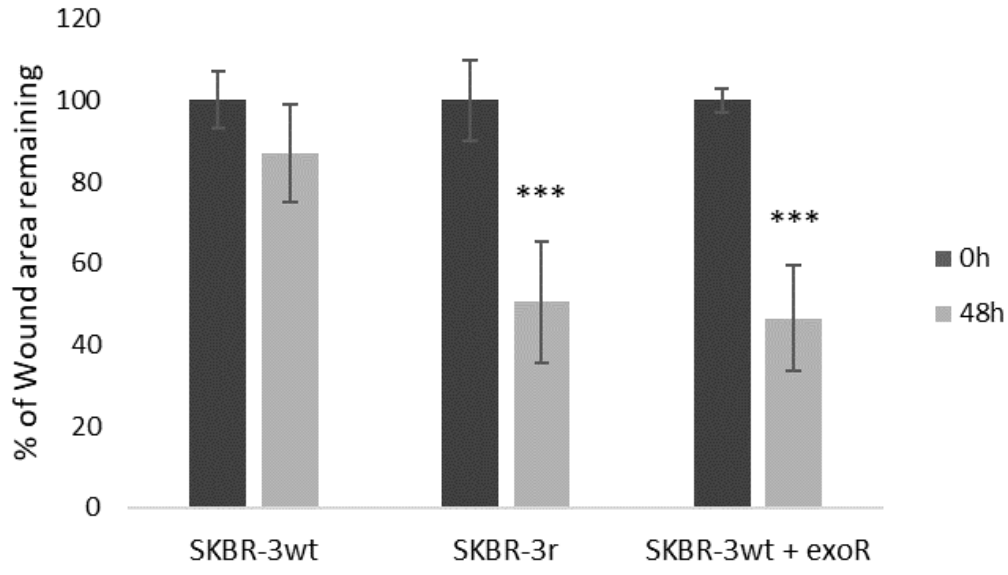

Figure 41. (A) Wound healing cell migration assay comparing exosome-treated SKBR-3wt cells with non-treated and SKBR-3r at $48 \mathrm{~h}$. (magnification 100x). (B) Quantification of the remaining area of the wound at $0 \mathrm{~h}$ and $48 \mathrm{~h}$.

\subsubsection{Angiogenesis assay}

We also studied the effect of exosomes derived from sensitive and resistant SKBR-3 cells in tube formation when co-cultured with HUVEC cells. For that, we performed an angiogenesis assay and checked the results at $8 \mathrm{~h}$ counting node formation and measuring relative tubular length. Results showed that exosomes increased in both cases angiogenesis significantly, showing its importance in cell to cell communication in cancer, in both sensitive and resistant cell lines compared to the control HUVEC with normal media, although increasement was higher with the exosomes from the resistant cell lines (Figure 42). 


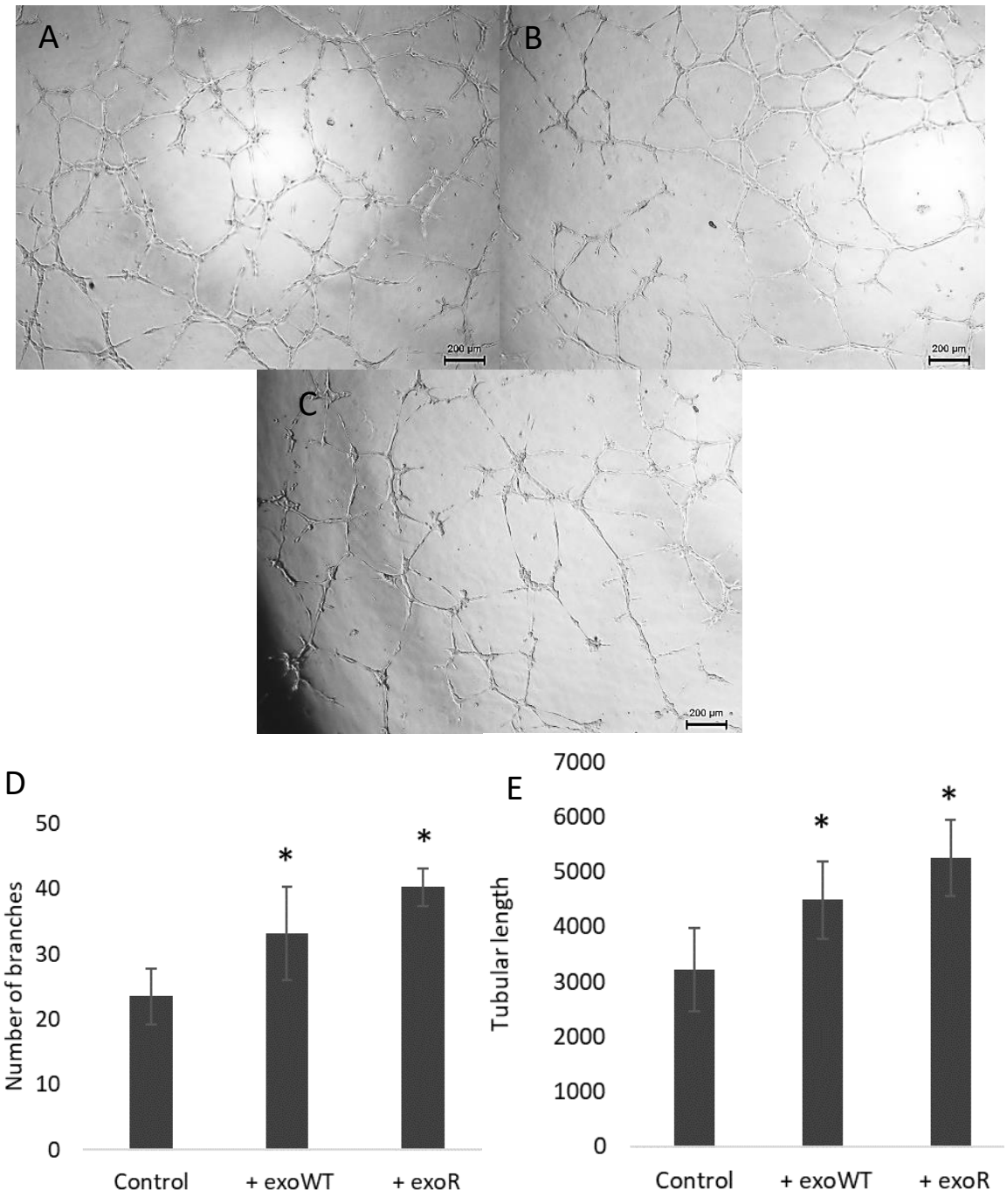

Figure 42. In vitro Matrigel angiogenesis assay measured at $8 \mathrm{~h}$ after seeding of HUVEC and adding of exosomes from sensitive and resistant cell lines. (A) Pictures taken with $5 x$ microscope of samples Control, +exoWT (B) and + exoR (C). (D) Representations of the number of branching points and $(E)$ the relative tubular length. Statistical significance was measured respect to control (Student T Test: ${ }^{*} p<0,05$ ). 
DISCUSSION 



\section{MetFormin}

Triple negative breast cancer is characterized by low expression or absence of estrogen receptor (ER), progesterone receptor (PGR), and receptor for human epidermal growth factor 2 (HER2) [203]. It currently represents a minority (15\%) of all breast cancers. However, despite its low prevalence, this form of cancer is now one of the most important targets of cancer research due to its highly aggressive and metastatic nature, and because it has a worse prognosis [204] than the other breast cancer subtypes [205]. This is mainly due to the lack of specific molecular targets [206], which means that conventional chemotherapy is the main treatment for these patients.

Evidence for the implication of miRNAs in cancer processes has been growing over the last decade, and many miRNAs have been described as being deregulated in cancer [207]. Consequently, investigation focusing on these small RNAs has increasingly focused on their therapeutic uses. Hence, several strategies have been designed based on miRNA inhibition or enhancement by ectopic expression [208].

We focused on miR-26a because it has been described to play an important role in several cancers, including hepatocellular carcinoma and lung and breast cancer [209][210][211][212]. Furthermore, some authors suggest that metformin, already used to treat diabetes, may 
modulate the expression of miR-26a. This miRNA is reported to be a tumour suppressor [209][210][213] whose increase leads to better outcomes in tamoxifen-treated breast cancer metastasis patients [214]. However, in lung cancer elevated miR-26a levels have been related to higher levels of tumour cell migration and invasion [211]. Low levels of miR-26a have been associated with TNBC [212] and with stimulating proliferation in ER+ breast cancer [215], and miR-26a expression levels have been associated with lymph node metastases in breast [212] and lung cancer [211]. Here we aimed to elucidate the role of miR-26a in modulating TNBC and ER+ breast cancer cell viability. Furthermore, we evaluated some of its targets, and finally, we assayed the effect of metformin on miR-26a and these targets.

The use of drugs already on the market for new medical applications significantly streamlines their incorporation into the clinical armamentarium. Therefore, compounds already approved for certain treatments are being re-evaluated to discover their mechanisms of action and to search for possible new therapeutic applications. Metformin, a compound approved for treating type II diabetes, is being evaluated in cancer with the rationale that the incidence of breast cancer is decreased in diabetic patients [141][216] and the risk of metastasis and death by cancer is reduced in breast cancer patients treated with this drug [217][218][219].

The molecular mechanisms of metformin in diabetes control are not completely understood; activation of AMP-activated protein 
kinase (AMPK), inhibition of the mitochondrial respiratory chain (complex I) and mitochondrial glycerol-3-phosphate dehydrogenase, and a reduction in protein kinase $A$ (PKA) activation have all been proposed as potential mechanisms [220]. The mechanisms by which metformin affects cancers are also unknown, although a large number of publications have shown that metformin could exert its antitumor effect by targeting AMPK/mTOR, anti-inflammatory, cell cycle/apoptosis, insulin/IGF-1R, and angiogenesis pathways in cancers [221][222][223][224]. It has also been shown that it can inactivate cells similar to breast cancer stem cells [225], also in triple negative breast cancer [226]. Specially, for triple negative breast cancer, it has been shown that metformin is able to reverse resistance to cisplatin [227], and increase sensitivity to PARP inhibitors [228] and pro-apoptotic TRAIL receptor agonists [229] in combination. It has been recently published that the mechanism for metformin in triple negative breast cancer involves targeting glucose metabolism [230], and this could be the reason why metformin is specially effective and toxic to this subtype of breast cancer, since TNBC is highly dependent on glucose (metabolized by anaerobic glycolysis) and lipids and its mitochondrial respiration is deficient [231].

For our experiments with triple negative cancer cells in culture, selected concentration that could kill half of the population (IC50) was $10 \mathrm{mM}$ of metformin. It has been observed that most of in vitro assays use very high concentrations of metformin ( $>5 \mathrm{mM}$ ) to achieve its 
apoptotic effect in cancer cells compared with the concentrations used usually for diabetic patients, who reach levels of $10 \mu \mathrm{M}$ of metformin in plasma. This huge difference in metformin concentration has been shown to be due to the high glucose present in the media for cell culture conditions, that seems to repress metformin anti-cancer effect [232][233]. This also explains why metformin seems more effective in TNBC in vitro than in diabetic patients with triple negative breast cancer who receive metformin for diabetes treatment, where the metastases is reduced but the anti-proliferative effects of metformin are less significant than expected [218], as they are receiving less metformin dosage in plasma and have hyperglycaemia. Reducing glucose levels in combination with metformin could increase its effect for breast cancer even in a lower dose.

Metformin has potent growth-inhibitory and proapoptotic effects in pancreatic cancer [234], and several authors suggest that its biological effects are mediated through miRNA expression [234][235]. Some authors believe that metformin inhibits proliferation by upregulating miR-26a expression which consequently downregulates the targets of this miRNA [236]. Yang et al. [236] first described the involvement of miR-26a and its targets in the metformin mechanism of antitumor action in renal cancer.

Our results confirmed previous data [209] in which miR-26a overexpression reduced cell viability, which was rescued with a miR$26 a$ inhibitor to reverse the effect of the mimetic. Although this effect 
was slight, it reinforces the potential importance of miR-26a in cell viability/apoptosis processes in breast cancer. We detected a bigger reduction in cell viability in MCF-7 (luminal/ER+) cells than in the MDAMB-468 and MDA-MB-231 (TNBC) cell lines. After evaluating miR-26a expression in different mammary cell line subtypes, one group reported that this miRNA is highly expressed in non-cancerous mammary cell lines but at lower levels in some breast cancer cell lines, in particular TNBC cells [212]. Differences in miR-26a expression in distinct breast cancer subtypes may also lead to different effects when it is exogenously overexpressed or downregulated. Similarly, other authors showed that miR-26a expression is higher in ER+ breast cancer [212]. In contrast with its effect on cell viability, miR-26 has been identified as a key mediator of estrogen-stimulated cell proliferation in ER+ breast cancer cells [215]. Furthermore, miR-26a seems to be strongly implicated in regulating ER+ breast cancer. Chen et al. [210] showed that miR-26a significantly downregulates $E R \alpha$ and prevents the stimulation of hepatoma cell growth by E2. Moreover, in MCF-7 cells, transient transfection of miR-26a initiates apoptosis [213].

Using bioinformatics tools, we selected some theoretical miR-26a targets based on their relevance in cancer and their implication in viability/apoptosis processes (in which we and others have found miR$26 \mathrm{a}$ to be involved). Interestingly, PTEN and E2F3 were downregulated after transfection with the miR-26a mimetic; PTEN is one of the most commonly mutated tumour suppressors in cancer and 
has been shown to negatively regulate the AKT/PKB signalling pathway, favouring tumour development and progression. Our data agree with studies showing that PTEN is a miR-26a target in glioma [237][238] and in lung cancer [211]; we also showed that PTEN is downregulated at the protein level in breast cancer cells overexpressing miR-26a.

The evaluation of metformin cellular effects reveals, according to other authors in kidney, pancreas and renal cancer [235][236], that the drug reduces cell viability in a dose-dependent manner in the breast cancer cell line MDA-MB-231 and that its administration increases miR-26a and reduces $B C L-2$ and PTEN expression. However, although the beneficial effects of metformin on breast cancer patient survival rates has been described by several authors [217][218][219][239][240][241][242] little is known about the mechanism. We show here that metformin up-regulated miR-26a and also downregulated its direct target PTEN. It is difficult to explain how metformin can have an anti-proliferative effect since PTEN is a tumour suppressor gene. Trying to understand how the PTEN inhibition by miR-26a can result in an anti-proliferative effect, we checked the effect of miR-26a overexpression in some additional targets of this miRNA. We identified $E Z H 2$, a miR-26a target that is downregulated by the miRNA and by metformin. $E Z H 2$ is a bona fide oncogene and acts as a dual function transcription regulator (not only repressor but also activator) [243] by converging on the methyltransferase-activity 
silencing tumour suppressor genes, which are implicated in neoplastic development and the transactivation property-activating genes involved in the late-stage process of cancer [244][245]. This gene has been implicated in promoting anchorage-independent growth and invasion of immortalized human mammary epithelial cells [213]. Retrospective studies from clinical breast cancer patients indicate that high expression of $E Z H 2$ is associated with short survival [246]. Therefore, it can be one of the effectors involved in the decrease in cell viability after treatment with metformin and overexpression of miR-26a and thus justify their anti-proliferative effect.

When studying cell migration, we observed slightly increased migration in the TNBC-model MDA-MB-231 cell line when the cells were treated with either a miR-26a mimetic or metformin. Our data are consistent with observations about the different behaviour of breast cancer subtypes when miR-26a was upregulated. Boning Liu et al. [211] demonstrated that miR-26a increases lung cancer cell migration and the risk of metastasis by modulating activation of the AKT pathway by suppressing PTEN, data which agrees with our results in MDA-MB-231 cells. PTEN loss promotes cell migration in cancer cells, as previously described in breast cancer [247][248][249]. Simultaneous downregulation of PTEN and DLC1 in MCF-7 cells does not enhance cell proliferation, however, enhances cell migration [247]. DLC1 is negatively regulated by miRNAs in colorectal cancer 
[250][251], however, the possible $D L C 1$ regulation by miR-26a has not been evaluated.

We believe that PTEN inhibition by metformin via miR-26a could explain the increased cell migration under the treatment, but the metformin antitumor activity must be due to other miR-26a targets. We checked the gene expression levels of MCL-1, MTDH, and $E Z H 2$ which are proven targets of miR-26a in breast cancer and could be responsible of its anti-proliferative effect. We observed that $E Z H 2$ expression under metformin treatment was also lower than in non-treated cells, suggesting that metformin antitumor effect could involve this gene [209][213]. We also checked EZH2 expression under metformin treatment when transfecting miR-26a inhibitor and their levels were partially rescued, suggesting not only that metformin antitumor effect can be through this gene, but also that it happens via miR-26a overexpression.

Furthermore, we have verified that it not only alters miR-26a levels but, curiously, also those of miR-146a, and that it affects the $E Z H 2$ and $M T D H$ targets also in HER2 + breast cancer (data not shown).

By performing bioinformatic database studies, we have also found that the miR-23b we studied with trastuzumab is statistically significantly altered in studies treating breast cancer cells with metformin, so that the metformin pathway could be complex regulating various microRNAs. 
In these experiments altogether, we have confirmed the antiproliferative effect of metformin in breast cancer. Our results suggest that upregulation of miR-26a and following downregulation of some of their miRNA-target genes are part of the action mechanisms of this drug. miR-26a is at least partially responsible for the metformin antineoplastic effect in breast cancer. These is especially relevant in triple negative breast cancer disease, where there is no treatment other than chemotherapy, and this drug that is already approved and used for diabetes type II could result in a real improvement in treating the disease.

Results of metformin experiments involving miR-26a are already published [252] and the article is included in Annex II. 


\section{TRASTUZUMAB}

HER2-positive breast tumours make up between $15-20 \%$ of diagnosed breast tumours. Initially, what constituted an aggressive entity with high mortality has become an entity with a favourable prognosis and an important 5-year disease-free survival thanks to the incorporation of anti-HER2 therapies into clinical practice, initially with trastuzumab and, subsequently, with the incorporation of new drugs. However, there are still $25 \%$ of HER2 positive patients treated with trastuzumab that do not respond to treatment due to the presence of resistance mechanisms present in the primary tumour or the acquisition of new molecular alterations that limit the action to treatment [253][254].

Trastuzumab is a monoclonal antibody agonist to receptor HER2 whose main role is to block this receptor activity, having a mostly antiproliferative effect [255]. The concentration of trastuzumab for treatment in cell culture was established at $15 \mu \mathrm{g} / \mathrm{ml}$ according to the Dr. Rojo's group that had developed the acquired resistant cell line models that we have used for this study [197]. This concentration is equivalent to the one detected in plasma from patients treated with the drug in preclinical trials [255][256][257], and matches also the concentration stablished for the first cellular model of trastuzumab resistance ever developed [258]. 
In order to evaluate the microRNAs involved in the mechanisms of resistance of our HER2+ breast cancer cellular model of trastuzumab resistance, we performed a microarray of microRNAs (GeneChip ${ }^{\mathrm{TM}}$ miRNA 4.0 Array from Affymetrix) with two HER2+ cell lines sensitive to trastuzumab (SKBR-3 and BT-474) and their acquired resistance models (SKBR-3r and BT-474r) [197], compared to an innate trastuzumab-resistant HER2 + cell line (HCC1954) and a triple negative breast cancer cell line as a control (MDA-MB-231).

Our main objective was to study the expression profiles of microRNAs (miRNAs) due to the fact that dysregulation of these small non-coding RNA molecules has been described to be common in many types of human cancer; because it regulates key transcripts that participate both in the initiation and progression of tumours. miRNAs can act either as oncogenes or as tumour suppressors, to inhibit or exacerbate the expression of target genes related to cancer, as well as to promote or suppress tumorigenesis [259][260]. They have been also previously described in drug generation in some cancer types [261][262], and so we believe they may be also implied in our acquired trastuzumab resistance, since differences in gene expression between the sensitive and resistant cell lines had been studied [263], but not its microRNAs.

One of the most notable microRNAs that was overexpressed in BT-474r cell line compared to BT-474wt was miR-23b-3p. This microRNA had been studied before in different types of cancer and 
had been previously demonstrated by 3'UTR reporter assays that has PTEN as a direct target in order to repress its expression [264]. We checked the effect of overexpressed miR-23b-3p in METABRIC patients' data, and HER2+ patients with higher expression of miR-23b$3 p$ showed worse OS than patients with lower levels. However, we were unable to see the same results in our patients' samples, but maybe due to the low cohort studied, so further analysis with higher number of patients must be done. We then overexpressed miR-23b$3 p$ by transitorily transfecting microRNA mimics and we could check by $\mathrm{qPCR}$ and Western Blot the resulting inhibition of PTEN. Knockdown of PTEN is a well-known mechanism of resistance to trastuzumab in HER2+ breast cancer [110][109][111][112] and so, we hypothesize that this inhibition of PTEN mediated by microRNAs, including its partial repression also by miR-23b-3p, is likely to be the mechanism of acquired resistance to trastuzumab developed by our BT-474r cell line after overexposure to the drug.

Among the other dysregulated microRNAs from the array, we also found that miR-146a-5p was overexpressed in all resistant cell lines compared to the sensitive, thus we thought it could be able to induce or modulate resistance in HER2+ breast cancer cells. We checked in different experiments that overexpressing miR-146a-5p into SKBR-3wt cells was able to slightly reduce its sensitivity to trastuzumab, although transfection with the inhibitor of this microRNA had no effect. However, when the SKBR-3r cell line was transfected with the 
inhibitor, it became more sensitive to trastuzumab. These results made us think that this microRNA was indeed modulating resistance and that repressing it could be an interesting way to turn resistant cells again into sensitive, suggesting a combination of trastuzumab with miR-146a-5p inhibitor as a possible therapy.

When studying the targets of miR-146a-5p looking for a possible mechanism of resistance generation, we observed that one of the main pathways affected by dysregulation of miR-146a-5p were genes involved in cell cycle. This microRNA had been previously described as well to be involved in cell cycle alterations through its effect on CCND1 (cyclin D1) [265].

We then checked cell cycle by flow cytometry and could observe a significant increase in $\mathrm{S}$ and $\mathrm{G} 2 / \mathrm{M}$ phases when overexpressing miR$146 a-5 p$ by transfection and a decrease of G1 phase. Therefore, we hypothesized that miR-146a enhanced growth and resistance of BT$474 r$ and SKBR-3r by promoting cell cycle progression at the G1-to-Sphase transition. This premise was consistent with our hypothesis of resistance and malignancy caused by miR-146a-5p, but other studies of miR-146a-5p showed opposite: Yan-Li li had described that the implication of miR-146a-5p in non-small cell lung cancer was by arresting cell cycle and proliferation through inhibition of cyclin D1 [265]. However, another more recent paper in cervical cancer by Qiming Hu observes that the relation between miR-146a-5p and cyclin D1 is indeed the opposite way, by miR-146a-5p increasing levels of 
cyclin D1 and so increasing phase $\mathrm{S}$, and they explain that this different function of miR-146a-5p may be because its oncogenic/suppressor role is dependent on the cell type [266].

This new results about miR-146a-5p are however also very consistent with our observation of an increase of phase $\mathrm{S}$. We looked for more miR-146a-5p theoretical gene targets involved in cell cycle apart from cyclin D1 and we analysed CCNB1 and CDKN1A, as they both appeared described as theoretical miR-146a-5p targets. CDKN1A encodes for p21, a protein that directly inhibits the cyclinA:CDK2 complex activity but also inhibits MPF kinase (cyclin B1/CCNB1:CDK1) indirectly [267]. Our results show that CDKN1A acts as a direct target of miR-146a-5p as we see a significant inhibition when we overexpress the microRNA. However, the oncogene CCNB1 shows a strong increasement with overexpression of miR-146a-5p, possibly induced by the reduction of its regulator inhibitor p21 (CDKN1A). p21 is the protein regulating cell cycle checkpoints such as G1 arrest and G2 arrest. We hypothesised that lower levels of p21 in resistant cell lines by knock-down of CDKN1A mediated through miR-146a-5p is avoiding cell cycle arrest in $G 1$ and $G 2$, thus increasing phases $S$ and $M$ as we could see in our results. This decreasing of p21 is strongly increasing levels of cyclin B1, which promotes cell cycle progression and malignancy of resistant cell lines, avoiding apoptosis and generating genomic instability (Figure 43). 


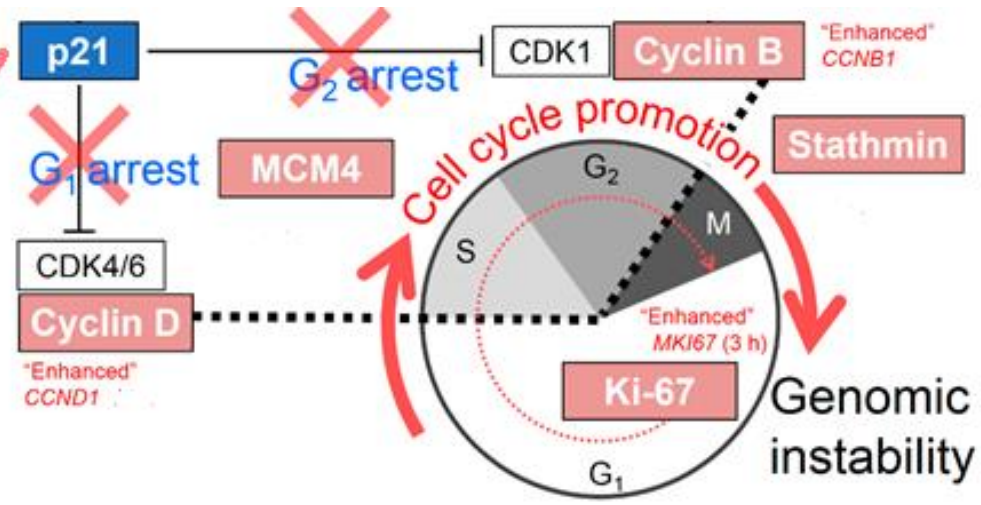

Figure 43. Schematic representation of the cell cycle pathway affected by miR-146a5p. (Adapted from Hiroko Ikeda et al., "Expression Profile of Cell Cycle-Related Genes in Human Fibroblasts Exposed Simultaneously to Radiation and Simulated Microgravity", Int. J. Mol. Sci. 2019, 20(19), 4791; https://doi.org/10.3390/ijms20194791).

Exosomes and other extracellular vesicles have been proved to be a potential mechanism to transmit drug resistance cell to cell horizontally [268][269][270][271][272]. This way, eukaryote human cells could be able to transmit genetic information not only vertically in their mitosis but also horizontally, including protection against drugs for cancer which leads to resistance to treatment for survival of the cell, the same way bacteria do with resistances to antibiotics. This genetic material, instead of being DNA plasmids as in bacteria, are usually RNAs that can be carried inside the exosomes and released into another cancer cell [273]. One of the most common RNA types 
observed to be involved in this resistance transmission via exosomes are microRNAs, described to increase many resistances to different chemotherapy drugs in breast cancer and other cancer types in this way [274][275][276][277][278][279][280].

When it comes to resistance to trastuzumab, exosomes from HER2+ cells were previously described to express HER2 receptor in their membranes and bind to trastuzumab molecules, thus being able to modulate sensitivity to the treatment and tumour aggressiveness [281]. About the specific topic of exosomes being able to transmit resistance to trastuzumab cell to cell, there was only one recent study made parallelly to this $\mathrm{PhD}$ project in 2018 that demonstrated that resistance could be disseminated through exosome communication involving an RNA, in this case a long non-coding RNA [282]. Recently this year, another paper about another long non-coding RNA promoting resistance to trastuzumab through exosomes has been released [283], and also the first paper to involve a microRNA in the modulation of resistance to trastuzumab transmitted by exosomes, reversing it in this case [284].

Following those many papers relating microRNAs transferred by exosomes as modulators of resistance to chemotherapy in breast cancer and the arise of studies relating them to resistance to trastuzumab, we think our hypothesis that resistance in our cell lines may be transmitted through exosomes involving some microRNAs is a good point to prove. Our assays with conditioned media and exosomes 
from SKBR-3r showed that resistance to trastuzumab in SKBR-3wt cell line could be partially induced. We wanted to check if this phenomenon had something to do also with microRNAs, as seen in the literature. Among the interesting microRNAs from our array, miR$146 a-5 p$ had been previously described to be present in exosomes, having a relevant role in several diseases such as sepsis [285], myasthenia gravis [286], EV71 infection [287], systemic lupus erythematosus [288] acute myocardial infarction [289], hypertension [290] or Alzheimer's disease [291], but also in different cancer types [292][293][294][295]. We checked the presence of miR-146a-5p in the exosomes of our cell lines and then combined the co-culture of exosomes from SKBR-3r (exoR) which had a high expression of this microRNA, with the inhibition of miR-146a-5p by transfection. This made the increase of resistance caused by exoR to be less potent, and we concluded then that the resistance transmitted by exosomes is partially mediated by miR-146a-5p.

In order to better know the effect of exosomes in resistance, that seems to be not only through miR-146a-5p, we analysed the expression of EMT gene markers after co-culturing SKBR-3wt with exosomes and also performed a wound healing assay in presence or not of exoR. Results showed that our exoR exosomes from more aggressive resistant cells induced in sensitive cells an increase in vimentin expression and in healing of the wound, concurring with 
exosome roles in cancer progression and aggressiveness previously described in the literature [296][297][298][299][300][301].

The only paper that involves so far exosomal miR-146a-5p with breast cancer is a recent study performed this year by Shan-Shan Yang, that does not talk about resistances but shows how miR-146a-5p is able to activate cancer associated fibroblasts (CAFs) in the tumour microenvironment through exosomes derived from breast cancer cells, promoting invasion and metastases [302]. Thinking about other possible effects that exosome derived miR-146a-5p could have in the microenvironment in order to promote resistance and aggressiveness of the tumour, we found that this microRNA has been shown to promote angiogenesis in HUVECs through different mechanisms [303][304]. Given that exosomes are known to promote angiogenesis in cancer [305], usually also through microRNAs [306][307][308], we conceived that exosomes from our breast cancer cell lines could also be promoting angiogenesis among its functions, specially exosomes from the resistant cell line, that has shown to be more aggressive and has higher levels of pro-angiogenic miR-146a-5p in its exosomes. In order to test this idea, we performed an in vitro angiogenesis assay culturing HUVECs in Matrigel and checking their capacity to form tubes in presence or not of exosomes. Our results show that exosomes in general increased significantly the angiogenic potential of HUVEC in terms of branches and tube length, but also exosomes from the 
resistant cell lines showed a slightly bigger increase, concurring with their high levels of miR-146a-5p.

This way, exosomes seem to have an important role in transmission of the resistance, partially performed by miR-146a-5p, but also in modulation of the microenvironment for tumour progression.

These results about miR-23b-3p and miR-146a-5p aim to represent another contribution to the knowledge of trastuzumab resistance and role of microRNAs and exosomes in breast cancer, with a view to solving the main problem of patients with this subtype of breast cancer. Further work needs to be done in order to understand the complex regulation between different types of tumour and microenvironment cells involving exosomes and microRNAs in cancer. 

CONCLUSIONS 



\section{CONCLUSIONS}

1. Overexpression of miR-26a in triple negative breast cancer cell lines resulted in a reduction of cell viability, that was partially recovered when the microRNA was inhibited. Its overexpression also increased the cell migration studied by wound healing assay.

2. The candidate gene targets E2F3, MCL-1, EZH2, MTDH, and PTEN were downregulated by miR-26a and the PTEN protein was also reduced after miR-26a overexpression.

3. Metformin treatment reduced breast cancer cell viability in MDA-MB231 triple negative breast cancer cell lines. MDA-MB-231 cells treated with metformin showed an increase in migration when it was studied by wound healing.

4. Treatment with metformin increased significantly miR-26a expression and led to a reduction of the expression of the genes BCL-2, and PTEN, and also PTEN protein, which are targets of miR-26a. Inhibition of miR26a partially prevents the effect of metformin treatment in MDA-MB231 triple negative breast cancer cell line viability and the PTEN and EZH2 expression reduction produced by metformin. Thus, we propose that the mechanism of metformin in triple negative breast cancer is partially mediated by miR-26a. 
5. miR-23b-3p was overexpressed in BT-474r cell line compared to BT474wt and its overexpression caused a reduction in PTEN expression, both at genetic and protein levels, suggesting this mechanism for resistance to trastuzumab of this cell line.

6. miR-146a-5p was overexpressed in BT-474r, SKBR-3r and HCC1954, being the only microRNA commonly overexpressed in the resistant cell lines compared to the sensitives. miR-146a-5p overexpression caused a reduction of efficiency of the trastuzumab in SKBR-3wt cells and inhibition of the microRNA leads to a higher sensitivity of SKBR-3r resistant cell line to trastuzumab.

7. Overexpression of miR-146a-5p has also an effect in cell cycle, as it increases phases $S$ and $G 2 / M$, reducing $G 1$ phase. This may be explained by the decrease of CDKN1A expression when overexpressing the microRNA, and the dramatic increase of CCNB1 levels.

8. Exosomes from SKBR-3wt and SKBR-3r cell lines contained miR-146a$5 p$, being much higher the levels of the microRNA in the exosomes from the resistant cell line than in the ones from the sensitive. Its relative expressions were also much higher in exosomes than in the cell lines. 
9. Exosomes from SKBR-3r cell line in co-culture with SKBR-3wt were able to reduce the effect of trastuzumab in cellular viability. This suggests that exosomes are able to transmit the resistance to trastuzumab. The effect of exosomes from SKBR-3r in the efficiency of trastuzumab over SKBR-3wt was partially rescued when miR-146a-5p was inhibited, so part of the transmission of resistance to trastuzumab by the exosomes may be mediated by miR-146a contained in them.

10. Exosomes from SKBR-3r cell line are able of increasing EMT marker VIM and reduce CCTNB1 in SKBR-3wt cell line, turning it more aggressive, and also increase their migration when studied by wound healing. This reveals the importance of exosomes in the progression of cancer, beyond the resistance.

11. Exosomes from SKBR-3wt and SKBR-3r were also able to increase angiogenesis in HUVECs compared to control media. The increase was higher with exosomes from the resistant cell line, showing the importance of malignant exosome secretion also modulating the microenvironment. 

REFERENCES 



\section{REFERENCES}

[1] E. J. Odes et al., "Earliest hominin cancer: 1.7-million-year-old osteosarcoma from Swartkrans Cave, South Africa," S. Afr. J. Sci., vol. 112, no. 7/8, pp. 5-5, Jul. 2016, doi: 10.17159/SAJS.2016/20150471.

[2] R. L. Siegel, K. D. Miller, and A. Jemal, "Cancer statistics, 2020," CA. Cancer J. Clin., vol. 70, no. 1, pp. 7-30, Jan. 2020, doi: 10.3322/caac.21590.

[3] G. R. Dagenais et al., "Variations in common diseases, hospital admissions, and deaths in middle-aged adults in 21 countries from five continents (PURE): a prospective cohort study," Lancet, vol. 395, no. 10226, pp. 785-794, Mar. 2020, doi: 10.1016/S0140-6736(19)32007-0.

[4] "WHO | World Health Organization." https://www.who.int/

[5] "Global Cancer Observatory." https://gco.iarc.fr/.

[6] “Asociación Española Contra el Cáncer." https://www.aecc.es/es

[7] “PRIMER INFORME SOBRE LA INVESTIGACIÓN E INNOVACIÓN EN CÁNCER EN ESPAÑA

http://observatorio.aecc.es/sites/default/files/informes/Informeinvestigacion-cancer_0.pdf

[8] J. Ferrando et al., "Trends in cancer mortality in Spain: the influence of the financial crisis," Gac. Sanit., vol. 33, no. 3, pp. 229-234, May 2019, doi: 10.1016/j.gaceta.2017.11.008. 
[9] “ICD-10 Version:2010." https://icd.who.int/browse10/2010/en\#/II

[10] X. Dai, L. Xiang, T. Li, and Z. Bai, “Cancer hallmarks, biomarkers and breast cancer molecular subtypes," Journal of Cancer, vol. 7, no. 10. Ivyspring International Publisher, pp. 1281-1294, 2016, doi: 10.7150/jca.13141.

[11] D. Hanahan and R. A. Weinberg, "Hallmarks of cancer: The next generation," Cell, vol. 144, no. 5. Elsevier, pp. 646-674, Mar. 04, 2011, doi: 10.1016/j.cell.2011.02.013.

[12] Y. A. Fouad and C. Aanei, "Revisiting the hallmarks of cancer," American Journal of Cancer Research, vol. 7, no. 5. E-Century Publishing Corporation, pp. 1016-1036, 2017.

[13] C. Tomasetti and B. Vogelstein, "Variation in cancer risk among tissues can be explained by the number of stem cell divisions," Science (80-. )., vol. 347, no. 6217, pp. 78-81, Jan. 2015, doi: 10.1126/science.1260825.

[14] F. Bray, J. Ferlay, I. Soerjomataram, R. L. Siegel, L. A. Torre, and A. Jemal, "Global cancer statistics 2018: GLOBOCAN estimates of incidence and mortality worldwide for 36 cancers in 185 countries," CA. Cancer J. Clin., vol. 68, no. 6, pp. 394-424, Nov. 2018, doi: 10.3322/caac.21492.

[15] M. De Sanidad and Y. Consumo, "La situación del cáncer en España." https://www.mscbs.gob.es/organizacion/sns/planCalidadSNS/pdf/excelenci a/cancer-cardiopatia/CANCER/opsc_est2.pdf.pdf

[16] M. Plummer, C. de Martel, J. Vignat, J. Ferlay, F. Bray, and S. Franceschi, "Global burden of cancers attributable to infections in 2012: a synthetic analysis," Lancet Glob. Heal., vol. 4, no. 9, pp. e609-e616, Sep. 2016, doi: 10.1016/S2214-109X(16)30143-7. 
[17] J. V. Lacey, S. S. Devesa, and L. A. Brinton, "Recent trends in breast cancer incidence and mortality," in Environmental and Molecular Mutagenesis, 2002, vol. 39, no. 2-3, pp. 82-88, doi: 10.1002/em.10062.

[18] K. Rojas and A. Stuckey, "Breast Cancer Epidemiology and Risk Factors," Clin. Obstet. Gynecol., vol. 59, no. 4, pp. 651-672, Dec. 2016, doi: 10.1097/GRF.0000000000000239.

[19] "Breast Cancer | Breast Cancer Information \& Overview." https://www.cancer.org/cancer/breast-cancer.html

[20] J. A. Cintolo-Gonzalez et al., "Breast cancer risk models: a comprehensive overview of existing models, validation, and clinical applications," Breast Cancer Research and Treatment, vol. 164, no. 2. Springer New York LLC, pp. 263-284, Jul. 01, 2017, doi: 10.1007/s10549-017-4247-z.

[21] Y. S. Sun et al., "Risk factors and preventions of breast cancer," International Journal of Biological Sciences, vol. 13, no. 11. Ivyspring International Publisher, pp. 1387-1397, 2017, doi: 10.7150/ijbs.21635.

[22] S. Winters, C. Martin, D. Murphy, and N. K. Shokar, "Breast Cancer Epidemiology, Prevention, and Screening," in Progress in Molecular Biology and Translational Science, vol. 151, Elsevier B.V., 2017, pp. 1-32.

[23] I. Kato, M. Cichon, C. L. Yee, S. Land, and J. F. Korczak, "African Americanpreponderant single nucleotide polymorphisms (SNPs) and risk of breast cancer," Cancer Epidemiol., vol. 33, no. 1, pp. 24-30, Jul. 2009, doi: 10.1016/j.canep.2009.04.009.

[24] "Ethnicity and Breast Cancer: Factors Influencing Differences in Incidence and Outcome | JNCl: Journal of the National Cancer Institute | Oxford Academic." https://academic.oup.com/jnci/article/97/6/439/2544155. 
[25] "Comparative Analysis of Breast Cancer Risk Factors among African-American Women and White Women | American Journal of Epidemiology | Oxford Academic." https://academic.oup.com/aje/article/161/1/40/73451.

[26] S. P. Pinheiro, M. D. Holmes, M. N. Pollak, R. L. Barbieri, and S. E. Hankinson, "Racial differences in premenopausal endogenous hormones," Cancer Epidemiol. Biomarkers Prev., vol. 14, no. 9, pp. 2147-2153, Sep. 2005, doi: 10.1158/1055-9965.EPI-04-0944.

[27] Y. Han et al., "Do breast quadrants explain racial disparities in breast cancer outcomes?," Cancer Causes Control, vol. 30, no. 11, pp. 1171-1182, Nov. 2019, doi: 10.1007/s10552-019-01222-x.

[28] B. A. Kohler et al., "Featuring Incidence of Breast Cancer Subtypes by Race/Ethnicity, Poverty, and State," JNCI J Natl Cancer Inst, vol. 107, no. 6, p. 25, 2015, doi: 10.1093/jnci/djv048.

[29] C. G. Yedjou et al., "Assessing the racial and ethnic disparities in breast cancer mortality in the United States," International Journal of Environmental Research and Public Health, vol. 14, no. 5. MDPI AG, May 01, 2017, doi: 10.3390/ijerph14050486.

[30] S. S. Coughlin, "Social determinants of breast cancer risk, stage, and survival," Breast Cancer Research and Treatment, vol. 177, no. 3. Springer New York LLC, pp. 537-548, Oct. 01, 2019, doi: 10.1007/s10549-019-05340-7.

[31] "Health status of Roma women in Spain | European Journal of Public Health I Oxford Academic." https://academic.oup.com/eurpub/article/21/6/793/493583. 
[32] L. Harris and H. Fritsche, "American society of clinical oncology. American society of clinical oncology 2007 update of recommendations for the use of tumor markers in breast cancer.," J. Clin. Oncol., vol. 25, pp. 5287-5312, 2007.

[33] V. J. Gnanapragasam, "Unlocking the molecular archive: The emerging use of formalin-fixed paraffin-embedded tissue for biomarker research in urological cancer," BJU International, vol. 105, no. 2. pp. 274-278, Jan. 2010, doi: 10.1111/j.1464-410X.2009.08665.x.

[34] N. S. Goldstein, M. Ferkowicz, E. Odish, A. Mani, and F. Hastah, "Minimum formalin fixation time for consistent estrogen receptor immunohistochemical staining of invasive breast carcinoma.," Am. J. Clin. Pathol., vol. 120, no. 1, pp. 86-92, Jul. 2003, doi: 10.1309/QPHD-RB00-QXGM-UQ9N.

[35] "WHO Classification of Tumours of the Breast. Fourth Edition - WHO - OMS ."https://apps.who.int/bookorders/anglais/detart1.jsp?codlan=1\&codcol=7 $0 \& \operatorname{codcch}=4004$.

[36] "Invasive Breast Cancer (IDC/ILC) | Types of Invasive Breast Carcinoma." https://www.cancer.org/cancer/breast-cancer/understanding-a-breastcancer-diagnosis/types-of-breast-cancer/invasive-breast-cancer.html.

[37] H. J. Bloom and W. W. Richardson, "Histological grading and prognosis in breast cancer a study of 1409 cases of which 359 have been followed for 15 years," Br. J. Cancer, vol. 11, no. 3, pp. 359-377, 1957, doi: 10.1038/bjc.1957.43.

[38] C. W. Elston, I. O. Ellis, and S. E. Pinder, "Pathological prognostic factors in breast cancer," Critical Reviews in Oncology/Hematology, vol. 31, no. 3. pp. 209-223, Aug. 1999, doi: 10.1016/S1040-8428(99)00034-7. 
[39] L. W. Dalton et al., "Histologic grading of breast caner: Linkage of patient outcome with level of pathologist agreement," Mod. Pathol., vol. 13, no. 7, pp. 730-735, Jul. 2000, doi: 10.1038/modpathol.3880126.

[40] H. F. Frierson et al., "Interobserver reproducibility of the Nottingham modification of the bloom and Richardson histologic grading scheme for infiltrating ductal carcinoma," Am. J. Clin. Pathol., vol. 103, no. 2, pp. 195198, 1995, doi: 10.1093/ajcp/103.2.195.

[41] L. W. Dalton, D. L. Page, and W. D. Dupont, "Histologic grading of breast carcinoma. A reproducibility study," Cancer, vol. 73, no. 11, pp. 2765-2770, Jun. 1994, doi: 10.1002/1097-0142(19940601)73:11<2765::AIDCNCR2820731119>3.0.CO;2-K.

[42] "Breast Cancer Grades | Grading Breast Cancer." https://www.cancer.org/cancer/breast-cancer/understanding-a-breastcancer-diagnosis/breast-cancer-grades.html.

[43] S. B. Edge and C. C. Compton, "The american joint committee on cancer: The 7th edition of the AJCC cancer staging manual and the future of TNM," Annals of Surgical Oncology, vol. 17, no. 6. Springer, pp. 1471-1474, Jun. 24, 2010, doi: 10.1245/s10434-010-0985-4.

[44] "Stages of Breast Cancer | Understand Breast Cancer Staging." https://www.cancer.org/cancer/breast-cancer/understanding-a-breastcancer-diagnosis/stages-of-breast-cancer.html.

[45] R. M. Tamimi et al., "Comparison of molecular phenotypes of ductal carcinoma in situ and invasive breast cancer," Breast Cancer Res., vol. 10, no. 4, p. R67, Aug. 2008, doi: 10.1186/bcr2128. 
[46] M. C. U. Cheang et al., "Ki67 index, HER2 status, and prognosis of patients with luminal B breast cancer.," J. Natl. Cancer Inst., vol. 101, no. 10, pp. 73650, May 2009, doi: 10.1093/jnci/djp082.

[47] L. A. Carey et al., "Race, breast cancer subtypes, and survival in the Carolina Breast Cancer Study," J. Am. Med. Assoc., vol. 295, no. 21, pp. 2492-2502, Jun. 2006, doi: 10.1001/jama.295.21.2492.

[48] X. R. Yang et al., "Differences in risk factors for breast cancer molecular subtypes in a population-based study," Cancer Epidemiol. Biomarkers Prev., vol. 16, no. 3, pp. 439-443, Mar. 2007, doi: 10.1158/1055-9965.EPI-06-0806.

[49] M. C. U. Cheang et al., "Basal-like breast cancer defined by five biomarkers has superior prognostic value than triple-negative phenotype," Clin. Cancer Res., vol. 14, no. 5, pp. 1368-1376, Mar. 2008, doi: 10.1158/1078-0432.CCR07-1658.

[50] A. A. Muftah et al., "Ki67 expression in invasive breast cancer: the use of tissue microarrays compared with whole tissue sections," Breast Cancer Res. Treat., vol. 164, no. 2, pp. 341-348, Jul. 2017, doi: 10.1007/s10549-017-42700 .

[51] C. M. Perou and T. Sørlie, "Molecular portraits of human breast tumours.," Nature, vol. 406, pp. 747-752, 2000.

[52] T. Sørlie et al., "Repeated observation of breast tumor subtypes in independent gene expression data sets," Proc. Natl. Acad. Sci. U. S. A., vol. 100, no. 14, pp. 8418-8423, Jul. 2003, doi: 10.1073/pnas.0932692100.

[53] P. Alluri and L. A. Newman, "Basal-like and triple-negative breast cancers. Searching for positives among many negatives," Surgical Oncology Clinics of North America, vol. 23, no. 3. W.B. Saunders, pp. 567-577, 2014. 
[54] P. Farmer et al., "Identification of molecular apocrine breast tumours by microarray analysis," Breast Cancer Res., vol. 7, no. S2, p. P2.11, Jun. 2005, doi: $10.1186 /$ bcr1122.

[55] Z. Hu et al., "The molecular portraits of breast tumors are conserved across microarray platforms," BMC Genomics, vol. 7, Apr. 2006, doi: 10.1186/14712164-7-96.

[56] B. Huber, P. Hsu, and N. Sutkowski, "Virus-Encoded superantigens.," Microbiol. Rev., vol. 60, no. 3, pp. 473-482, 1996. [Online]. Available: http://mmbr.asm.org/content/60/3/473.short.

[57] Y. J. Cha, W. H. Jung, and J. S. Koo, "The clinicopathologic features of molecular apocrine breast cancer," Korean J. Pathol., vol. 46, no. 2, pp. 169176, Apr. 2012, doi: 10.4132/KoreanJPathol.2012.46.2.169.

[58] W. Guo, W. Wang, Y. Zhu, X. Zhu, Z. Shi, and Y. Wang, "HER2 status in molecular apocrine breast cancer: Associations with clinical, pathological, and molecular features," Int. J. Clin. Exp. Pathol., vol. 8, no. 7, pp. 8008-8017, 2015.

[59] J. I. Herschkowitz et al., "Identification of conserved gene expression features between murine mammary carcinoma models and human breast tumors," Genome Biol., vol. 8, no. 5, May 2007, doi: 10.1186/gb-2007-8-5-r76.

[60] P. S. Bernard et al., "Supervised risk predictor of breast cancer based on intrinsic subtypes," J. Clin. Oncol., vol. 27, no. 8, pp. 1160-1167, Mar. 2009, doi: 10.1200/JCO.2008.18.1370.

[61] S. Paik et al., "A Multigene Assay to Predict Recurrence of Tamoxifen-Treated, Node-Negative Breast Cancer," N. Engl. J. Med., vol. 351, no. 27, pp. 28172826, Dec. 2004, doi: 10.1056/NEJMoa041588. 
[62] R. Kirk, "Risk factors: Oncotype $D{ }^{\circledR}$ assay predicts local recurrence in breast cancer," Nat. Rev. Clin. Oncol., vol. 7, no. 6, p. 300, Jun. 2010, doi: 10.1038/nrclinonc.2010.75.

[63] N. Galanina, V. Bossuyt, and L. N. Harris, "Molecular Predictors of Response to Therapy for Breast Cancer," Cancer J., vol. 17, no. 2, pp. 96-103, Mar. 2011, doi: 10.1097/PPO.0b013e318212dee3.

[64] R. Mehta, R. Jain, and S. Badve, "Personalized medicine: The road ahead," Clinical Breast Cancer, vol. 11, no. 1. Elsevier Inc., pp. 20-26, Mar. 01, 2011, doi: 10.3816/CBC.2011.n.004.

[65] T. O. Nielsen et al., "A comparison of PAM50 intrinsic subtyping with immunohistochemistry and clinical prognostic factors in tamoxifen-treated estrogen receptor-positive breast cancer," Clin. Cancer Res., vol. 16, no. 21 , pp. 5222-5232, Nov. 2010, doi: 10.1158/1078-0432.CCR-10-1282.

[66] K. S. Saini et al., "Beyond trastuzumab: New treatment options for HER2positive breast cancer," Breast, vol. 20, no. SUPPL. 3, 2011, doi: 10.1016/S0960-9776(11)70289-2.

[67] M. Xiao-Jun et al., "A five-gene molecular grade index and HOXB13.IL17BR are complementary prognostic factors in early stage breast cancer," Clin. Cancer Res., vol. 14, no. 9, pp. 2601-2608, May 2008, doi: 10.1158/10780432.CCR-07-5026.

[68] X. J. Ma et al., "A two-gene expression ratio predicts clinical outcome in breast cancer patients treated with tamoxifen," Cancer Cell, vol. 5, no. 6, pp. 607-616, Jun. 2004, doi: 10.1016/j.ccr.2004.05.015. 
[69] T. Iwamoto and L. Pusztai, "Predicting prognosis of breast cancer with gene signatures: Are we lost in a sea of data?," Genome Medicine, vol. 2, no. 11. Nov. 12, 2010, doi: 10.1186/gm202.

[70] F. Reyal et al., "A comprehensive analysis of prognostic signatures reveals the high predictive capacity of the Proliferation, Immune response and RNA splicing modules in breast cancer," Breast Cancer Res., vol. 10, no. 6, Nov. 2008, doi: 10.1186/bcr2192.

[71] L. J. Van't Veer et al., "Gene expression profiling predicts clinical outcome of breast cancer," Nature, vol. 415, no. 6871, pp. 530-536, Jan. 2002, doi: 10.1038/415530a.

[72] L. J. Van 't Veer and R. Bernards, "Enabling personalized cancer medicine through analysis of gene-expression patterns," Nature, vol. 452, no. 7187. Nature Publishing Group, pp. 564-570, Apr. 03, 2008, doi: $10.1038 /$ nature06915.

[73] E. C. Inwald et al., "4-IHC classification of breast cancer subtypes in a large cohort of a clinical cancer registry: use in clinical routine for therapeutic decisions and its effect on survival," Breast Cancer Res. Treat., vol. 153, no. 3, pp. 647-658, Oct. 2015, doi: 10.1007/s10549-015-3572-3.

[74] N. Harbeck and M. Gnant, "Breast cancer," The Lancet, vol. 389, no. 10074. Lancet Publishing Group, pp. 1134-1150, Mar. 18, 2017, doi: 10.1016/S01406736(16)31891-8.

[75] W. J. Gradishar et al., "Invasive breast cancer version 1.2016," JNCCN Journal of the National Comprehensive Cancer Network, vol. 14, no. 3. Harborside Press, pp. 324-354, Mar. 01, 2016, doi: 10.6004/jnccn.2016.0037. 
[76] P. T. Truong, I. A. Olivotto, T. J. Whelan, and M. Levine, "Clinical practice guidelines for the care and treatment of breast cancer: 16. Locoregional postmastectomy radiotherapy," CMAJ, vol. 170, no. 8. pp. 1263-1273, Apr. 13, 2004, doi: 10.1503/cmaj.1031000.

[77] "Randomized multicenter trial of sentinel node biopsy versus standard axillary treatment in operable breast cancer: the ALMANAC Trial. - PubMed NCBI." https://www.ncbi.nlm.nih.gov/pubmed/16670385.

[78] F. Sedlmayer, F. Zehentmayr, and G. Fastner, "Partial breast re-irradiation for local recurrence of breast carcinoma: Benefit and long term side effects," Breast, vol. 22, no. S2, Aug. 2013, doi: 10.1016/j.breast.2013.07.026.

[79] J. Specht and J. R. Gralow, “Neoadjuvant Chemotherapy for Locally Advanced Breast Cancer," Seminars in Radiation Oncology, vol. 19, no. 4. pp. 222-228, Oct. 2009, doi: 10.1016/j.semradonc.2009.05.001.

[80] A. Paul Launchbury and N. Habboubi, "Epirubicin and doxorubicin: a comparison of their characteristics, therapeutic activity and toxicity," Cancer Treat. Rev., vol. 19, no. 3, pp. 197-228, 1993, doi: 10.1016/03057372(93)90036-Q.

[81] E. Bria et al., "Benefit of taxanes as adjuvant chemotherapy for early breast cancer: Pooled analysis of 15,500 patients," Cancer, vol. 106, no. 11, pp. 2337-2344, Jun. 2006, doi: 10.1002/cncr.21886.

[82] B. L. Riggs and L. C. Hartmann, "Selective estrogen-receptor modulators Mechanisms of action and application to clinical practice," New England Journal of Medicine, vol. 348, no. 7. pp. 618-629, Feb. 13, 2003, doi: 10.1056/NEJMra022219. 
[83] O. C. Freedman et al., "Adjuvant endocrine therapy for early breast cancer: A systematic review of the evidence for the 2014 cancer care Ontario systemic therapy guideline," Curr. Oncol., vol. 22, no. Suppl 1, pp. S95-S113, Mar. 2015, doi: $10.3747 /$ co.22.2326.

[84] J. Baselga et al., "Everolimus in Postmenopausal Hormone-Receptor-Positive Advanced Breast Cancer," N. Engl. J. Med., vol. 366, no. 6, pp. 520-529, Feb. 2012, doi: 10.1056/NEJMoa1109653.

[85] N. C. Turner et al., "Palbociclib in Hormone-Receptor-Positive Advanced Breast Cancer," N. Engl. J. Med., vol. 373, no. 3, pp. 209-219, Jul. 2015, doi: 10.1056/NEJMoa1505270.

[86] W. Tai, R. Mahato, and K. Cheng, "The role of HER2 in cancer therapy and targeted drug delivery," Journal of Controlled Release, vol. 146, no. 3. pp. 264-275, Sep. 2010, doi: 10.1016/j.jconrel.2010.04.009.

[87] J. Baselga, "Treatment of HER2-overexpressing breast cancer," Educ. B. 35th ESMO Congr. Milan, Italy 8-12 Oct. 2010, vol. 21, pp. vii36-vii40, 2010, doi: 10.1093/annonc/mdq421.

[88] H. S. Cho et al., "Structure of the extracellular region of HER2 alone and in complex with the Herceptin Fab," Nature, vol. 421, no. 6924, pp. 756-760, Feb. 2003, doi: 10.1038/nature01392.

[89] M. J. Higgins and J. Baselga, "Targeted therapies for breast cancer," J. Clin. Invest., vol. 121, no. 10, pp. 3797-3803, Oct. 2011, doi: 10.1172/JCI57152.

[90] J. Baselga, "Targeting the Phosphoinositide-3 (PI3) Kinase Pathway in Breast Cancer," Oncologist, vol. 16, no. S1, pp. 12-19, Jan. 2011, doi: 10.1634/theoncologist.2011-s1-12. 
[91] "The cell : a molecular approach / Geoffrey M. Cooper, Robert E. Hausman Details - Trove." https://trove.nla.gov.au/work/7264643.

[92] M. Hubalek, C. Brantner, and C. Marth, "Role of pertuzumab in the treatment of HER2-positive breast cancer," Breast Cancer: Targets and Therapy, vol. 4. Dove Press, pp. 65-73, 2012, doi: 10.2147/bctt.s23560.

[93] D. Gajria and S. Chandarlapaty, "HER2-amplified breast cancer: Mechanisms of trastuzumab resistance and novel targeted therapies," Expert Review of Anticancer Therapy, vol. 11, no. 2. pp. 263-275, Feb. 2011, doi: 10.1586/era.10.226.

[94] V. Guarneri, E. Barbieri, M. V. Dieci, F. Piacentini, and P. Conte, "Anti-HER2 neoadjuvant and adjuvant therapies in HER2 positive breast cancer," Cancer Treat. Rev., vol. 36, no. SUPPL. 3, Nov. 2010, doi: 10.1016/S03057372(10)70022-0.

[95] D. L. Nielsen, M. Andersson, and C. Kamby, "HER2-targeted therapy in breast cancer. Monoclonal antibodies and tyrosine kinase inhibitors," Cancer Treatment Reviews, vol. 35, no. 2. pp. 121-136, Apr. 2009, doi: 10.1016/j.ctrv.2008.09.003.

[96] S. Di Cosimo and J. Baselga, "Management of breast cancer with targeted agents: Importance of heterogenicity," Nature Reviews Clinical Oncology, vol. 7, no. 3. Nature Publishing Group, pp. 139-147, 2010, doi: 10.1038/nrclinonc.2009.234.

[97] D. de M. Gagliato, D. L. F. Jardim, M. S. P. Marchesi, and G. N. Hortobagyi, "Mechanisms of resistance and sensitivity to anti-HER2 therapies in HER2+ breast cancer," Oncotarget, vol. 7, no. 39. Impact Journals LLC, pp. 6443164446, 2016, doi: 10.18632/oncotarget.7043. 
[98] S. P. Fessler, M. T. Wotkowicz, S. K. Mahanta, and C. Bamdad, "MUC1 is a determinant of trastuzumab (Herceptin) resistance in breast cancer cells," Breast Cancer Res. Treat., vol. 118, no. 1, pp. 113-124, Nov. 2009, doi: 10.1007/s10549-009-0412-3.

[99] M. Gerlinger et al., "Intratumor Heterogeneity and Branched Evolution Revealed by Multiregion Sequencing," N. Engl. J. Med., vol. 366, no. 10, pp. 883-892, Mar. 2012, doi: 10.1056/NEJMoa1113205.

[100] J. C. Montero, R. Rodríguez-Barrueco, A. Ucana, E. Diaz-Rodríguez, A. EsparísOgando, and A. Pandiella, "Neuregulins and cancer," Clin. Cancer Res., vol. 14, no. 11, pp. 3237-3241, Jun. 2008, doi: 10.1158/1078-0432.CCR-07-5133.

[101] A. Chakrabarty, B. N. Rexer, S. E. Wang, R. S. Cook, J. A. Engelman, and C. L. Arteaga, "H1047R phosphatidylinositol 3-kinase mutant enhances HER2mediated transformation by heregulin production and activation of HER3," Oncogene, vol. 29, no. 37, pp. 5193-5203, Sep. 2010, doi: 10.1038/onc.2010.257.

[102] M. Luque-Cabal, P. García-Teijido, Y. Fernández-Pérez, L. Sánchez-Lorenzo, and I. Palacio-Vázquez, "Mechanisms behind the resistance to trastuzumab in HER2-amplified breast cancer and strategies to overcome It," Clin. Med. Insights Oncol., vol. 10, pp. 21-30, Mar. 2016, doi: 10.4137/CMO.S34537.

[103] J. Arribas, J. Baselga, K. Pedersen, and J. L. Parra-Palau, "p95HER2 and breast cancer," Cancer Research, vol. 71, no. 5. pp. 1515-1519, Mar. 01, 2011, doi: 10.1158/0008-5472.CAN-10-3795.

[104] "Expression of p95HER2, a truncated form of the HER2 receptor, and response to anti-HER2 therapies in breast cancer. - PubMed - NCBI." https://www.ncbi.nlm.nih.gov/pubmed/17440164. 
[105] Y. H. F. Teng et al., "Mutations in the epidermal growth factor receptor (EGFR) gene in triple negative breast cancer: Possible implications for targeted therapy," Breast Cancer Res., vol. 13, no. 2, Apr. 2011, doi: 10.1186/bcr2857.

[106] C. Montagut et al., "Identification of a mutation in the extracellular domain of the Epidermal Growth Factor Receptor conferring cetuximab resistance in colorectal cancer," Nat. Med., vol. 18, no. 2, pp. 221-223, Jan. 2012, doi: 10.1038/nm.2609.

[107] D. L. Shattuck, J. K. Miller, K. L. Carraway, and C. Sweeney, "Met receptor contributes to trastuzumab resistance of Her2-overexpressing breast cancer cells," Cancer Res., vol. 68, no. 5, pp. 1471-1477, Mar. 2008, doi: 10.1158/0008-5472.CAN-07-5962.

[108] "Insulin-like growth factor-I receptor signaling and resistance to trastuzumab (Herceptin). https://www.ncbi.nlm.nih.gov/pubmed/11752009.

[109] Y. Nagata et al., "PTEN activation contributes to tumor inhibition by trastuzumab, and loss of PTEN predicts trastuzumab resistance in patients," Cancer Cell, vol. 6, no. 2, pp. 117-127, Aug. 2004, doi: 10.1016/j.ccr.2004.06.022.

[110] B. Dave et al., "Loss of phosphatase and tensin homolog or phosphoinositol3 kinase activation and response to trastuzumab or lapatinib in human epidermal growth factor receptor 2 - Overexpressing locally advanced breast cancers," J. Clin. Oncol., vol. 29, no. 2, pp. 166-173, Jan. 2011, doi: 10.1200/JCO.2009.27.7814.

[111] P. P. Pandolfi, "Breast cancer - Loss of PTEN predicts resistance to treatment," N. Engl. J. Med., vol. 351, no. 22, pp. 2337-2338, Nov. 2004, doi: 10.1056/NEJMcibr043143. 
[112] T. Mukohara, "Mechanisms of resistance to anti-human epidermal growth factor receptor 2 agents in breast cancer," Cancer Science, vol. 102, no. 1. pp. 1-8, Jan. 2011, doi: 10.1111/j.1349-7006.2010.01711.x.

[113] J. D. Carpten et al., "A transforming mutation in the pleckstrin homology domain of AKT1 in cancer," Nature, vol. 448, no. 7152, pp. 439-444, Jul. 2007, doi: $10.1038 /$ nature05933.

[114] K. R. Bauer, M. Brown, R. D. Cress, C. A. Parise, and V. Caggiano, "Descriptive analysis of estrogen receptor (ER)-negative, progesterone receptor (PR)negative, and HER2-negative invasive breast cancer, the socalled triplenegative phenotype: a population-based study from the California cancer Registry.," Cancer, vol. 109, pp. 1721-1728, 2007.

[115] L. A. Carey et al., "The triple negative paradox: primary tumor chemosensitivity of breast cancer subtypes.," Clin Cancer Res., vol. 13, pp. 2329-2334, 2007.

[116] F. Heitz and P. Harter, "Triple-negative and HER2-overexpressing breast cancers exhibit an elevated risk and an earlier occurrence of cerebral metastases.," Eur. J. Cancer, vol. 45, pp. 2792-2798, 2009.

[117] C. Liedtke and C. Mazouni, "Response to neoadjuvant therapy and long-term survival in patients with triple-negative breast cancer.," J. Clin. Oncol., vol. 26, pp. 1275-1281, 2008.

[118] C. M. Perou, "Molecular stratification of triple-negative breast cancers.," Oncologist, vol. 16, pp. 61-70, 2011. 
[119] G. Von Minckwitz and M. Untch, "Definition and impact of pathologic complete response on prognosis after neoadjuvant chemotherapy in various intrinsic breast cancer subtypes.," J. Clin. Oncol., vol. 30, pp. 1796-1804, 2012.

[120] R. Rouzier et al., "Breast cancer molecular subtypes respond differently to preoperative chemotherapy.," Clin Cancer Res., vol. 11, pp. 5678-5685., 2005.

[121] F. M. Blows and K. E. Driver, "Subtyping of breast cancer by immunohistochemistry to investigate a relationship between subtype and short and long term survival: A collaborative analysis of data for 10,159 cases from 12 studies.," PLoS Med., vol. 7, 2010.

[122] H. Masuda et al., "Differential response to neoadjuvant chemotherapy among 7 triple-negative breast cancer molecular subtypes.," Clin. Cancer Res., vol. 19, no. 19, pp. 5533-40, Oct. 2013, doi: 10.1158/1078-0432.CCR13-0799.

[123] B. D. Lehmann, J. A. Bauer, X. Chen, M. E. Sanders, A. B. Chakravarthy, and Y. Shyr, "Identification of human triple-negative breast cancer subtypes and preclinical models for selection of targeted therapies.," J Clin Invest., vol. 121, 2011.

[124] G. I. Uscanga-Perales, S. K. Santuario-Facio, and R. Ortiz-López, "Triple negative breast cancer: Deciphering the biology and heterogeneity," Med. Univ., vol. 18, no. 71, pp. 105-114, Apr. 2016, doi: 10.1016/j.rmu.2016.05.007.

[125] B. D. Lehmann et al., "Refinement of triple-negative breast cancer molecular subtypes: Implications for neoadjuvant chemotherapy selection," PLoS One, vol. 11, no. 6, Jun. 2016, doi: 10.1371/journal.pone.0157368. 
[126] M. D. Burstein et al., "Comprehensive genomic analysis identifies novel subtypes and targets of triple-negative breast cancer," Clin. Cancer Res., vol. 21, no. 7, pp. 1688-1698, Apr. 2015, doi: 10.1158/1078-0432.CCR-14-0432.

[127] B. Z. Ring et al., "Generation of an algorithm based on minimal gene sets to clinically subtype triple negative breast cancer patients," BMC Cancer, vol. 16, no. 1, Feb. 2016, doi: 10.1186/s12885-016-2198-0.

[128] E. D'Ippolito and M. V Iorio, "MicroRNAs and triple negative breast cancer.," Int. J. Mol. Sci., vol. 14, no. 11, pp. 22202-20, Jan. 2013, doi: 10.3390/ijms141122202.

[129] C. Oakman et al., "Adjuvant systemic treatment for individual patients with triple negative breast cancer.," Breast, vol. 20(Suppl3), pp. S135-S141., 2011.

[130] H. Joensuu and J. Gligorov, "Adjuvant treatments for triple-negative breast cancers.," Ann Oncol, vol. 23(Suppl6), pp. 40-45, 2012.

[131] C. Christowitz, T. Davis, A. Isaacs, G. Van Niekerk, S. Hattingh, and A. M. Engelbrecht, "Mechanisms of doxorubicin-induced drug resistance and drug resistant tumour growth in a murine breast tumour model," BMC Cancer, vol. 19, no. 1, p. 757, Aug. 2019, doi: 10.1186/s12885-019-5939-z.

[132] A. Cerrato, F. Morra, and A. Celetti, "Use of poly ADP-ribose polymerase [PARP] inhibitors in cancer cells bearing DDR defects: The rationale for their inclusion in the clinic," Journal of Experimental and Clinical Cancer Research, vol. 35, no. 1. BioMed Central Ltd., Nov. 24, 2016, doi: 10.1186/s13046-0160456-2.

[133] M. Keung, Y. Wu, and J. Vadgama, "PARP Inhibitors as a Therapeutic Agent for Homologous Recombination Deficiency in Breast Cancers," J. Clin. Med., vol. 8 , no. 4, p. 435, Mar. 2019, doi: 10.3390/jcm8040435. 
[134] A. Gucalp et al., "Phase II trial of bicalutamide in patients with androgen receptor-positive, estrogen receptor-negative metastatic breast cancer," Clin. Cancer Res., vol. 19, no. 19, pp. 5505-5512, Oct. 2013, doi: 10.1158/1078-0432.CCR-12-3327.

[135] Y. Mao, Q. Qu, X. Chen, O. Huang, J. Wu, and K. Shen, "The prognostic value of tumor-infiltrating lymphocytes in breast cancer: A systematic review and meta-analysis," PLoS One, vol. 11, no. 4, Apr. 2016, doi: 10.1371/journal.pone.0152500.

[136] M. Hubalek, T. Czech, and H. Müller, "Biological Subtypes of Triple-Negative Breast Cancer," Breast Care, vol. 12, no. 1. S. Karger AG, pp. 8-14, Mar. 01, 2017, doi: 10.1159/000455820.

[137] R. Nanda et al., "Pembrolizumab in patients with advanced triple-negative breast cancer: Phase Ib keynote-012 study," J. Clin. Oncol., vol. 34, no. 21, pp. 2460-2467, Jul. 2016, doi: 10.1200/JCO.2015.64.8931.

[138] B. Viollet, B. Guigas, N. Sanz Garcia, J. Leclerc, M. Foretz, and F. Andreelli, "Cellular and molecular mechanisms of metformin: An overview," Clinical Science, vol. 122, no. 6. pp. 253-270, Mar. 2012, doi: 10.1042/CS20110386.

[139] B. Viollet et al., "AMP-activated protein kinase in the regulation of hepatic energy metabolism: From physiology to therapeutic perspectives," in Acta Physiologica, May 2009, vol. 196, no. 1, pp. 81-98, doi: 10.1111/j.17481716.2009.01970.x.

[140] R. J. Shaw et al., "The kinase LKB1 mediates glucose homeostasis in liver and therapeutic effects of metformin.," Science (80-. )., vol. 310, pp. 1642-1646, 2005. 
[141] G. Libby, L. A. Donnelly, P. T. Donnan, D. R. Alessi, A. D. Morris, and J. M. Evans, "New Users of Metformin Are at Low Risk of Incident Cancer A cohort study among people with type 2 diabetes.," Diabetes Care, vol. 32, pp. 16201625, 2009.

[142] B. J. Quinn, H. Kitagawa, R. M. Hemmott, J. J. Gills, and P. A. Dennis, "Repositioning metformin for cancer prevention and treatment.," Trends Endocrinol Metab, vol. 24, pp. 469-480, 2013.

[143] M. Buzzai et al., "Systemic treatment with the antidiabetic drug metformin selectively impairs p53-deficient tumor cell growth.," Cancer Res, vol. 67, pp. 6745-6752., 2007.

[144] Y. Wang, W. Dai, X. Chu, B. Yang, M. Zhao, and S. Y., "Metformin inhibits lung cancer cells proliferation through repressing microRNA-222.," Biotechnol Lett, vol. 35, pp. 2013-2019, 2013.

[145] V. Nair et al., "Metformin inhibits pancreatic cancer cell and tumor growth and downregulates Sp transcription factors.," Carcinogenesis, vol. 34, pp. 2870-2879, 2013.

[146] D. R. Morales and A. D. Morris, "Metformin in Cancer Treatment and Prevention," Annu. Rev. Med., vol. 66, no. 1, pp. 17-29, Jan. 2015, doi: 10.1146/annurev-med-062613-093128.

[147] A. Vazquez-Martin, R. Colomer, J. Brunet, R. Lupu, and J. A. Menendez, "Overexpression of fatty acid synthase gene activates HER1/HER2 tyrosine kinase receptors in human breast epithelial cells," Cell Prolif., vol. 41, no. 1, pp. 59-85, Feb. 2008, doi: 10.1111/j.1365-2184.2007.00498.x. 
[148] H. A. Hirsch, D. Iliopoulos, and K. Struhl, "Metformin inhibits the inflammatory response associated with cellular transformation and cancer stem cell growth," Proc. Natl. Acad. Sci. U. S. A., vol. 110, no. 3, pp. 972-977, Jan. 2013, doi: 10.1073/pnas.1221055110.

[149] V. N. Kim and J. W. Nam, "Genomics of microRNA," Trends in Genetics, vol. 22, no. 3. pp. 165-173, Mar. 2006, doi: 10.1016/j.tig.2006.01.003.

[150] S. L. Lin and H. Kim, "Intron-mediated RNA interference and microRNA (miRNA).," Front Biosci., vol. 13, pp. 2216-2230, 2008.

[151] Y. Lee et al., "MicroRNA genes are transcribed by RNA polymerase II," EMBO J., vol. 23, no. 20, pp. 4051-4060, Oct. 2004, doi: 10.1038/sj.emboj.7600385.

[152] R. Yi and Y. Qin, "Exportin-5 mediates the nuclear export of pre-microRNAs and short hairpin RNAs.," Genes Dev., vol. 17, pp. 3011-3016, 2003.

[153] S. M. Hammond, "Dicing and slicing: The core machinery of the RNA interference pathway.," FEBS Lett., vol. 579, pp. 5822-5829, 2005.

[154] A. Eulalio and E. Huntzinger, "Deadenylation is a widespread effect of miRNA regulation.," RNA, vol. 15, pp. 21-32, 2009.

[155] W. Qin and Y. Shi, "miR-24 regulates apoptosis by targeting the open reading frame (ORF) region of FAF1 in cancer cells.," PLoS One, vol. 5, p. e9429, 2010.

[156] J. J. Forman and A. Legesse-Miller, "A search for conserved sequences in coding regions reveals that the let-7 microRNA targets Dicer within its coding sequence.," Proc. Natl. Acad. Sci. USA, vol. 105, pp. 14879-14884, 2008.

[157] H. W. Hwang and E. A. Wentzel, "A hexanucleotide element directs microRNA nuclear import.," Science (80-. )., vol. 315, pp. 97-100, 2007. 
[158] R. F. Place and L. C. Li, "MicroRNA-373 induces expression of genes with complementary promoter sequences.," Proc. Natl. Acad. Sci. USA, vol. 105, pp. 1608-1613, 2008.

[159] L. C. Li and S. T. Okino, "Small dsRNAs induce transcriptional activation in human cells.," Proc. Natl. Acad. Sci. USA, vol. 103, pp. 17337-17342, 2006.

[160] Z. Shi and J. Zhang, "AC1MMYR2, an inhibitor of dicer-mediated biogenesis of oncomir miR-21, reverses epithelial-mesenchymal transition and suppresses tumor growth and progression.," Cancer Res., vol. 73, pp. 5519-5531, 2013.

[161] H. Valadi and K. Ekström, "Exosome-mediated transfer of mRNAs and microRNAs is a novel mechanism of genetic exchange between cells.," Nat. Cell Biol., vol. 6, pp. 654-659, 2007.

[162] P. S. Mitchell and R. K. Parkin, "Circulating microRNAs as stable blood-based markers for cancer detection.," Proc. Natl. Acad. Sci. USA, vol. 105, pp. 10513-10518, 2008.

[163] H. Schwarzenbach and D. S. Hoon, "Cell-free nucleic acids as biomarkers in cancer patients.," Nat. Rev. Cancer, vol. 11, pp. 426-437, 2011.

[164] N. J. Park and H. Zhou, "Salivary microRNA: Discovery, characterization, and clinical utility for oral cancer detection.," Clin. Cancer Res., vol. 15, pp. 5473$5477,2009$.

[165] A. Michael and S. D. Bajracharya, "Exosomes from human saliva as a source of microRNA biomarkers.," Oral. Dis., vol. 16, pp. 34-38, 2010.

[166] M. V. lorio and M. Ferracin, "MicroRNA gene expression deregulation in human breast cancer.," Cancer Res., vol. 65, pp. 7065-7070, 2005. 
[167] N. Yanaihara and N. Caplen, "Unique microRNA molecular profiles in lung cancer diagnosis and prognosis.," Cancer Cell, vol. 9, pp. 189-198, 2006.

[168] X. Li and Y. Zhang, "Survival prediction of gastric cancer by a seven-microRNA signature.," Gut, vol. 59, pp. 579-585, 2010.

[169] S. Caramuta and S. Egyházi, "MicroRNA expression profiles associated with mutational status and survival in malignant melanoma.," J. Invest Dermatol., vol. 130, pp. 2062-2070, 2010.

[170] M. Dillhoff and J. Liu, "MicroRNA-21 is overexpressed in pancreatic cancer and a potential predictor of survival.," J. Gastrointest. Surg., vol. 12, pp. 21712176, 2008.

[171] S. Rossi and M. Shimizu, "microRNA fingerprinting of CLL patients with chromosome $17 p$ deletion identify a miR-21 score that stratifies early survival.," Blood, vol. 116, pp. 945-952, 2010.

[172] A. G. Bader, "miR-34-A microRNA replacement therapy is headed to the clinic.," Front Genet., vol. 3, doi:10., 2012.

[173] P. Trang and J. F. Wiggins, "Systemic delivery of tumor suppressor microRNA mimics using a neutral lipid emulsion inhibits lung tumors in mice.," Mol. Ther., vol. 19, pp. 1116-1122, 2011.

[174] C. Blenkiron and L. D. Goldstein, "MicroRNA expression profiling of human breast cancer identifies new markers of tumor subtype.," Genome Biol., vol. 8, doi:10., 2007.

[175] L. F. Sempere and M. Christensen, "Altered MicroRNA expression confined to specific epithelial cell subpopulations in breast cancer.," Cancer Res., vol. 67, pp. 11612-11620, 2007. 
[176] M. D. Mattie and C. C. Benz, "Optimized high-throughput microRNA expression profiling provides novel biomarker assessment of clinical prostate and breast cancer biopsies.," Mol. Cancer, vol. 5, doi:10., 2006.

[177] A. J. Lowery and N. Miller, "MicroRNA signatures predict oestrogen receptor, progesterone receptor and HER2/neu receptor status in breast cancer.," Breast Cancer Res., vol. 11, doi:10, 2009.

[178] E. A. Janssen and A. Slewa, "Biologic profiling of lymph node negative breast cancers by means of microRNA expression.," Mod. Pathol., vol. 23, pp. 15671576, 2010.

[179] T. A. Farazi and H. M. Horlings, "MicroRNA sequence and expression analysis in breast tumors by deep sequencing.," Cancer Res., vol. 71, pp. 4443-4453, 2011.

[180] E. Tormo et al., "MicroRNA Profile in Response to Doxorubicin Treatment in Breast Cancer.," J. Cell. Biochem., vol. 116, no. 9, pp. 2061-73, Sep. 2015, doi: 10.1002/jcb.25162.

[181] P. Vader, X. O. Breakefield, and M. J. A. Wood, "Extracellular vesicles: Emerging targets for cancer therapy," Trends in Molecular Medicine, vol. 20, no. 7. Elsevier Ltd, pp. 385-393, Jul. 01, 2014, doi: 10.1016/j.molmed.2014.03.002.

[182] C. Grange et al., "Microvesicles released from human renal cancer stem cells stimulate angiogenesis and formation of lung premetastatic niche," Cancer Res., vol. 71, no. 15, pp. 5346-5356, Aug. 2011, doi: 10.1158/0008-5472.CAN11-0241. 
[183] A. Janowska-Wieczorek et al., "Microvesicles derived from activated platelets induce metastasis and angiogenesis in lung cancer," Int. J. Cancer, vol. 113, no. 5, pp. 752-760, Feb. 2005, doi: 10.1002/ijc.20657.

[184] A. Bobrie et al., "Rab27a supports exosome-dependent and -independent mechanisms that modify the tumor microenvironment and can promote tumor progression," Cancer Res., vol. 72, no. 19, pp. 4920-4930, Oct. 2012, doi: 10.1158/0008-5472.CAN-12-0925.

[185] L. Mao et al., "Exosomes decrease sensitivity of breast cancer cells to adriamycin by delivering microRNAs," Tumor Biol., vol. 37, no. 4, pp. 52475256, 2016, doi: 10.1007/s13277-015-4402-2.

[186] W. xian Chen et al., "Exosomes from docetaxel-resistant breast cancer cells alter chemosensitivity by delivering microRNAs," Tumor Biol., vol. 35, no. 10, pp. 9649-9659, 2014, doi: 10.1007/s13277-014-2242-0.

[187] J. Rak, "Extracellular vesicles - biomarkers and effectors of the cellular interactome in cancer," Frontiers in Pharmacology, vol. 4 MAR. 2013, doi: 10.3389/fphar.2013.00021.

[188] C. Corrado, S. Raimondo, A. Chiesi, F. Ciccia, G. De Leo, and R. Alessandro, "Exosomes as intercellular signaling organelles involved in health and disease: Basic science and clinical applications," International Journal of Molecular Sciences, vol. 14, no. 3. pp. 5338-5366, Mar. 2013, doi: 10.3390/ijms14035338.

[189] M. Tomasetti, W. Lee, L. Santarelli, and J. Neuzil, "Exosome-derived microRNAs in cancer metabolism: Possible implications in cancer diagnostics and therapy," Experimental and Molecular Medicine, vol. 49, no. 1. Nature Publishing Group, Jan. 13, 2017, doi: 10.1038/emm.2016.153. 
[190] K. E. Gilligan and R. M. Dwyer, "Engineering exosomes for cancer therapy," International Journal of Molecular Sciences, vol. 18, no. 6. MDPI AG, Jun. 01, 2017, doi: 10.3390/ijms18061122.

[191] A. Srivastava et al., "Exploitation of exosomes as nanocarriers for gene-, chemo-, and immune-therapy of cancer," J. Biomed. Nanotechnol., vol. 12, no. 6, pp. 1159-1173, Jun. 2016, doi: 10.1166/jbn.2016.2205.

[192] N. L. Syn, L. Wang, E. K. H. Chow, C. T. Lim, and B. C. Goh, "Exosomes in Cancer Nanomedicine and Immunotherapy: Prospects and Challenges," Trends in Biotechnology, vol. 35, no. 7. Elsevier Ltd, pp. 665-676, Jul. 01, 2017, doi: 10.1016/j.tibtech.2017.03.004.

[193] R. Alfonsi, L. Grassi, M. Signore, and D. Bonci, "The double face of exosomecarried micrornas in cancer immunomodulation," International Journal of Molecular Sciences, vol. 19, no. 4. MDPI AG, Apr. 13, 2018, doi: 10.3390/ijms19041183.

[194] B. M. Bell, I. D. Kirk, S. Hiltbrunner, S. Gabrielsson, and J. J. Bultema, “Designer exosomes as next-generation cancer immunotherapy," Nanomedicine: Nanotechnology, Biology, and Medicine, vol. 12, no. 1. Elsevier Inc., pp. 163169, Jan. 01, 2016, doi: 10.1016/j.nano.2015.09.011.

[195] N. Bastos, C. F. Ruivo, S. da Silva, and S. A. Melo, "Exosomes in cancer: Use them or target them?," Seminars in Cell and Developmental Biology, vol. 78. Elsevier Ltd, pp. 13-21, Jun. 01, 2018, doi: 10.1016/j.semcdb.2017.08.009.

[196] A. Elsherbini and E. Bieberich, "Ceramide and Exosomes: A Novel Target in Cancer Biology and Therapy," Adv. Cancer Res., vol. 140, pp. 121-154, Jan. 2018, doi: 10.1016/bs.acr.2018.05.004. 
[197] S. Zazo et al., "Original Article Generation, characterization, and maintenance of trastuzumab-resistant HER2+ breast cancer cell lines," 2016. Available: www.ajcr.us/.

[198] C. M. Perou et al., "Molecular portraits of human breast tumours," Nature, vol. 406, no. 6797, pp. 747-752, Aug. 2000, doi: 10.1038/35021093.

[199] D. A. Scudiero et al., "Evaluation of a Soluble Tetrazolium/Formazan Assay for Cell Growth and Drug Sensitivity in Culture Using Human and Other Tumor Cell Lines," Cancer Res., vol. 48, no. 17, 1988.

[200] L. G. Rodriguez, X. Wu, and J. L. Guan, "Wound-healing assay.," Methods Mol. Biol., vol. 294, pp. 23-29, 2005, doi: 10.1385/1-59259-860-9:023.

[201] K. J. Livak and T. D. Schmittgen, "Analysis of relative gene expression data using real-time quantitative PCR and the 2- $\Delta \Delta C T$ method," Methods, vol. 25, no. 4, pp. 402-408, 2001, doi: 10.1006/meth.2001.1262.

[202] N. A. O'Brien et al., "Activated phosphoinositide 3-kinase/AKT signaling confers resistance to trastuzumab but not lapatinib," Mol. Cancer Ther., vol. 9, no. 6, pp. 1489-1502, Jun. 2010, doi: 10.1158/1535-7163.MCT-09-1171.

[203] S. Y. Yi et al., "Favorable response to doxorubicin combination chemotherapy does not yield good clinical outcome in patients with metastatic breast cancer with triple-negative phenotype," BMC Cancer, vol. 10, pp. 527-527, Oct. 2010, doi: 10.1186/1471-2407-10-527.

[204] L. A. Carey, "Directed Therapy of Subtypes of Triple-Negative Breast Cancer," Oncologist, vol. 16, no. S1, pp. 71-78, Jan. 2011, doi: 10.1634/theoncologist.2011-s1-71. 
[205] P. Boyle, "Triple-negative breast cancer: epidemiological considerations and recommendations," Triple-negative breast cancer Focus From Biol. to Nov. Ther., vol. 23, pp. vi7-vi12, 2012, doi: 10.1093/annonc/mds187.

[206] M. A. Locatelli, G. Curigliano, and A. Eniu, "Extended adjuvant chemotherapy in triple-negative breast cancer," Breast Care, vol. 12, no. 3. S. Karger AG, pp. 152-158, Jul. 01, 2017, doi: 10.1159/000478087.

[207] P. E. Asensio, E. T. Martin, B. P. Merlo, E. E. Armas, and A. L. Hernández, “MicroRNAs in Breast Cancer: One More Turn in Regulation," Curr. Drug Targets, vol. 17, no. 9, pp. 1083-1100, May 2016, doi: 10.2174/1389450116666150213114103.

[208] A. L. Kasinski and F. J. Slack, "MicroRNAs en route to the clinic: Progress in validating and targeting microRNAs for cancer therapy," Nature Reviews Cancer, vol. 11, no. 12. pp. 849-864, Dec. 2011, doi: 10.1038/nrc3166.

[209] J. Gao et al., "MiR-26a Inhibits Proliferation and Migration of Breast Cancer through Repression of MCL-1," PLoS One, vol. 8, no. 6, Jun. 2013, doi: 10.1371/journal.pone.0065138.

[210] L. Chen et al., "Tumor-specific expression of MicroRNA-26a suppresses human hepatocellular carcinoma growth via cyclin-dependent and independent pathways," Mol. Ther., vol. 19, no. 8, pp. 1521-1528, 2011, doi: 10.1038/mt.2011.64.

[211] B. Liu et al., "MiR-26a enhances metastasis potential of lung cancer cells via AKT pathway by targeting PTEN," Biochim. Biophys. Acta-Mol. Basis Dis., vol. 1822, no. 11, pp. 1692-1704, Nov. 2012, doi: 10.1016/j.bbadis.2012.07.019. 
[212] P. Liu et al., "MiR-26a suppresses tumour proliferation and metastasis by targeting metadherin in triple negative breast cancer," Cancer Lett., vol. 357, no. 1, pp. 384-392, Feb. 2015, doi: 10.1016/j.canlet.2014.11.050.

[213] B. Zhang et al., "Pathologically decreased miR-26a antagonizes apoptosis and facilitates carcinogenesis by targeting MTDH and EZH2 in breast cancer," Carcinogenesis, vol. 32, no. 1, pp. 2-9, 2011, doi: 10.1093/carcin/bgq209.

[214] M. P. H. M. Jansen et al., "High miR-26a and low CDC2 levels associate with decreased EZH2 expression and with favorable outcome on tamoxifen in metastatic breast cancer," Breast Cancer Res. Treat., vol. 133, no. 3, pp. 937947, Jun. 2012, doi: 10.1007/s10549-011-1877-4.

[215] S. Tan et al., "Identification of miR-26 as a key mediator of estrogen stimulated cell proliferation by targeting CHD1, GREB1 and KPNA2," Breast Cancer Res., vol. 16, no. 2, Apr. 2014, doi: 10.1186/bcr3644.

[216] B. J. Quinn, H. Kitagawa, R. M. Memmott, J. J. Gills, and P. A. Dennis, "Repositioning metformin for cancer prevention and treatment," Trends in Endocrinology and Metabolism, vol. 24, no. 9. pp. 469-480, Sep. 2013, doi: 10.1016/j.tem.2013.05.004.

[217] H. J. Kim et al., "Metformin increases survival in hormone receptor-positive, HER2-positive breast cancer patients with diabetes," Breast Cancer Res., vol. 17, no. 1, May 2015, doi: 10.1186/s13058-015-0574-3.

[218] S. Bayraktar et al., "Effect of metformin on survival outcomes in diabetic patients with triple receptor-negative breast cancer," Cancer, vol. 118, no. 5 , pp. 1202-1211, Mar. 2012, doi: 10.1002/cncr.26439. 
[219] X. He, F. Esteva, J. Ensor, G. Hortobagyi, M. Lee, and S. J. Yeung, "Metformin and thiazolidinediones are associated with improved breast cancer-specific survival of diabetic women with HER2+ breast cancer," 2011, doi: 10.1093/annonc/mdr534.

[220] A. K. Madiraju et al., "Metformin suppresses gluconeogenesis by inhibiting mitochondrial glycerophosphate dehydrogenase," Nature, vol. 510, no. 7506, pp. 542-546, 2014, doi: 10.1038/nature13270.

[221] V. N. Anisimov et al., "Effect of metformin on life span and on the development of spontaneous mammary tumors in HER-2/neu transgenic mice," Exp. Gerontol., vol. 40, no. 8-9, pp. 685-693, Aug. 2005, doi: 10.1016/j.exger.2005.07.007.

[222] I. Ben Sahra et al., "The antidiabetic drug metformin exerts an antitumoral effect in vitro and in vivo through a decrease of cyclin D1 level," Oncogene, vol. 27 , no. 25, pp. 3576-3586, Jun. 2008, doi: 10.1038/sj.onc.1211024.

[223] R. J. O. Dowling, M. Zakikhani, I. G. Fantus, M. Pollak, and N. Sonenberg, "Metformin inhibits mammalian target of rapamycin-dependent translation initiation in breast cancer cells," Cancer Res., vol. 67, no. 22, pp. 1080410812, Nov. 2007, doi: 10.1158/0008-5472.CAN-07-2310.

[224] B. Martin-Castillo et al., "Incorporating the antidiabetic drug metformin in HER2-positive breast cancer treated with neo-adjuvant chemotherapy and trastuzumab: an ongoing clinical-translational research experience at the Catalan Institute of Oncology," Ann. Oncol., vol. 21, pp. 187-189, 2009, doi: 10.1093/annonc/mdp494. 
[225] H. A. Hirsch, D. Iliopoulos, P. N. Tsichlis, and K. Struhl, "Metformin selectively targets cancer stem cells, and acts together with chemotherapy to block tumor growth and prolong remission," Cancer Res., vol. 69, no. 19, pp. 75077511, Oct. 2009, doi: 10.1158/0008-5472.CAN-09-2994.

[226] P. Shi et al., "Metformin suppresses triple-negative breast cancer stem cells by targeting KLF5 for degradation," Cell Discov., vol. 3, Apr. 2017, doi: 10.1038/celldisc.2017.10.

[227] J. O. Lee et al., "Metformin overcomes resistance to cisplatin in triplenegative breast cancer (TNBC) cells by targeting RAD51," Breast Cancer Res., vol. 21, no. 1, Oct. 2019, doi: 10.1186/s13058-019-1204-2.

[228] "Metformin Reverses PARP Inhibitors-Induced Epithelial-Mesenchymal Transition and PD-L1 Upregulation in Triple-Negative Breast Cancer PubMed." https://pubmed.ncbi.nlm.nih.gov/31106005/.

[229] E. Strekalova, D. Malin, H. Rajanala, and V. L. Cryns, "Metformin sensitizes triple-negative breast cancer to proapoptotic TRAIL receptor agonists by suppressing XIAP expression," Breast Cancer Res. Treat., vol. 163, no. 3, pp. 435-447, Jun. 2017, doi: 10.1007/s10549-017-4201-0.

[230] W. Alaswad RS, E. SM, S. HS, and T. AD, "Metformin Targets Glucose Metabolism in Triple Negative Breast Cancer," J. Oncol. Transl. Res., vol. 04, no. 01,2018 , doi: 10.4172/2476-2261.1000129.

[231] N. J. Lanning et al., "Metabolic profiling of triple-negative breast cancer cells reveals metabolic vulnerabilities," Cancer Metab., vol. 5, no. 1, Dec. 2017, doi: 10.1186/s40170-017-0168-x. 
[232] R. Wahdan-Alaswad et al., "Glucose promotes breast cancer aggression and reduces metformin efficacy," Cell Cycle, vol. 12, no. 24, pp. 3759-3769, Dec. 2013, doi: $10.4161 /$ cc.26641.

[233] S. Varghese, S. M. Samuel, E. Varghese, P. Kubatka, and D. Büsselberg, "High glucose represses the anti-proliferative and pro-apoptotic effect of metformin in triple negative breast cancer cells," Biomolecules, vol. 9, no. 1, Jan. 2019, doi: 10.3390/biom9010016.

[234] W. Li, Y. Yuan, L. Huang, M. Qiao, and Y. Zhang, "Metformin alters the expression profiles of microRNAs in human pancreatic cancer cells," Diabetes Res. Clin. Pract., vol. 96, no. 2, pp. 187-195, May 2012, doi: 10.1016/j.diabres.2011.12.028.

[235] B. Bao et al., "Metformin inhibits cell proliferation, migration and invasion by attenuating CSC function mediated by deregulating miRNAs in pancreatic cancer cells," Cancer Prev. Res., vol. 5, no. 3, pp. 355-364, Mar. 2012, doi: 10.1158/1940-6207.CAPR-11-0299.

[236] F. Yang, J. Wang, J. Yan, J. Huang, W. Li, and J. Che, "Metformin inhibits cell growth by upregulating microRNA-26a in renal cancer cells," vol. 7, no. 10, pp. 3289-3296, 2014.

[237] J. T. Huse et al., "The PTEN-regulating microRNA miR-26a is amplified in highgrade glioma and facilitates gliomagenesis in vivo," Genes Dev., vol. 23, no. 11, pp. 1327-1337, Jun. 2009, doi: 10.1101/gad.1777409.

[238] H. Kim, W. Huang, X. Jiang, B. Pennicooke, P. J. Park, and M. D. Johnson, "Integrative genome analysis reveals an oncomir/ oncogene cluster regulating glioblastoma survivorship," Proc. Natl. Acad. Sci. U. S. A., vol. 107, no. 5, pp. 2183-2188, Feb. 2010, doi: 10.1073/pnas.0909896107. 
[239] G. Hou, S. Zhang, X. Zhang, P. Wang, X. Hao, and J. Zhang, "Clinical pathological characteristics and prognostic analysis of 1,013 breast cancer patients with diabetes," Breast Cancer Res. Treat., vol. 137, no. 3, pp. 807816, Feb. 2013, doi: 10.1007/s10549-012-2404-y.

[240] I. C. Lega, P. C. Austin, A. Gruneir, P. J. Goodwin, P. A. Rochon, and L. L. Lipscombe, "Association between metformin therapy and mortality after breast cancer: A population-based study," Diabetes Care, vol. 36, no. 10, pp. 3018-3026, Oct. 2013, doi: 10.2337/dc12-2535.

[241] P. Peeters et al., "Use of Metformin and Survival of Diabetic Women with Breast Cancer," Curr. Drug Saf., vol. 8, no. 5, pp. 357-363, Dec. 2013, doi: $10.2174 / 15680266113136660069$.

[242] Y. Xiao, S. Zhang, G. Hou, X. Zhang, X. Hao, and J. Zhang, "Clinical pathological characteristics and prognostic analysis of diabetic women with luminal subtype breast cancer," Tumor Biol., vol. 35, no. 3, pp. 2035-2045, 2014, doi: 10.1007/s13277-013-1270-5.

[243] B. Shi et al., "Integration of Estrogen and Wnt Signaling Circuits by the Polycomb Group Protein EZH2 in Breast Cancer Cells," Mol. Cell. Biol., vol. 27, no. 14 , pp. 5105-5119, Jul. 2007, doi: 10.1128/mcb.00162-07.

[244] A. P. Bracken et al., "The Polycomb group proteins bind throughout the INK4A-ARF locus and are disassociated in senescent cells," Genes Dev., vol. 21, no. 5, pp. 525-530, Mar. 2007, doi: 10.1101/gad.415507.

[245] B. Schuettengruber, D. Chourrout, M. Vervoort, B. Leblanc, and G. Cavalli, "Genome Regulation by Polycomb and Trithorax Proteins," Cell, vol. 128, no. 4. pp. 735-745, Feb. 23, 2007, doi: 10.1016/j.cell.2007.02.009. 
[246] C. G. Kleer et al., "EZH2 is a marker of aggressive breast cancer and promotes neoplastic transformation of breast epithelial cells," Proc. Natl. Acad. Sci. U. S. A., vol. 100, no. 20, pp. 11606-11611, Sep. 2003, doi: 10.1073/pnas.1933744100.

[247] J. Heering, P. Erlmann, and M. A. Olayioye, "Simultaneous loss of the DLC1 and PTEN tumor suppressors enhances breast cancer cell migration," Exp. Cell Res., vol. 315, no. 15, pp. 2505-2514, Sep. 2009, doi: 10.1016/j.yexcr.2009.05.022.

[248] M. Tamura, J. Gu, K. Matsumoto, S. I. Aota, R. Parsons, and K. M. Yamada, "Inhibition of cell migration, spreading, and focal adhesions by tumor suppressor PTEN," Science (80-. )., vol. 280, no. 5369, pp. 1614-1617, Jun. 1998, doi: 10.1126/science.280.5369.1614.

[249] "Tumor Suppressor PTEN Inhibition of Cell Invasion, Migration, and Growth: Differential Involvement of Focal Adhesion Kinase and p130Cas | Cancer Research." https://cancerres.aacrjournals.org/content/59/2/442.long.

[250] P. P. Wu, H. Y. Zhu, X. F. Sun, L. X. Chen, Q. Zhou, and J. Chen, "MicroRNA-141 regulates the tumor suppressor DLC1 in colorectal cancer," Neoplasma, vol. 62, no. 5, pp. 705-712, 2015, doi: 10.4149/neo_2015_084.

[251] G. J. Zhang, J. S. Li, H. Zhou, H. X. Xiao, Y. Li, and T. Zhou, “MicroRNA-106b promotes colorectal cancer cell migration and invasion by directly targeting DLC1," J. Exp. Clin. Cancer Res., vol. 34, no. 1, p. 73, Dec. 2015, doi: 10.1186/s13046-015-0189-7.

[252] P. Cabello, B. Pineda, E. Tormo, A. Lluch, and P. Eroles, "The antitumor effect of metformin is mediated by miR-26a in breast cancer," Int. J. Mol. Sci., vol. 17, no. 8, Aug. 2016, doi: 10.3390/ijms17081298. 
[253] D. de M. Gagliato, D. L. F. Jardim, M. S. P. Marchesi, and G. N. Hortobagyi, "Mechanisms of resistance and sensitivity to anti-HER2 therapies in HER2+ breast cancer," Oncotarget, vol. 7, no. 39. Impact Journals LLC, pp. 6443164446, 2016, doi: 10.18632/oncotarget.7043.

[254] S. P. Fessler, M. T. Wotkowicz, S. K. Mahanta, and C. Bamdad, "MUC1 is a determinant of trastuzumab (Herceptin) resistance in breast cancer cells," Breast Cancer Res. Treat., vol. 118, no. 1, pp. 113-124, Nov. 2009, doi: 10.1007/s10549-009-0412-3.

[255] M. D. Pegram et al., "Phase II study of receptor-enhanced chemosensitivity using recombinant humanized anti-p185(HER2/neu) monoclonal antibody plus cisplatin in patients with HER2/neu-overexpressing metastatic breast cancer refractory to chemotherapy treatment," J. Clin. Oncol., vol. 16, no. 8, pp. 2659-2671, 1998, doi: 10.1200/JCO.1998.16.8.2659.

[256] G. E. Konecny et al., "Activity of the dual kinase inhibitor lapatinib (GW572016) against HER-2-overexpressing and trastuzumab-treated breast cancer cells," Cancer Res., vol. 66, no. 3, pp. 1630-1639, Feb. 2006, doi: 10.1158/0008-5472.CAN-05-1182.

[257] C. T. Chan, M. Z. Metz, and S. E. Kane, "Differential sensitivities of trastuzumab (Herceptin $\left.{ }^{\circledR}\right)$-resistant human breast cancer cells to phosphoinositide-3 kinase (PI-3K) and epidermal growth factor receptor (EGFR) kinase inhibitors," Breast Cancer Res. Treat., vol. 91, no. 2, pp. 187201, May 2005, doi: 10.1007/s10549-004-7715-1.

[258] T. Kute et al., "Development of Herceptin Resistance in Breast Cancer Cells," Cytom. Part A, vol. 57, no. 2, pp. 86-93, 2004, doi: 10.1002/cyto.a.10095. 
[259] B. Zhang, X. Pan, G. P. Cobb, and T. A. Anderson, "microRNAs as oncogenes and tumor suppressors," Developmental Biology, vol. 302, no. 1. Academic Press Inc., pp. 1-12, Feb. 01, 2007, doi: 10.1016/j.ydbio.2006.08.028.

[260] C. Lopez-Camarillo et al., "Functional Roles of microRNAs in Cancer: microRNomes and oncomiRs Connection," in Oncogenomics and Cancer Proteomics - Novel Approaches in Biomarkers Discovery and Therapeutic Targets in Cancer, InTech, 2013.

[261] L. Hong et al., "Drug resistance-related microRNAs in esophageal cancer," Expert Opinion on Biological Therapy, vol. 12, no. 11. Informa Healthcare, pp. 1487-1494, 2012, doi: 10.1517/14712598.2012.711309.

[262] X. Chen et al., "MiRNAs-mediated cisplatin resistance in breast cancer," Tumor Biology, vol. 37, no. 10. Springer Netherlands, pp. 12905-12913, Oct. 01, 2016, doi: 10.1007/s13277-016-5216-6.

[263] S. (Universidad A. de M. Zazo Hernández, "Mecanismos de resistencia primaria y adquirida a trastuzumab en cáncer de mama HER2 positivo," Jan. 2019.

[264] M. S. Zaman et al., "Inhibition of PTEN Gene Expression by Oncogenic miR23b-3p in Renal Cancer," PLoS One, vol. 7, no. 11, Nov. 2012, doi: 10.1371/journal.pone.0050203.

[265] Y. L. Li et al., "MiR-146a-5p inhibits cell proliferation and cell cycle progression in NSCLC cell lines by targeting CCND1 and CCND2," Oncotarget, vol. 7, no. 37, pp. 59287-59298, 2016, doi: 10.18632/oncotarget.11040.

[266] Q. Hu, J. Song, B. Ding, Y. Cui, J. Liang, and S. Han, "miR-146a promotes cervical cancer cell viability via targeting IRAK1 and TRAF6," Oncol. Rep., vol. 39, no. 6, pp. 3015-3024, Jun. 2018, doi: 10.3892/or.2018.6391. 
[267] J. W. Harper et al., "Inhibition of cyclin-dependent kinases by p21," Mol. Biol. Cell, vol. 6, no. 4, pp. 387-400, 1995, doi: 10.1091/mbc.6.4.387.

[268] H. Da Zhang et al., "Exosome: A novel mediator in drug resistance of cancer cells," Epigenomics, vol. 10, no. 11. Future Medicine Ltd., pp. 1499-1509, Nov. 01, 2018, doi: 10.2217/epi-2017-0151.

[269] H. Da Zhang et al., "Exosome: A novel mediator in drug resistance of cancer cells," Epigenomics, vol. 10, no. 11. Future Medicine Ltd., pp. 1499-1509, Nov. 01, 2018, doi: 10.2217/epi-2017-0151.

[270] D. dan Yu et al., "Exosomes in development, metastasis and drug resistance of breast cancer," Cancer Science, vol. 106, no. 8. Blackwell Publishing Ltd, pp. 959-964, Aug. 01, 2015, doi: 10.1111/cas.12715.

[271] P. Samuel, M. Fabbri, and D. R. F. Carter, "Mechanisms of Drug Resistance in Cancer: The Role of Extracellular Vesicles.," Proteomics, vol. 17, no. 23-24, Dec. 2017, doi: 10.1002/pmic.201600375.

[272] N. M. Namee and L. O’Driscoll, “Extracellular vesicles and anti-cancer drug resistance," Biochimica et Biophysica Acta-Reviews on Cancer, vol. 1870, no. 2. Elsevier B.V., pp. 123-136, Dec. 01, 2018, doi: 10.1016/j.bbcan.2018.07.003.

[273] R. Bayraktar, K. Van Roosbroeck, and G. A. Calin, "Cell-to-cell communication: microRNAs as hormones," Molecular Oncology, vol. 11, no. 12. John Wiley and Sons Ltd., pp. 1673-1686, Dec. 01, 2017, doi: 10.1002/1878-0261.12144.

[274] B. Wang, Y. Zhang, M. Ye, J. Wu, L. Ma, and H. Chen, "Cisplatin-resistant MDAMB-231 Cell-derived Exosomes Increase the Resistance of Recipient Cells in an Exosomal miR-423-5p-dependent Manner," Curr. Drug Metab., vol. 20, no. 10, pp. 804-814, Aug. 2019, doi: 10.2174/1389200220666190819151946. 
[275] H. Najminejad et al., "Emerging roles of exosomal miRNAs in breast cancer drug resistance," IUBMB Life, vol. 71, no. 11. Blackwell Publishing Ltd, pp. 1672-1684, Nov. 01, 2019, doi: 10.1002/iub.2116.

[276] D. H. Bach, J. Y. Hong, H. J. Park, and S. K. Lee, "The role of exosomes and miRNAs in drug-resistance of cancer cells," International Journal of Cancer, vol. 141, no. 2. Wiley-Liss Inc., pp. 220-230, Jul. 15, 2017, doi: 10.1002/ijc.30669.

[277] L. Mao et al., "Exosomes decrease sensitivity of breast cancer cells to adriamycin by delivering microRNAs," Tumor Biol., vol. 37, no. 4, pp. 52475256, Apr. 2016, doi: 10.1007/s13277-015-4402-2.

[278] L. Zhao, W. Liu, J. Xiao, and B. Cao, "The role of exosomes and 'exosomal shuttle microRNA' in tumorigenesis and drug resistance," Cancer Letters, vol. 356, no. 2. Elsevier Ireland Ltd, pp. 339-346, Jan. 28, 2015, doi: 10.1016/j.canlet.2014.10.027.

[279] W.-X. Chen et al., "Analysis of miRNA signature differentially expressed in exosomes from adriamycin-resistant and parental human breast cancer cells.," Biosci. Rep., vol. 38, no. 6, Nov. 2018, doi: 10.1042/BSR20181090.

[280] X. Pan et al., "Exosomal MicroRNA-221-3p Confers Adriamycin Resistance in Breast Cancer Cells by Targeting PIK3R1," Front. Oncol., vol. 10, Apr. 2020, doi: $10.3389 /$ fonc. 2020.00441 .

[281] V. Ciravolo et al., "Potential role of HER2-overexpressing exosomes in countering trastuzumab-based therapy," J. Cell. Physiol., vol. 227, no. 2, pp. 658-667, Jan. 2012, doi: 10.1002/jcp.22773. 
[282] H. Dong et al., "Exosome-mediated transfer of IncRNA-SNHG14 promotes trastuzumab chemoresistance in breast cancer," Int. J. Oncol., vol. 53, no. 3, pp. 1013-1026, Sep. 2018, doi: 10.3892/ijo.2018.4467.

[283] M. Han et al., "Exosome-mediated IncRNA AFAP1-AS1 promotes trastuzumab resistance through binding with AUF1 and activating ERBB2 translation," Mol. Cancer, vol. 19, no. 1, Feb. 2020, doi: 10.1186/s12943-020-1145-5.

[284] M. Han et al., "Exosome-transmitted miR-567 reverses trastuzumab resistance by inhibiting ATG5 in breast cancer," Cell Death Dis., vol. 11, no. 1, Jan. 2020, doi: 10.1038/s41419-020-2250-5.

[285] Y. Song et al., "Exosomal miR-146a Contributes to the Enhanced Therapeutic Efficacy of Interleukin-1ß-Primed Mesenchymal Stem Cells Against Sepsis," Stem Cells, vol. 35, no. 5, pp. 1208-1221, May 2017, doi: 10.1002/stem.2564.

[286] W. Yin et al., "Immature Exosomes Derived from MicroRNA-146a Overexpressing Dendritic Cells Act as Antigen-Specific Therapy for Myasthenia Gravis," Inflammation, vol. 40, no. 4, pp. 1460-1473, Aug. 2017, doi: 10.1007/s10753-017-0589-2.

[287] Y. Fu et al., "Exosome-mediated miR-146a transfer suppresses type I interferon response and facilitates EV71 infection," PLoS Pathog., vol. 13, no. 9, Sep. 2017, doi: 10.1371/journal.ppat.1006611.

[288] D. C et al., "Circulating Exosomes Derived-miR-146a from Systemic Lupus Erythematosus Patients Regulates Senescence of Mesenchymal Stem Cells," Biomed Res. Int., vol. 2019, 2019, doi: 10.1155/2019/6071308. 
[289] J. Pan, M. Alimujiang, Q. Chen, H. Shi, and X. Luo, "Exosomes derived from miR-146a-modified adipose-derived stem cells attenuate acute myocardial infarction-induced myocardial damage via downregulation of early growth response factor 1," J. Cell. Biochem., vol. 120, no. 3, pp. 4433-4443, Mar. 2019, doi: $10.1002 / j c b .27731$.

[290] J. Perez-Hernandez et al., "Urinary exosome miR-146a is a potential marker of albuminuria in essential hypertension," J. Transl. Med., vol. 16, no. 1, Aug. 2018, doi: 10.1186/s12967-018-1604-6.

[291] S. Kumar and P. H. Reddy, "Are circulating microRNAs peripheral biomarkers for Alzheimer's disease?," Biochimica et Biophysica Acta - Molecular Basis of Disease, vol. 1862, no. 9. Elsevier B.V., pp. 1617-1627, Sep. 01, 2016, doi: 10.1016/j.bbadis.2016.06.001.

[292] "MiR-146a-5p level in serum exosomes predicts therapeutic effect of cisplatin in non-small cell lung cancer - PubMed." https://pubmed.ncbi.nlm.nih.gov/28678319/.

[293] W. C. Cheng et al., "RAB27B-activated secretion of stem-like tumor exosomes delivers the biomarker microRNA-146a-5p, which promotes tumorigenesis and associates with an immunosuppressive tumor microenvironment in colorectal cancer," Int. J. Cancer, vol. 145, no. 8, pp. 2209-2224, 2019, doi: 10.1002/ijc.32338.

[294] N. Zare, N. Eskandari, V. Mehrzad, and S. Javanmard, "The expression level of hsa-miR-146a-5p in plasma-derived exosomes of patients with diffuse large B-cell lymphoma," J. Res. Med. Sci., vol. 24, no. 1, Jan. 2019, doi: 10.4103/jrms.JRMS_507_18. 
[295] U. Warnecke-Eberz, S. H. Chon, A. H. Hölscher, U. Drebber, and E. Bollschweiler, "Exosomal onco-miRs from serum of patients with adenocarcinoma of the esophagus: comparison of miRNA profiles of exosomes and matching tumor," Tumor Biol., vol. 36, no. 6, pp. 4643-4653, Jun. 2015, doi: 10.1007/s13277-015-3112-0.

[296] R. Kalluri, "The biology and function of exosomes in cancer," Journal of Clinical Investigation, vol. 126, no. 4. American Society for Clinical Investigation, pp. 1208-1215, Apr. 01, 2016, doi: 10.1172/JCI81135.

[297] W. Guo et al., "Exosomes: New players in cancer (Review)," Oncology Reports, vol. 38, no. 2. Spandidos Publications, pp. 665-675, Aug. 01, 2017, doi: 10.3892/or.2017.5714.

[298] H. Kim et al., "The Emerging Roles of Exosomes as EMT Regulators in Cancer," Cells, vol. 9, no. 4, p. 861, Apr. 2020, doi: 10.3390/cells9040861.

[299] A. S. Azmi, B. Bao, and F. H. Sarkar, "Exosomes in cancer development, metastasis, and drug resistance: A comprehensive review," Cancer and Metastasis Reviews, vol. 32, no. 3-4. NIH Public Access, pp. 623-642, Dec. 2013, doi: 10.1007/s10555-013-9441-9.

[300] L. Zhang and D. Yu, "Exosomes in cancer development, metastasis, and immunity," Biochimica et Biophysica Acta - Reviews on Cancer, vol. 1871, no. 2. Elsevier B.V., pp. 455-468, Apr. 01, 2019, doi: 10.1016/j.bbcan.2019.04.004.

[301] D. Xiao et al., "Melanoma cell-derived exosomes promote epithelialmesenchymal transition in primary melanocytes through paracrine/autocrine signaling in the tumor microenvironment," Cancer Lett., vol. 376, no. 2, pp. 318-327, Jul. 2016, doi: 10.1016/j.canlet.2016.03.050. 
[302] S. S. Yang et al., "Breast cancer-derived exosomes regulate cell invasion and metastasis in breast cancer via miR-146a to activate cancer associated fibroblasts in tumor microenvironment," Exp. Cell Res., vol. 391, no. 2, Jun. 2020, doi: 10.1016/j.yexcr.2020.111983.

[303] "LPS induces HUVEC angiogenesis in vitro through miR-146a-mediated TGF$\beta 1$ inhibition - PubMed." https://pubmed.ncbi.nlm.nih.gov/28337286/.

[304] H. Y. Zhu et al., "Up-regulation of FGFBP1 signaling contributes to MIR-146ainduced angiogenesis in human umbilical vein endothelial cells," Sci. Rep., vol. 6, Apr. 2016, doi: 10.1038/srep25272.

[305] K. Horie et al., "Exosomes expressing carbonic anhydrase 9 promote angiogenesis," Biochem. Biophys. Res. Commun., vol. 492, no. 3, pp. 356-361, Oct. 2017, doi: 10.1016/j.bbrc.2017.08.107.

[306] M. Gong et al., "Mesenchymal stem cells release exosomes that transfer miRNAs to endothelial cells and promote angiogenesis," Oncotarget, vol. 8, no. 28 , pp. 45200-45212, 2017, doi: 10.18632/oncotarget.16778.

[307] J. Zhang et al., "Exosome and exosomal microRNA: Trafficking, sorting, and function," Genomics, Proteomics and Bioinformatics, vol. 13, no. 1. Beijing Genomics Institute, pp. 17-24, Feb. 01, 2015, doi: 10.1016/j.gpb.2015.02.001.

[308] X. Liang, L. Zhang, S. Wang, Q. Han, and R. C. Zhao, "Exosomes secreted by mesenchymal stem cells promote endothelial cell angiogenesis by transferring miR-125a," J. Cell Sci., vol. 129, no. 11, pp. 2182-2189, Jun. 2016, doi: $10.1242 /$ jcs.170373. 
ANNEXES 



\section{Annexes}

Annex I.

Results obtained in the array of miRNAs expression in the cell BT474wt/r, SKBR-3wt/r, HCC-1954 and MDA-MB-231.

BT-474wt vs BT-474r statistically significant microRNAs:

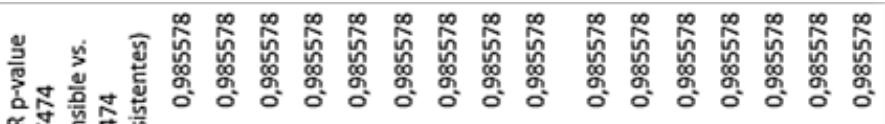

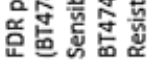

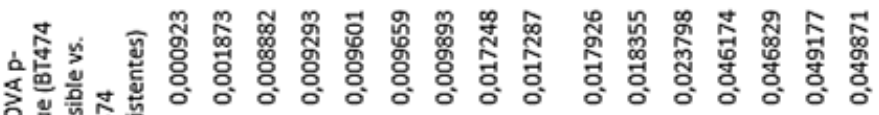

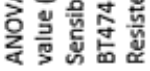

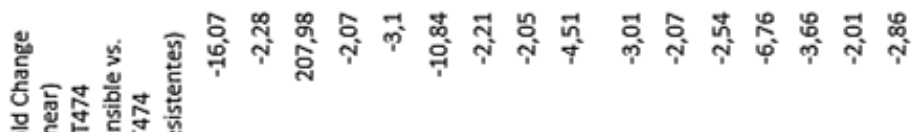

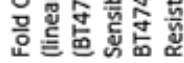

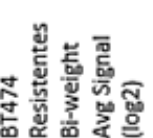

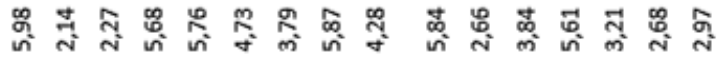
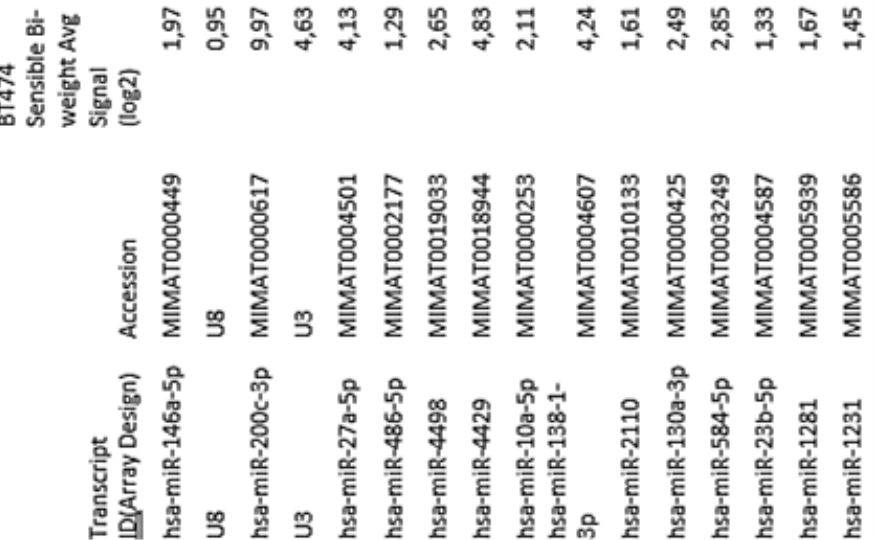

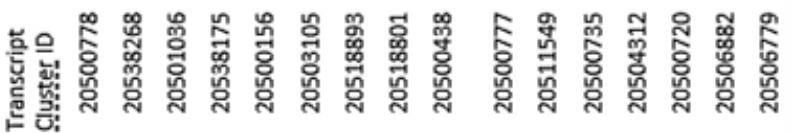




\section{Annexes}

BT-474wt vs HCC1954 statistically significant microRNAs:

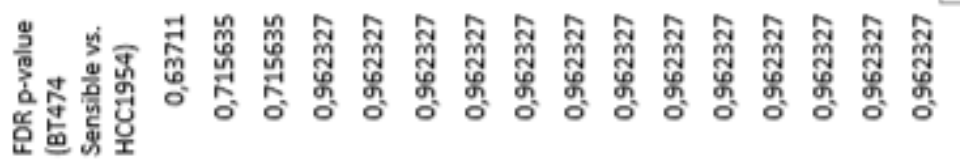

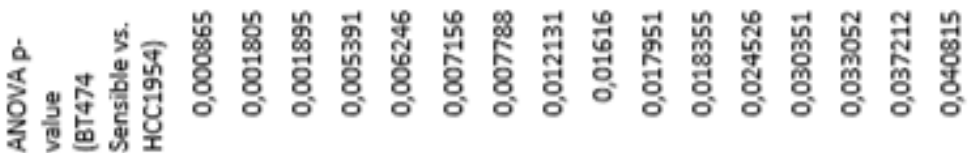

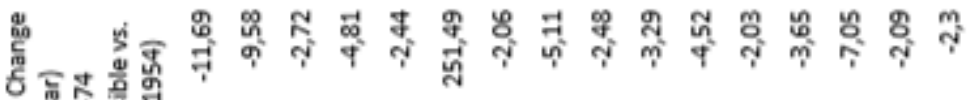

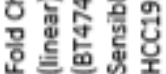

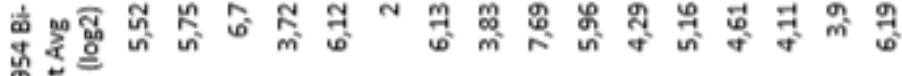

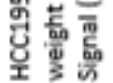

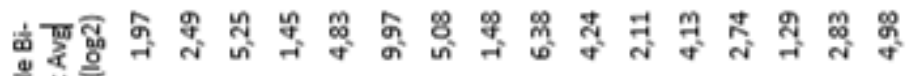

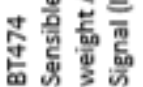
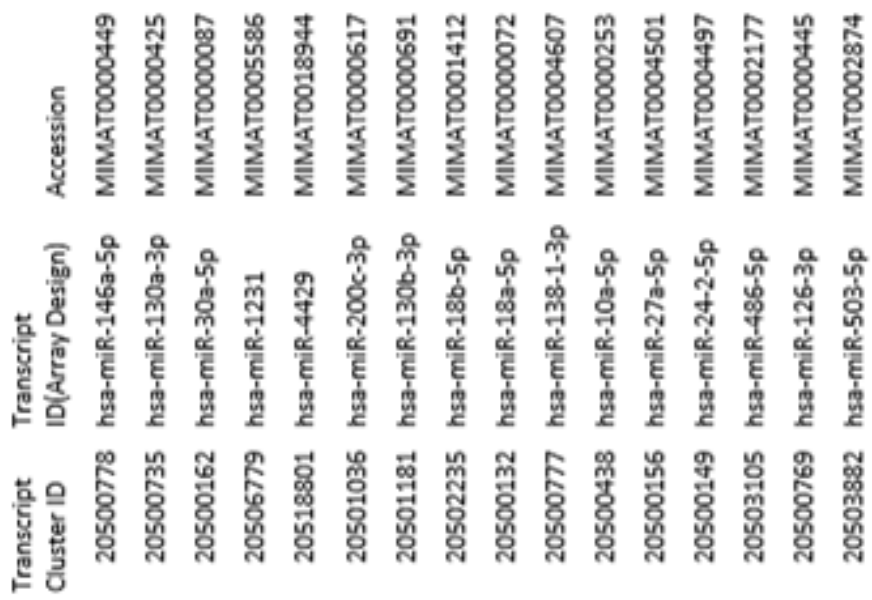
BT-474r vs HCC1954 statistically significant microRNAs:

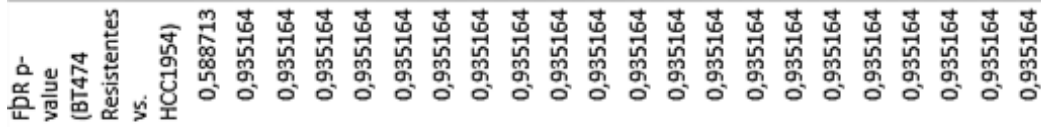

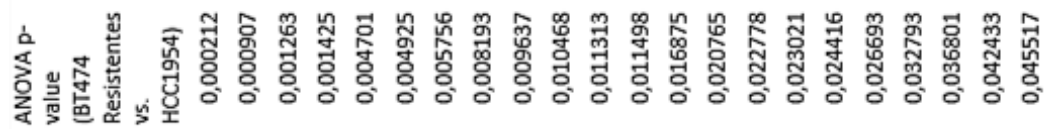

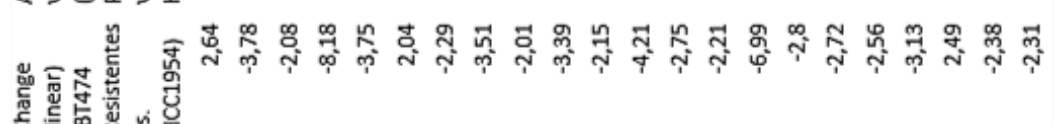

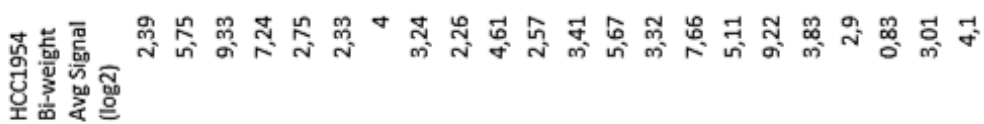

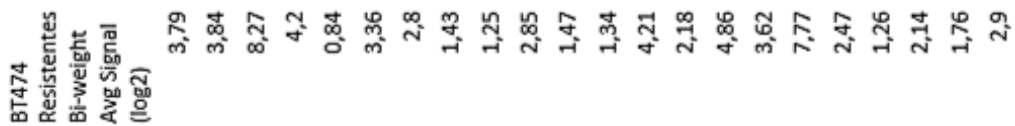
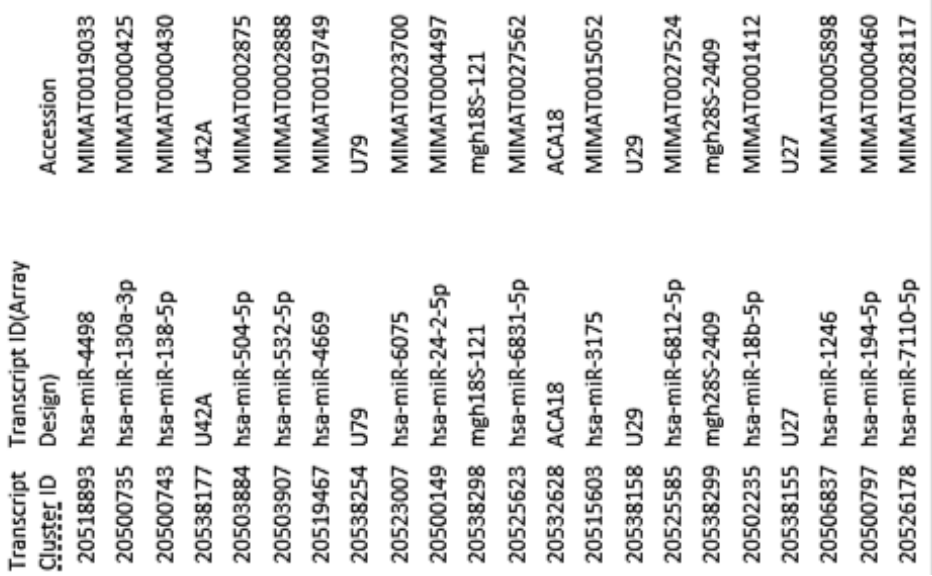


\section{Annexes}

SKBR-3wt vs SKBR-3r statistically significant microRNAs:

\begin{tabular}{|c|c|c|c|c|c|c|c|}
\hline & & & SKBR3 & & Fold & & \\
\hline & & & Sensibles & & Change & & \\
\hline & & & & SKBR3 & (linear) & value & FDR $p$-value \\
\hline & & & weight & Resistentes & (SKBR3 & $(S$ & KKBR3 \\
\hline & & & Avg & Bi-weight & Sensibles & Sensibles & Sensibles \\
\hline $\begin{array}{l}\text { Transcript } \\
\text { Cluster ID }\end{array}$ & Transcript & & Signal & Avg Signal & vs. SKBR3 & vs. SKBR3 & vs. SKBR3 \\
\hline Cluster ID & ID(Array Design) & Accession & $(\log 2)$ & $(\log 2)$ & Resistentes) & Resistentes) & Resistentes) \\
\hline 20500778 & hsa-miR-146a-5p & MIMAT0000449 & 5,12 & 7,47 & $-5,1$ & 0,000347 & 0,97962 \\
\hline 20506712 & hsa-miR-1180-3p & MIMAT0005825 & 2,49 & 3,59 & $-2,15$ & 0,010645 & 0,97962 \\
\hline 20501293 & hsa-miR-331-3p & MIMAT0000760 & 1,97 & 3,08 & $-2,15$ & 0,014275 & 0,97962 \\
\hline 20518844 & hsa-miR-4462 & MIMAT0018986 & 0,84 & 1,92 & $-2,12$ & 0,022156 & 0,97962 \\
\hline
\end{tabular}

SKBR-3wt vs HCC1954 statistically significant microRNAs:

$\begin{array}{cl}\text { Transcript } & \text { Transcript } \\ \text { Cluster ID } & \text { ID(Array Design) } \\ 20532628 & \text { ACA18 } \\ 20506712 & \text { hsa-miR-1180-3p } \\ 20504298 & \text { hsa-miR-574-3p } \\ 20503884 & \text { hsa-miR-504-5p } \\ 20538298 & \text { mgh18S-121 } \\ 20517675 & \text { hsa-miR-378c } \\ 20501293 & \text { hsa-miR-331-3p } \\ 20506837 & \text { hsa-miR-1246 } \\ 20518785 & \text { hsa-miR-4417 } \\ 20500432 & \text { hsa-miR-139-5p } \\ 20517902 & \text { hsa-miR-3651 } \\ 20517816 & \text { hsa-miR-3609 } \\ 20538218 & \text { U63 } \\ 20538149 & \text { U23 } \\ 20502235 & \text { hsa-miR-18b-5p } \\ 20504408 & \text { hsa-miR-652-3p } \\ 20519409 & \text { hsa-miR-4634 }\end{array}$

Accession ( $\log 2)$

ACA18

MIMAT0005825

MIMAT0003239

MIMAT0002875

mgh18S-121

MIMAT0016847

MIMAT0000760

MIMAT0005898

MIMAT0018929

MIMAT0000250

MIMAT0018071

MIMAT0017986

U63

U23

MIMAT0001412

MIMAT0003322

MIMAT0019691
SKBR3

Sensibles

Bi-weight

Avg Signal

$(\log 2)$
Fold

Change

(linear)

(SKBR3

Sensibles

vs.

HCC1954

$(\log 2)$
5,67

3,97

6,01

2,75

2,57

2,71

3,1

0,83

2,65

3,85

4,51

4,06

2,31

1,93

3,83

4,62

3,64
ANOVA p-

value

(SKBR3

Sensibles

vs.

HCC1954)

0,001655

0,002066

0,003745

0,00449

0,005179

0,012405

0,014233

0,015667

0,016222

0,016799

0,021831

0,026343

0,027864

0,029479

0,034835

0,03927

0,045097
FDR p-

value

(SKBR3

Sensibles

vs.

HCC1954)

0,609662

0,721015

0,830061

0,830061

0,830061

0,941234

0,941234

0,941234

0,941234

0,941234

0,941234

0,941234

0,941234

0,941234

0,941234

0,941234

0,941234 


\section{Annexes}

SKBR-3r vs HCC-1954 statistically significant microRNAs:

$\begin{array}{lll}\begin{array}{l}\text { Transcript } \\ \text { Cluster ID }\end{array} & \text { ID(Arrayscript } & \\ 20500778 & \text { hsa-miR-146a-5p } & \text { MIMAT0000449 } \\ 20538298 & \text { mgh18S-121 } & \text { mgh18S-121 } \\ 20500150 & \text { hsa-miR-25-5p } & \text { MIMAT0004498 } \\ 20503884 & \text { hsa-miR-504-5p } & \text { MIMAT0002875 } \\ 20518432 & \text { hsa-miR-3911 } & \text { MIMAT0018185 } \\ 20519467 & \text { hsa-miR-4669 } & \text { MIMAT0019749 } \\ 20502235 & \text { hsa-miR-18b-5p } & \text { MIMAT0001412 } \\ 20538204 & \text { U55 } & \text { U55 } \\ 20500149 & \text { hsa-miR-24-2-5p } & \text { MIMAT0004497 } \\ 20538256 & \text { U81 } & \text { U81 } \\ 20519595 & \text { hsa-miR-4743-5p } & \text { MIMAT0019874 } \\ 20525623 & \text { hsa-miR-6831-5p } & \text { MIMAT0027562 }\end{array}$

\begin{tabular}{|c|c|c|c|c|}
\hline & & Fold & & \\
\hline SKBR3 & HCC1954 & $\begin{array}{l}\text { Change } \\
\text { (linear) }\end{array}$ & $\begin{array}{l}\text { ANOVA p- } \\
\text { value }\end{array}$ & $\begin{array}{l}\text { FDR } p- \\
\text { value }\end{array}$ \\
\hline Resistentes & Bi-weight & (SKBR3 & (SKBR3 & (SKBR3 \\
\hline Bi-weight & Avg & Resistentes & Resistentes & Resistentes \\
\hline $\begin{array}{l}\text { Avg Signal } \\
(\log 2)\end{array}$ & $\begin{array}{l}\text { Signal } \\
(\log 2)\end{array}$ & $\begin{array}{l}\text { vs. } \\
\text { HCC1954) }\end{array}$ & $\begin{array}{l}\text { vs. } \\
\text { HCC1954) }\end{array}$ & $\begin{array}{l}\text { vs. } \\
\text { HCC1954) }\end{array}$ \\
\hline 7,47 & 5,52 & 3,85 & 0,000025 & 0,166382 \\
\hline 1,33 & 2,57 & $-2,36$ & 0,000603 & 0,734154 \\
\hline 3,15 & 1,71 & 2,72 & 0,000893 & 0,734154 \\
\hline 0,74 & 2,75 & $-4,02$ & 0,003881 & 0,871577 \\
\hline 1,53 & 2,66 & $-2,2$ & 0,005815 & 0,871577 \\
\hline 2,62 & 4 & $-2,6$ & 0,008852 & 0,871577 \\
\hline 2,45 & 3,83 & $-2,6$ & 0,01225 & 0,871577 \\
\hline 4,85 & 6,05 & $-2,3$ & 0,015208 & 0,871577 \\
\hline 3,55 & 4,61 & $-2,08$ & 0,016308 & 0,871577 \\
\hline 0,95 & 2,19 & $-2,35$ & 0,033478 & 0,871577 \\
\hline 1,29 & 2,38 & $-2,13$ & 0,045002 & 0,871577 \\
\hline 2,13 & 3,41 & $-2,43$ & 0,049608 & 0,871577 \\
\hline
\end{tabular}




\section{Annexes}

BT-474wt vs MDA-MB-231 statistically significant microRNAs:

\begin{tabular}{|c|c|c|c|c|c|c|c|}
\hline & & & & & Fold & & \\
\hline & & & $\begin{array}{l}\text { BT474 } \\
\text { Sensible }\end{array}$ & $\begin{array}{l}\text { MDA-MB- } \\
231 \mathrm{Bi}-\end{array}$ & $\begin{array}{l}\text { Change } \\
\text { (linear) } \\
\text { (BT474 }\end{array}$ & $\begin{array}{l}\text { ANOVA p- } \\
\text { value } \\
\text { (BT474 }\end{array}$ & $\begin{array}{l}\text { FDR p- } \\
\text { value } \\
\text { (BT474 }\end{array}$ \\
\hline & Transcript & & Bi-weight & weight & Sensible & Sensible & Sensible \\
\hline $\begin{array}{l}\text { Transcript } \\
\text { Cluster ID }\end{array}$ & $\begin{array}{l}\text { ID(Array } \\
\text { Design) }\end{array}$ & Accession & $\begin{array}{l}\text { Avg Signal } \\
(\log 2)\end{array}$ & $\begin{array}{l}\text { Avg Signal } \\
(\log 2)\end{array}$ & $\begin{array}{l}\text { vs. MDA- } \\
\text { MB-231) }\end{array}$ & $\begin{array}{l}\text { vs. MDA- } \\
\text { MB-231) }\end{array}$ & $\begin{array}{l}\text { vs. MDA- } \\
\text { MB-231) }\end{array}$ \\
\hline & hsa-miR- & & & & & & \\
\hline 20501036 & $\begin{array}{l}\text { 200c-3p } \\
\text { hsa-miR- }\end{array}$ & MIMAT0000617 & 9,97 & 1,4 & 379,77 & 0,001354 & 0,934308 \\
\hline 20500778 & $146 a-5 p$ & MIMAT0000449 & 1,97 & 6,35 & $-20,81$ & 0,004525 & 0,934308 \\
\hline 20515550 & $\begin{array}{l}\text { hsa-miR-3141 } \\
\text { hsa-miR- }\end{array}$ & MIMAT0015010 & 6,12 & 4,94 & 2,27 & 0,007888 & 0,934308 \\
\hline 20525523 & $\begin{array}{l}\text { 6781-5p } \\
\text { hsa-miR- }\end{array}$ & MIMAT0027462 & 2,17 & 1,15 & 2,04 & 0,008821 & 0,934308 \\
\hline 20506763 & $1225-5 p$ & MIMAT0005572 & 2,93 & 1,64 & 2,45 & 0,011679 & 0,934308 \\
\hline 20517824 & $\begin{array}{l}\text { hsa-miR-3615 } \\
\text { hsa-miR- }\end{array}$ & MIMAT0017994 & 1,2 & 2,67 & $-2,76$ & 0,021238 & 0,934308 \\
\hline 20506776 & $1229-5 p$ & MIMAT0022942 & 3,09 & 0,87 & 4,66 & 0,021949 & 0,934308 \\
\hline 20518931 & $\begin{array}{l}\text { hsa-miR-4530 } \\
\text { hsa-miR-27b- }\end{array}$ & MIMAT0019069 & 7,4 & 8,56 & $-2,24$ & 0,024186 & 0,934308 \\
\hline 20500723 & $\begin{array}{l}3 p \\
\text { hsa-miR-625- }\end{array}$ & MIMAT0000419 & 6,37 & 7,51 & $-2,2$ & 0,036798 & 0,934308 \\
\hline 20504372 & $\begin{array}{l}5 p \\
\text { hsa-miR-21- }\end{array}$ & MIMAT0003294 & 4,44 & 3,25 & 2,28 & 0,038022 & 0,934308 \\
\hline 20500141 & $\begin{array}{l}5 p \\
\text { hsa-miR-455- }\end{array}$ & MIMAT0000076 & 5,07 & 2,5 & 5,96 & 0,038871 & 0,934308 \\
\hline 20504187 & $\begin{array}{l}3 p \\
\text { hsa-miR-584- }\end{array}$ & MIMAT0004784 & 6,07 & 7,46 & $-2,61$ & 0,039515 & 0,934308 \\
\hline 20504312 & $5 p$ & MIMAT0003249 & 2,85 & 5,11 & $-4,78$ & 0,039572 & 0,934308 \\
\hline 20538113 & SNORD123 & SNORD123 & 4,87 & 3,43 & 2,71 & 0,041502 & 0,934308 \\
\hline 20500120 & hsa-let-7d-3p & MIMAT0004484 & 3,45 & 1,62 & 3,57 & 0,04453 & 0,934308 \\
\hline 20519467 & hsa-miR-4669 & MIMAT0019749 & 3,67 & 2,31 & 2,57 & 0,045697 & 0,934308 \\
\hline 20518432 & $\begin{array}{l}\text { hsa-miR-3911 } \\
\text { hsa-miR-574- }\end{array}$ & MIMAT0018185 & 3,29 & 1,63 & 3,17 & 0,046304 & 0,934308 \\
\hline 20504298 & $3 p$ & MIMAT0003239 & 2,98 & 6,42 & $-10,81$ & 0,046526 & 0,934308 \\
\hline
\end{tabular}




\section{Annexes}

\begin{tabular}{|c|c|c|c|c|c|c|c|}
\hline & & & $\begin{array}{l}\text { BT474 } \\
\text { Resistentes }\end{array}$ & $\begin{array}{l}\text { MDA- } \\
\text { MB-231 } \\
\text { Bi- } \\
\text { weight }\end{array}$ & $\begin{array}{l}\text { Fold } \\
\text { Change } \\
\text { (linear) } \\
\text { (BT474 }\end{array}$ & $\begin{array}{l}\text { ANOVA p- } \\
\text { value } \\
\text { (BT474 }\end{array}$ & $\begin{array}{l}\text { FDR p- } \\
\text { value } \\
\text { (BT474 }\end{array}$ \\
\hline & Transcript & & Bi-weight & Avg & Resistentes & Resistentes & Resistentes \\
\hline ranscript & $\mathrm{ID}$ (Array & & Avg Signal & Signal & vs. MDA- & vs. MDA- & vs. MDA- \\
\hline luster ID & $\begin{array}{l}\text { Design) } \\
\text { hsa-miR- }\end{array}$ & Accession & $(\log 2)$ & $(\log 2)$ & MB-231) & MB-231) & MB-231) \\
\hline 20503907 & $\begin{array}{l}\text { 532-5p } \\
\text { hsa-miR- }\end{array}$ & MIMAT0002888 & 3,36 & 1,1 & 4,79 & 0,000023 & 0,071464 \\
\hline 20518893 & $\begin{array}{l}4498 \\
\text { hsa-miR- }\end{array}$ & MIMAT0019033 & 3,79 & 1,81 & 3,95 & 0,000032 & 0,071464 \\
\hline 20500452 & $183-5 p$ & MIMAT0000261 & 4,1 & 1,98 & 4,37 & 0,000375 & 0,32577 \\
\hline 20538268 & $\begin{array}{l}\text { U8 } \\
\text { hsa-miR- }\end{array}$ & U8 & 2,14 & 0,81 & 2,5 & 0,000393 & 0,32577 \\
\hline 20504372 & $\begin{array}{l}625-5 p \\
\text { hsa-miR- }\end{array}$ & MIMAT0003294 & 4,82 & 3,25 & 2,97 & 0,000505 & 0,334864 \\
\hline 20515617 & $\begin{array}{l}3185 \\
\text { hsa-miR- }\end{array}$ & MIMAT0015065 & 5,73 & 4,49 & 2,37 & 0,000942 & 0,417985 \\
\hline 20526861 & $\begin{array}{l}7150 \\
\text { hsa-miR- }\end{array}$ & MIMAT0028211 & 2,96 & 1,51 & 2,73 & 0,001948 & 0,578701 \\
\hline 20506763 & $\begin{array}{l}1225-5 p \\
\text { hsa-miR- }\end{array}$ & MIMAT0005572 & 3,14 & 1,64 & 2,82 & 0,002113 & 0,578701 \\
\hline 20519607 & $\begin{array}{l}\text { 4749-5p } \\
\text { hsa-miR- }\end{array}$ & MIMAT0019885 & 2,96 & 1,55 & 2,66 & 0,002619 & 0,578701 \\
\hline 20503105 & $\begin{array}{l}486-5 p \\
\text { hsa-miR- }\end{array}$ & MIMAT0002177 & 4,73 & 2,27 & 5,51 & 0,002675 & 0,578701 \\
\hline 20517835 & $\begin{array}{l}3621 \\
\text { hsa-miR- }\end{array}$ & MIMAT0018002 & 5,83 & 4,15 & 3,2 & 0,002676 & 0,578701 \\
\hline 20511549 & $\begin{array}{l}2110 \\
\text { hsa-miR- }\end{array}$ & MIMAT0010133 & 2,66 & 1,27 & 2,63 & 0,003268 & 0,596435 \\
\hline 20506779 & $\begin{array}{l}1231 \\
\text { hsa-miR- }\end{array}$ & MIMAT0005586 & 2,97 & 1,39 & 3 & 0,005092 & 0,695537 \\
\hline 20518425 & $\begin{array}{l}3180 \\
\text { hsa-miR- }\end{array}$ & МIMAT0018178 & 3,19 & 1,44 & 3,35 & 0,005141 & 0,695537 \\
\hline 20506771 & $\begin{array}{l}\text { 1227-5p } \\
\text { hsa-miR- }\end{array}$ & MIMAT0022941 & 5,99 & 4,81 & 2,27 & 0,005236 & 0,695537 \\
\hline 20518785 & $\begin{array}{l}4417 \\
\text { hsa-miR-21- }\end{array}$ & MIMAT0018929 & 3,19 & 1,91 & 2,43 & 0,005284 & 0,695537 \\
\hline 20500141 & $\begin{array}{l}5 p \\
\text { hsa-miR- }\end{array}$ & MIMAT0000076 & 5,65 & 2,5 & 8,9 & 0,006942 & 0,695537 \\
\hline 20518940 & $\begin{array}{l}1587 \\
\text { hsa-miR- }\end{array}$ & MIMAT0019077 & 3,38 & 1,56 & 3,54 & 0,00727 & 0,695537 \\
\hline 20517824 & $\begin{array}{l}3615 \\
\text { hsa-miR- }\end{array}$ & MIMAT0017994 & 1,36 & 2,67 & $-2,47$ & 0,008186 & 0,695537 \\
\hline 20500737 & $\begin{array}{l}132-3 p \\
\text { hsa-miR- }\end{array}$ & MIMAT0000426 & 6,02 & 4,79 & 2,33 & 0,00822 & 0,695537 \\
\hline 20525657 & $\begin{array}{l}\text { 6848-5p } \\
\text { hsa-miR- }\end{array}$ & MIMAT0027596 & 2,79 & 1,62 & 2,25 & 0,008525 & 0,695537 \\
\hline 20505790 & $\begin{array}{l}\text { 885-3p } \\
\text { hsa-miR- }\end{array}$ & MIMAT0004948 & 2,37 & 1,34 & 2,03 & 0,009066 & 0,695537 \\
\hline 20519429 & $4649-5 p$ & MIMAT0019711 & 4,11 & 2,39 & 3,29 & 0,010224 & 0,695537 \\
\hline
\end{tabular}




\section{Annexes}

\begin{tabular}{|c|c|c|c|c|c|c|c|}
\hline \multirow{2}{*}{20518625} & \multicolumn{7}{|l|}{ hsa-miR- } \\
\hline & $\begin{array}{l}3937 \\
\text { hsa-miR- }\end{array}$ & MIMAT0018352 & 3,95 & 2,45 & 2,84 & 0,010582 & 0,695537 \\
\hline 20509227 & $\begin{array}{l}\text { 1909-3p } \\
\text { hsa-miR- }\end{array}$ & MIMAT0007883 & 3,88 & 2,61 & 2,41 & 0,011625 & 0,695537 \\
\hline 20519494 & $\begin{array}{l}1343-5 p \\
\text { hsa-miR- }\end{array}$ & MIMAT0027038 & 5,41 & 3,61 & 3,48 & 0,011733 & 0,695537 \\
\hline 20525557 & $\begin{array}{l}\text { 6798-5p } \\
\text { hsa-miR- }\end{array}$ & MIMAT0027496 & 4,32 & 2,15 & 4,5 & 0,012665 & 0,696306 \\
\hline 20500156 & $\begin{array}{l}27 a-5 p \\
\text { hsa-miR- }\end{array}$ & MIMAT0004501 & 5,76 & 3,92 & 3,59 & 0,016092 & 0,769509 \\
\hline 20518852 & 4467 & MIMAT0018994 & 6,1 & 4,46 & 3,12 & 0,016283 & 0,769509 \\
\hline 20538113 & $\begin{array}{l}\text { SNORD123 } \\
\text { hsa-miR- }\end{array}$ & SNORD123 & 4,85 & 3,43 & 2,66 & 0,017921 & 0,770327 \\
\hline 20525571 & $\begin{array}{l}6805-5 p \\
\text { hsa-miR- }\end{array}$ & MIMAT0027510 & 6,76 & 5,6 & 2,24 & 0,018028 & 0,770327 \\
\hline 20519524 & $\begin{array}{l}4706 \\
\text { hsa-miR- }\end{array}$ & MIMAT0019806 & 3,56 & 1,99 & 2,97 & 0,018123 & 0,770327 \\
\hline 20525535 & $\begin{array}{l}\text { 6787-5p } \\
\text { hsa-miR- }\end{array}$ & MIMAT0027474 & 3,39 & 2,17 & 2,33 & 0,020499 & 0,781206 \\
\hline 20519405 & $\begin{array}{l}\text { 4632-5p } \\
\text { hsa-miR- }\end{array}$ & MIMAT0022977 & 5,08 & 3,95 & 2,19 & 0,020818 & 0,782992 \\
\hline 20517899 & $\begin{array}{l}3648 \\
\text { hsa-miR- }\end{array}$ & MIMAT0018068 & 3,1 & 2 & 2,14 & 0,024989 & 0,791829 \\
\hline 20500432 & $\begin{array}{l}\text { 139-5p } \\
\text { hsa-miR- }\end{array}$ & MIMAT0000250 & 3,93 & 2,64 & 2,44 & 0,030546 & 0,791829 \\
\hline 20500746 & $\begin{array}{l}140-3 p \\
\text { hsa-miR- }\end{array}$ & MIMAT0004597 & 5,7 & 3,99 & 3,28 & 0,031458 & 0,791829 \\
\hline 20500769 & $\begin{array}{l}\text { 126-3p } \\
\text { hsa-miR- }\end{array}$ & MIMAT0000445 & 3,65 & 2,64 & 2,02 & 0,032846 & 0,812703 \\
\hline 20525503 & $\begin{array}{l}6771-5 p \\
\text { hsa-let-7g- }\end{array}$ & MIMAT0027442 & 4,76 & 3,65 & 2,16 & 0,034748 & 0,820136 \\
\hline 20500713 & $\begin{array}{l}5 p \\
\text { hsa-miR- }\end{array}$ & MIMAT0000414 & 6,32 & 5,09 & 2,34 & 0,035624 & 0,828808 \\
\hline 20515610 & $\begin{array}{l}\text { 3180-3p } \\
\text { hsa-miR- }\end{array}$ & MIMAT0015058 & 2,88 & 1,73 & 2,21 & 0,040297 & 0,828838 \\
\hline 20501293 & $\begin{array}{l}\text { 331-3p } \\
\text { hsa-miR- }\end{array}$ & MIMAT0000760 & 3,36 & 2,29 & 2,11 & 0,043567 & 0,828838 \\
\hline 20525394 & $\begin{array}{l}6722-3 p \\
\text { hsa-miR- }\end{array}$ & MIMAT0025854 & 5,75 & 4,74 & 2,02 & 0,044582 & 0,828838 \\
\hline 20519525 & $\begin{array}{l}\text { 4707-5p } \\
\text { hsa-miR- }\end{array}$ & MIMAT0019807 & 6,75 & 5,74 & 2,02 & 0,04983 & 0,828838 \\
\hline 20524053 & 6132 & MIMAT0024616 & 4,04 & 2,11 & 3,82 & 0,04984 & 0,828838 \\
\hline
\end{tabular}


SKBR-3wt vs MDA-MB-231 statistically significant microRNAs:

\begin{tabular}{|c|c|c|c|c|c|c|c|}
\hline & & & $\begin{array}{l}\text { SKBR3 } \\
\text { Sensibles } \\
\text { Bi-weight }\end{array}$ & $\begin{array}{l}\text { MDA- } \\
\text { MB-231 } \\
\text { Bi-weight }\end{array}$ & $\begin{array}{l}\text { Fold } \\
\text { Change } \\
\text { (linear) } \\
\text { (SKBR3 }\end{array}$ & $\begin{array}{l}\text { ANOVA } \\
\text { p-value } \\
\text { (SKBR3 }\end{array}$ & $\begin{array}{l}\text { FDR p- } \\
\text { value } \\
\text { (SKBR3 }\end{array}$ \\
\hline $\begin{array}{l}\text { Transcrip } \\
\text { t Cluster } \\
\text { ID }\end{array}$ & $\begin{array}{l}\text { Transcript ID(Array } \\
\text { Design) }\end{array}$ & Accession & $\begin{array}{l}\text { Avg } \\
\text { Signal } \\
(\log 2)\end{array}$ & $\begin{array}{l}\text { Avg } \\
\text { Signal } \\
(\log 2)\end{array}$ & $\begin{array}{l}\text { Sensibles } \\
\text { vs. MDA- } \\
\text { MB-231) }\end{array}$ & $\begin{array}{l}\text { Sensibles } \\
\text { vs. MDA- } \\
\text { MB-231) }\end{array}$ & $\begin{array}{l}\text { Sensibles } \\
\text { vs. MDA- } \\
\text { MB-231) }\end{array}$ \\
\hline 20504372 & hsa-miR-625-5p & MIMAT0003294 & 4,74 & 3,25 & 2,81 & 0,000082 & 0,542353 \\
\hline 20501280 & hsa-miR-342-3p & MIMAT0000753 & 0,56 & 5,19 & $-24,76$ & 0,000776 & 0,77732 \\
\hline 20518893 & hsa-miR-4498 & MIMAT0019033 & 2,82 & 1,81 & 2,02 & 0,000888 & 0,77732 \\
\hline 20518785 & hsa-miR-4417 & MIMAT0018929 & 3,85 & 1,91 & 3,83 & 0,00178 & 0,861931 \\
\hline 20503907 & hsa-miR-532-5p & MIMAT0002888 & 2,14 & 1,1 & 2,05 & 0,00197 & 0,87074 \\
\hline 20504187 & hsa-miR-455-3p & MIMAT0004784 & 6,37 & 7,46 & $-2,12$ & 0,002904 & 0,9354 \\
\hline 20519607 & hsa-miR-4749-5p & MIMAT0019885 & 3 & 1,55 & 2,74 & 0,004596 & 0,9354 \\
\hline 20525444 & hsa-miR-6741-5p & MIMAT0027383 & 2,58 & 1,39 & 2,28 & 0,00573 & 0,9354 \\
\hline 20504298 & hsa-miR-574-3p & MIMAT0003239 & 4,82 & 6,42 & $-3,02$ & 0,006061 & 0,9354 \\
\hline 20538113 & SNORD123 & SNORD123 & 5,25 & 3,43 & 3,52 & 0,008582 & 0,9354 \\
\hline 20518625 & hsa-miR-3937 & MIMAT0018352 & 3,76 & 2,45 & 2,48 & 0,0108 & 0,9354 \\
\hline 20506712 & hsa-miR-1180-3p & MIMAT0005825 & 2,49 & 3,66 & $-2,26$ & 0,011276 & 0,9354 \\
\hline 20526861 & hsa-miR-7150 & MIMAT0028211 & 2,73 & 1,51 & 2,33 & 0,014814 & 0,9354 \\
\hline 5 & $\begin{array}{l}\text { ACA44 } \\
\text { ENSG0000025284 }\end{array}$ & $\begin{array}{l}\text { ACA44 } \\
\text { ENSG0000025284 }\end{array}$ & 6,07 & 7,33 & $-2,4$ & 0,017157 & 0,93545 \\
\hline 20534056 & $\begin{array}{l}0 \\
\text { ENSG0000026628 }\end{array}$ & $\begin{array}{l}0 \\
\text { ENSG0000026628 }\end{array}$ & 6,07 & 7,33 & $-2,4$ & 0,017157 & 093 \\
\hline 20534179 & 4 & 4 & 3,66 & 2,19 & 2,77 & 0,022116 & 0,93545 \\
\hline 20538168 & U36A & U36A & 3,66 & 2,19 & 2,77 & 0,022116 & 0,93545 \\
\hline 20519494 & hsa-miR-1343-5p & MIMAT0027038 & 5,43 & 3,61 & 3,52 & 0,022694 & 0,9354 \\
\hline 20525571 & hsa-miR-6805-5p & 0027510 & 6,82 & 5,6 & 2,34 & 0,023422 & ,9354 \\
\hline 20529782 & hsa-miR-8072 & MIMAT0030999 & 8,14 & 7,12 & 2,03 & 0,031464 & 0,9354 \\
\hline 20517835 & hsa-miR-3621 & MIMAT0018002 & 5,96 & 4,15 & 3,51 & 0,033054 & 0,9354 \\
\hline 20500141 & sa-miR-21-5p & MIMAT000007 & 4,82 & 2,5 & 4,98 & 0,034644 & 0,9354 \\
\hline 20517902 & hsa-miR-3651 & MIMAT0018071 & 3,48 & 4,92 & $-2,71$ & 0,036816 & 0,9354 \\
\hline 20518852 & hsa-miR-4467 & MIMAT0018994 & 5,63 & 4,46 & 2,26 & 0,038438 & 0,93545 \\
\hline 20525557 & hsa-miR-6798-5p & MIMAT0027496 & 4,63 & 2,15 & 5,58 & 0,039323 & 0,9354 \\
\hline 20518425 & hsa-miR-3180 & MIMAT0018178 & 3,13 & 1,44 & 3,23 & 0,042243 & 0,9354 \\
\hline 20525677 & hsa-miR-6858-5p & MIMAT0027616 & 6,87 & 5,74 & 2,2 & 0,044544 & 0,9354 \\
\hline 20506779 & $\begin{array}{l}\text { hsa-miR-1231 } \\
\text { ENSG0000026594 }\end{array}$ & $\begin{array}{l}\text { MIMAT0005586 } \\
\text { ENSG0000026594 }\end{array}$ & 2,8 & 1,39 & 2,66 & 0,047013 & 0,93545 \\
\hline 20534176 & 1 & 1 & 3,77 & 1,75 & 4,05 & 0,047704 & 0,93545 \\
\hline 538169 & U36B & U36B & 3,77 & 1,75 & 4,05 & 0,047704 & 0,9354 \\
\hline
\end{tabular}




\section{Annexes}

SKBR-3r vs MDA-MB-231 statistically significant microRNAs:

\begin{tabular}{|c|c|c|}
\hline $\begin{array}{l}\text { Transcr } \\
\text { ipt }\end{array}$ & Transcript & \\
\hline Cluster & ID(Array & \\
\hline ID & Design) & Accession \\
\hline 205043 & hsa-miR-625- & MIMAT00032 \\
\hline 72 & $5 p$ & 94 \\
\hline 205060 & hsa-miR-937- & MIMAT00229 \\
\hline 06 & $5 p$ & 38 \\
\hline 205012 & hsa-miR-342- & MIMAT00007 \\
\hline 80 & $3 p$ & 53 \\
\hline 205196 & hsa-miR-4749- & MIMAT00198 \\
\hline 07 & $5 p$ & 85 \\
\hline 205189 & & MIMAT00190 \\
\hline 40 & hsa-miR-1587 & 77 \\
\hline 205205 & hsa-miR-5196- & MIMAT00211 \\
\hline 77 & $5 p$ & 28 \\
\hline 205067 & hsa-miR-1225- & MIMAT00055 \\
\hline 63 & $5 p$ & 72 \\
\hline 205188 & & MIMAT00190 \\
\hline 93 & hsa-miR-4498 & 33 \\
\hline 205184 & & MIMAT00181 \\
\hline 25 & hsa-miR-3180 & 78 \\
\hline 205194 & hsa-miR-4632- & MIMAT00229 \\
\hline 05 & $5 p$ & 77 \\
\hline 205012 & hsa-miR-328- & MIMAT00264 \\
\hline 77 & $5 p$ & 86 \\
\hline 205177 & & MIMAT00169 \\
\hline 36 & R-4281 & 07 \\
\hline 205196 & hsa-miR-4750- & MIMAT00198 \\
\hline 09 & $5 p$ & 87 \\
\hline 205068 & hsa-miR-1207- & MIMAT00058 \\
\hline 01 & $5 p$ & 71 \\
\hline 205057 & hsa-miR-885- & MIMAT00049 \\
\hline 90 & $3 p$ & 48 \\
\hline 205067 & & T00055 \\
\hline 79 & hsa-miR-1231 & 86 \\
\hline 205042 & hsa-miR-92b- & 00047 \\
\hline 73 & $5 p$ & 92 \\
\hline 205186 & & MIMAT00183 \\
\hline 25 & hsa-miR-3937 & 52 \\
\hline 205255 & hsa-miR-6798- & MIMAT00274 \\
\hline 57 & $5 p$ & 96 \\
\hline 205268 & & MIMAT00282 \\
\hline 61 & mir & 11 \\
\hline
\end{tabular}

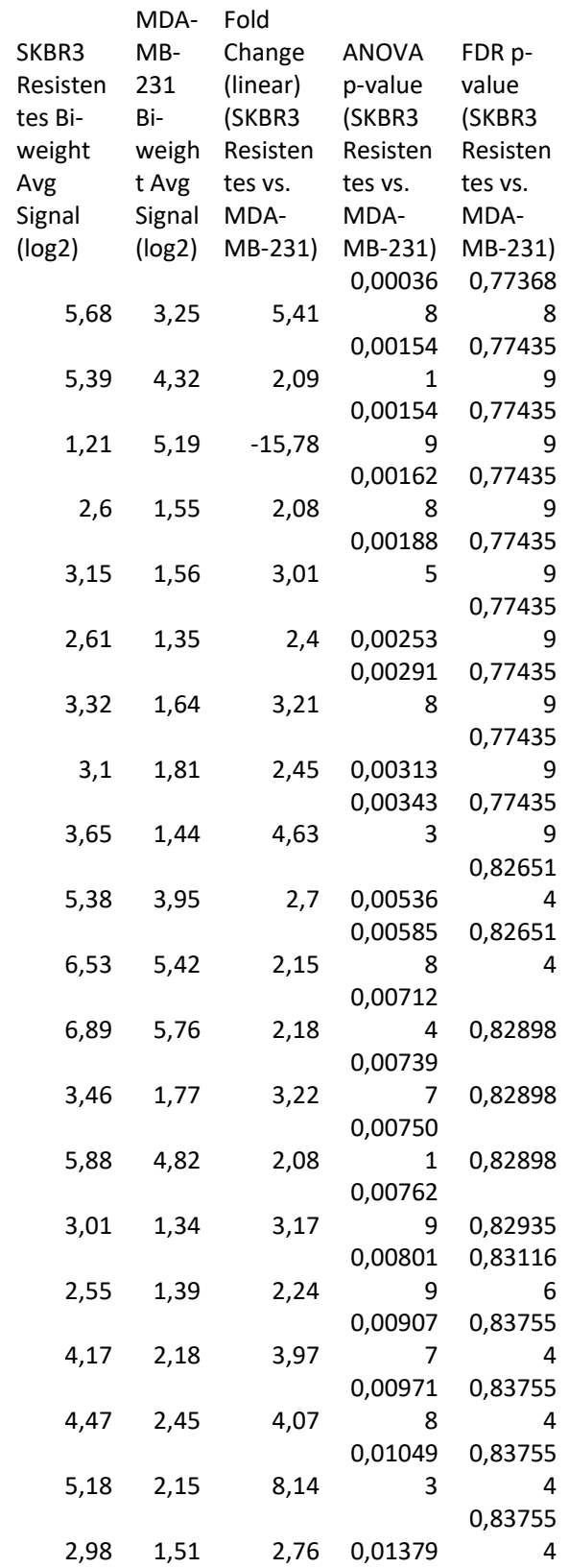


Annexes

\begin{tabular}{|c|c|c|c|c|c|c|c|}
\hline 205255 & hsa-miR-6787- & MIMAT00274 & & & & 0,01551 & 0,83755 \\
\hline 35 & $5 p$ & 74 & 4,03 & 2,17 & 3,62 & 1 & 4 \\
\hline 205255 & hsa-miR-6771- & MIMAT00274 & & & & 0,01567 & 0,83755 \\
\hline 03 & $5 p$ & 42 & 5,24 & 3,65 & 3,02 & 8 & 4 \\
\hline 205042 & hsa-miR-574- & MIMAT00032 & & & & 0,01619 & 0,83755 \\
\hline 98 & $3 p$ & 39 & 4,26 & 6,42 & $-4,47$ & 1 & \\
\hline 205187 & & MIMAT00189 & & & & 0,01711 & 0,83755 \\
\hline 85 & hsa-miR-4417 & 29 & 3,37 & 1,91 & 2,74 & 6 & \\
\hline 205067 & hsa-miR-1227- & MIMAT00229 & & & & 0,01784 & 0,83755 \\
\hline 71 & $5 p$ & 41 & 5,96 & 4,81 & 2,22 & 3 & \\
\hline 205326 & & & & & & 0,02121 & 0,83755 \\
\hline 75 & ACA44 & ACA44 & 6,28 & 7,33 & $-2,07$ & 1 & \\
\hline 205340 & ENSG0000025 & ENSG0000025 & & & & 0,02121 & 0,83755 \\
\hline 56 & 2840 & 2840 & 6,28 & 7,33 & $-2,07$ & 1 & \\
\hline 205178 & & MIMAT00180 & & & & 0,02176 & 0,83755 \\
\hline 35 & hsa-miR-3621 & 02 & 5,54 & 4,15 & 2,62 & 1 & \\
\hline 205194 & & MIMAT00197 & & & & 0,02245 & 0,83755 \\
\hline 33 & hsa-miR-4651 & 15 & 6,05 & 4,88 & 2,25 & 6 & \\
\hline 205001 & & MIMAT00044 & & & & 0,02301 & 0,83755 \\
\hline 50 & hsa-miR-25-5p & 98 & 3,15 & 1,28 & 3,64 & 7 & 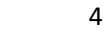 \\
\hline 205255 & hsa-miR-6781- & MIMAT00274 & & & & & 0,83755 \\
\hline 23 & $5 p$ & 62 & 2,63 & 1,15 & 2,8 & 0,02352 & \\
\hline 205255 & hsa-miR-6802- & MIMAT00275 & & & & 0,02656 & 0,84503 \\
\hline 65 & $5 p$ & 04 & 3,61 & 1,89 & 3,3 & 3 & 3 \\
\hline 205194 & hsa-miR-1343- & MIMAT00270 & & & & & 0,84503 \\
\hline 94 & $5 p$ & 38 & 5,25 & 3,61 & 3,1 & 0,02726 & 3 \\
\hline 205196 & hsa-miR-4763- & MIMAT00199 & & & & 0,02798 & 0,84503 \\
\hline 36 & $3 p$ & 13 & 7,12 & 6,01 & 2,15 & 5 & 3 \\
\hline 205254 & hsa-miR-6741- & MIMAT00273 & & & & 0,02862 & 0,84503 \\
\hline 44 & $5 p$ & 83 & 2,47 & 1,39 & 2,11 & 8 & \\
\hline 205255 & hsa-miR-6805- & MIMAT00275 & & & & 0,02892 & 0,84503 \\
\hline 71 & $5 p$ & 10 & 6,78 & 5,6 & 2,28 & 5 & 3 \\
\hline 205255 & hsa-miR-6776- & MIMAT00274 & & & & 0,03020 & 0,84503 \\
\hline 13 & $5 p$ & 52 & 2,75 & 1,63 & 2,18 & 3 & 3 \\
\hline 205156 & & MIMAT00150 & & & & 0,03066 & 0,85275 \\
\hline 03 & R-3175 & 52 & 4,38 & 2,21 & 4,5 & 2 & 7 \\
\hline 205039 & hsa-miR-532- & MIM & & & & 0,03241 & \\
\hline 07 & $5 p$ & 88 & 2,4 & 1,1 & 2,46 & 9 & 0,86745 \\
\hline 205194 & hsa-miR-4655- & MIMAT00197 & & & & 0,03396 & \\
\hline 39 & $5 p$ & 21 & 1,96 & 0,93 & 2,04 & 6 & 0,86745 \\
\hline 205194 & hsa-miR-4649- & MIMAT00197 & & & & 0,03449 & \\
\hline 29 & $5 p$ & 11 & 3,97 & 2,39 & 2,98 & 2 & 0,86745 \\
\hline 205188 & & MIN & & & & 0,03693 & \\
\hline 52 & hsa-miR-4467 & 94 & 5,93 & 4,46 & 2,78 & 4 & 0,86745 \\
\hline 205261 & hsa-miR-7110- & MIN & & & & & \\
\hline 78 & $5 p$ & 17 & 4,37 & 2,52 & 3,61 & 0,03999 & 0,86745 \\
\hline 205156 & & MIMAT00150 & & & & 0,04114 & \\
\hline 17 & hsa-miR-3185 & 65 & 5,98 & 4,49 & 2,8 & 2 & 0,86745 \\
\hline 205092 & hsa-miR-1909- & MIMAT00078 & & & & & \\
\hline 27 & $3 p$ & 83 & 3,72 & 2,61 & 2,15 & 0,04204 & 0,86745 \\
\hline 205057 & hsa-miR-877- & MIMAT00049 & & & & 0,04301 & \\
\hline 91 & $5 p$ & 49 & 5,64 & 4,51 & 2,2 & 1 & 0,86745 \\
\hline
\end{tabular}




\section{Annexes}

$\begin{array}{rll}205341 & \text { ENSG0000026 } & \text { ENSG0000026 } \\ 79 & 6284 & 6284 \\ 205381 & & \\ 68 & \text { U36A } & \text { U36A } \\ 205010 & \text { hsa-miR-200c- } & \text { MIMAT00006 } \\ 36 & 3 p & 17 \\ 205001 & & \text { MIMAT00000 } \\ 41 & \text { hsa-miR-21-5p } & 76 \\ 205253 & \text { hsa-miR-6722- } & \text { MIMAT00258 } \\ 94 & 3 p & 54 \\ 205381 & & \\ 13 & \text { SNORD123 } & \text { SNORD123 }\end{array}$

$\begin{array}{rrrrr} & & & 0,04372 & \\ 3,41 & 2,19 & 2,32 & 9 & 0,86745 \\ & & & 0,04372 & \\ 3,41 & 2,19 & 2,32 & 9 & 0,86745 \\ & & & 0,04605 & \\ 3,82 & 1,4 & 5,32 & 1 & 0,86745 \\ & & & 0,04685 & \\ 4,46 & 2,5 & 3,9 & 3 & 0,86745 \\ & & & 0,04747 & \\ 5,81 & 4,74 & 2,1 & 4 & 0,86745 \\ & & & 0,04773 & \\ 4,84 & 3,43 & 2,65 & 4 & 0,86745\end{array}$


Annexes

Annex II.

The results presented in this Doctoral Thesis have been partially collected in the next published paper:

Cabello, P.; Pineda, B.; Tormo, E.; Lluch, A.; Eroles, P. "The Antitumor Effect of Metformin Is Mediated by miR-26a in Breast Cancer." Int. J. Mol. Sci. 2016, 17, 1298. 


\title{
Article
}

\section{The Antitumor Effect of Metformin Is Mediated by miR-26a in Breast Cancer}

\author{
Paula Cabello ${ }^{1}$, Begoña Pineda ${ }^{1}$, Eduardo Tormo ${ }^{1}$, Ana Lluch ${ }^{1,2}$ and Pilar Eroles ${ }^{1, *}$ \\ 1 Biomedical Research Institute INCLIVA, 46010 Valencia, Spain; paucanavarro@gmail.com (P.C.); \\ bepime@hotmail.com (B.P.); eduardo.tormo@uv.es (E.T.); lluch_ana@gva.es (A.L.) \\ 2 Oncology and Hematology Department, Hospital Clinico Universitario, 46010 Valencia, Spain \\ * Correspondence: pilar.eroles@uv.es; Tel.: +34-96-3864100 (ext. 51920) \\ Academic Editor: Y-h. Taguchi \\ Received: 20 May 2016; Accepted: 4 August 2016; Published: 10 August 2016
}

\begin{abstract}
Metformin, a drug approved for diabetes type II treatment, has been associated with a reduction in the incidence of breast cancer and metastasis and increased survival in diabetic breast cancer patients. High levels of miR-26a expression have been proposed as one of the possible mechanisms for this effect; likewise, this miRNA has also been associated with survival/apoptosis processes in breast cancer. Our aim was to evaluate if miR-26a and some of its targets could mediate the effect of metformin in breast cancer. The viability of MDA-MB-231, MDA-MB-468, and MCF-7 breast cancer cell lines was evaluated with an MTT assay after ectopic overexpression and/or downregulation of miR-26a. Similarly, the expression levels of the miR-26a targets CASP3, CCNE2, ABL2, APAF1, XIAP, BCL-2, PTEN, p53, E2F3, CDC25A, BCL2L1, MCL-1, EZH2, and MTDH were assessed by quantitative polymerase chain reaction (PCR). The effect of metformin treatment on breast cancer cell viability and miR-26a, BCL-2, PTEN, MCL-1, EZH2, and MTDH modulation were evaluated. Wound healing experiments were performed to analyze the effect of miR-26a and metformin treatment on cell migration. MiR-26a overexpression resulted in a reduction in cell viability that was partially recovered by inhibiting it. E2F3, MCL-1, EZH2, MTDH, and PTEN were downregulated by miR-26a and the PTEN (phosphatase and tensin homolog) protein was also reduced after miR-26a overexpression. Metformin treatment reduced breast cancer cell viability, increased miR-26a expression, and led to a reduction in BCL-2, EZH2, and PTEN expression. miR-26a inhibition partly prevents the metformin viability effect and the PTEN and EZH2 expression reduction. Our results indicate that metformin effectively reduces breast cancer cell viability and suggests that the effects of the drug are mediated by an increase in miR-26a expression and a reduction of its targets, PTEN and EHZ2 Thus, the use of metformin in breast cancer treatment constitutes a promising potential breast cancer therapy.
\end{abstract}

Keywords: miR-26a; metformin; breast cancer

\section{Introduction}

Breast cancer is the most frequent cancer among women worldwide and the leading cause of death by cancer in women [1]. Breast cancer is a clinically, morphologically, and molecularly-heterogeneous disease [2,3]. In the year 2000, Perou et al. [4] classified it into five molecular subtypes according to its intrinsic genetic signature, however, immunohistochemical classification is still used in clinics. Treatment is based on the differential characteristics of breast cancer subtypes and is largely successful in human epidermal growth factor receptor 2 (HER2) and estrogen receptor (ER) positive (luminal) cancers (using anti-HER2 ${ }^{+}$and hormonal therapies, respectively). However, in triple negative breast cancer (TNBC; HER2, ER, and progesterone receptor negative), representing about $15 \%-20 \%$ of all breast cancer patients, there are no well-defined molecular targets. This subtype is related to 


\section{Annexes}

an elevated recurrence rate, worse prognosis and a lower survival rate compared to other types of breast cancer [5,6] due, among other reasons, to the heterogeneity and aggressive nature of TNBC [6] This peculiarity, and the fact that targeted treatments in $\mathrm{HER}^{+}$and $\mathrm{ER}^{+}$breast cancers are not always beneficial, has led to the continued search for alternative therapies. However, extending the use of already approved drugs to new pathologies is a promising and rapid strategy for expanding the clinical therapeutic arsenal.

Metformin (1,1-dimetilbiguanide hydrochloride) is a hypoglycemic oral biguanide drug that is prescribed and commercialized worldwide to treat diabetes type II. Epidemiological studies have revealed that oral use of metformin has a protective effect against tumors, reducing their incidence and improving the prognosis of cancer patients [7,8]. This drug can inhibit cancer cell proliferation, although its molecular mechanisms of action are not yet completely understood [9].

MicroRNAs (miRNAs or miRs) are small non-coding endogenous RNA molecules (approximately 22 nucleotides long) encoded in the introns of protein-coding genes and in the introns and exons of non-protein coding genes, which regulate gene expression at the post-transcriptional level $[10,11]$ MicroRNAs have already proven to be reliable biomarkers for predicting therapeutic response in several cancers [12-16] or as therapeutic tools in other types of cancer, not only by inhibiting them with drugs [17] but also, for example, by introducing them into liposomal vehicles for systemic distribution in lung cancer or hepatocellular carcinoma model mice [18,19].

In a previous study from our group [20], we observed significant changes in miR-26a levels when treating breast cancer cell lines with doxorubicin. This miRNA has also been previously studied in other types of cancer including renal and lung cancer. In 2014, Yang et al. [21] demonstrated that metformin inhibits renal cancer cell growth by inducing overexpression of the oncogenic microRNA, miR-26a, which has BCL-2 and PTEN among its targets. In this study we aimed to determine if miR-26a and/or some of its effector targets are implicated in the antitumor effect of metformin in TNBC and $\mathrm{ER}^{+}$breast cancer, particularly in cell viability and/or migration.

\section{Results}

\section{1. miR-26a Expression Modulates Cell Viability}

We studied the effect of exogenous miR-26a on cell viability by transfecting three cell lines (MDA-MB-231, MDA-MB-468, and MCF-7) with a miR-26a mimetic. Compared to the miRNA control (Cy3), miR-26a overexpression decreased cell viability in all three cell lines at all of the time-points we assayed (1, 4, and 7 days), and the difference was statistically significant at four days $(36 \%(p=0.0004)$, $31.11 \%(p=0.0009)$, and $73.89 \%\left(p=4.7 \times 10^{-10}\right)$ decrease in viability for MDA-MB-231, MDA-MB-468, and MCF-7 cells, respectively) and 7 days $\left(75.47 \%\left(p=9.66 \times 10^{-5}\right)\right.$, and $92.32 \%\left(p=3.78 \times 10^{-6}\right)$ decrease in viability for MDA-MB-468 and MCF-7 respectively) (Figure 1).

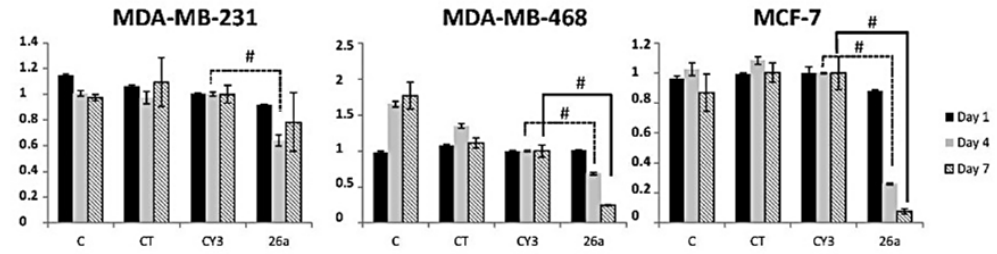

Figure 1. The effect of miR-26a on cell viability. MDA-MB-231, MDA-MB-468, and MCF-7 at days 1, 4, and 7 after transfection with miR-26a. C: non-treated control, CT: cells with transfection reagents, CY3: control with CY3 miRNA, 26a: miR-26a mimetic; $50 \mathrm{nM}$ of pre-miRNA were transfected in all cases. Error bars represent the standard deviation of three experiments. Statistically significant differences comparing cells transfected with miR-26a to CY3 cells are shown at the respective time points. (Student $t$ test: \# $p<0.001$ ). 


\section{Annexes}

However, rather than reducing cell viability, miR-26a inhibition increased viability, in some cases significantly (for example at $24 \mathrm{~h}$ in MDA-MB-468). This effect was partially reverted when the mimetic and miR-26a inhibitor were combined (Figure 2). These data support a role for miR-26a in breast cancer cell viability/apoptosis pathways acting as a tumor suppressor.
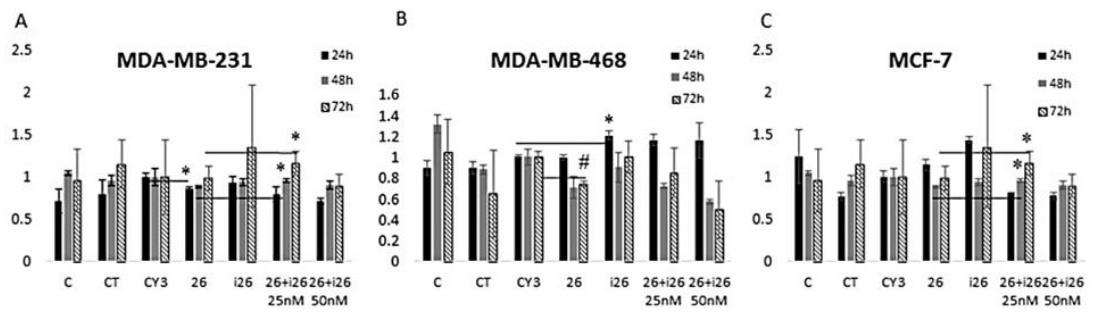

Figure 2. Determination of the miR-26a mimetic (26), the inhibitor (i26), and their combined effects on the viability of the (A) MDA-MB-231; (B) MDA-MB-468; and (C) MCF-7 cell lines at 24, 48, and $72 \mathrm{~h}$ after transfection; C: non-treated control, CT: cells with transfection reagents, CY3: control CY3 miRNA, 26: cells treated with $50 \mathrm{nM}$ miR-26a mimetic; i26: cells treated with $50 \mathrm{nM}$ miR-26a inhibitor, $26+\mathrm{i} 26$ is a combination of $25+25 \mathrm{nM}$ or $50+50 \mathrm{nM}$. Error bars show the standard deviation of three experiments. (Student $t$ test: ${ }^{*} p<0.05$; $\#<0.001$ ).

\subsection{Effect of miR-26a on Cell Migration}

To evaluate the physiological impact of miR-26a regulation we also studied the migration capacity of MDA-MB-231, MDA-MB-468, and MCF-7 cell lines when miR-26a was overexpressed in a wound-healing assay. From $25 \mathrm{~h}$, cell migration was higher in MDA-MB-231 and MDA-MB-468 cells transfected with the miR-26a mimetic compared to control cells, and the effect was more dramatic at $45 \mathrm{~h}$, especially in MDA-MB-231 cells (Figure 3).

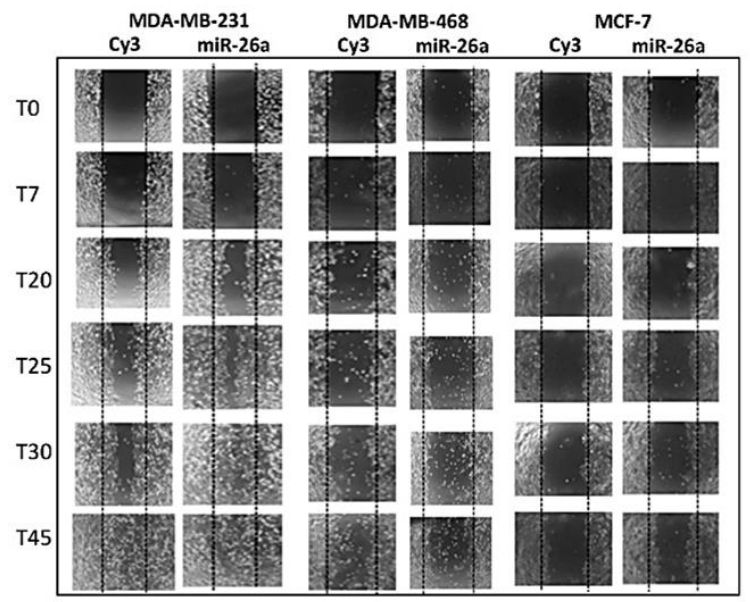

Figure 3. Wound healing cell migration assay comparing cells transfected with $50 \mathrm{nM}$ miR-26a or CY3 (control). Cells transfected with miR-26a closed the wound before the CY3-transfected cells ( $24 \mathrm{vs.} 30 \mathrm{~h}$ ). 


\section{Annexes}

\subsection{Evaluation of Potential miR-26a Targets}

We searched for and selected theoretical miR-26a target-genes in the miRTarBase and used DAVID Bioinformatics Resources and miRBase. From 950 potential targets detected in the miRTarBase, we selected 11 based of their relevance to cancer and cell viability and apoptosis processes: CASP3, CCNE2, ABL2, APAF1, XIAP, BCL-2, PTEN, p53, E2F3, CDC25A, and BCL2L1 ligand (Table 1). We differentiate between theoretical and proven targets, and note if the targets have been validated in cancer.

Table 1. Theoretical and demonstrated miR-26a selected gene targets obtained with miRTarBase, and selected by DAVID Bioinformatics Resources and miRBase. Demonstrated targets are experimentally proveN targets by techniques such as RT-qPCR or Western Blot, although none of them are proven in breast cancer.

\begin{tabular}{cc}
\hline \multicolumn{2}{c}{ miR-26a Target Genes } \\
\hline CASP3 & Theoretical \\
CCNE2 & Demonstrated \\
$A B L 2$ & Theoretical \\
$A P A F 1$ & Theoretical \\
XIAP & Theoretical \\
BCL2 & Theoretical \\
PTEN & Demonstrated \\
TP53 & Theoretical \\
$E 2 F 3$ & Theoretical \\
$C D C 25 A$ & Theoretical \\
$B C L 2 L 1$ & Theoretical \\
\hline
\end{tabular}

We evaluated the expression of these 11 genes in the three breast cancer cell lines, after transfecting them with a miR-26a mimetic or inhibitor, by RT-qPCR. CASP3 expression significantly increased $(p=0.012)$ in the MDA-MB-468 cell line, and CCNE2 expression significantly increased in both the MDA-MB-231 $(p=0.002)$ and MDA-MB-468 $(p=0.0008)$ cell lines after transfection with the miR-26a inhibitor (Figure 4); in MDA-MB-231 cells $A B L-2$ was diminished after miR-26a transfection ( $p=0.06$ ) and increased after its inhibition ( $p=0.027$; Figure 4); APAF1 expression was higher in MDA-MB-231 $(p=0.00015)$ and MDA-MB-468 ( $p=0.04)$ cells with miR-26a inhibition, and decreased in MCF-7 cells upon mimetic transfection (not significant); XIAP expression increased with miR-26a inhibition in the MDA-MB-231 and MCF-7 cell lines, significantly in the last ( $p=0.00025) ; B C L-2$ increased in the MDA-MB-231 ( $p=0.018)$ and MDA-MB-468 $(p=0.023)$ cell lines in the presence of the miR-26a inhibitor; PTEN expression diminished upon miR-26a transfection in the MDA-MB-231 $(p=0.006)$ and MCF-7 $(p=0.002)$ cell lines, and significantly increased when miR-26a was inhibited in MDA-MB-468 cells $\left(p=2.45 \times 10^{-5}\right)$; miR-26a inhibition increased TP53 expression in the MDA-MB-468 cell line $(p=0.0009) ; E 2 F 3$ expression diminished in all three cell lines after miR-26a transfection and significantly increased in MCF-7 cells when miR-26a was inhibited ( $p=0.0005)$; both CDC25A and $B C L 2 L 1$ expression significantly increased after inhibiting miR-26a in the MDA-MB-468 cell line ( $p=0.024$ and $p=0.001$, respectively) (Figure 4).

For us, PTEN and E2F3 downregulation after miR-26a transfection was the most relevant finding because it suggests that this miRNA directly targets genes; this was especially interesting for PTEN as it has proven relevance in cancer processes. Thus, we focused on studying the implications of miR-26a in the modulation of this gene in the context of breast cancer. 


\section{Annexes}
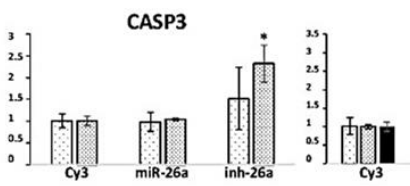

CCNE2
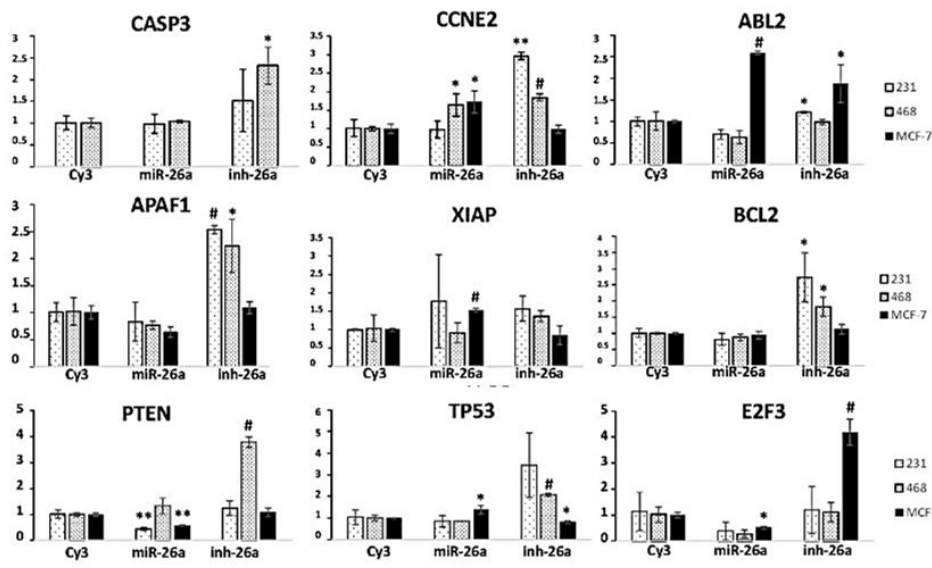

TP53
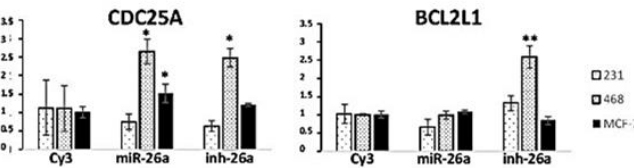

Figure 4. Gene expression of different miR-26a targets four days after transfection with either $50 \mathrm{nM}$ miR-26a or its inhibitor in MDA-MB-231, MDA-MB-468, and MCF-7 cell lines, as measured by RT-qPCR. CY3: CY3 control miRNA. Error bars represent triplicate experiments. (Student $t$ test: ${ }^{*} p<0.05$; $\left.{ }^{* *} p<0.005 ; \# p<0.001\right)$.

\subsection{Phosphatase and Tensin Homolog (PTEN) Regulation by miR-26a}

In order to validate PTEN as a miR-26a target in breast cancer, we transfected miR-26a mimetic into the MDA-MB-231 cell line and analyzed PTEN protein expression. Western blot analysis showed that levels of this protein significantly decreased (by $35.2 \%$ vs. control, $p=0.008$ ) after miR-26a overexpression (Figure 5), in concordance with downregulation of this gene after miR-26a transfection (Figure 4).

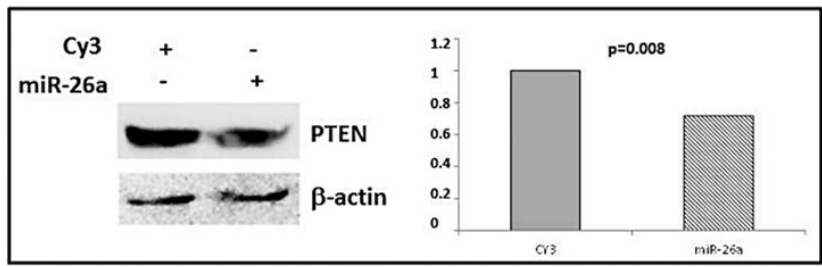

Figure 5. PTEN protein expression was measured by Western blot after transfection with miR-26a or CY3 in MDA-MB-231 cell line. $\beta$-Actin was used as a control.

\subsection{Effect of Metformin on Breast Cancer Cells}

In order to study if metformin induces miR-26a overexpression in breast cancer, as previously described in renal [21] and pancreatic [22] cancer, we tested mRNA and protein expression in metformin-treated MDA-MB-231 cells. First we assessed the effect of metformin on cell viability 


\section{Annexes}

using a MTT viability test at five different concentrations $(1,5,10,20$, and $40 \mathrm{mM})$ at 24,48 , and $72 \mathrm{~h}$ of metformin treatment. At concentrations of $10 \mathrm{mM}$ or higher, metformin decreased cell viability at 48 and $72 \mathrm{~h}$ ( $58 \%$ and $66 \%$ decrease, respectively) (Figure 6). We further analyzed the effect of metformin on the expression of miR-26a and its proposed targets, PTEN and BCL-2. MiR-26a was significantly increased after treating the cells with metformin $(p=0.012)$, however, both its potential targets showed a significant decrease in expression with the same treatment $(p=0.038$ and $p<0.001$ for PTEN and $B C L-2$, respectively) compared to non-treated cells (Figure 7A). PTEN protein levels were also lower after treatment with the drug (Figure 7B). These data correlate with our results from RT-qPCR.

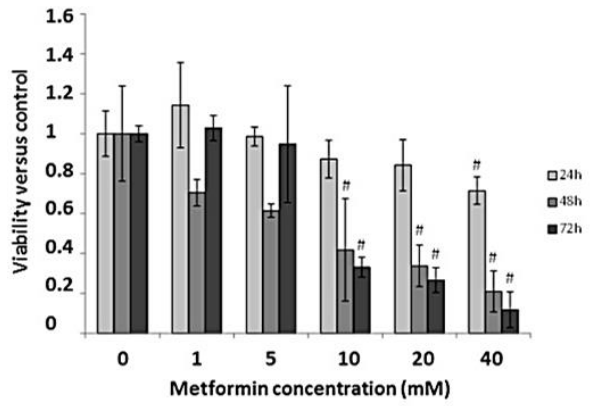

Figure 6. The effect of metformin on MDA-MB-231 cell line viability at different time-points and concentrations. Error bars represent the standard deviation of triplicate experiments. Statistically significant differences are shown for the comparison between treated cells and the control (not treated) at respective time-points (Student $t$ test: $\# p<0.001$ ).

A
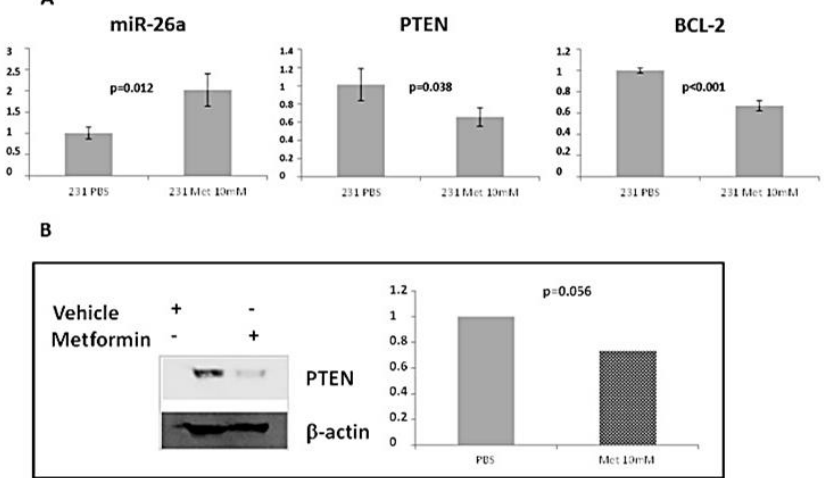

Figure 7. (A) Expression of miR-26a and two of its targets in MDA-MB-231 measured by RT-qPCR four days after treatment with $10 \mathrm{mM}$ metformin or vehicle (PBS). Error bars represent triplicate experiments; (B) PTEN protein expression measured by Western blot. MDA-MB-231 was treated with $10 \mathrm{mM}$ metformin or PBS, and $\beta$-actin was used as a control.

Finally, cell migration during metformin treatment was also checked using a wound healing assay to see if treatment with this drug reproduced the effects seen with miR-26a. Treating MDA-MB-231 cells with metformin increased migration, as shown by faster gap-closing at 24 and $30 \mathrm{~h}$ compared to non-treated cells (Figure 8). 


\section{Annexes}

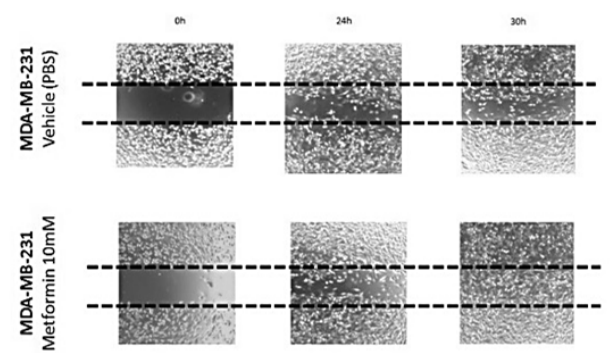

Figure 8. Wound healing cell migration assay comparing metformin-treated (10 mM) MDA-MB-231 cells with non-treated cells at 24 and $30 \mathrm{~h}$. (magnification $100 \times$ ).

\subsection{Effect of Metformin through miR-26a on Breast Cancer Cells}

To clarify if the effect of metformin is mediated by upregulation of miR-26a we performed viab and expression analysis combining the miR-26a inhibitor and metformin. The cell viability reduc induced by metformin was partially rescued by miR-26a inhibitor (Figure 9A). We further analy the effect of metformin on the miR-26a proposed targets: MCL-1, EZH2, and MTDH. MCL-1 (myel cell leukemia 1) is a pro-survival member of the Bcl-2 (B-cell CLL/lymphoma 2) family [23], MT facilitates malignant transformation of normal immortal cloned rat embryo fibroblast cells [24], : $E Z H 2$ promotes anchorage-independent growth and invasion of immortalized human mamm epithelial cells [24].

$M C L-1, E Z H 2$, and $M T D H$ showed significantly decreased expression (Figure 9B) after transfec with miR-26a mimetic ( $p=0.02, p=0.0004$, and $p=0.0004$, respectively) as was seen also for PI (Figures 4 and 9B). Metformin significantly reduced $E Z H 2$ expression $(p=0.02)$ and the combinat of miR-26a inhibitor with the drug significantly reversed the expression levels of EZH2 and PT ( $p=0.019$ and $p=0.05$ respectively) (Figure 9C).

A

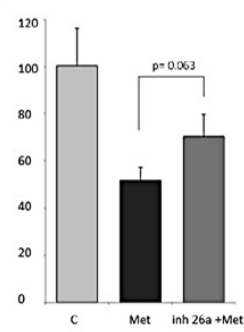

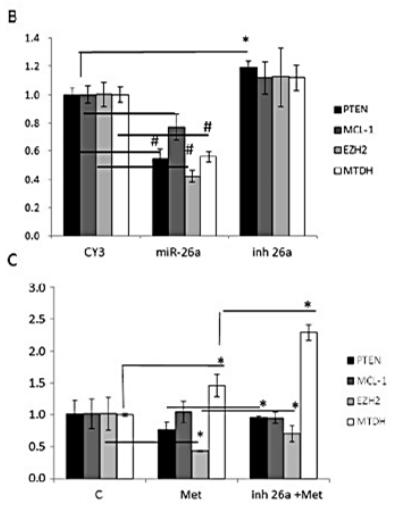

Figure 9. The effect of metformin through miR-26a on MDA-MB-231 cells. (A) Cell viability at $48 \mathrm{~h}$ after $10 \mathrm{mM}$ metformin treatment with or without the miR-26a inhibitor (50 nM); (B) Gene expression of miR-26a targets after transfection with either $50 \mathrm{nM}$ miR-26a mimetic or its inhibitor, as measured by RT-qPCR. CY3: CY3 control miRNA; (C) Expression of miR-26a targets measured by RT-qPCR after treatment with $10 \mathrm{mM}$ metformin (in presence or not of miR-26a inhibitor) or vehicle (PBS). Error bars represent triplicate experiments. (Student $t$ test: ${ }^{*} p<0.05 ; \# p<0.001$ ). 


\section{Annexes}

\section{Discussion}

Evidence for the implication of miRNAs in cancer processes has been growing over the last decade, and many miRNAs have been described as being deregulated in cancer [25]. Consequently, investigation focusing on these small RNAs has increasingly focused on their therapeutic uses. Hence, several strategies have been designed based on miRNA inhibition or enhancement by ectopic expression [26].

We focused on miR-26a because it has been described to play an important role in several cancers, including hepatocellular carcinoma and lung and breast cancer [23,27-29]. Furthermore, some authors suggest that metformin, already used to treat diabetes, may modulate the expression of miR-26a. This miRNA is reported to be a tumor suppressor $[23,24,27]$ whose increase leads to better outcomes in tamoxifen-treated breast cancer metastasis patients [30]. However, in lung cancer elevated miR-26a levels have been related to higher levels of tumor cell migration and invasion [28]. Low levels of miR-26a have been associated with TNBC [29] and with stimulating proliferation in $\mathrm{ER}^{+}$ breast cancer [31], and miR-26a expression levels have been associated with lymph node metastases in breast [29] and lung cancer [28]. Here we aimed to elucidate the role of miR-26a in modulating TNBC and $\mathrm{ER}^{+}$breast cancer cell viability. Furthermore, we evaluated some of its targets, and finally, we assayed the effect of metformin on miR-26a and these targets.

The use of drugs already on the market for new medical applications significantly streamlines their incorporation into the clinical armamentarium. Therefore, compounds already approved for certain treatments are being re-evaluated to discover their mechanisms of action and to search for possible new therapeutic applications. Metformin, a compound approved for treating type II diabetes, is being evaluated in cancer with the rationale that the incidence of breast cancer is decreased in diabetic patients $[7,8]$ and the risk of metastasis and death by cancer is reduced in breast cancer patients treated with this drug [32-34].

The molecular mechanisms of metformin in diabetes control are not completely understood; activation of AMP-activated protein kinase (AMPK), inhibition of the mitochondrial respiratory chain (complex I) and mitochondrial glycerol-3-phosphate dehydrogenase, and a reduction in protein kinase A (PKA) activation have all been proposed as potential mechanisms [9]. The mechanisms by which metformin affects cancers are also unknown, although a large number of publications have shown that metformin could exert its antitumor effect by targeting AMPK/mTOR, anti-inflammatory, cell cycle/apoptosis, insulin/IGF-1R, and angiogenesis pathways in cancers [35-38]. It has also been shown that it can inactivate cells similar to breast cancer stem cells [39]. Metformin has potent growth-inhibitory and proapoptotic effects in pancreatic cancer [40], and several authors suggest that its biological effects are mediated through miRNA expression [22,40]. Some authors believe that metformin inhibits proliferation by upregulating miR-26a expression which consequently downregulates the targets of this miRNA [21]. Yang et al. [21] first described the involvement of miR-26a and its targets in the metformin mechanism of antitumor action in renal cancer.

Our results confirmed previous data [23] in which miR-26a overexpression reduced cell viability, which was rescued with a miR-26a inhibitor to reverse the effect of the mimetic. Although this effect was slight, it reinforces the potential importance of miR-26a in cell viability/apoptosis processes in breast cancer. We detected a bigger reduction in cell viability in MCF-7 (luminal/ER ${ }^{+}$) cells than in the MDA-MB-468 and MDA-MB-231 (TNBC) cell lines. After evaluating miR-26a expression in different mammary cell line subtypes, one group reported that this miRNA is highly expressed in non-cancerous mammary cell lines but at lower levels in some breast cancer cell lines, in particular TNBC cells [29]. Differences in miR-26a expression in distinct breast cancer subtypes may also lead to different effects when it is exogenously overexpressed or downregulated. Similarly, other authors showed that miR-26a expression is higher in $\mathrm{ER}^{+}$breast cancer [29]. In contrast with its effect on cell viability, miR-26 has been identified as a key mediator of estrogen-stimulated cell proliferation in $\mathrm{ER}^{+}$breast cancer cells [31]. Furthermore, miR-26a seems to be strongly implicated in regulating $\mathrm{ER}^{+}$ breast cancer. Chen et al. [27] showed that miR-26a significantly downregulates ER $\alpha$ and prevents the 


\section{Annexes}

stimulation of hepatoma cell growth by E2. Moreover, in MCF-7 cells, transient transfection of miR-26a initiates apoptosis [24].

Using bioinformatics tools we selected some theoretical miR-26a targets based on their relevance in cancer and their implication in viability/apoptosis processes (in which we and others have found miR-26a to be involved). Interestingly, PTEN and E2F3 were downregulated after transfection with the miR-26a mimetic; PTEN is one of the most commonly mutated tumor suppressors in cancer and has been shown to negatively regulate the AKT/PKB signaling pathway, favoring tumor development and progression. Our data agree with studies showing that PTEN is a miR-26a target in glioma [41,42] and in lung cancer [28]; we also showed that PTEN is downregulated at the protein level in breast cancer cells overexpressing miR-26a.

The evaluation of metformin cellular effects reveals, according to other authors in kidney, pancreas and renal cancer $[21,22]$, that the drug reduces cell viability in a dose-dependent manner in the breast cancer cell line MDA-MB-231 and that its administration increases miR-26a and reduces $B C L-2$ and PTEN expression. However, although the beneficial effects of metformin on breast cancer patient survival rates has been described by several authors [32-34,43-46], little is known about the mechanism. We show here that metformin up-regulated miR-26a and also downregulated its direct target PTEN. It is difficult to explain how metformin can have an anti-proliferative effect since PTEN is a tumor suppressor gene. Trying to understand how the PTEN inhibition by miR-26a can result in an anti-proliferative effect, we checked the effect of miR-26a overexpression in some additional targets of this miRNA. We identified $E Z H 2$, a miR-26a target that is downregulated by the miRNA and by metformin. $E Z H 2$ is a bona fide oncogene and acts as a dual function transcription regulator (not only repressor but also activator) [47] by converging on the methyltransferase-activity silencing tumor suppressor genes, which are implicated in neoplastic development and the transactivation property-activating genes involved in the late-stage process of cancer [48,49]. This gene has been implicated in promoting anchorage-independent growth and invasion of immortalized human mammary epithelial cells [24]. Retrospective studies from clinical breast cancer patients indicate that high expression of $E Z H 2$ is associated with short survival [50]. Therefore, it can be one of the effectors involved in the decrease in cell viability after treatment with metformin and overexpression of miR-26a and thus justify their anti-proliferative effect.

It has been shown that metformin reduces cell migration. In general, we confirmed these data, although we observed slightly increased migration in the TNBC-model MDA-MB-231 cell line when the cells were treated with either a miR-26a mimetic or metformin. Our data are consistent with observations about the different behavior of breast cancer subtypes when miR-26a was upregulated. Boning Liu et al. [28] demonstrated that miR-26a increases lung cancer cell migration and the risk of metastasis by modulating activation of the AKT pathway by suppressing PTEN, data which agrees with our results in MDA-MB-231 cells. PTEN loss promotes cell migration in cancer cells, as previously described in breast cancer [51-53]. Simultaneous downregulation of PTEN and DLC1 in MCF-7 cells does not enhance cell proliferation, however, enhances cell migration [51]. DLC1 is negatively regulated by miRNAs in colorectal cancer [54,55], however, the possible DLC1 regulation by miR-26a has not been evaluated.

We believe that PTEN inhibition by metformin via miR-26a could explain the increased cell migration under the treatment, but the metformin antitumor activity must be due to other miR-26a targets. We checked the gene expression levels of $M C L-1, M T D H$, and $E Z H 2$ which are proven targets of miR-26a in breast cancer and could be responsible of its anti-proliferative effect. We observed that $E Z H 2$ expression under metformin treatment was also lower than in non-treated cells, suggesting that metformin antitumor effect could involve this gene [23,24]. We also checked EZH2 expression under metformin treatment when transfecting miR-26a inhibitor and their levels were partially rescued, suggesting not only that metformin antitumor effect can be through this gene, but also that it happens via miR-26a overexpression. 


\section{Annexes}

\section{Materials and Methods}

\subsection{Cell Lines and Culture}

The human MDA-MB-231 and MDA-MB-468 (both TNBC), and MCF-7 (luminal) cell lines were obtained from ATCC (ATCC, Manassas, VA, USA). The TNBC cell lines were maintained in DMEM/F12 medium with $10 \%$ fetal bovine serum (FBS) and MCF-7 cells were maintained in DMEM with $10 \%$ FBS; all the cell lines were cultured with $1 \%$ antibiotics $(100 \mathrm{U} / \mathrm{mL}$ penicillin and $100 \mathrm{mg} / \mathrm{L}$ streptomycin) and were maintained in a humidified atmosphere with $5 \% \mathrm{CO}_{2}$ at $37^{\circ} \mathrm{C}$.

\subsection{Cell Viability Assay}

Cell viability was measured using a MTT-based cell growth [56] determination kit (\#GDC1; Sigma-Aldrich, St. Louis, MO, USA). At the indicated intervals, MTT was added to each well and incubated for four hours at $37^{\circ} \mathrm{C}$. The medium was then carefully discarded and $50 \mu \mathrm{L}$ MTT solvent was added to each well to dissolve the formazan crystals. Purple formazan crystals are formed from yellow MTT by succinate dehydrogenase in viable cells. The absorbance at 570 and $690 \mathrm{~nm}$ was measured using a microplate spectrophotometer and the percentage of surviving cells from each group relative to controls were calculated in triplicate.

For the viability assays, cells were seeded at an initial density of $3 \times 10^{3}$ cells $/ \mathrm{mL}$ in a 96-well plate and incubated with medium, transfection reagents Cy3 miRNA and $50 \mathrm{nM} \mathrm{miR-26a} \mathrm{mimic} \mathrm{or}$ inhibitor for different time periods at $37^{\circ} \mathrm{C}$. For metformin (Sigma-Aldrich) treatment, $24 \mathrm{~h}$ after seeding, the cells were treated with metformin $(0,1,5,10,20,40 \mathrm{mM})$ and viability was measured at 24,48 , and $72 \mathrm{~h}$ as described above.

\subsection{MicroRNA Transfection}

To increase or reduce the miR-26a levels, $50 \mathrm{nM}$ of miR-26a mimetic miRNA or inhibitor (Applied Biosystems, Foster City, CA, USA) were transfected using a TransIT-X2TM [57] polymeric non-liposomal system (Mirus Bio Corporation (Madison, WI, USA) following the manufacturer's instructions; $50 \mathrm{nM}$ of CyTM3 dye-labeled Pre-miRTM negative control was transfected as a negative control.

\subsection{Analysis of miRNA and mRNA Expression by Quantitative Real-Time PCR}

RNA from cell lines was harvested using a miRNA isolation kit (mirVana, Ambion, Inc., 2130 Woodward Street, Austin, TX, USA) for miRNA and a TRIzol procedure for mRNA. The concentration and quality of the extracted RNA were determined by measuring $\mathrm{OD}_{260}$ and the $\mathrm{OD}_{260}: \mathrm{OD}_{280}$ ratio. First, 150 ng RNA were reverse transcribed to cDNA with specific stem-loop RT primers using a TaqMan microRNA reverse transcription kit (Applied Biosystems) for miRNA, and then $150 \mathrm{ng}$ RNA were reverse transcribed to $C D N A$ with random primers using a high-capacity cDNA reverse transcription kit (Applied Biosystems) from TaqMan for mRNA samples. RT-qPCR was performed using an ABI 7900HT fast RT-qPCR system and a TaqMan universal master mix (Applied Biosystems). All the primers were obtained from the TaqMan miRNA and mRNA assay kits (Applied Biosystems). The endogenous microRNA RNU43 [58] was used as an internal control for miRNA expression, and the housekeeping gene GAPDH was used as an internal control for mRNA expression.

\subsection{Western Blot Assays}

Cells were lysed in a radio-immunoprecipitation assay (RIPA) lysis buffer containing protease inhibitor. Protein concentrations were determined using the Lowry-Folin method. Following SDS-PAGE separation, $50 \mu \mathrm{g}$ of protein were transferred to polyvinylidene difluoride membranes (Bio-Rad) The membranes were blocked in tris-buffered saline (TBS) containing $5 \%$ non-fat milk and were subsequently incubated at $4{ }^{\circ} \mathrm{C}$ overnight with specific PTEN (1:500 in TBS with $0.1 \%$ Tween 20 


\section{Annexes}

(TBS-T) and $5 \%$ bovine serum albumin (BSA)) or $\beta$-actin (1:1000 5\% non-fat milk in TBS-T) primary antibodies, and then washed repeatedly for $5 \mathrm{~min}$ with $1 \%$ BSA-TBS-T followed by incubation with anti-rabbit-horseradish peroxidase (HRP; 1:2500 5\% non-fat milk in TBS-T) or anti-mouse-HRP (1:7500 $5 \%$ non-fat milk in TBS-T) secondary antibodies for $1 \mathrm{~h}$ at room temperature (all antibodies were from Cell Signaling, Beverly, MA, USA). ECL reagent (Amersham Life Science, Piscataway, NJ, USA) was used for detection and the membranes were developed in an ImageQuant LAS 4000 (GE Healthcare Life Sciences, Princeton, NJ, USA).

\subsection{Wound Healing Assay}

Cell migration was examined using a wound-healing assay [59]. Cells were cultured in six-well plates to $100 \%$ confluence. A plastic pipette tip was used to generate a wound area across the center of each well and after the wells were washed with PBS the medium was replaced and they were allowed to migrate. Micrograph images were taken with a microscope at $40 \times$ magnification at the indicated time points. All these experiments were repeated in triplicate.

\subsection{Bioinformatic Databases}

miRBase database (http:/ /www.mirbase.org/) was used to obtain information about miR-26a, and miRTarBase (http://mirtarbase.mbc.nctu.edu.tw/) was used to look for its gene targets. The first 950 genes were selected and analyzed in DAVID [60] (the database for annotation, visualization, and integrated discovery) bioinformatics resources to select targets involved in the most relevant pathways for cancer such as proliferation and apoptosis.

\subsection{Statistical Analysis}

The data were presented as the mean \pm standard deviation (SD) of the triplicate experiments. We analyzed the significance of any difference between the control and treatment groups using the Student $t$ test and the level of statistical significance was set at $95 \%$ confidence $(p<0.05)$.

\section{Conclusions}

We have confirmed the anti-proliferative effect of metformin in breast cancer. Our results suggest that upregulation of miR-26a and downregulation of some of these miRNA-targets are part of the action mechanisms of this drug. miR-26a is at least partially responsible for the metformin antineoplastic effect in breast cancer, even in triple negative breast cancer where there is no treatment other than chemotherapy, and this drug could result in a real improvement in treating the disease.

Author Contributions: Pilar Eroles and Ana Lluch designed the research and wrote the manuscript; Paula Cabello, Begoña Pineda, and Eduardo Tormo performed the molecular techniques; Paula Cabello and Begoña Pineda analyzed the data; All authors revised and approved the final version of the manuscript.

Conflicts of Interest: The authors declare no conflict of interest.

\section{References}

1. Torre, L.A.; Bray, F.; Siegel, R.L.; Ferlay, J.; Lortet-Tieulent, J.; Jemal, A. Global cancer statistics, 2012. CA Cancer J. Clin. 2015, 65, 87-108. [CrossRef] [PubMed]

2. Eroles, P.; Bosch, A.; Perez-Fidalgo, J.A.; Lluch, A. Molecular biology in breast cancer: Intrinsic subtypes and signaling pathways. Cancer Treat. Rev. 2012, 38, 698-707. [CrossRef] [PubMed]

3. Rivenbark, A.G.; O'Connor, S.M.; Coleman, W.B. Molecular and cellular heterogeneity in breast cancer: Challenges for personalized medicine. Am. J. Pathol. 2013, 183, 1113-1124. [CrossRef] [PubMed]

4. Perou, C.M.; Sorlie, T.; Eisen, M.B.; van de Rijn, M.; Jeffrey, S.S.; Rees, C.A.; Pollack, J.R.; Ross, D.T.; Johnsen, H.; Akslen, L.A.; et al. Molecular portraits of human breast tumours. Nature 2000, 406, 747-752. [CrossRef] [PubMed] 


\section{Annexes}

5. Bauer, K.R.; Brown, M.; Cress, R.D.; Parise, C.A.; Caggiano, V. Descriptive analysis of estrogen receptor (ER)-negative, progesterone receptor (PR)-negative, and HER2-negative invasive breast cancer, the so-called triple-negative phenotype: A population-based study from the California cancer Registry. Cancer 2007, 109, 1721-1728. [CrossRef] [PubMed]

6. Carey, L.A.; Dees, E.C.; Sawyer, L.; Gatti, L.; Moore, D.T.; Collichio, F.; Ollila, D.W.; Sartor, C.I.; Graham, M.L.; Perou, C.M. The triple negative paradox: Primary tumor chemosensitivity of breast cancer subtypes. Clin. Cancer Res. 2007, 13, 2329-2334. [CrossRef] [PubMed]

7. Libby, G.; Donnelly, L.A.; Donnan, P.T.; Alessi, D.R.; Morris, A.D.; Evans, J.M. New users of metformin are at low risk of incident cancer: A cohort study among people with type 2 diabetes. Diabetes Care 2009, 32, 1620-1625. [CrossRef] [PubMed]

8. Quinn, B.J.; Kitagawa, H.; Memmott, R.M.; Gills, J.J.; Dennis, P.A. Repositioning metformin for cancer prevention and treatment. Trends Endocrinol. Metab. 2013, 24, 469-480. [CrossRef] [PubMed]

9. Madiraju, A.K.; Erion, D.M.; Rahimi, Y.; Zhang, X.M.; Braddock, D.T.; Albright, R.A.; Prigaro, B.J.; Wood, J.L.; Bhanot, S.; MacDonald, M.J.; et al. Metformin suppresses gluconeogenesis by inhibiting mitochondrial glycerophosphate dehydrogenase. Nature 2014, 510, 542-546. [CrossRef] [PubMed]

10. Kim, V.N.; Nam, J.W. Genomics of microRNA. Trends Genet. 2006, 22, 165-173. [CrossRef] [PubMed]

11. Lin, S.L.; Kim, H.; Ying, S.Y. Intron-mediated RNA interference and microRNA (miRNA). Front. Biosci. 2008, 13, 2216-2230. [CrossRef] [PubMed]

12. Caramuta, S.; Egyhazi, S.; Rodolfo, M.; Witten, D.; Hansson, J.; Larsson, C.; Lui, W.O. MicroRNA expression profiles associated with mutational status and survival in malignant melanoma. J. Investig. Dermatol. 2010, 130, 2062-2070. [CrossRef] [PubMed]

13. Dillhoff, M.; Liu, J.; Frankel, W.; Croce, C.; Bloomston, M. MicroRNA-21 is overexpressed in pancreatic cancer and a potential predictor of survival. J. Gastrointest. Surg. 2008, 12, 2171-2176. [CrossRef] [PubMed]

14. Li, X.; Zhang, Y.; Ding, J.; Wu, K.; Fan, D. Survival prediction of gastric cancer by a seven-microRNA signature. Gut 2010, 59, 579-585. [CrossRef] [PubMed]

15. Rossi, S.; Shimizu, M.; Barbarotto, E.; Nicoloso, M.S.; Dimitri, F.; Sampath, D.; Fabbri, M.; Lerner, S.; Barron, L.L.; Rassenti, L.Z.; et al. microRNA fingerprinting of CLL patients with chromosome 17p deletion identify a miR-21 score that stratifies early survival. Blood 2010, 116, 945-952. [CrossRef] [PubMed]

16. Yanaihara, N.; Caplen, N.; Bowman, E.; Seike, M.; Kumamoto, K.; Yi, M.; Stephens, R.M.; Okamoto, A.; Yokota, J.; Tanaka, T.; et al. Unique microRNA molecular profiles in lung cancer diagnosis and prognosis. Cancer Cell 2006, 9, 189-198. [CrossRef] [PubMed]

17. Shi, Z.; Zhang, J.; Qian, X.; Han, L.; Zhang, K.; Chen, L.; Liu, J.; Ren, Y.; Yang, M.; Zhang, A.; et al. AC1MMYR2, an inhibitor of dicer-mediated biogenesis of Oncomir miR-21, reverses epithelial-mesenchymal transition and suppresses tumor growth and progression. Cancer Res. 2013, 73, 5519-5531. [CrossRef] [PubMed]

18. Bader, A.G. miR-34-A microRNA replacement therapy is headed to the clinic. Front. Genet. 2012, 3, 120. [CrossRef] [PubMed]

19. Trang, P.; Wiggins, J.F.; Daige, C.L.; Cho, C.; Omotola, M.; Brown, D.; Weidhaas, J.B.; Bader, A.G.; Slack, F.J. Systemic delivery of tumor suppressor microRNA mimics using a neutral lipid emulsion inhibits lung tumors in mice. Mol. Ther. 2011, 19, 1116-1122. [CrossRef] [PubMed]

20. Tormo, E.; Pineda, B.; Serna, E.; Guijarro, A.; Ribas, G.; Fores, J.; Chirivella, E.; Climent, J.; Lluch, A.; Eroles, P. MicroRNA Profile in Response to Doxorubicin Treatment in Breast Cancer. J. Cell. Biochem. 2015, 116, 2061-2073. [CrossRef] [PubMed]

21. Yang, F.Q.; Wang, J.J.; Yan, J.S.; Huang, J.H.; Li, W.; Che, J.P.; Wang, G.C.; Liu, M.; Zheng, J.H. Metformin inhibits cell growth by upregulating microRNA-26a in renal cancer cells. Int. J. Clin. Exp. Med. 2014, 7, 3289-3296. [PubMed]

22. Bao, B.; Wang, Z.; Ali, S.; Ahmad, A.; Azmi, A.S.; Sarkar, S.H.; Banerjee, S.; Kong, D.; Li, Y.; Thakur, S.; et al. Metformin inhibits cell proliferation, migration and invasion by attenuating CSC function mediated by deregulating miRNAs in pancreatic cancer cells. Cancer Prev. Res. (Phila) 2012, 5, 355-364. [CrossRef] [PubMed]

23. Gao, J.; Li, L.; Wu, M.; Liu, M.; Xie, X.; Guo, J.; Tang, H. MiR-26a inhibits proliferation and migration of breast cancer through repression of MCL-1. PLoS ONE 2013, 8, e65138. [CrossRef] [PubMed] 


\section{Annexes}

24. Zhang, B.; Liu, X.X.; He, J.R.; Zhou, C.X.; Guo, M.; He, M.; Li, M.F.; Chen, G.Q.; Zhao, Q. Pathologically decreased miR-26a antagonizes apoptosis and facilitates carcinogenesis by targeting MTDH and EZH2 in breast cancer. Carcinogenesis 2011, 32, 2-9. [CrossRef] [PubMed]

25. Eroles, P.; Tormo, E.; Pineda, B.; Espin, E.; Lluch, A. MicroRNAs in breast cancer: One More Turn in Regulation. Curr. Drug Targets 2015, in press.

26. Kasinski, A.L.; Slack, F.J. Epigenetics and genetics. MicroRNAs en route to the clinic: Progress in validating and targeting microRNAs for cancer therapy. Nat. Rev. Cancer 2011, 11, 849-864. [CrossRef] [PubMed]

27. Chen, L.; Zheng, J.; Zhang, Y.; Yang, L.; Wang, J.; Ni, J.; Cui, D.; Yu, C.; Cai, Z. Tumor-specific expression of microRNA-26a suppresses human hepatocellular carcinoma growth via cyclin-dependent and -independent pathways. Mol. Ther. 2011, 19, 1521-1528. [CrossRef] [PubMed]

28. Liu, B.; Wu, X.; Wang, C.; Liu, Y.; Zhou, Q.; Xu, K. MiR-26a enhances metastasis potential of lung cancer cells via AKT pathway by targeting PTEN. Biochim. Biophys. Acta 2012, 1822, 1692-1704. [CrossRef] [PubMed]

29. Liu, P.; Tang, H.; Chen, B.; He, Z.; Deng, M.; Wu, M.; Liu, X.; Yang, L.; Ye, F.; Xie, X. miR-26a suppresses tumour proliferation and metastasis by targeting metadherin in triple negative breast cancer. Cancer Lett. 2015, 357, 384-392. [CrossRef] [PubMed]

30. Jansen, M.P.; Reijm, E.A.; Sieuwerts, A.M.; Ruigrok-Ritstier, K.; Look, M.P.; Rodriguez-Gonzalez, F.G.; Heine, A.A.; Martens, J.W.; Sleijfer, S.; Foekens, J.A.; et al. High miR-26a and low CDC2 levels associate with decreased EZH2 expression and with favorable outcome on tamoxifen in metastatic breast cancer Breast Cancer Res. Treat. 2012, 133, 937-947. [CrossRef] [PubMed]

31. Tan, S.; Ding, K.; Li, R.; Zhang, W.; Li, G.; Kong, X.; Qian, P.; Lobie, P.E.; Zhu, T. Identification of miR-26 as a key mediator of estrogen stimulated cell proliferation by targeting CHD1, GREB1 and KPNA2. Breast Cancer Res. 2014, 16, R40. [CrossRef] [PubMed]

32. Kim, H.J.; Kwon, H.; Lee, J.W.; Lee, S.B.; Park, H.S.; Sohn, G.; Lee, Y.; Koh, B.S.; Yu, J.H.; Son, B.H.; et al. Metformin increases survival in hormone receptor-positive, HER2-positive breast cancer patients with diabetes. Breast Cancer Res. 2015, 17, 64. [CrossRef] [PubMed]

33. Bayraktar, S.; Hernadez-Aya, L.F.; Lei, X.; Meric-Bernstam, F.; Litton, J.K.; Hsu, L.; Hortobagyi, G.N.; Gonzalez-Angulo, A.M. Effect of metformin on survival outcomes in diabetic patients with triple receptor-negative breast cancer. Cancer 2012, 118, 1202-1211. [CrossRef] [PubMed]

34. He, X.; Esteva, F.J.; Ensor, J.; Hortobagyi, G.N.; Lee, M.H.; Yeung, S.C. Metformin and thiazolidinediones are associated with improved breast cancer-specific survival of diabetic women with HER2 ${ }^{+}$breast cancer. Ann. Oncol. 2012, 23, 1771-1780. [CrossRef] [PubMed]

35. Anisimov, V.N.; Berstein, L.M.; Egormin, P.A.; Piskunova, T.S.; Popovich, I.G.; Zabezhinski, M.A.; Kovalenko, I.G.; Poroshina, T.E.; Semenchenko, A.V.; Provinciali, M.; et al. Effect of metformin on life span and on the development of spontaneous mammary tumors in HER-2/Neu transgenic mice. Exp. Gerontol. 2005, 40, 685-693. [CrossRef] [PubMed]

36. Ben Sahra, I.; Laurent, K.; Loubat, A.; Giorgetti-Peraldi, S.; Colosetti, P.; Auberger, P.; Tanti, J.F.; Le Marchand-Brustel, Y.; Bost, F. The antidiabetic drug metformin exerts an antitumoral effect in vitro and in vivo through a decrease of cyclin D1 level. Oncogene 2008, 27, 3576-3586. [CrossRef] [PubMed]

37. Dowling, R.J.; Zakikhani, M.; Fantus, I.G.; Pollak, M.; Sonenberg, N. Metformin inhibits mammalian target of rapamycin-dependent translation initiation in breast cancer cells. Cancer Res. 2007, 67, 10804-10812. [CrossRef] [PubMed]

38. Martin-Castillo, B.; Dorca, J.; Vazquez-Martin, A.; Oliveras-Ferraros, C.; Lopez-Bonet, E.; Garcia, M.; del Barco, S.; Menendez, J.A. Incorporating the antidiabetic drug metformin in HER2-positive breast cancer treated with neo-adjuvant chemotherapy and trastuzumab: An ongoing clinical-translational research experience at the Catalan Institute of Oncology. Ann. Oncol. 2010, 21, 187-189. [CrossRef] [PubMed]

39. Hirsch, H.A.; Iliopoulos, D.; Tsichlis, P.N.; Struhl, K. Metformin selectively targets cancer stem cells, and acts together with chemotherapy to block tumor growth and prolong remission. Cancer Res. 2009, 69, 7507-7511. [CrossRef] [PubMed]

40. Li, W.; Yuan, Y.; Huang, L.; Qiao, M.; Zhang, Y. Metformin alters the expression profiles of microRNAs in human pancreatic cancer cells. Diabetes Res. Clin. Pract. 2012, 96, 187-195. [CrossRef] [PubMed]

41. Huse, J.T.; Brennan, C.; Hambardzumyan, D.; Wee, B.; Pena, J.; Rouhanifard, S.H.; Sohn-Lee, C.; le Sage, C.; Agami, R.; Tuschl, T.; et al. The PTEN-regulating microRNA miR-26a is amplified in high-grade glioma and facilitates gliomagenesis in vivo. Genes Dev. 2009, 23, 1327-1337. [CrossRef] [PubMed] 


\section{Annexes}

42. Kim, H.; Huang, W.; Jiang, X.; Pennicooke, B.; Park, P.J.; Johnson, M.D. Integrative genome analysis reveals an oncomir/oncogene cluster regulating glioblastoma survivorship. Proc. Natl. Acad. Sci. USA 2010, 107, 2183-2188. [CrossRef] [PubMed]

43. Hou, G.; Zhang, S.; Zhang, X.; Wang, P.; Hao, X.; Zhang, J. Clinical pathological characteristics and prognostic analysis of 1,013 breast cancer patients with diabetes. Breast Cancer Res. Treat. 2013, 137, 807-816. [CrossRef] [PubMed]

44. Lega, I.C.; Austin, P.C.; Gruneir, A.; Goodwin, P.J.; Rochon, P.A.; Lipscombe, L.L. Association between metformin therapy and mortality after breast cancer: A population-based study. Diabetes Care 2013, 36, 3018-3026. [CrossRef] [PubMed]

45. Peeters, P.J; Bazelier, M.T.; Vestergaard, P.; Leufkens, H.G.; Schmidt, M.K.; de Vries, F.; de Bruin, M.L. Use of metformin and survival of diabetic women with breast cancer. Curr. Drug Saf. 2003, 8, 357-363. [CrossRef]

46. Xiao, Y.; Zhang, S.; Hou, G.; Zhang, X.; Hao, X.; Zhang, J. Clinical pathological characteristics and prognostic analysis of diabetic women with luminal subtype breast cancer. Tumour Biol. 2014, 35, 2035-2045. [CrossRef] [PubMed]

47. Shi, B.; Liang, J.; Yang, X.; Wang, Y.; Zhao, Y.; Wu, H.; Sun, L.; Zhang, Y.; Chen, Y.; Li, R.; et al. Integration of estrogen and Wnt signaling circuits by the polycomb group protein EZH2 in breast cancer cells. Mol. Cell. Biol. 2007, 27, 5105-5119. [CrossRef] [PubMed]

48. Bracken, A.P.; Kleine-Kohlbrecher, D.; Dietrich, N.; Pasini, D.; Gargiulo, G.; Beekman, C.; Theilgaard-Monch, K.; Minucci, S.; Porse, B.T.; Marine, J.C.; et al. The Polycomb group proteins bind throughout the INK4A-ARF locus and are disassociated in senescent cells. Genes Dev. 2007, 21, 525-530. [CrossRef] [PubMed]

49. Schuettengruber, B.; Chourrout, D.; Vervoort, M.; Leblanc, B.; Cavalli, G. Genome regulation by polycomb and trithorax proteins. Cell 2007, 128, 735-745. [CrossRef] [PubMed]

50. Kleer, C.G.; Cao, Q.; Varambally, S.; Shen, R.; Ota, I.; Tomlins, S.A.; Ghosh, D.; Sewalt, R.G.; Otte, A.P.; Hayes, D.F.; et al. EZH2 is a marker of aggressive breast cancer and promotes neoplastic transformation of breast epithelial cells. Proc. Natl. Acad. Sci. USA 2003, 100, 11606-11611. [CrossRef] [PubMed]

51. Heering, J.; Erlmann, P.; Olayioye, M.A. Simultaneous loss of the DLC1 and PTEN tumor suppressors enhances breast cancer cell migration. Exp. Cell Res. 2009, 315, 2505-2514. [CrossRef] [PubMed]

52. Tamura, M.; Gu, J.; Matsumoto, K.; Aota, S.; Parsons, R.; Yamada, K.M. Inhibition of cell migration, spreading, and focal adhesions by tumor suppressor PTEN. Science 1998, 280, 1614-1617. [CrossRef] [PubMed]

53. Tamura, M.; Gu, J.; Takino, T.; Yamada, K.M. Tumor suppressor PTEN inhibition of cell invasion, migration, and growth: Differential involvement of focal adhesion kinase and p130Cas. Cancer Res. 1999, 59, 442-449. [PubMed]

54. Wu, P.P.; Zhu, H.Y.; Sun, X.F.; Chen, L.X.; Zhou, Q.; Chen, J. MicroRNA-141 regulates the tumour suppressor DLC1 in colorectal cancer. Neoplasma 2015, 62, 705-712. [CrossRef] [PubMed]

55. Zhang, G.J.; Li, J.S.; Zhou, H.; Xiao, H.X.; Li, Y.; Zhou, T. MicroRNA-106b promotes colorectal cancer cell migration and invasion by directly targeting DLC1. J. Exp. Clin. Cancer Res. 2015, 34, 73. [CrossRef] [PubMed]

56. Mosmann, T. Rapid colorimetric assay for cellular growth and survival: Application to proliferation and cytotoxicity assays. J. Immunol. Methods 1983, 65, 55-63. [CrossRef]

57. Shopsowitz, K.E.; Wu, C.; Liu, G.; Dreaden, E.C.; Hammond, P.T. Periodic-shRNA molecules are capable of gene silencing, cytotoxicity and innate immune activation in cancer cells. Nucleic Acids Res. 2016, 44, 545-557. [CrossRef] [PubMed]

58. Gyongyosi, A.; Docs, O.; Czimmerer, Z.; Orosz, L.; Horvath, A.; Torok, O.; Mehes, G.; Nagy, L.; Balint, B.L. Measuring expression levels of small regulatory RNA molecules from body fluids and formalin-fixed, paraffin-embedded samples. Methods Mol. Biol. 2014, 1182, 105-119. [PubMed]

59. Rodriguez, L.G.; Wu, X.; Guan, J.L. Wound-healing assay. Methods Mol. Biol. 2005, 294, 23-29. [PubMed]

60. Huang, D.W.; Sherman, B.T.; Tan, Q.; Kir, J.; Liu, D.; Bryant, D.; Guo, Y.; Stephens, R.; Baseler, M.W.; Lane, H.C.; et al. DAVID Bioinformatics Resources: Expanded annotation database and novel algorithms to better extract biology from large gene lists. Nucleic Acids Res. 2007, 35, W169-W175. [CrossRef] [PubMed]

(C) 2016 by the authors; licensee MDPI, Basel, Switzerland. This article is an open access article distributed under the terms and conditions of the Creative Commons Attribution (CC-BY) license (http://creativecommons.org/licenses/by/4.0/). 
